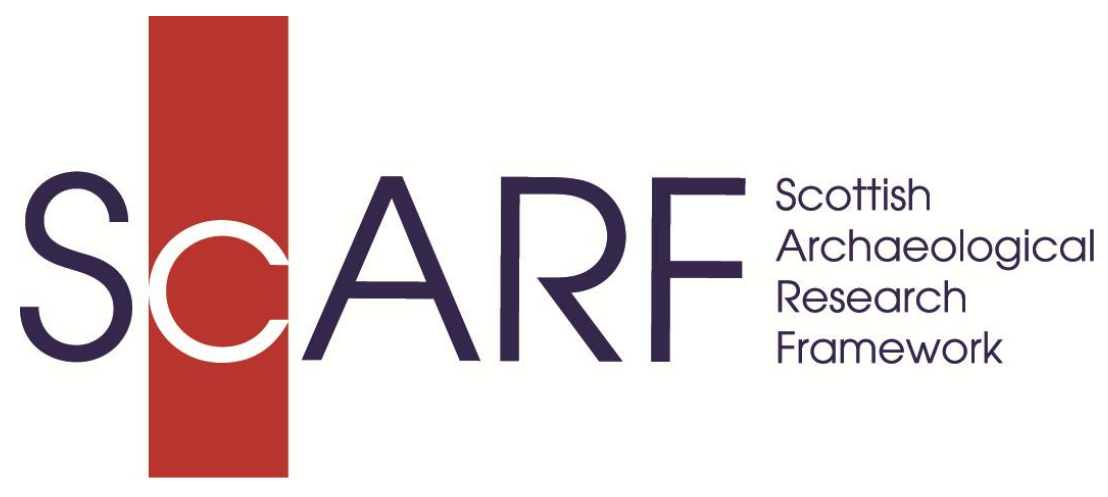

\title{
Neolithic Scotland:
}

\section{ScARF Panel Report}

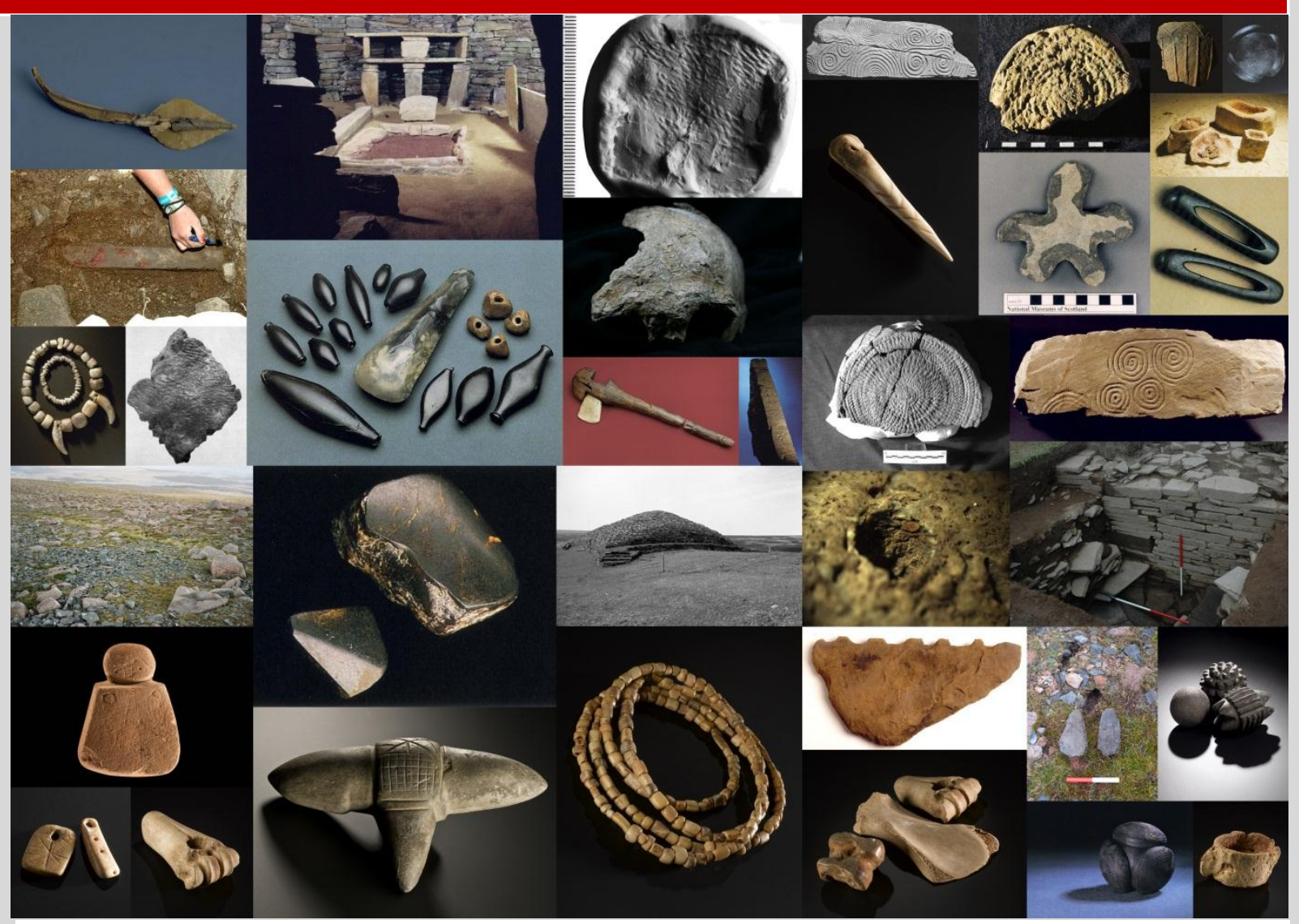

Images (C) as noted in the text

ScARF Summary Neolithic Panel Document June 2012 


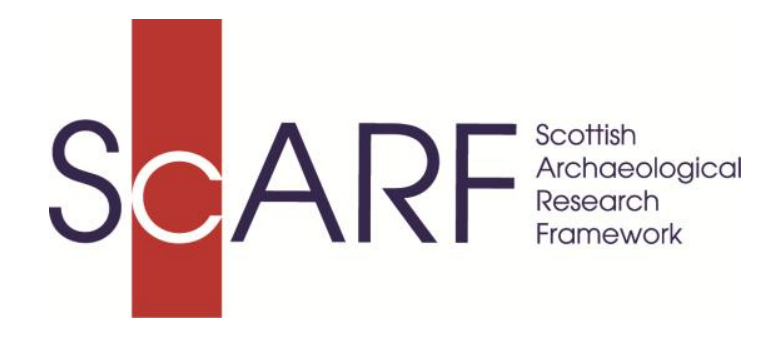

ScARF Summary Neolithic Report

Kenny Brophy \& Alison Sheridan (editors)

With panel member contributions from John Barber, Kenneth Brophy, Vicki Cummings, Gavin MacGregor, Jane Murray, Gordon Noble, Alison Sheridan, Richard Tipping, and Graeme Warren.

For contributions, images, feedback, critical comment and participation at workshops: Patrick Ashmore, Torben Bjarke Ballin, Richard Bradley, Nick Card, Anne Clarke, Gabriel Cooney, Rebecca Crozier, Mark Edmonds, Julie Franklin, Shannon Fraser, Dorothy Graves, Ann MacSween, Rowan McLaughlin, Nigel Melton, Roger Mercer, Kirsty Millican, Jane Murray, Yvan Pallier, Emma Philip, Colin Richards, Alan Saville, Rick Schulting, Richard Strachan, Julian Thomas, Scott Timpany, Clive Waddington, Alastair Whittle, and Caroline Wickham-Jones, and Rebecca Younger. 


\section{Executive Summary}

\section{Why research Neolithic Scotland?}

The appearance in Scotland of domesticated animals and plants, and of novel technology (pottery manufacture), material culture, monuments, traditions, practices and beliefs - the elements that define what we call the Neolithic - marks a major change from what had gone before, and profoundly affected what came afterwards. How these novelties appeared has been the topic of heated debate for the last 25 years (and for less heated speculation for over a century. Characterising this change, understanding what happened to Scotland's indigenous inhabitants and building a narrative for subsequent developments (which include the secondary spread of the Neolithic 'package', a process of regionalisation and then an interesting broad spread of beliefs and practices associated with Grooved Ware use around 3000-2900 BC), are vital tasks. To this end, this document seeks to take stock of what we can say and do know, to highlight the principal gaps in our knowledge, and to suggest ways in which these can be filled.

We are fortunate in that Scotland is very rich in Neolithic sites and artefacts, and there have been many recent discoveries through developer-funded and research excavation. This, plus an evergrowing body of high-quality radiocarbon dates, and the results of several exciting research projects (e.g. on human remains and on absorbed lipids in pottery), allows us to make sense of the mass of information now available to us: at the most basic of levels, we now have a clearer picture of what happened and when (if we cannot always explain how and why).

It is our belief that we can only understand Scotland's Neolithic by adopting a multi-scale approach, situating developments here within a broader picture of European developments from the fifth to the mid-third millennium BC and developing narratives at the (present-day) national, regional and local scales. That is what we set out to do in this document.

\section{Panel Task and Remit}

The Neolithic panel was tasked to undertake a critical review of the current state of knowledge, and identify areas requiring future research into the Scottish Neolithic. This was undertaken with a view to identifying the key research areas that will help build narratives that describe and explain what happened in Scotland from the first appearance of new lifeways, some time between 4300 BC and $4000 \mathrm{BC}$, until the appearance of Beaker pottery and other associated novelties during the $25^{\text {th }}$ century BC. The panel also sought to maintain a balance between describing the Scottish overview of major developments at the period and building regional and local narratives for Scotland's disparate 'Neolithics'.

The result is this report, outlining by theme the different areas of research in which work is taking place and highlighting the research topics to which archaeologists aspire. The report is structured by the following themes: The Overall Picture; The Detailed Picture - Issues of Regional and Chronological Resolution; Lifeways and Lifestyles; Material Culture and Use of Resources; Identity, Society, Belief Systems; and Research and Methodological issues. The document is reinforced by material on-line that provides additional (and alternative) discussion and further information. The Neolithic ScARF (Scottish Archaeological Research Framework) is intended as a resource to be utilised, built upon and kept updated, by those it has helped inspire and inform as well as those who follow them. 


\section{Future Research}

The main recommendations of the Panel report can be summarised as follows:

The Overall Picture: more needs to be understood about the process of acculturation of indigenous communities; about the Atlantic, Breton strand of Neolithisation; about the 'how and why' of the spread of Grooved Ware use and its associated practices and traditions; and about reactions to Continental Beaker novelties which appeared from the $25^{\text {th }}$ century.

The Detailed Picture: Our understanding of developments in different parts of Scotland is very uneven, with Shetland and the north-west mainland being in particular need of targeted research. Also, here and elsewhere in Scotland, the chronology of developments needs to be clarified, especially as regards developments in the Hebrides.

Lifeways and Lifestyles: Research needs to be directed towards filling the substantial gaps in our understanding of: i) subsistence strategies; ii) landscape use (including issues of population size and distribution); iii) environmental change and its consequences - and in particular issues of sea level rise, peat formation and woodland regeneration; and iv) the nature and organisation of the places where people lived; and to track changes over time in all of these.

Material Culture and Use of Resources: In addition to fine-tuning our characterisation of material culture and resource use (and its changes over the course of the Neolithic), we need to apply a wider range of analytical approaches in order to discover more about manufacture and use.Some basic questions still need to be addressed (e.g. the chronology of felsite use in Shetland; what kind of pottery was in use, c 3000-2500, in areas where Grooved Ware was not used, etc.) and are outlined in the relevant section of the document. Our knowledge of organic artefacts is very limited, so research in waterlogged contexts is desirable.

Identity, Society, Belief Systems: Basic questions about the organisation of society need to be addressed: are we dealing with communities that started out as egalitarian, but (in some regions) became socially differentiated? Can we identify acculturated indigenous people? How much mobility, and what kind of mobility, was there at different times during the Neolithic? And our chronology of certain monument types and key sites (including the Ring of Brodgar, despite its recent excavation) requires to be clarified, especially since we now know that certain types of monument (including Clava cairns) were not built during the Neolithic. The way in which certain types of site (e.g. large palisaded enclosures) were used remains to be clarified.

Research and methodological issues: There is still much ignorance of the results of past and current research, so more effective means of dissemination are required. Basic inventory information (e.g. the Scottish Human Remains Database) needs to be compiled, and Canmore and museum database information needs to be updated and expanded - and, where not already available online, placed online, preferably with a Scottish Neolithic e-hub that directs the enquirer to all the available sources of information. The Historic Scotland on-line radiocarbon date inventory needs to be resurrected and kept up to date. Under-used resources, including the rich aerial photography archive in the NMRS, need to have their potential fully exploited. Multi-disciplinary, collaborative research (and the application of GIS modelling to spatial data in order to process the results) is vital if we are to escape from the current 'silo' approach and address key research questions from a range of perspectives; and awareness of relevant research outside Scotland is essential if we are to avoid reinventing the wheel. Our perspective needs to encompass multi-scale approaches, so that 
developments within Scotland can be understood at a local, regional and wider level. Most importantly, the right questions need to be framed, and the right research strategies need to be developed, in order to extract the maximum amount of information about the Scottish Neolithic. 


\section{Contents}

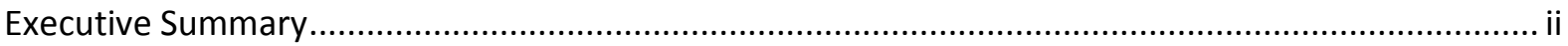

1. Background: the history of research into Neolithic Scotland, $1840-2007$................................ 1

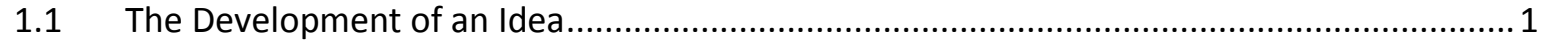

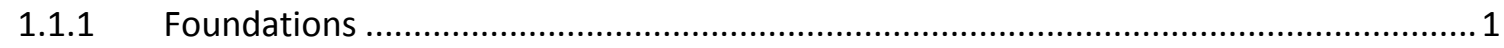

1.1.2 The first Research Framework ...................................................................... 2

1.1.3 The Neolithic Defined ..................................................................................... 3

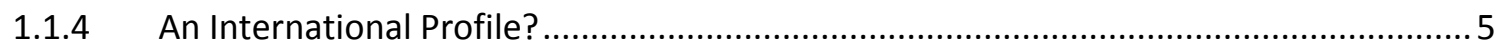

1.2 The advent of Childe - the Idea Rebuilt..................................................................... 6

1.2.1 The Accumulation of Data............................................................................... 7

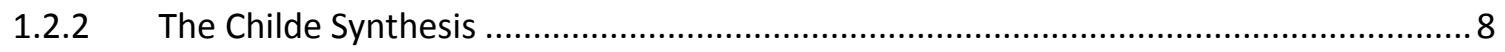

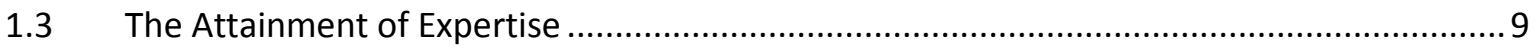

1.3.1 Post-World War II Developments ...................................................................... 9

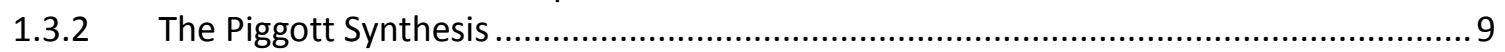

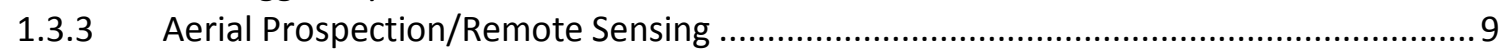

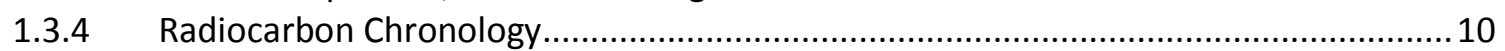

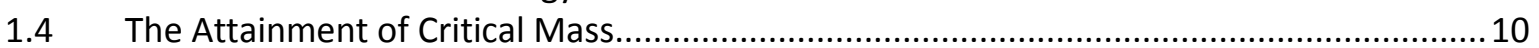

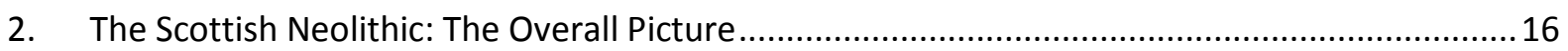

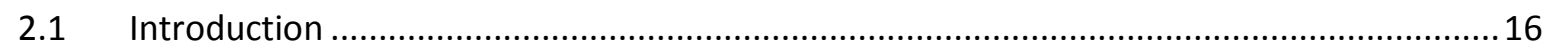

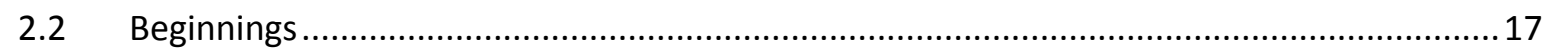

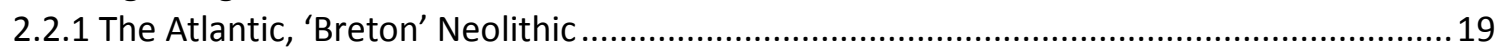

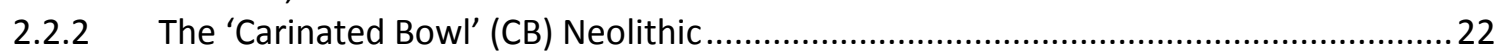

2.3 Subsequent developments during the Early and Middle Neolithic, c 3800-c 3000 BC.......27

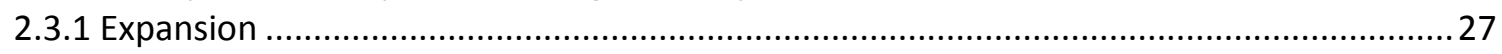

2.3.2 Diversification and hybridisation in material culture, monuments and traditions............27

2.3.3 Social differentiation and strategies of competitive conspicuous consumption...............28

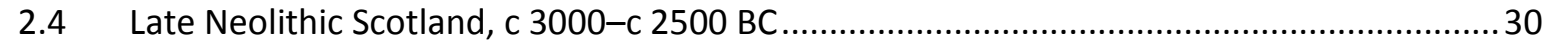

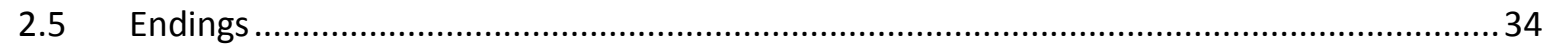

3. The Detailed Picture: issues of regional and chronological resolution .................................40

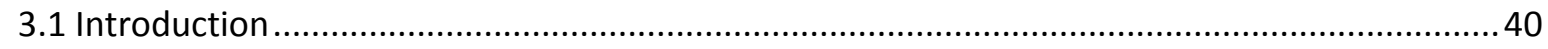

3.2 Levels of resolution and narrative ..................................................................... 40

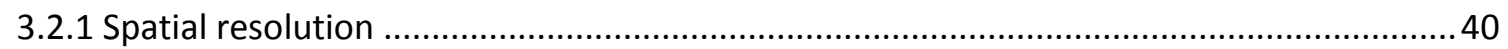

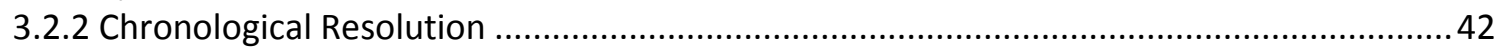

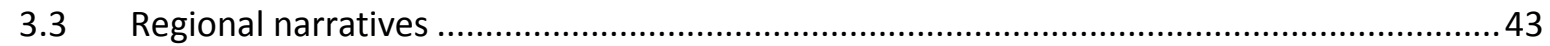

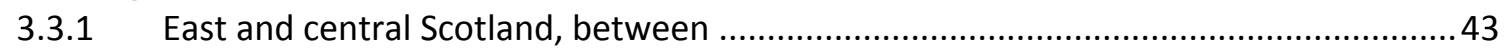

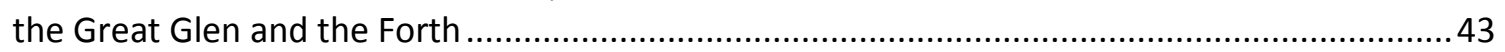

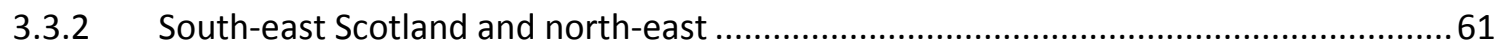

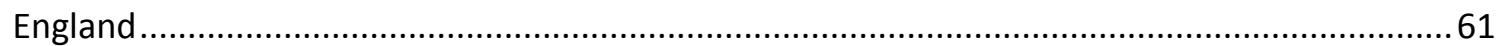

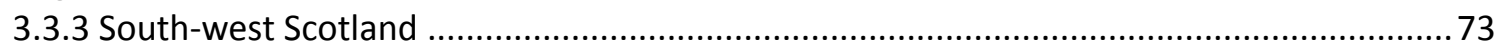

3.3.4 Western Scotland, the islands of the Clyde and the Inner Hebrides, south of the Great

Glen 74

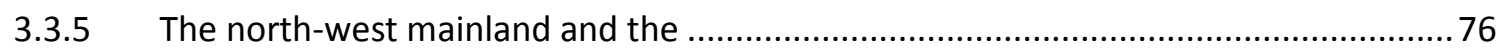

Hebrides north of the Great Glen ................................................................................... 76

3.3.6 The north-east mainland (north of the Great Glen) and Orkney..............................77

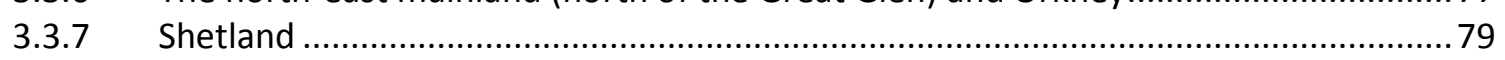

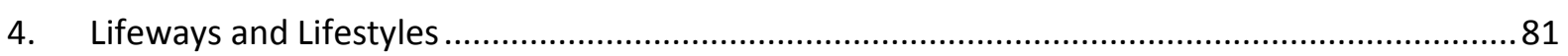

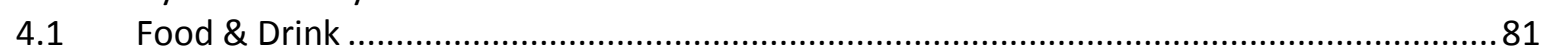

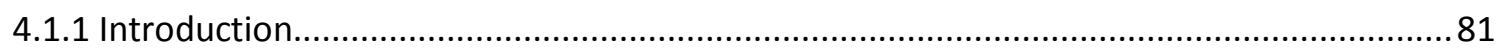




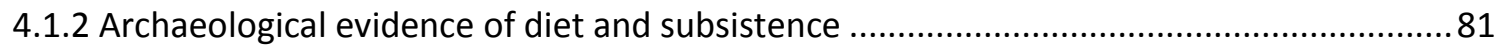

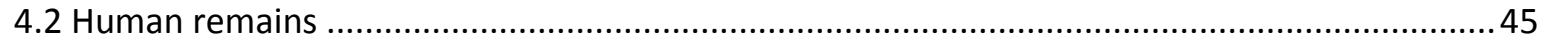

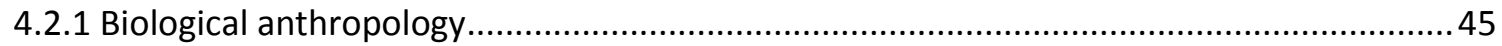

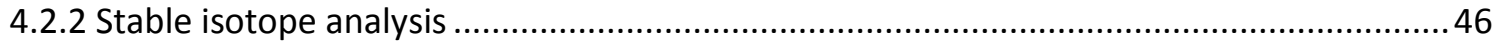

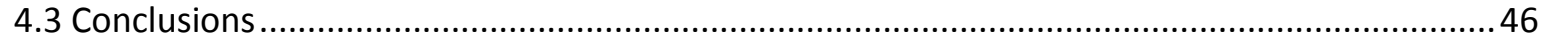

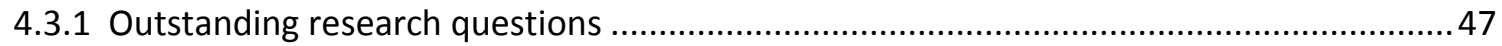

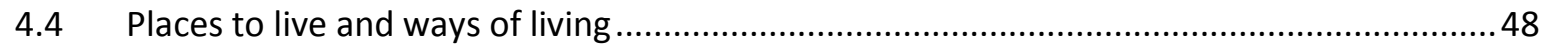

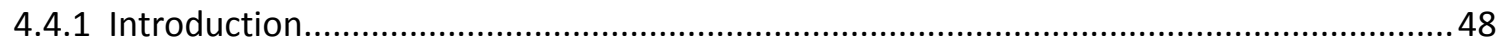

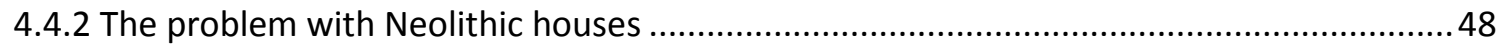

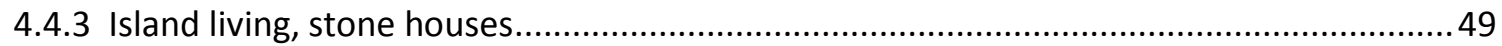

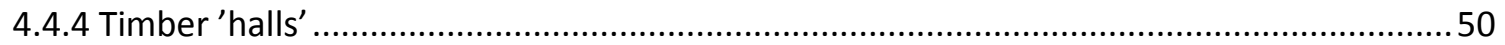

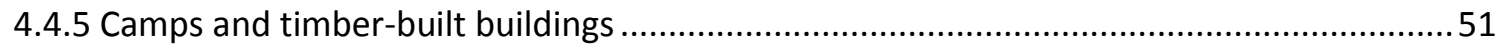

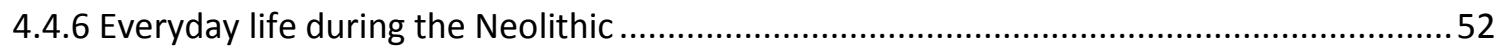

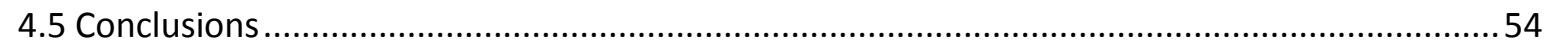

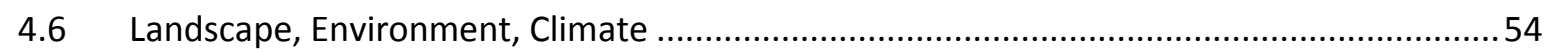

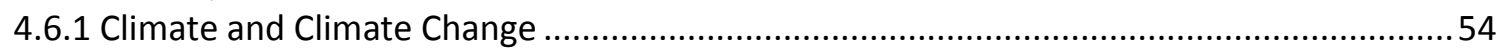

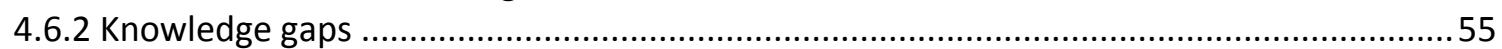

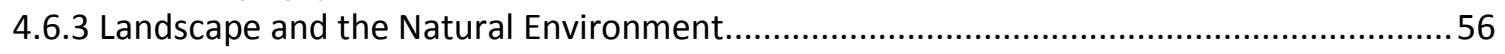

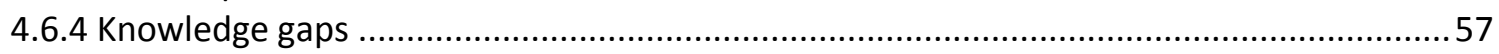

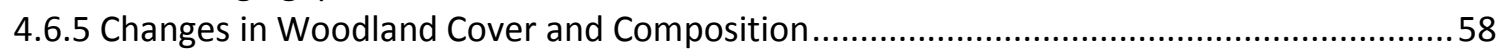

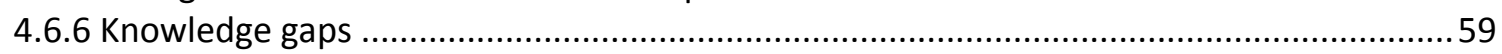

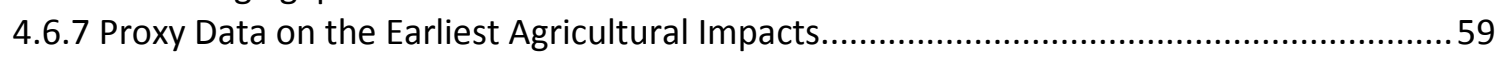

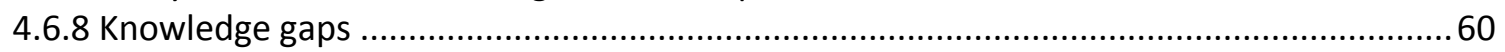

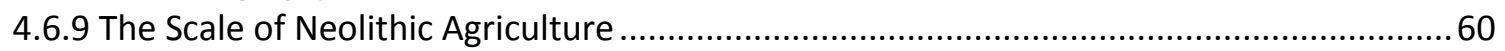

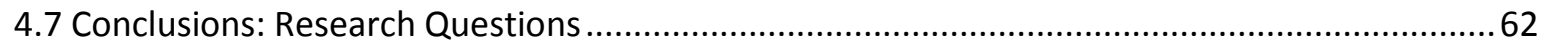

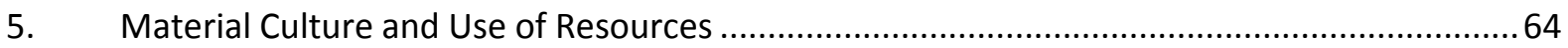

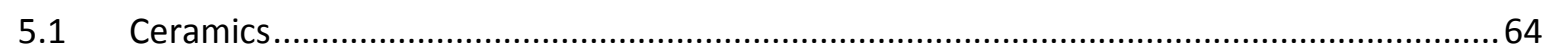

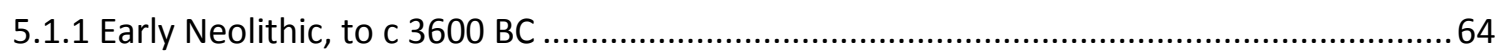

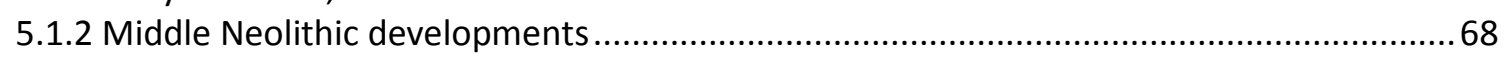

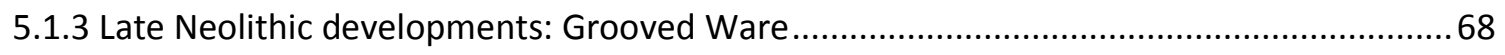

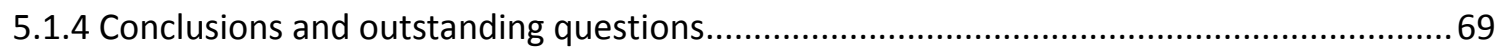

5.2 Stone

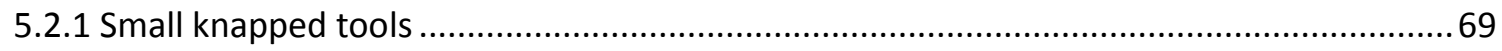

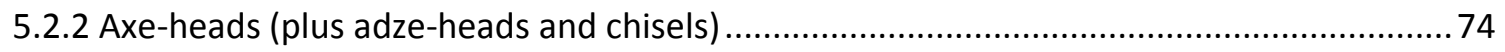

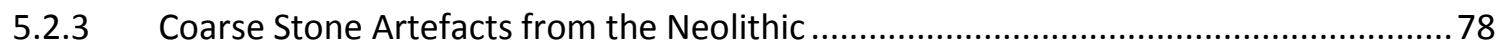

5.2.4 Special' stone artefacts (e.g. carved stone balls and maceheads) ................................ 80

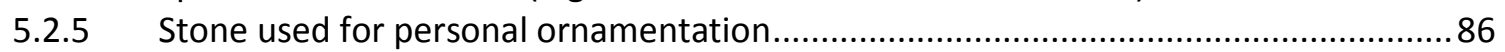

5.2.6 Stone as used as a building material, and for interior fittings .................................... 89

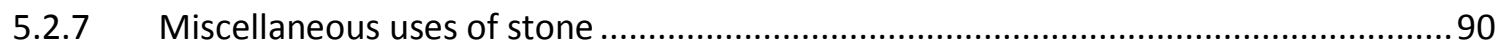

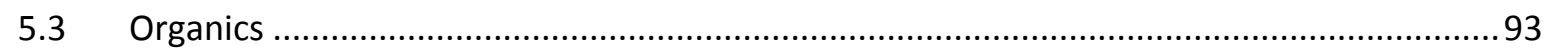

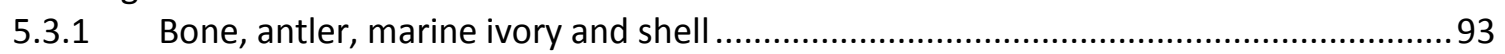

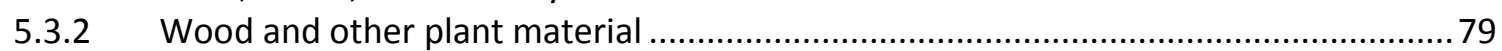

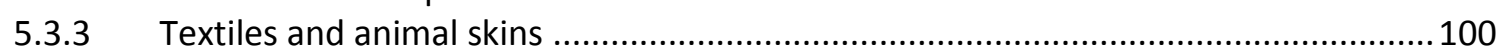

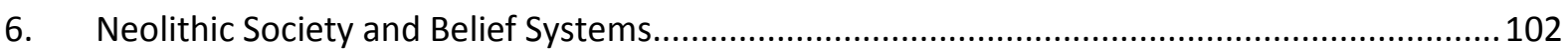

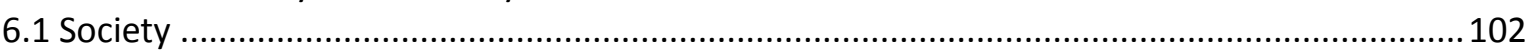

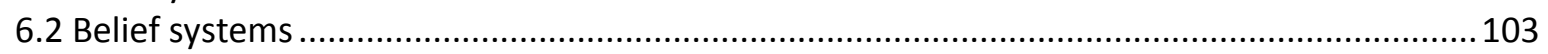

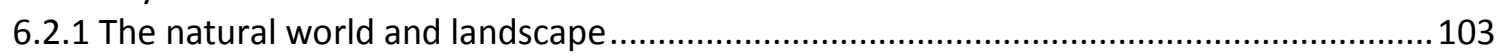

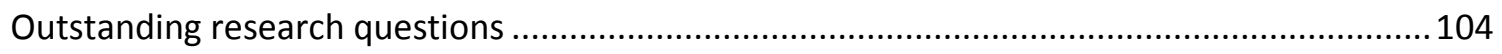

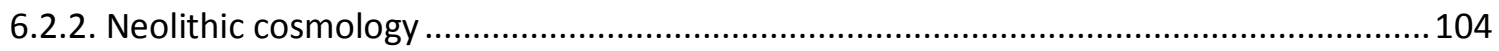


Outstanding research questions .............................................................................. 106

6.2.3. The chronological framework and overview of monuments monuments .................... 107

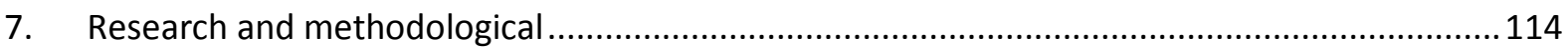

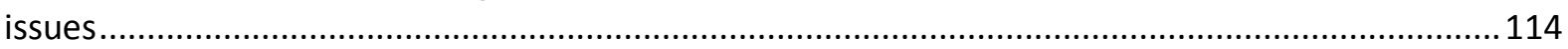

7.1 Introduction .................................................................................................. 114

7.2 Accessibility and quality of existing information (ie dissemination and awareness issues) ...115

7.3 Overall approach, scope of the questions posed and organisation of research ....................116

7.4 Recommendations ..................................................................................... 116

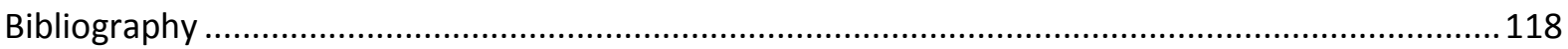

\section{List of Figures}

Figure 1: Neolithic sites (starred) discovered as a result of developer-funded archaeology, 1990-

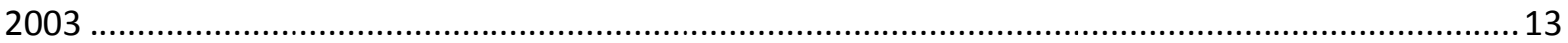

Figure 2: Distribution map of sites mentioned in the text........................................................ 16

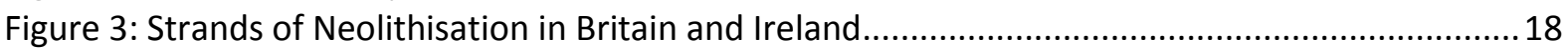

Figure 4: The Atlantic façade, 'Breton' Neolithic strand of Neolithisation........................................19

Figure 5: Plan and section of Achnacreebeag chamber tomb. Crown copyright. ..............................20

Figure 6: The pottery from Achnacreebeag (1-3), and some comparanda for the decorated bipartite

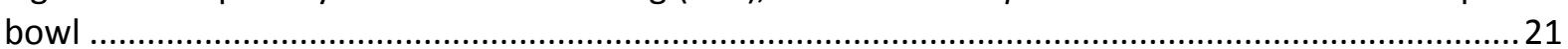

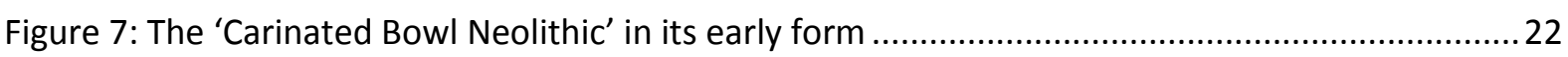

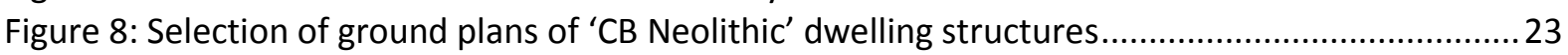

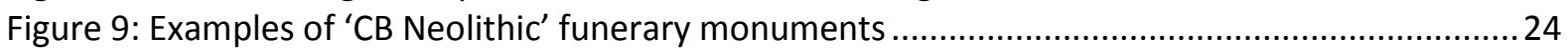

Figure 10: Reconstruction of 'linear zone' mortuary structure. Fr ...............................................25

Figure 11: Carinated Bowl pottery: 1. Carinated and S-profile bowls; 2. Uncarinated bowls and cups;

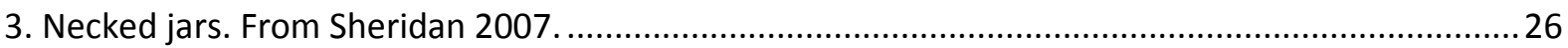

Figure 12: Multi-phase monument construction at Camster Long, Caithness ....................................28

Figure 13: Massive horned cairn: façade of Camster Long, Caithness. Photo: Mick Sharp................. 29

Figure 14: Large buildings at Ness of Brodgar, Orkney. Illustration: Nick Card .................................30

Figure 15: Late Neolithic oblique and petit tranchet derivative arrowheads of black flint, along with other (probably earlier) flint artefacts, from Ormiegill passage tomb, photo NMS..........................31

Figure 16: Bedrock adorned with 'rock art', Ormaig, Argyll \& Bute. (C) Mike Brooks..........................32

Figure 17: The Orkney Vole: a Continental arrival around or just before 3000 BC. Photo: (C) Dr Peter

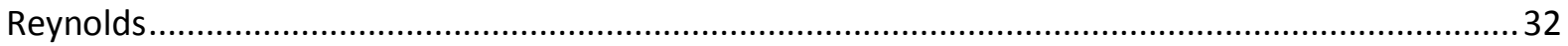

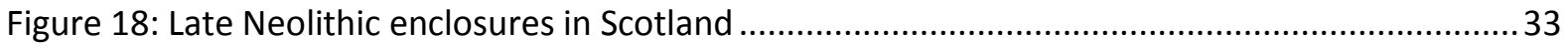

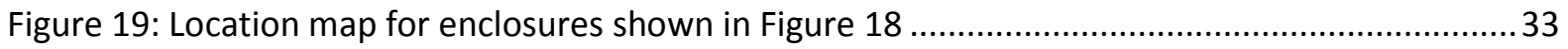

Figure 20: White-tailed sea eagle. From Pitts 2006; Photo: Nature Picture Library ...........................35

Figure 22: Distribution of non-megalithic long barrows in Scotland.............................................44

Figure 23: Distribution of non-megalithic round barrows in Scotland. From Sheridan 2010b ...........45

Figure 24: The 'halls' at Balbridie and Warren Field, Crathes. Reproduced by permission of Historic Scotland and Murray Archaeological Services .........................................................................4 45

Figure 25: Plan of Pitnacree round barrow.....................................................................46

Figure 26: Rectangular timber-built mortuary enclosure at Douglasmuir, Angus. From Brophy 1998

Figure 27: Aerial photograph and plan of cursus at Milton of Guthrie, Angus. From Brophy 1998; Crown copyright.....................................................................................................48

Figure 28: Auchenlaich bank 'barrow' (actually cairn). From Brophy 1998; Crown copyright............49

Figure 29: Unstan Bowl from Spurryhillock, Aberdeenshire. ................................................ 49 
Figure 30: Jadeitite axehead from Garvock, Aberdeenshire (Nationalmuseet, Copenhagen, NM

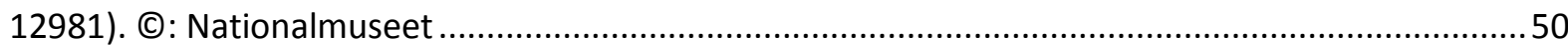

Figure 31: Distribution of Alpine axeheads in Scotland. Image: Projet JADE ......................................50

Figure 32: All-over-polished flint axehead from Bolshan Hill, Angus. CNMS .................................... 51

Figure 33: Distribution of Antrim porcellanite axeheads.................................................................... 51

Figure 34: Example of truncoconic Impressed Ware bowl from Meadowend Farm. Reproduced

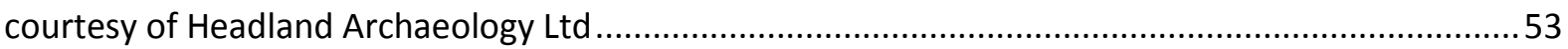

Figure 35: Discoidal flint knife, Pitforthie, Aberdeenshire.@ NMS............................................... 54

Figure 36: Distribution of axeheads of tuff from Great Langdale, Cumbria. From Clough \& Cummins

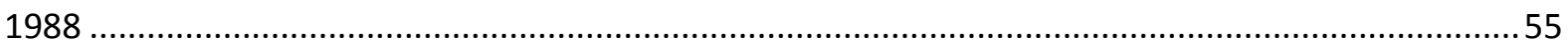

Figure 37: Plan of the flint mines at Den of Boddam, Aberdeenshire. From Saville 2008; plan by

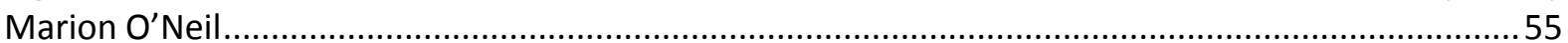

Figure 38: Ground plan of timber building at Stoneyfield, Raigmore, Highland. From Simpson 199656 Figure 39: 'Four-poster' timber structures (A and B) at Greenbogs, Aberdeenshire. From Noble et al.

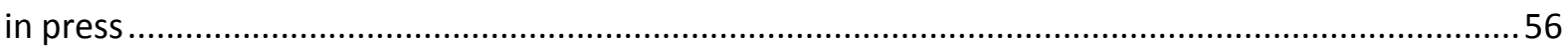

Figure 40: Plan of timber circles at Balfarg henge. From Mercer 1981 ............................................58

Figure 41: Timber circle at Forteviot, Perth \& Kinross. From Noble \& Brophy 2011a.........................59

Figure 42: Edge-polished discoidal flint knife from near Huntly, Aberdeenshire. From Wickham-Jones 1987

Figure 43: Very similar Grooved Ware pots found at Midmill, Aberdeenshire and North Carnaby Temple 2, Yorkshire

Figure 44: Comparative ground plans of known and putative Early Neolithic 'halls' at Doon Hill, East Lothian, Balbridie, Aberdeenshire and Sprouston, Scottish Borders ..............................................63

Figure 45: Plan of rectangular Neolithic house at Ratho, City of Edinburgh. From Smith 1995 ..........64

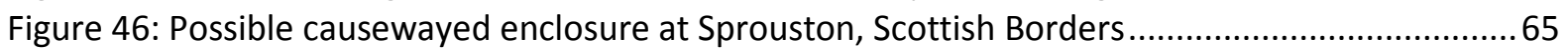

Figure 47: Aerial photo of cursus at Inveresk, Midlothian. CRCAHMS ...........................................66

Figure 48: Bowl of 'modified Carinated Bowl' type from Lanton Quarry. Photo: Clive Waddington...66

Figure 49: Jadeitite axehead from the Traquair Estates, Scottish Borders (C) NMS..............................67

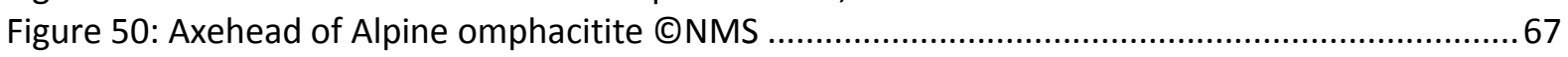

Figure 51: 'Cumbrian club' of Langdale tuff found at Upper Hindhope, Scottish Borders. CNMS......67

Figure 52: Distribution of axeheads of calc-silicate hornfels from Craig na Caillich. From Edmonds et al. 1992.

Figure 53: Middle Neolithic 'cemetery' of cremated remains, plus probably contemporary stone

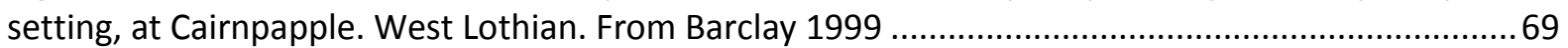

Figure 54: Grooved Ware from Yeavering, Northumberland. From Hope-Taylor 1977 ...................... 70

Figure 55: Stone (or possibly timber) circle at Cairnpapple. After Barclay 1999................................. 71

Figure 62: Large Carinated Bowl pot from Knocknab, Glenluce. Photo: Alison Sheridan .....................66

Figure 63: Felsite workshop within the Neolithic quarry complex at Midfield, North Roe, Shetland.

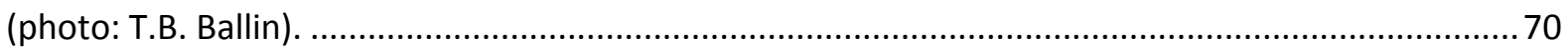

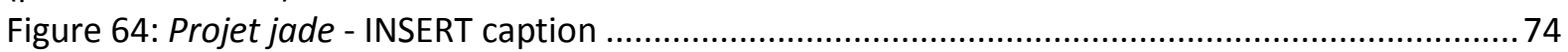

Figure 72: Neolithic axe, with Antrim porcellanite axehead, from Shulishader, Lewis, (C NMS ...........76

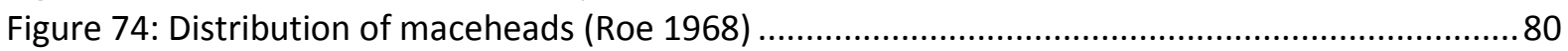

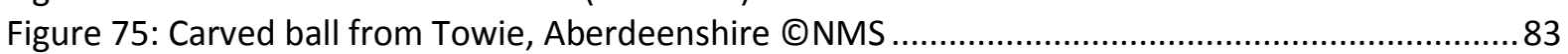

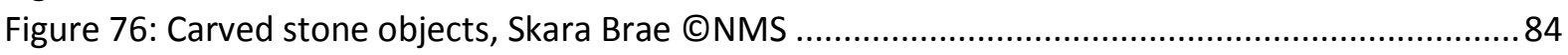

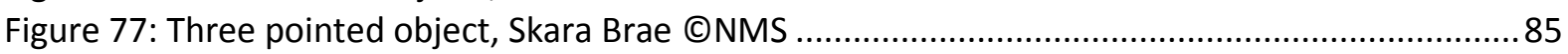

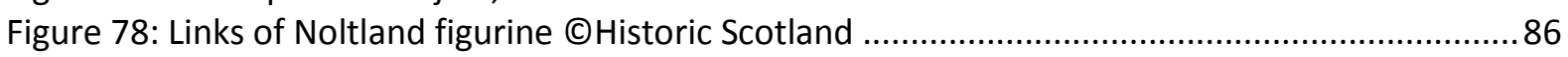

Figure 79: Necklace of jet and amber beads, and associated flint axehead, from Greenbrae (C) NMS 87

Figure 80: Belt sliders from (top) 'Skye' and (bottom) Beacharra, Argyll \& Bute. CNMS....................87

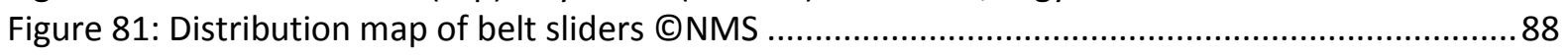




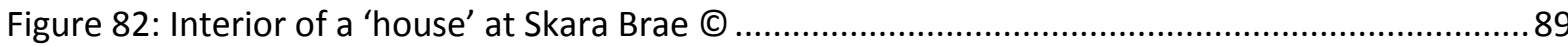

Figure 83: The Lesser Wall of Brodgar revealed to its full surviving height $\mathbb{C}$ ORCA ...........................89

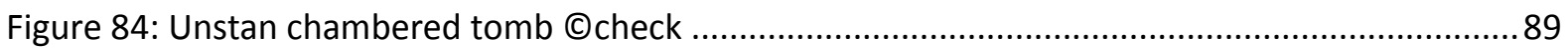

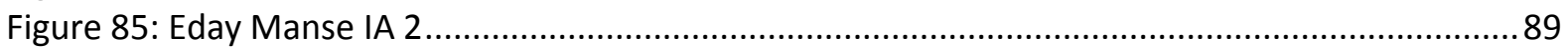

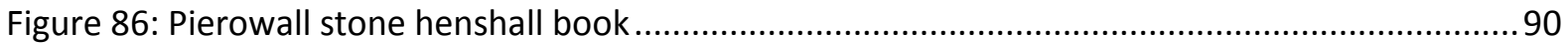

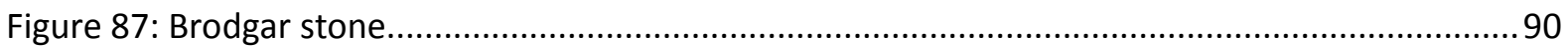

Figure 88: Used piece of pumice from Skara Brae CNMS.......................................................... 91

Figure 89: Painted slab discovered in Structure Eight at the Ness of Brodgar (CORCA....................... 91

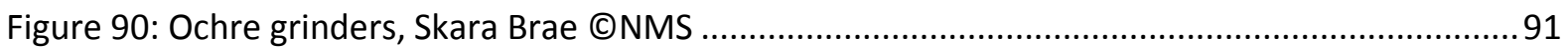

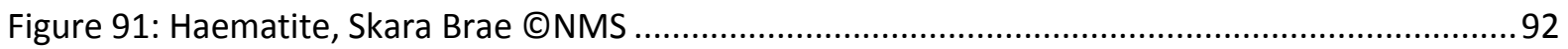

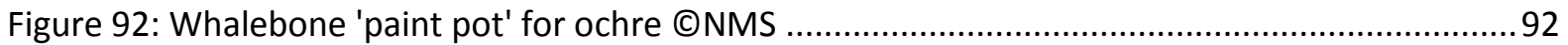

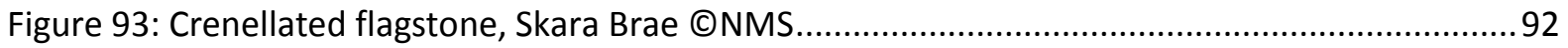

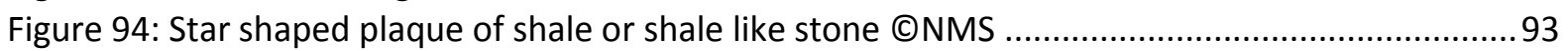

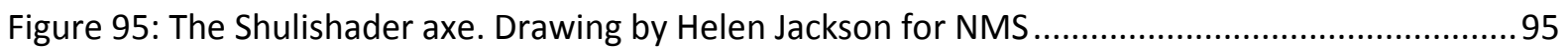

Figure 96: The Rotten Bottom bow Drawing: Marion O'Neil for NMS. ...........................................96

Figure 97: Leaf-shaped arrowhead with traces of shaft of viburnum, from Blackhillock, Fyvie, (C)

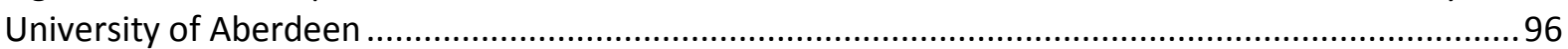

Figure 98: Large part of Grooved Ware pot from Powmyre Quarry. Photo: Headland Archaeology. . 97

Figure 99: Matting impression on the base of a Grooved Ware pot (V275) from Forest Road (C) AOC

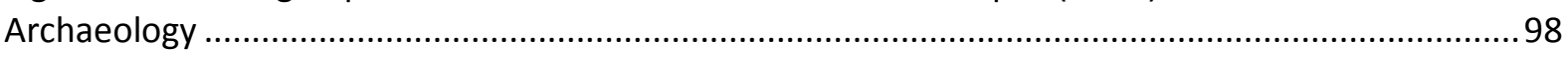

Figure 100: Matting impression on the base of a Grooved Ware pot from House 3, Barnhouse. Photo

by Lynda Aiano, Orkney Museum................................................................................................. 99

Figure 101: Photo of 'mould' made after laser-scanning the Flint Howe sherd (CArchaeology

Department, Exeter University, courtesy of Dr Linda Hurcombe...............................................100

Figure 102: One of five crania from the Orcadian chamber tomb of Cuween Hill. (c) R Crozier .........102

Figure 103: Drill holes identified on a fragment of sternum from the Orcadian chamber tomb of

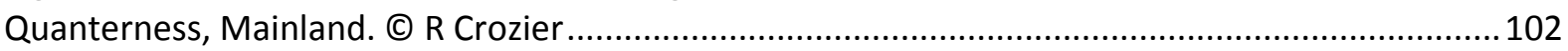

Figure 104: Transcription of the putative causewayed enclosure at Sprouston, Scottish Borders.... 107

Figure 105: Patrick Ashmore's schematic map showing the distribution of chambered tombs and

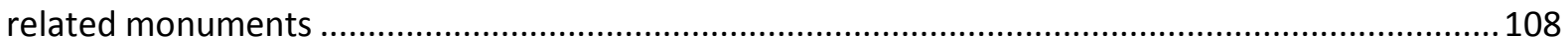

Figure 106: The Droughduil mound artificial mound (photo: K Brophy) .........................................112

\section{List of Tables}

Table 1: Neolithic artefacts held by National Museum of Antiquities of Scotland in 1902, after

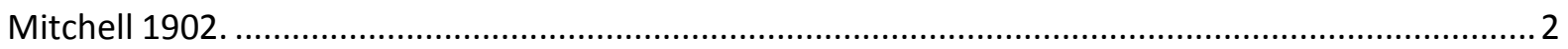

Table 2: Dates for Neolithic cultivation from sites across Scotland; an example of collated data......41

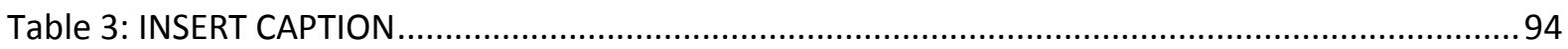




\section{Background: the history of research into Neolithic Scotland, 1840-2007}

This account of the progress of archaeological research into the Neolithic (New Stone Age) in Scotland will be divided into four chronological stages. It will reflect the national, indeed the international stage, upon which this research has taken place over a century and a half.

The Stages nominated are:

- Stage I: The Development of an Idea

- Stage II: The Advent of Childe - the Idea Rebuilt

- Stage III: The Attainment of Expertise

- Stage IV: The Attainment of Critical Mass

\subsection{The Development of an Idea}

\subsubsection{Foundations}

The articulated study of the New Stone Age in Scotland began in a sun-burst of enlightenment generated by Daniel Wilson (1816-1892) with the publication of his seminal work Prehistoric Annals of Scotland in 1851. Wilson was a Secretary of the Society of Antiquaries of Scotland (henceforward SoAS) at this juncture, a body preoccupied with the burden of the accommodation and curation of its collection of some 7000 objects, and he it was who, with David Laing (1793-1878), bibliophile and Treasurer of the Society, negotiated the transfer of the collection to the Crown in this same year although the fruit of these new arrangements was not to be seen for some seven or eight years after this date. Wilson's interest had led him to follow closely the ideas of Christian Jurgensen Thomsen (1788-1865) who, as Secretary of the Danish Royal Commission charged with forming a National Museum of Antiquities in Copenhagen from 1816, ultimately was made first curator of the Museum and published a guide book, Het Ledetraad til Nordisk Oldkyndighed (An Introduction to Nordic Antiquities), that ordered the content of the museum according to the three ages of Stone, Bronze and Iron, in 1836. This volume was translated into English by Lord Ellesmere as A Guide to Northern Antiquities (1848). Thomsen (who was ultimately to be made corresponding fellow of SoAS at its Anniversary Meeting of 1851) was assisted by Jens Jacob Asmussen Worsaae (1821-85) who, in due course, succeeded Thomsen in his post and, in addition, became The King's Antiquary and Professor of Archaeology in the University of Copenhagen. Worsaae was eventually made an Honorary Fellow of SoAS in 1874. He was already a noted barrow excavator and made a truly remarkable contribution by cross-linking Thomsen's relatively simple materials-based system to differential archaeological contexts across Denmark thereby establishing, for the first time, an extended archaeological system that recognised that an age of polished stone was represented only in certain types of sepulchral monuments and associated with certain classes of ceramic artefacts. He published this work in 1843, Danmarks Oldtid oplyst ved Oldsager og Gravhoje (Denmark's Antiquity shown through Ancient Objects and Grave Mounds, linking the antiquities with the burial monuments), a book that was translated by William Thoms, Secretary of the Camden Society, and issued in Britain as The Primeval Antiquities of Denmark in 1849.

Wilson had met Worsaae during his visit to Edinburgh in 1846 when a copy of his book was presented to the SoAS Library. With this example he prepared and published his Synopsis of the Museum of the Society of Antiquaries of Scotland (Edinburgh 1849) and this led directly to his completion of the work cited above that he states had been his intention since his return to Scotland from London and his election to the SoAS in 1846. Thus Wilson's book brought Scotland's (and secondarily Britain's and Ireland's) archaeology to the forefront of European progress in this sphere. Thus his initial chapters contain 'Stone Age' artefacts polished axes, perforated axes and discoid 
knives but also menhirs, cromlechs, stone circles and megaliths.

But Wilson also, (in conjunction with David Laing, and, later, Laing with the support of Arthur Henry Rhind (1833-1863, and elected fellow of SoAS in 1853), also sought to address a number of inadequacies in the current arrangements for the retrieval of material for the museum. The Law of Treasure Trove lacked any of the precision contained in equivalent enactments in Scandinavia. Good relations with the Queen's Lord Treasurer and Remembrancer, a Fellow of SoAS, eventually brought these issues to a solution including appropriate compensation for the finder. Other initiatives included correspondence with the authorities to allow the routine inclusion of antiquities information on Ordnance ('military') maps again successful and a move that was to lead eventually to the foundation of the Archaeology Division of the Ordnance Survey under OGS Crawford - a development of equally huge significance to researches in British archaeology as a whole. Finally circulars corresponding with school masters and local landowners drawing attention to the potential for, and responsibilities of, finds recovery were at least initiated and had a locally varied but important impact.

\section{The Accumulation of Resources}

The revival of SoAS by these dynamic individuals also led to the resolution, after the 70 moribund years since the enthusiasm of foundation in 1780, to publish biennial Proceedings that would appear annually from 1878 onwards - in itself a principal aid to archaeological and (and historical) research in Scotland.

The 'National Museum' (National Museum of Antiquities of Scotland, henceforth NMAS) came into being in 1859, and from 1860 was attracting more than 70,000 paying visitors per annum. The impact of the efforts of Wilson, Laing and Rhind in the 1850s is illustrated by figures given fifty years later
(Mitchell 1902, 11). Here Arthur Mitchell indicates, in the area of Neolithic artefacts alone, that:

Table 1: Neolithic artefacts held by National Museum of Antiquities of Scotland in 1902, after Mitchell 1902.

\begin{tabular}{ll}
\hline $\begin{array}{l}\text { stone ball held in the } \\
\text { collection in } 1851\end{array}$ & $\begin{array}{l}\text { increased to } 134 \\
\text { acquired by } 1901\end{array}$ \\
\hline $\begin{array}{l}32 \text { Skaill knives in } 1851 \\
1901\end{array}$ & $\begin{array}{l}3460 \text { by } 1901 \\
61 \text { flint arrowheads }\end{array}$ \\
$\begin{array}{l}\text { 49 stone axes and } \\
\text { hammers }\end{array}$ & 358 by 1901 \\
18 'urns of all kinds' & 3901 \\
\hline
\end{tabular}

While the era of infrastructural construction and agricultural intensification must account for some of this, awareness and eager anticipation of a reward must also have played a major role. It is probably significant to note that, over the same period as well as the Museum increasing from 1560 catalogued objects in 1851 to 70,654 by 1901 , the Library, another major energiser of research, expanded from 226 volumes in 1851 to 10,875 in 1901 . These are crude measures, but must surely be (and shall be seen clearly are) a measure of research intensity and yield.

By 1860 Wilson had disappeared from the scene. Having failed to attract by his extraordinary accomplishments a Chair in a Scottish University, he emigrated to Canada to take up the Chair of English and History at Toronto University. This, however, was not the sole reason for his disillusion as Wilson also felt acutely the lack of support from "the political establishment" in Scotland for the study of the past - plus ça change.

\subsubsection{The first Research Framework}

Nevertheless by 1860 Archaeology had attracted a new champion - Sir James Young Simpson (1811-1870), probably the greatest friend of womankind, who developed chloroform as an anaesthetic and proved, and 
perhaps more importantly fought for (it was seen as harmful to health, morals and religion) its application in obstetrics - he was, effectively, the founder of the study of obstetrics and gynaecology in the UK and also a primary pioneer of anaesthesia - although to his discredit, an opponent of Listerian antiseptics. His statue stands in Princes Street Gardens and his most appropriate monument used to be the Simpson Maternity Hospital. He was also an enthusiastic and devoted Antiquary who addressed the Society in 1860 in inauguration of its new (Government funded) premises (Simpson 1862, 5-51). His delivery was the first 'Research Framework' in Scottish Archaeology - and idiosyncratic, top/down, incoherent and impressionistic as it is, it is an ambitious 'shopping-list' by the light of its time.

There are about forty (it is impossible to be more precise) suggestions on Sir James' list. Many are Ossianic/Dalriadic. Some are Toponymic/Philological. Some are quite specific, some very general. However the New Stone Age attracts his attention and he seeks to know more of the chambered barrows and cairns at Clava, Yarrows and Brogar and who lies buried there. He also recommends enquiry into the significance of cup and ring marks and Megalithic Circles and Monoliths. He exhorts the Fellowship to contribute to the accurate drawing and description of all classes of antiquity - a theme that is to dominate Scottish prehistoric and historic studies for a century and more leading ultimately to the initial foundation of the Royal Commission ideal in Scotland in 1908.

By 1863 Rhind, who had been elected an Honorary Fellow of SoAS in 1857, died at the age of 30 and his will, as well as diverting monies $(f 5,500)$ originally intended for the University to the Society to establish a lectureship, also allocated $£ 400$ "to be expended in practical archaeological excavations in the NE portion of Scotland.... And I point more particularly, but not exclusively, to the upland districts of Caithness, Sutherland and Ross". Thus was enabled the investigation of one component of Simpson's "shopping-list". By 1866 Joseph Anderson was reporting on the exploration of cairns in the Yarrows area of Caithness, work that continued until a final report in PSAS 1870-72.

Here was a most auspicious commencement to research. A formulated research proposal stimulated the accrual of resources, which led to a planned campaign of excavation in order to isolate and understand, as we shall see, a specific monument type - the horned cairn. The procedure is very close to Worsaae (see Anderson's copy of Worsaae's Museum Guide dated 1862 in which the Danish text is translated into English by Anderson) and vastly ahead of any equivalent archaeological work in Britain and Ireland. (Thomas Bateman's Ten Years' Diggings was published in 1861). Sadly, it will emerge that this momentum was not to be maintained.

\subsubsection{The Neolithic Defined}

In 1865 there appeared, perhaps, the next seminal work in English after Wilson's "sunburst". Half adopting Wilson's invented term (much to the latter's chagrin) Sir John Lubbock (later to be created Lord Avebury and to play a vital role in the ultimate passage through the House of Lords of the first Ancient Monuments Act of 1881) published his important study of archaeology and ethnography Pre-historic times as illustrated by ancient Remains and the Manners and customs of Modern Savages (1865 and successive editions until 1913). The book is important, from this immediate standpoint, as it is the setting for Lubbock's own terminological innovation; "The later or polished Stone Age: a period characterised by beautiful weapons and instruments made of flint and other kinds of stone; in which, however, we find no trace of the knowledge of any metal, excepting gold, which seems to have been sometimes used for ornaments. 
This we may call the "Neolithic" period." Sir John was eventually elected Hon Fellow SoAS in 1873.

By 1874 Joseph Anderson (1832-1916) had been appointed as salaried curator of the NMAS, a development that must have severely restricted any future capacity in him to carry out excavation. Indeed his time was limited for he was appointed Rhind Lecturer for four successive years (1879-82) - lectures that provided the foundation for his important contribution to Neolithic research in Scotland. With logic seldom emulated, and only logical in dealing with periods with no understood internal chronology, Anderson began his account from the most recent time proceeding backwards chronologically. His account of the 'The Age of Stone' therefore occurs in the second part ( $p 229$ onward) of the last volume of the four that cover the entirety of Scottish archaeology as it was seen at the time.

His avoidance of the word 'Neolithic' is indicative, in that he, clearly, felt little point in differentiating that which was, in the Scottish context at that time, unnecessary. We must note that it was clearly seen as necessary by John Evans in 1872 when, working principally in Southern Britain, but perusing material from Scotland to France, he did feel the need to adopt the term in his Ancient Stone Implements and, furthermore, to invent another, 'Palaeolithic' to describe tools associated with 'the Drift' - even if he recognised the singularity of Upper Palaeolithic industries.

Anderson's account of the 'Neolithic' in Scotland is firmly Worsaaean. He opens Lecture IV (Scotland in Pagan Times - Bronze and Stone Ages 1886, 229) by noting the different, collective, highly ordered nature of 'Stone Age' sepulchre and points to his own research in 1865-66 mentioned above which saw excavations of the chambers of a series of cairns, two long cairns at Yarrows and that at Camster, short-horned cairns at Ormiegill and
Garrywhin as well as a series of round cairns at Camster and at Warehouse and the example at Bruan all in the County of Caithness. Cairns excavated at Skelpick and Rhinavie in Strathnaver (Munro 1884, 228-33) are described and the character of these northern long cairns compared to examples elsewhere in Britain - notably in Gloucestershire as well as Yorkshire, Wiltshire and Somerset with the congruity of material culture in terms of flint knives and leaf arrowheads also noted. Lecture $\mathrm{V}$ proceeds to expand upon this, using the observed research of others - $\mathrm{Dr}$ R. Angus Smith at Achnacree, Argyll (Smith 1872, 396) and the work of Canon W. Greenwell at Largie, Kilmartin also in Argyll (Greenwell 1866, 336351). Anderson goes on to examine the work of Farrer at Maes Howe (where interest is almost completely monopolised by the Norse inscriptions!), the work of Thomas in 1851 (Archaeologia 34, 127) at the Holm of Papa Westray and the excavation conducted by Farrer and Petrie (Farrer 1868, 398) and the exiguous description of the entry of Quanterness by George Low as transmitted by the Rev Barry (1805).

Much of this is unsatisfactory but brought to a climax by Anderson's account of R.S. Clouston's work at Unstan, near Stenness (Clouston 1885, 341-351) and an analysis of the associated ceramic assemblage assigned to the period by the association with leaf arrowheads. Anderson recognised the similarity embodied in the design of all of these Orcadian tombs and the relationships, intimate or distant with parallel monuments in Caithness and Argyll.

Finally he considers the rather different situation in the cairn cemeteries of Nairn encountering some difficulty over the associated stone circles which, when not apparently associated with a cairn, available artefactual associations recognised at that time suggested a Bronze Age date - a difficulty that thanks to the efforts of Richard 
Bradley can now be overidden with confidence.

Finally Anderson moves from this courageous associational analysis of immobile and mobile artefacts to a descriptive chapter on the mainly unassociated, randomly located, diagnostic stone tools and weapons perforated and polished hammers, axes and mace-heads and unperforated polished axes and adzes of stone and of flint, leaf and barbed arrowheads, discoid knives and flakeknives and scrapers which, by dint of ingenious experiment, Anderson was able to try to relate to particular functions. He is acknowledged by John Evans as having read and commented upon the Scottish component of his book, Ancient Stone Implements of Great Britain, published in 1872, and Anderson uses that source critically to enlighten his own account.

Within the publication of Anderson's account the expansion of Neolithic research seems to have received new stimulus after a period of relative stasis in the 1870s. Two scholars enter the field who are to make an important contribution - David Christison (1830-1912) and Frederick R. Coles (c.1860-c.1925) whose work in producing the 'drawings and description' of enclosures, stone circles and other monuments, which Simpson had demanded, are a leitmotif of the coming 30 years.

\subsubsection{An International Profile?}

Another important development at this time was a quite perceptible inclination for the interest in Scottish archaeology (prescribed by Prof Simpson as the search for a Scottish prehistory just as there is a Scottish history) to move towards a more international perspective. An important figure in this regard is the Rhind lecturer for 1888, $\mathrm{Dr}$ Robert Munro, who had published Ancient Scottish Lake-Dwellings or Crannogs, 1882 (Edinburgh) after engaging for some years in investigation of such sites in SW Scotland. He was engaged to lecture on Lake Dwellings in Europe - an excursus on the Balkan, North Italian, Swiss, S German, SW French Lake dwellings, the Dutch Terpen as well as English, Welsh and Irish sites. Munro was eventually to endow an important lectureship in the University of Edinburgh - modelled on the Rhind antecedent - lectures to explore the spheres of both Archaeology and Anthropology. He published a successor to Anderson's survey (Prehistoric Scotland and its Place in European Civilisation, 1899, Edinburgh) which was an important advance of that broader view of prehistoric study.

That development is, however, to be quite abruptly curtailed shortly before the turn of the century. In 1896 Oscar Montelius (Professor, National Museum of Sweden, Stockholm) and Sophus Müller (Director of the National Museum, Copenhagen) were elected as Honorary Fellows thus re-affirming that umbilical research link to the Baltic established by Wilson. Furthermore the focus of SoAS energy moves away from prehistory with the limelight shed upon the important Early Christian Monuments project, being pursued by Anderson and Romilly Allen and the long series of resource-hungry Roman period excavations largely around the course of the Antonine Wall, but commencing at Burnswark in 1898 and continuing until Cappuck, Roxburgh in 1912. It is also interesting and puzzling that, apparently at a date around 1900 the steady rise in number of the fellowship of SoAS ceases and the attendance figures at the NMAS as recorded and published show a quite sudden reversal of their steady increase [linked to the move in 1891 from Princes Street to the Findlay Building in Queen Street (Stevenson 1981, 173)] until, from 1907, they are no longer published.

The steady and valuable recording of stone circles continues by F.R.Coles, a landscape painter as well as archaeologist living in Kirkcudbrightshire prior to his taking up post as curator of the Museum. There is, however, 
relatively little other indication of interest among Fellows in 'the Neolithic' other, perhaps, than the intervention of another important individual who is to shape the way forward.

Baron Abercromby of Aboukir and Tullibody (1841-1924) was a soldier in the Rifle Brigade who had developed a very considerable gift for foreign languages (he spoke Italian, French, Spanish, German and Russian and had some knowledge of Finnish and Old Irish Gaelic. He was elected to SoAS in 1879 , and became President in succession to Sir Herbert Maxwell in 1913. From 1904 to 1907 he published three papers in PSAS (Abercromby 1904, 323-410 - Chronology of Beakers; Abercromby 1905, 326-44 - Ornament of Beakers; Abercromby 1907, 185-274 Relative chronology of Cinerary Urns (which were eventually expanded and given final form in his two volume A Study of the Bronze Age Pottery of Great Britain and Ireland (1912). For this work Abercromby travelled extensively, commissioned photographs on a massive scale and set an entirely new standard for prehistoric studies in Europe. His achievement matches that of his contemporary soldier, Augustus Lane-Fox, later Pitt-Rivers, in the field. The somewhat insular (with exceptions indicated), faltering performance of the Society with its two decade-long focus away from prehistoric study may well have been sufficient to persuade Abercromby that rather than see any further sums made available to the Society consumed in such pursuits he would turn to the University (in yet another link in the long chain of conflict of interest between the two organisations - beginning in 1782), to expend his bequest in a manner more closely allied to his interests - prehistoric in focus, European in extent and internationalist in attitude.

Thus it was that, by 1916 , the Abercromby bequest in favour of the University of Edinburgh for the foundation of a Chair to be named after its benefactor was made, to become reality after Abercromby's death in October 1924.

By this time the catastrophe of the First World War had been enacted (although it was by no means 'over'). The SoAS had managed to continue from 1914-24 its excavation at Traprain Law (although suspended in 191618). F.R.Cole's work on Stone Circles was over - his desire to continue the work possibly eroded by the death of his son, a brilliant young composer and protégé of Gustav Holst, at the Third Battle of Ypres. Joseph Anderson had died in 1917, David Christison had died just before the War.

J.G. Callender ultimately succeeded Curle (who became Keeper of the Royal Scottish Museum) as Keeper of the National Museum of Antiquities and A.J.H. Edwards, returned from service with the RAMC, to become his assistant. The latter commenced a series of excavations in the far north (Chambered Tomb at Ham, Caithness) very much in the Andersonian tradition, if not method; Callender (see Graham 1981, 221) was to produce useful studies of artefacts located in the collection including a seminal, if rather conservative, study of Scottish Neolithic pottery (Callander 1929, 29-98) which, however, did not draw in any comparison with wider British or Continental material, indeed Graham recollected that Callender held anything to come from south of the border in low regard.

\subsection{The advent of Childe - the Idea Rebuilt}

At this point begins, very suddenly, the second phase of Neolithic research in Scotland. Vere Gordon Childe (1892-1957) is appointed to the newly established Abercromby Chair in the winter of 1926-27-a man of single-minded and seemingly boundless energy who had already reshaped contemporary thought about early farming prehistory. In 1925 he had published The Dawn of European Civilisation in which was 
evolved, quite suddenly, an entirely new vision of archaeological material encompassing in both the widest geographical sense and in the totality of its view of the local context. The 'archaeological culture', was much more than the sum of its parts. Hitherto with a few hesitant further steps within the Worsaaen approach, most archaeologists had looked only at the parts. Now the archaeological imagination was liberated, and was offered a disciplinary framework, a model, within which it could operate efficiently, usefully and consistently.

\subsubsection{The Accumulation of Data}

Childe had virtually no extended experience of excavation but was almost immediately invited by the Office of Works to conduct excavation in advance of consolidation of the site at Skara Brae, Orkney. He was also elected a Fellow of SoAS in 1927, immediately on his arrival, and was a member of Council by 1930 - he was, in other words, wellintegrated into Scottish Archaeology (although his unorthodox persona inevitably alienated some of the more conservative element). What was the effect of this integration?

1) Orkney replaces the Northern Mainland as a 'laboratory' for Scottish Archaeology. 'Anderson Land' becomes 'Childe/ultimately Renfrew Land'. This imbalance still, to some extent, embarrasses the discipline now, just as it formerly did.

2) Skara Brae was ultimately well dealt with in narrative, but not in detail. Consequently as an internationally important site it has generated its own harvest of off-shoot projects (including Rinyo), only one of which has been thus far adequately published. Childe went on digging important sites on Orkney at the peak of his reputation.

3) 'The Neolithic agenda' is subsumed by Childe and for some years his reports of Skara Brae PSAS 63 (1928-29), PSAS 64 (1929-30), PSAS 65 (1930-31), 2277 (Callender J.G. Relics from Skara Brae) dominated the menu. Childe also excavated Kindrochat Chambered Tomb, (PSAS 65 (1929-30), 78-114) and Chambered Tombs at Kilfinan, Argyll (PSAS 66 (1931-32). He also conducted work at Old Keig Recumbent Stone Circle, Abers. (PSAS 68, 1933 -34) when his research students Margaret Mitchell and Howard Kilbride-Jones also played a part carrying out work in Neolithic sites (Mitchell at Nether Largie Chambered Tomb (PSAS 64 (1929-30) and Kilbride-Jones - Recumbent stone circles at Loanhead of Daviot and Cullerlie (PSAS 69 (1934-35) 168223). Margaret Mitchell also was to publish her Doctoral thesis in PSAS 68 (1933-34), 132-89, on A New Analysis of Beaker pottery.

Sir W. Lindsay Scott was a close friend of Childe from the latter's days in London as librarian of the Royal Anthropological Institute. After service in the Great War he became a civil servant living in London. With Childe's encouragement he excavated the Chambered Cairn at Rubh an Dunain, Isle of Skye (PSAS 68 (1933-34), 194-223, that at Clettraval, N.Uist (PSAS 69 (1934-35), 480536) and that at Unival, N Uist (conducted in 1935 and 1939 and fully published in PSAS 82 (1947-48), 1-49). In 1937 he undertook the excavation of the island occupation site at Eilean an Tighe, N Uist (PSAS 85 (1950-51), 137).

Childe's excavation at Skara Brae had brought him close Orcadian associates, among them Walter Grant who went on to excavate a number of Orcadian chambered cairns (Westness, Rousay (PSAS 68 (1933-34), 7173), and Taversoe Tuick (PSAS 73 (1938-39), 6-31). His initial work at Rinyo led to Childe taking over the work in 1938. J.G. Callender, Keeper of the National Museum of Antiquities 
and C.S.T. Calder, Investigator in RCAHMS, were also active at this time in Neolithic matters. Callender, one may suspect in direct response to Childe's influence, pursued his Neolithic interests excavating three of the long stalled cairns of Orkney (Knowe of Yarso (PSAS 69 (1934-35), 325-51) (Knowe of Rousay PSAS 70 (1935-36), 407-19) and (Blackhammer PSAS 71 (1936-37), 297-308).

Altogether this was a magnificent display of the outcome of archaeological energy in the twelve years between 1927 and the advent of the Second World War. It furnished a massive accession to the data available for interpretation and broadened, quite intentionally on Childe's part, the geographical evenness with which the country was covered. The development of research in Aberdeenshire, Perthshire and the Western Isles was to balance previous emphasis on Caithness and Orkney and where work continued in Orkney emphasis shifted somewhat towards settlement archaeology and broadened approaches to funerary sites.

\subsubsection{The Childe Synthesis}

A great deal of this influx of data was available to Childe for synthesis into The Prehistory of Scotland (1935) - a stunning achievement for its time - unrivalled elsewhere in Europe and a more than worthy successor to Anderson's innovative volume. The Prehistory of Scotland, however, stands prominently as the inspiration, whether by reaction or support, for all subsequent work on the period. In the course of two chapters the Neolithic in Scotland is given its current 'shape' in terms of its material culture and its classification - with the exception, perhaps, of Grooved Ware which Childe was only to understand correctly by 1938 . This is not to suggest that there is any single component of which our understanding has not changed since 1935. One may choose to eschew some of its 'migrationist' content, but the origins of our current state of knowledge are all visible there. It was a profoundly revolutionary decade for the evolution of the Scottish
Neolithic in a way that it was not for any other period.

The Second World War, of course, brought a quite sudden break to this extraordinary period of development. Childe spent the war writing a number of 'generalist' archaeological titles "What happened in History" (1942) and "Progress and Archaeology" (1945) among them, but also produced Prehistoric Scotland (1940) a revision of the 1935 synthesis; carrying out the assessment and rapid survey of sites threatened by war-work with Angus Graham, and after the death of Edwards in 1943 , the general direction of the National Museum prior to R.B.K. Stevenson's return from war service. In 1940 he did further service for Scottish prehistory by publishing Prehistoric Communities of Britain and Ireland (1940) a synthesis of British prehistory within which Scottish developments at all periods were accorded appropriate attention and incorporated within the over-arching narrative. (cf. Prehistoric England by J.G.D Clark, published in the same year) This precedent imposed additional responsibilities upon Scottish researchers which had, perhaps, not received appropriate emphasis previously; and simultaneously ventilated, illuminated and stimulated research at every level and in all parts of the United Kingdom..

With the end of the War came changes of personnel across archaeology in Scotland and the valedictory survey by Childe, Scotland before the Scots,(1946), in which some of the 'migrationist' excesses of Prehistoric Communities were softened in order to lend weight to a more formally Marx/Engels related view of socio-economic stages of development - a treatment that Childe himself felt was more appropriate than his 1935 approach, and which certainly has, in some quarters, complied more readily with the thinking of the decades since 1946.

However, as Scotland's archaeology came out of its Anderson shelter in 1946 (to use Stuart Piggott's expression) there remained 
enormous challenges to face. The archaeology of the Neolithic, as understood, was still almost entirely the archaeology of upstanding monuments. There was no chronology that could be said to be clearly indicative of succession in the Neolithic and indeed the duration of the period was wholly misunderstood. Excavation standards were, even with respect to the temporal limitations, below the standards of much that was being accomplished elsewhere in Britain. And thus begins the third phase of research into the Scottish Neolithic.

\subsection{The Attainment of Expertise}

\subsubsection{Post-World War II Developments}

Changes in personnel (Stevenson replacing Edwards as keeper of NMAS, Piggott replacing Childe etc) do not appear to this writer to have exercised quite the same impact as the appearance of Childe in 1926. The change is subtler and more prolonged. It is true that Stuart and C.M. (Peggy)_ Piggott (Stuart Piggott 1910-1996) brought to Scotland an intimate knowledge of excavation techniques, much improved by (Pitt Rivers through St.George Gray to) Wheeler with Dorothy Liddell, the Curwens, Piggott himself and especially W.F. Grimes as important practitioners throughout the 1930s and the exigencies of the recording of "Defence Sites" in the war years. The opening of altogether larger areas, greater skills in the treatment and analysis of subsoil types and their anomalies, and a vastly greater awareness of the importance of accumulated stratigraphy, as well as an enhanced awareness of the nature of research-design were all formulated for the first time in Wheeler's Archaeology from the Earth published after much delay in 1954 - the outcome of the 1951 Rhind Lectures entitled "The Discipline of Field Archaeology". As important was the contribution by Richard Atkinson, published in 1946 - Field Archaeology - which, in many ways, was more severely practical and suited to British experience than Wheeler's compendium. It is not insignificant that Piggott sought Atkinson as his assistant in Edinburgh in 1949. The 1958 publication of W.F. (Peter) Grimes' Excavation of Defence Sites, 1939-1945, with its revelation, by example, of an entirely new standard of recording and publication, was also a key to the development of the new approaches emergent in the 1960s.

\subsubsection{The Piggott Synthesis}

As important (and even more delayed in coming to press) was the magisterial survey of the British Neolithic (that gave full and balanced weight to the Scottish dimension) that appeared from Cambridge in 1954, Stuart Piggott's Neolithic Culture of Britain and Ireland (reprinted in 1972).

\subsubsection{Aerial Prospection/Remote Sensing}

The principle of recording ancient sites from the air, details of which are invisible to the ground observer, had been well known since before the First World War and practised consistently for archaeological purposes since at least the 1924 season of photography undertaken by O.G.S. Crawford and Alexander Keiller in Wessex and published as Wessex from the Air (1928). However Scotland was not initially seen as a propitious location for such prospection and transit costs rendered it a difficult subject for sorties from England. In 1945, however, the Cambridge University Committee for Aerial Photography was established and, under the direction of $\mathrm{Dr}$ (later Professor) J.K. St. Joseph, flew extensive sorties seeking, primarily, evidence for Roman military sites in southern Scotland but demonstrating the receptive nature of, particularly, lowland soils in Scotland to this form of remote sensing and, often, recording prehistoric sites. These lessons were learnt and programmes of aerial photography were established that were eventually consolidated into the RCAHMS Aerial Photographic Survey programme begun in 1976 . 
The massive impact of the accretion of knowledge of sites of all periods, but not least the Neolithic, by means of this approach is difficult to overstate. Most importantly, and particularly with the Neolithic in view, it rebalanced the modern view of the monument inventory revealing whole classes of site hitherto invisible (i.e. very largely speaking non-stone built) which often are the host to deposits, cumulative and undisturbed, able to offer stratified deposits of cultural material unlikely to have been disturbed. These are circumstances difficult to encounter with confidence in voids natural, or manmade, in stone built monuments. The number of such sites recorded since the 1960s, in the Neolithic alone, numbers in the hundreds.

\subsubsection{Radiocarbon Chronology}

Finally among the very many laboratory techniques that have emerged to enable the analysis of residues upon, or the innate content of, archaeologically recovered materials, among the earliest and certainly the most consistently important to date, is the radiocarbon dating method developed in Chicago in the late 1940s with the first dates in Scotland becoming available in the 1960s. More and more dates of greater and greater internal precision have appeared since and the statistical and mathematical sophistication in their treatment has increasingly refined their interpretation.

These innovations dependent upon availability of aeroplanes, fast film, the study of radioactive decay, and the advent of largescale 'rescue' excavation were, among many other things, all products of war-time developments. They have had the potential for the total re-shaping of the research environment in Neolithic archaeology, although, as will be explored below, this did not happen in Scotland with immediate effect due to relatively slow adoption.

\subsection{The Attainment of Critical Mass}

Since 1945 the progress of archaeological research in the Scottish Neolithic has been well summarised by Dr lan Kinnes (PSAS 115 (1985), 15-57) and latterly by $\operatorname{Dr}$ Kenneth Brophy (PSAS 136 (2006), 7-46) and the reader is referred to these papers for detailed analysis of Neolithic research since the Second World War.

What were these potentially re-shaping developments?

a) Piggott's study, still essential and foundatory to any understanding of the period, was rendered in one important regard obsolescent overnight. His chronology was clearly wrong (and became progressively 'more wrong' as the issues surrounding calibration were fought out in the mid-1960s). As a consequence there was no sense of a 'grand legacy' with the possible stultifying effect that might have ensued.

b) The rapid increase in palaeoenvironmental information, notably pollen analysis, through the 1950s and 1960s brought about the general rejection of the simplistic and misleading 'Foxian' Highland/Lowland Zone determinist view (C.J. Fox The Personality of Britain, Cardiff, 1932). This, together with a re-appraisal of the nature of early agriculture, saw a rapid change in dealing with the question of farming settlement in remote Atlantic locations.

c) Radiocarbon dating from the outset, but increasingly with calibration, physical dating demonstrated that the Neolithic was three to four times longer than originally thought although with 'the same amount of material culture' to fill the much expanded time-span. This changed attitudes to any sense of instantaneity of change, perception of continuity, 
and 'completeness/integrity' of dataset.

d) Absolute dating - has had the effect of "internationalising" the Scottish Neolithic as immediately and directly comparable chronology was available, so that meaningful and increasingly precise comparisons could be made from Orkney to S England, - or to the Pyramids for that matter (see the Historic Scotland erected walk-way to Skara Brae!). New questions and narratives could thus emerge about directionality of influence, autonomy of design and cultural and social interrelationships. It may even be possible to predict a resurgence of the historico-cultural school's role in modelling the past.

e) Recovery of evidence of new sitetypes such as cursus monuments, henges (see Atkinson PSAS 84, (1949$50), 57-66$ as an early example), henge-enclosures, long barrows, 'halls', long mortuary enclosures etc). These all provide additional specific comparators over and above the generalised links provided by megalithic building and ceramic techniques to the remainder of Britain and Ireland and indeed into Europe. This has been a further force in the development of wider perspectives for Scottish Neolithic studies.

f) The Study of organic residues in and on artefacts, and of manufacture and use-wear traces offers limitless opportunities for international crossreferencing, relative and absolute dating, and also, alongside palaeoenvironmental study, socio-economic investigation.

g) The larger scale of excavations made possible by increased resources, the increased realisation of the sensitive control capacity of earthmoving machines, and the feed-back of the questions asked of landscape and environmental approaches themselves (see 2 and 6 above).

h) Diffusionist arguments. A number of the above considerations have applied considerable restraint to the consideration of the diffusion of the cultural record through artefactual typology. The advent of absolute dating has also diminished the perceived requirement for evidence for direct contact with locations where established chronology can be drawn upon has also resulted in arguments for migration and diffusion losing force, and the current of archaeological enquiry has been diverted in new directions.

From 1945 until c.1960 there is a relatively slow reassertion of the research profile that had existed prior to the War. Childe, his affection for the far north undimmed, was to continue investigation in Orkney even from his new eminence at the Institute of Archaeology in London - continuing and completing his work at Rinyo and conducting for the Office of Works investigations prior to the conservation and restoration for public display of the chambered tombs at Quoyness and Maes Howe. C.T.S. Calder also continued his work (after the publication of the Inventory for Orkney and Shetland in 1946) which brought to a profoundly important climax his work on prehistoric (notably Neolithic) settlement on Shetland as well as the distribution of chambered cairns there (PSAS 96 (1965), 37-86).

However the Piggotts were introducing a new style of excavation featuring complex project design to answer specific questions and consideration of diachronic development (at Cairnpapple PSAS 82 (1947-48), 68-123), while Audrey Henshall was initiating her creation of the tool-kit for the comparative analysis of the chambered tombs of Scotland - following in the footsteps of Christison, Coles, Anderson and Romilly Allen, but 
setting, with Jimmy Davidson, an elevated standard all of her own.

These forces were combined in the prosecution of a series of excavations of Clyde Cairns by Stuart Piggott and Terence Powell at Cairnholy, Galloway (PSAS 83 (1948-49), 10361); Audrey Henshall and Margaret Stewart (formerly Crichton Mitchell) at Clach na Tiompan, Perthshire (PSAS 88 (1954-56), 11224); Euan Mackie at Monamore, Arran (PSAS 97 (1963-64), 1-35); J.X.W.P. Corcoran at Mid Gleniron, Galloway (1969a; 1969b); and Jack Scott at Brackley, Kintyre (PSAS 89 (1955-56), 22-54) and at Beacharra, Kintyre (PPS 30 (1964), 134-58). Add to this Corcoran's work at Loch Calder, Caithness (PSAS 98 (1966-67), 1-75), Henshall's and Wallace's work at Embo, Sutherland (PSAS 96 (1962-63), 9-36, and Coles' and Simpson's work at Pitnacree, Perth (PPS 31 (1965), 34-57) and we will observe an enthusiasm for Neolithic funerary monuments that equals the ferment of the 1920 s and 30s, in the 1950s and 60s but in a far more proficient and technically accomplished way than the very best of earlier work. It was, however, "the same as before but better" and indeed continued as a dominant theme well into the 1970s.

The vision began to broaden with the move, inevitable and inexorable, within Orkney to the questions of a broader nature prompted by the variety and sheer quantity of relatively well documented evidence within a defined landscape. The modern phase of work was pioneered by Graham and Anna Ritchie's work at Stenness and the Knap of Howar, David Clarke's work at Skara Brae, John Hedges' operation at Isbister and John Hunter's in Sanday. Renfrew's campaigns of excavations at Quanterness and the Ring of Brodgar offered a seed bed for ideas and research that has created the 'pull' to draw further generations of scholars into opening a truly bewildering variety of sites, many producing astounding quantities of data. An enlightened approach by Historic Scotland has selectively supported elements of this work enabling the introduction of excellent research design to the deployment of the highest standards. The approaches pioneered by the Piggotts in Scotland of project design (they wouldn't have called it that!) and large-scale exploration have been exploited widely. In a sense, Orkney introduced the fourth phase of Scottish Neolithic research - the stage of 'Critical Mass'. Resources have become available that allow the input of effort and technique that promote a proportionate response to the challenge of the obtainable knowledge that waits untapped.

Yet, in Orkney, these extraordinary developments have brought with them problems of their own making.

The sheer volume of work has led to massive back-logs (in some cases "preparationperiods") some as many as twenty or even thirty years long. It is, however, a cautionary thought that more excavation is proceeding now than ever before, and the consequent data and conclusions not even prepared for general assimilation before equivalent or closely related sites are being excavated in succession. That cannot, of course, support the ideal of 'project design' as the foundation of good excavation and, therefore research practice, (as described by Martin Carver recently in his 2010 Rhind Lectures). Perhaps the time has come to call at least a selective moratorium on further purely research work in Orkney until this mountain of undigested data is diminished - bearing in mind that the capacity to diminish it, and any further account, may itself, in the future, decline with the public funds that, generally, are its chief means of support.

Gordon Barclay has not been alone in questioning the legitimacy of sometimes allowing the 'tail' of Wessex (England) or Orkney (Scotland) to 'wag the (Scottish) dog'. It has been accepted that developments in Orkney may, perhaps, have unduly influenced research project design elsewhere in Scotland from a stand-point that is, presumably, 
scarcely 'typical'. The major breakthrough towards a resolution of this conundrum came with the whole ethos of 'developer funded archaeology', and NPPG5, compelling archaeologists (usually commercial archaeologists) to dig in areas favoured by developers rather than by archaeologists themselves. It is these interventions that have, in many instances, led to patternbreaking discoveries rather than the patterndetermined ones chosen by the archaeologists themselves.

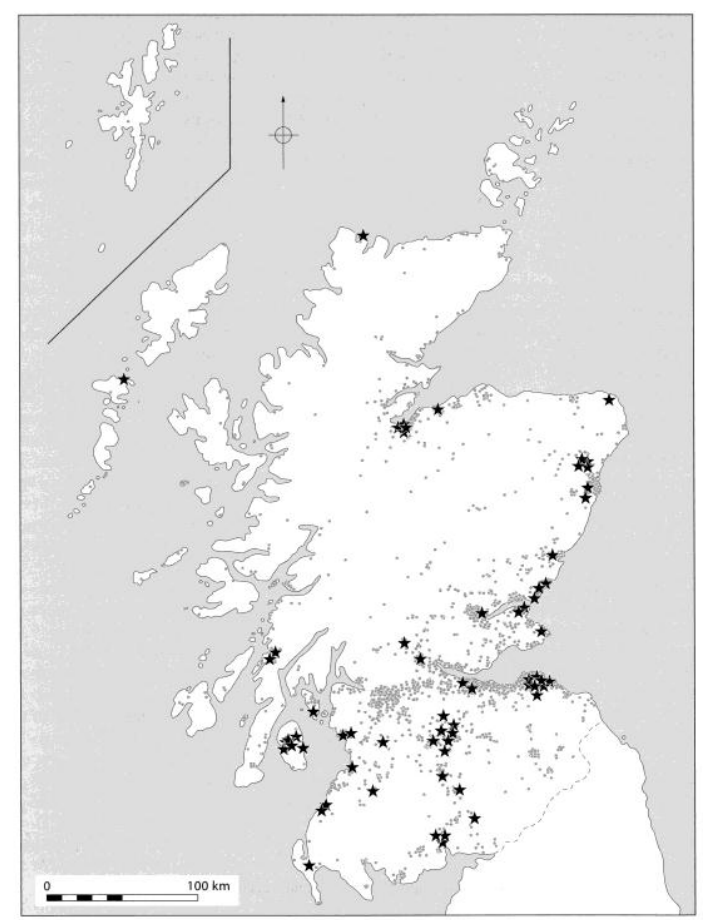

Figure 1: Neolithic sites (starred) discovered as a result of developer-funded archaeology, 19902003; paler dots show all other archaeological sites thus discovered in Scotland over this period. From Phillips \& Bradley 2004

Since 1976 hundreds of potential Neolithic sites have been discovered that, usually in combination with pragmatic 'rescue' stimuli, and enabled by the "Critical Mass" issues, (themselves engendered by the NPPG5, 'Developer Pays' initiative by Government and the skilful exercise of legal and quasi-legal authority by Local Authority archaeologists and, of course, by Historic Scotland Inspectors), have resulted in dramatic rates of discovery. These are, perhaps, best illustrated by the work of Philips and Bradley (PSAS 134 (2004), 17-51) and the splendid series of maps prepared by them, most notably in this context their Illustration 4 for the Neolithic (reproduced here as Fig. 1).

By this means since the mid 1970s the complexion of the Scottish Neolithic has changed to reveal cursus monuments, hengiforms, bank barrows, timber-built halls and enclosures, post-defined major enclosures and modest rectilinear 'house' structures. With the exception of the continued absence of causewayed enclosures this expanded inventory has a distinctly 'English' feel about it. Traces of Neolithic cultivation have been located but (as might be expected) are very rare. The far greater (wider - more sites; deeper - more dates per site) availability of radiocarbon dating has also enabled far more directly valid comparison of related phenomena between Scotland and Southern England or Ireland where formerly precision in chronological parity was elusive (cf. Whittle et al. 2011). Thus the complex relationships and associations of Grooved Ware from Orkney to Cornwall have been, if not simplified, placed on a more equitable footing.

It is, thus curious that it is at this juncture that between Kinnes (1985), Barclay 2001 (PPS 67 (2001), 1-18) and Brophy there has emerged a prolonged debate about marginality, coreperiphery relations, parochialism in design and interpretation and unevenness of treatment at the point when "the playing field" would appear at last to have the wind blowing equally from both ends.

Partly due to enlightened policies on the part of Historic Scotland, partly due to historic processes alluded to above with especial (but not sole) relevance to Orkney and mainly because exceptional archaeological conditions prevail in terms of preservation, Scotland has attracted the resources and input of numbers of English and Welsh Universities (Exeter, Cardiff, Reading, Birmingham, Sheffield, York, 
Manchester, Durham and Newcastle come to mind) which is an unreciprocated gain to Scottish archaeology in general. The tradition of focused research (project) design has been assisted by 'foreign' intervention where researches either brought ideas from familiar but non-Scottish sources - as in the case of Colin Burgess' excavations at Meldon Bridge, Scottish Borders (Burgess 1976; Speak \& Burgess 1999). These developments were taken up and expanded by excavators such as Barclay, Barber, McCullagh and perhaps Mercer tackling very large scale projects attempting to analyse entire monument complexes and landscapes echoed in later treatment of Forteviot's multi-period complexity by Brophy, Noble and Driscoll.

Despite this, however, the major impact on Scottish Neolithic is the growth of commercial archaeology in response to the planning improvements noted above. The growth of archaeological fieldwork reported annually in Discovery and Excavation in Scotland, as reported by Jones R. and McKeague in 2007 (DES 2007, 218) is presumably as good a measure as we can hope for of increased effort - although we may wish to reflect upon whether there are more, smaller projects and fewer larger ones. The emergent picture is striking. From 1947-1990 (43 years) the number of projects reported per annum rose from 16 to c.200. After 1990 the figures rose from 200 to over 1000 in seventeen years. Development control inspired 300-900 of these entries over this period.

Scotland is lucky indeed to have succeeded in supporting DES consistently for sixty-three years. Again Historic Scotland and the Royal Commission's entirely enlightened policies have, alongside the dedication of Archaeology Scotland, ensured that it should. This publication alone stands between the discipline in Scotland and its loss from sight of the majority of work it conducts. Historic Scotland, LA archaeologists and all commercial archaeologists working in Scotland have adopted the procedure of placing archive reports with the central repository of the RCAHMS. Thus it was that Prof. Bradley found Scotland's archive most easily used as an archaeological resource (pers. comm.). Nothing, however could be worse than a false sense of security built upon such vulnerable foundations. It is a matter of vital importance to establish how authoritative and relatively complete accounts can be furnished of all archaeological interventions in Scotland on an internationally available basis and that knowledge of their existence is easy to trace. Only then can Scotland seek to participate effectively in the new accessible atmosphere. The existence of Discovery and Excavation Scotland is an extraordinarily powerful asset for the Neolithic as for every other aspect of Scottish archaeology. Nevertheless the growth of grey literature sources, the growing back-log of any sort of publication is, in the face of the volume of work proceeding since 1990 a major hazard to effective project design and synthesis. Scottish archaeology urgently needs to develop a more effective way of enabling scholars to gain easy access to their requirements and to a clear picture of the precise content of the source indicated, with clear instructions as to how the source may then be accessed. But this is a problem of success, not failure!

The current weakness in university-based Artefact Studies has been substantially avoided by Scottish Neolithic enquiry in recent years, with much of the groundbreaking research being carried out by researchers not based in universities. Caroline Wickham-Jones' work on lithic sources (PSAS 109 (1977-8), 7-21); Stephen Green's Britainwide survey of arrowheads (Brit. Arch. Reps. 15, 1980; Trevor Cowie and Ann MacSween's work on Neolithic pottery (Cowie T.G. PSAS 123 (1993), 13-41; Cowie and MacSween A. in Cleal R. and MacSween A. eds. 48-57) and other major contributions all emphasise this adherence to the study of the objects made by the people under study. Among the contributions made to the study of Neooithic 
Scotland's material culture by Alison Sheridan is her involvement, as Co-Ordinator for Britain, Ireland, the Isle of Man and the Channel Islands, in the recent (2006-2010) international research project into axeheads of Alpine rock, Projet JADE (Sheridan et al. 2011; Pétrequin et al. 2012).

Perhaps Scotland now needs to take a leaf from Ireland's book and follow Professor Gabriel Cooney in his major research project on the sources of the island's ground stone axes, the Irish Stone Axe Project (Cooney \& Mandal 1999; Cooney et al. 2011). Here Scotland does lag, despite some false starts, behind developments elsewhere in Britain and Ireland, despite useful contributions from the 1950 s to the 1990s by Roy Ritchie (e.g. P.R. Ritchie 1968) and despite excavations at Creag na Caillich (Edmonds et al. 1992) . 


\section{The Scottish Neolithic: The Overall Picture}

\section{$2.1 \quad$ Introduction}

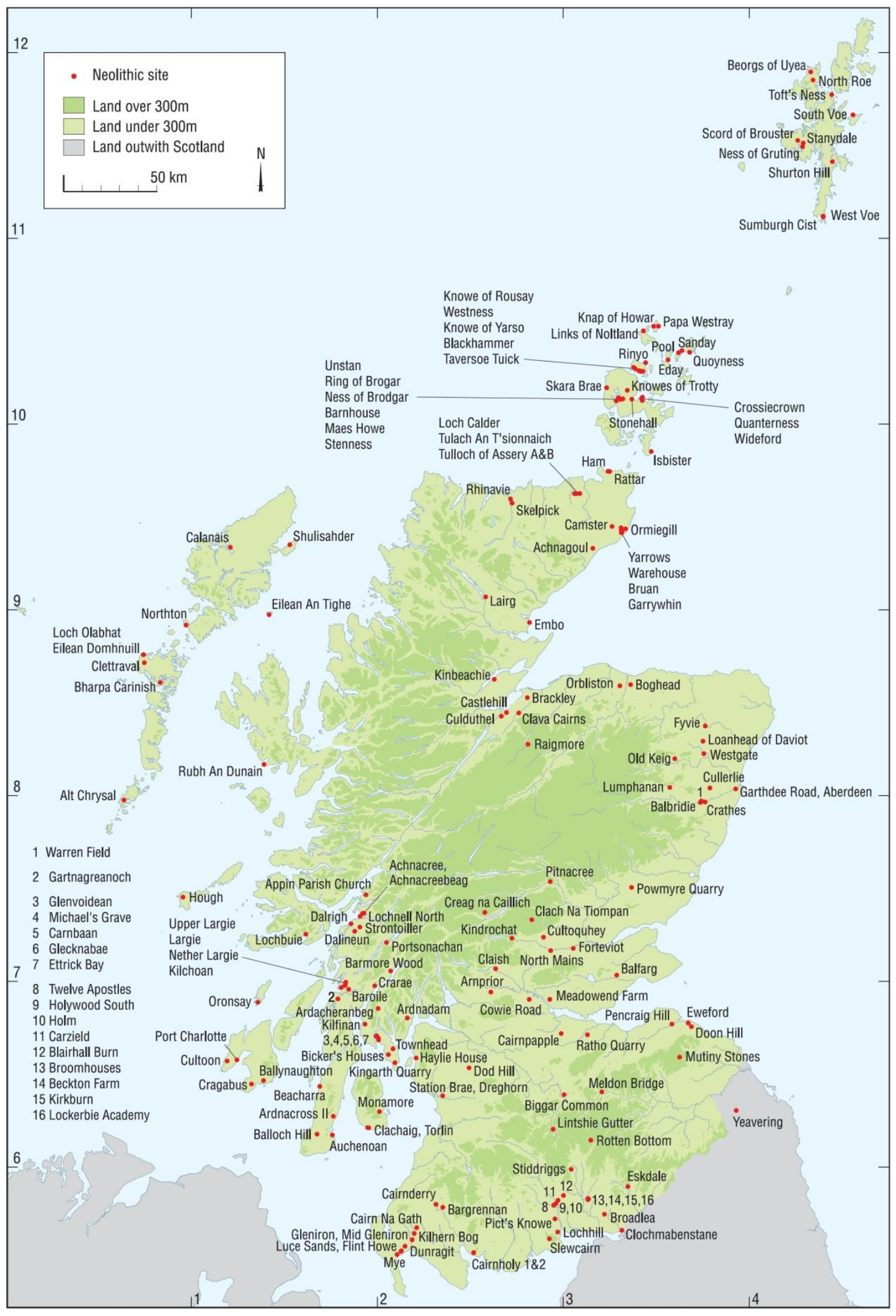

Figure 2: Distribution map of sites mentioned in the text 
Research into Neolithic Scotland is currently at an interesting juncture since there is currently little consensus on key questions such as:

- The agency, nature and timing of the transition from a lifestyle based solely on wild food resources to one based largely on food production using domesticates; and

- The nature of the farming-based subsistence economy (and associated settlement pattern): sedentary, mobile, or somewhere in between.

The Neolithic Panel needed to find a way to accommodate the radically differing perspectives of its own members on such matters, and so it was agreed to produce an 'Overview' narrative that reflects the strong beliefs of this section's author, and yet acknowledges the main areas where opinions differ. The resulting research questions address ways of resolving differences of opinion.

Some definition of 'Neolithic' is required. Theme 1 introduced Worsaae's definition now long-since obsolete - which had been based on the typology of stone artefacts; and Childe's definition, which focused on the production of food using domesticated plants and animals - in other words, farming. It is the latter which has been, and continues to be, the principal defining characteristic, although it is not the only one, since by the time that the use of domesticates appeared in Scotland, in northern France (whence Scotland's 'Neolithics' seem to have come see below) this subsistence strategy was associated with a range of other practices, traditions and beliefs that had not previously formed part of the lifestyle of Scotland's indigenous inhabitants: a novel technology (i.e. pottery manufacture); new styles of artefact (e.g. leaf-shaped arrowheads) and new ways of exploiting and working lithic resources; rectangular (and other), timberbuilt houses; funerary monuments; and other practices (e.g. modes of deposition) that indicate the appearance of novel ways of making sense of the world. As will be argued below, within the insular context of Britain and Ireland, it does indeed appear that these novelties appeared as 'packages', rather than as individual traits that had been selectively adopted by Scotland's indigenous inhabitants.

The broad-brush approach used in this theme describes the main features of what happened in Scotland from the late $5^{\text {th }}$ millennium to around the $25^{\text {th }}$ century $B C$ (when metal objects and other associated Continental novelties including Beaker pottery use first appear). Indeed, this 'Neolithic narrative' should not end abruptly at this point; instead, some indication of the reaction to these novelties is provided, as a way of articulating with the Chalcolithic \& Bronze Age Panel document.

The following division of this $1500+$ year-long period is proposed here:

1. Beginnings - the appearance of 'the Neolithic' and the MesolithicNeolithic transition, between 4300 BC and $3800 \mathrm{BC}$;

2. Subsequent developments, c 3800-c 3000 BC (i.e. Early to Middle Neolithic);

3. Late Neolithic developments, 3000-c 2500 BC;

4. Endings: appearance of Continental novelties including Beaker use, and reactions to them, $25^{\text {th }}-22^{\text {nd }}$ centuries BC.

For each of these sections, a summary of the main characteristics will be offered, together with the main outstanding research questions.

\subsection{Beginnings}

The appearance of the novelties outlined above needs to be seen within the broader context of the overall, long-term spread of farming across Europe from its origins in the Near East. Within this scenario, Scotland - 
and the rest of Britain and Ireland - lie at the end of, and at the geographical periphery of, this process. By the time the first signs of 'the Neolithic' appeared in Scotland, at some time between $4300 \mathrm{BC}$ and $4000 / 3900 \mathrm{BC}$, communities over most of the north-west European mainland had been practising farming for over a millennium and this fact must inform our understanding of the capabilities and perspectives of Scotland's first farmers. Furthermore, we can only understand the Neolithisation of Scotland (and the rest of Britain and Ireland) by understanding the broader dynamics of social and economic change in northern France: in other words, 'the Neolithic' came with baggage of its own. And we should not underestimate the 'shock of the new': the novelties outlined above represent a radically different set of practices, traditions and belifs from those which had obtained over the previous four millennia in Scotland.
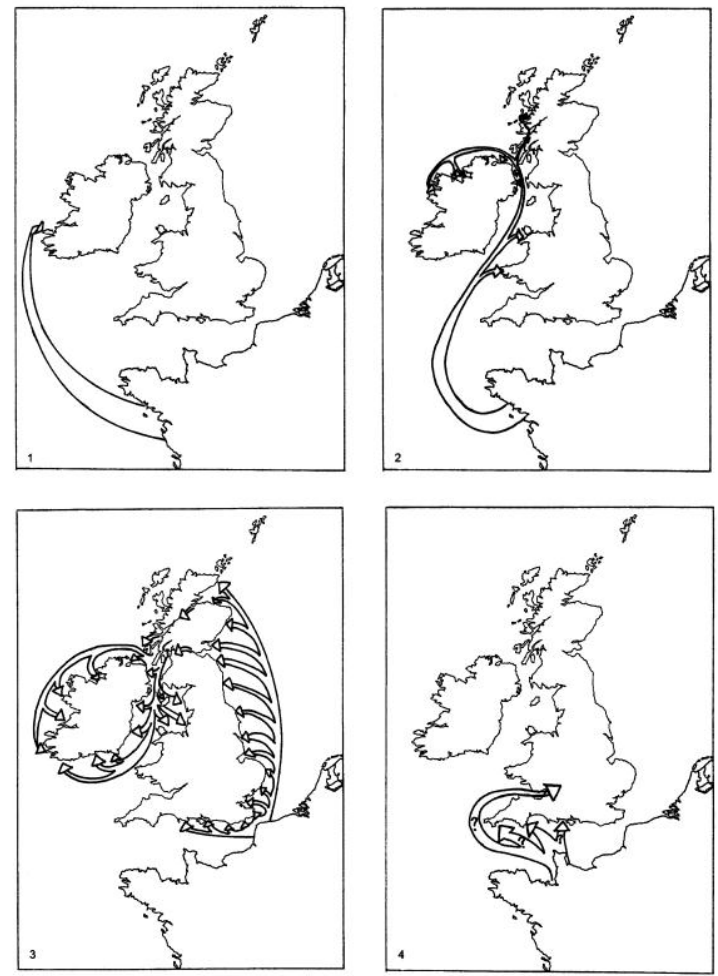

Figure 3: Strands of Neolithisation in Britain and Ireland; Nos 2 and 3 pertain to Scotland (From Sheridan 2010a)

The diversity in the material culture and structural evidence relating to Scotland's earliest 'Neolithic' indicates that we are not dealing with a single process of Neolithisation, but rather with two strands of a complex, multi-strand process that has been identified for Britain and Ireland, as summarised in Figure 3 (and see Sheridan 2010a for details). As will be argued below, these strands originated in different parts of northern France and were brought to Scotland by small groups of immigrant farmers.

It should be noted, however, that the model presented here represents one of at least four models that have been proposed to account for the Mesolithic-Neolithic transition in Britain and Ireland. The other three can be summarised as follows:

1. Adoption of traits by indigenous Mesolithic communities - i.e. huntergatherer-fishers as the prime movers for this change. This view has been championed by Julian Thomas (e.g. Thomas 2003, 2004, 2007, 2008), with Clive Bonsall arguing that climate change played a role in this (Bonsall et al. 2002).

2. Immigration of small farming groups from the far north of France to southeast England around 4100-4000 BC, and subsequent spread northwards and westwards, picking up momentum around $3800 \mathrm{BC}$ (Whittle et al. 2011).

3. Immigration of small farming groups from northern France to central Southern England, and then to Scotland, and expansion from these areas (Collard et al. 2010).

A detailed critique of these other models has been presented elsewhere (Sheridan 2010a; 2012) and need not be repeated here, other than to highlight the following principal objections:

1. The 'Mesolithic communities as prime movers' model is predicated on a model of acculturation borrowed from southern Scandinavia, where 
fisher-hunter-gatherer communities came into contact with their farming neighbours - with whom they shared the same landmass - and selectively adopted (and adapted) traits of their lifestyle. In Britain and Ireland, by contrast, there is not a shred of evidence for the existence of interaction between Mesolithic communities and their farming 'neighbours' across the sea prior to the appearance of the Neolithic 'package' - and attempts to unpick this 'package' (Thomas 2003) have been robustly rebutted (e.g. by Rowley-Conwy 2004 and Schulting 2004). Furthermore, the evidence used to support the idea of selective acculturation - e.g. the fact that hunting continued after the appearance of farming (Cummings \& Harris 2011), or that some Neolithic sites coincide spatially with Mesolithic sites - is weak: farming communities in northern France hunted wild animals as well as herding domesticates, and in cases where Neolithic material immediately overlies Mesolithic material - as at Glecknabae chamber tomb, or Warren Field, Crathes - radiocarbon dating has demonstrated that the activity is separated by millennia. And finally, the characterisation of the 'colonisation' model in tems of a 'massive, co-ordinated seaborne invasion' (Thomas 2008,65 ) is actually a caricature, which misunderstands and misrepresents the scale and dynamics of the process.

2. The Whittle et al. and Collard et al. models place too much reliance on radiocarbon dating and fail to account adequately for the observed variability in material culture and monuments across Britain and Ireland. Furthermore, Whittle et al.'s attempted negation of the Breton strand of Neolithisation (see below) betrays a misunderstanding of the sequence of pottery and monument building in Scotland, failing to grasp that the Achnacreebeag monument and its pottery lies at the very beginning of a long and complex sequence of developments, in both passage tomb building and in pottery.

Having carefully considered the matter for over a quarter of a century, it is the firm opinion of this theme's author that the 'multistrand colonisation followed by acculturation' model offers the best fit with the evidence currently available; irrespective of whether the reader agrees, the text below will provide the evidential basis for understanding the nature of Scotland's earliest Neolithics.

The two strands of Neolithisation to affect Scotland can be characterised as follows (and see Sheridan 2010 a for further details):

\subsubsection{The Atlantic, 'Breton' Neolithic}

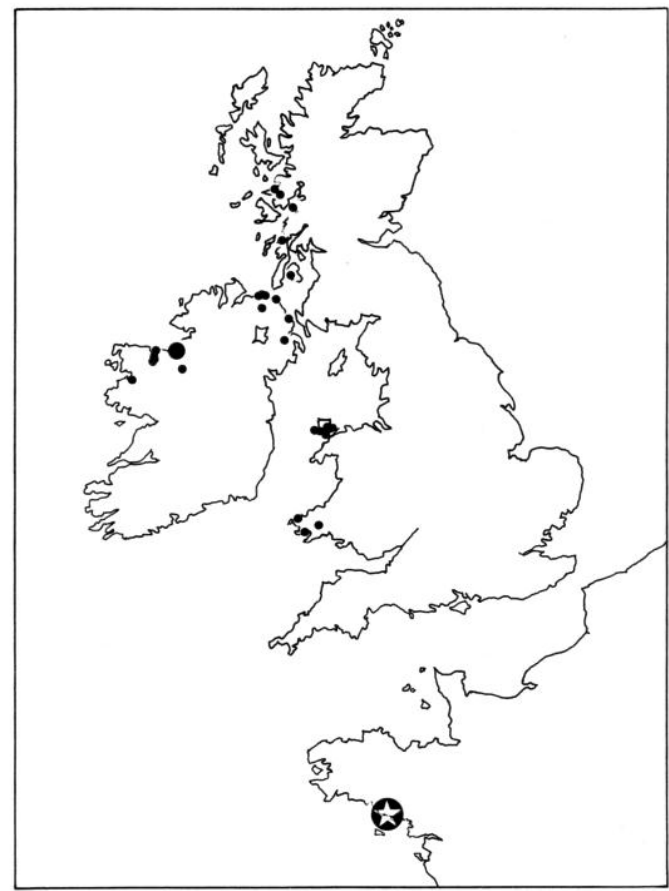

Figure 4: The Atlantic façade, 'Breton' Neolithic strand of Neolithisation: distribution of megalithic closed polygonal chambers and simple passage tombs. From Sheridan 2010

This is found on the western seaboard of Scotland - where it forms part of an Atlantic 
façade

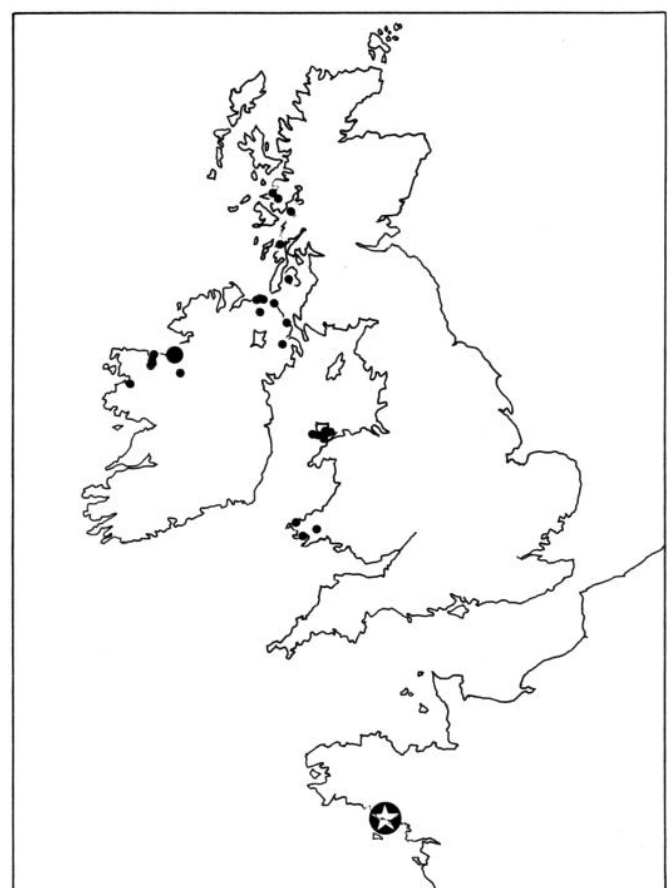

Figure 4) - and is currently attested solely by funerary monuments (in the form of small closed polygonal megalithic chambers and simple passage tombs) and by pottery. These constitute the earliest funerary monuments and the earliest pottery in Britain and Ireland, and the origin of both lies in the Morbihan region of south-eastern Brittany (Sheridan 2010a).

The best-known site is Achnacreebeag, Argyll \& Bute (J.N.G. Ritchie 1970; Figure 5): this is a two-phase monument, consisting of a polygonal chamber in a low round cairn, succeeded by a simple passage tomb, with a cairn extension that makes the cairn pearshaped. (See Ritchie 1970 for other similar monuments in the region.)

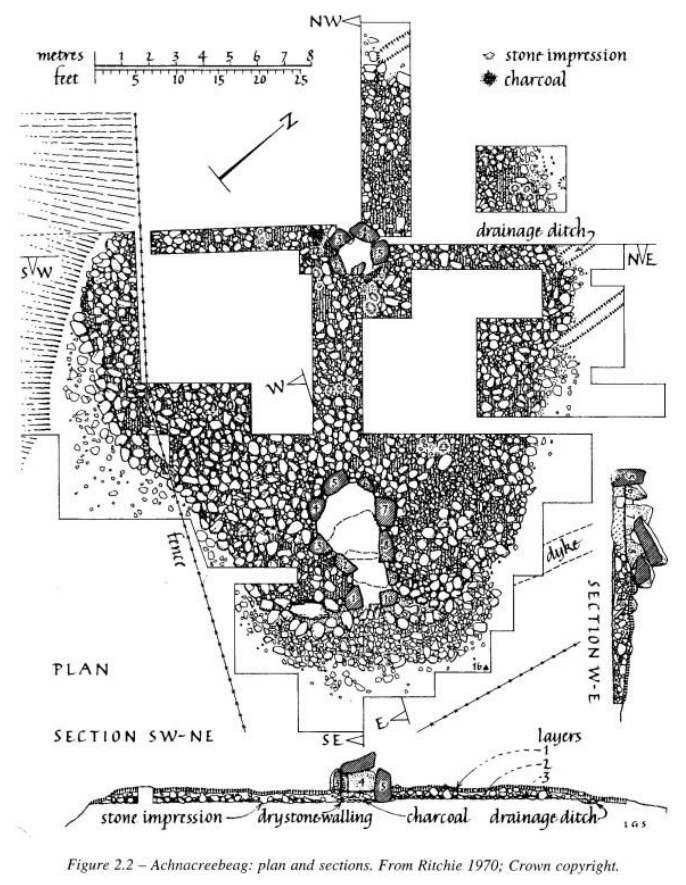

Figure 5: Plan and section of Achnacreebeag chamber tomb, with closed polygonal chamber and simple passage tomb. From Ritchie 1970; Crown copyright.

The pottery (Figure 6) was found in the passage tomb and consists of a decorated bipartite bowl of Late Castellic style, along with sherds of two other pots that are of types in contemporary use with Late Castellic pottery in the Morbihan. (Incidentally, the resemblance between the Late Castellic bowl and its progenitors in Brittany had been pointed out as long ago as 1975 , by Gérard Bailloud (Bailloud 1975). Furthermore, it should be noted that an attempt was made, by Gwenaëlle Hamon on behalf of Alison Sheridan, to determine through thin-section petrography whether the Achnacreebeag pots could have been made in Brittany; unfortunately, the fineness of the fabric made it impossible to determine this.) 


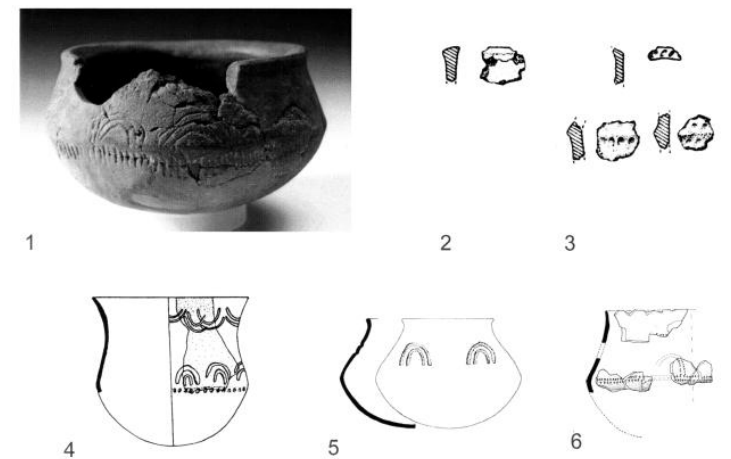

Figure 6: The pottery from Achnacreebeag (1-3), and some comparanda for the decorated bipartite bowl among Late Castellic pottery in Brittany and Normandy (4. Le Castellic, Brittany; 5. Vierville, Normandy; 6. Er Grah, Brittany). From Sheridan 2010 (where the sources of the images used as 2-6 are cited)

No radiocarbon-datable material relating to this phase of the site's use was found - or, at least, the small flecks of charcoal found on the old ground surface under the monument (Ritchie 1970., 34) were so tiny that they were not retained, and in any case they would not be large enough to provide a single-entity AMS date. Instead, the dating relies on the dating of Late Castellic monuments and pottery in north-west France, and particularly in the Locmariaquer complex in the Morbihan (Cassen et al. 2009, 761, fig. 13). This suggests that this strand of Neolithisation arrived in Britain and Ireland at some time between $4300 \mathrm{BC}$ and $4000 / 3900 \mathrm{BC}$; it is currently not possible to be more precise than that. The contemporary indigenous inhabitants of western Scotland would have included the groups who moved around the Inner Hebrides and who placed their dead on the shell middens of Oronsay (but see Milner 2010 for a re-calibration of the relevant human remains dates that places these within the first few centuries of the fourth millennium; whatever their actual date, the point to be noted here is the stark contrast with the practice of building megalithic funerary monuments.)

As to why people should have chosen to leave the Morbihan and sail northwards, the main reason may well be the transformation of Morbihannais society around the $44^{\text {th }}$ century
BC. (See Cassen 2009 for a recent discussion of this.) Prior to this, from c $4600 \mathrm{BC}$, there had flourished a 'theocratic big man' society - its roots lying in the local Mesolithic groups, who selectively adoptied and adapted elements of the farming lifestyle - which featured the erection of massive funerary mounds and standing stones, and the deposition of precious exotic objects (Alpine axeheads and Spanish fibrolite axeheads and variscite jewellery). This society, with its explicitly phallocentric expressions of power and fertility, its competitive conspicuous consumption and its rich mythology, gave way to a fully agricultural society in which power and fertility was expressed in a more maternal idiom, including in the construction of womblike passage tombs. It may be that seismic activity, which seems to have been responsible for the collapse of many huge standing stones including the Grand Menhir at Locmariaquer, provided the catalyst for this change. At any rate, the departure northwards of the families who ended up along the Atlantic façade of Britain and Ireland formed part of a long-standing tradition of deep sea, long-distance sailing by the Morbihannais. Other northerly movement is attested by Early Castellic influence on the pottery of the Channel Islands, and on the presence of a Late Castellic bowl, very similar to the Achnacreebeag bowl, in a simple passage tomb at Vierville in Normandy (Sheridan 2010a).

The outstanding research questions relating to this strand of the Neolithic are as follows:

1. Was this strand restricted to parts of the west coast, as appears to be the case? We need to excavate more closed megalithic chambers and simple passage tombs.

2. Where and how did the people live? There are currently no settlements associated with this strand of Neolithisation, and we can only assume that, by analogy with Brittany, the people practised farming (although lipid analysis of the pottery 
will demonstrate whether this was the case).

3. Did these people, or their descendants, play a role in the eventual disappearance of the Mesolithic lifestyle in this part of Scotland? On current evidence, it seems quite possible that the small numbers and low density of indigenes and immigrants alike was such that both could have co-existed in ignorance of each other for some considerable time.

4. This strand needs to be underpinned by Scottish radiocarbon dates, to complement the evidence from northwest France.To this end, we need to excavate more closed megalithic chambers and simple passage tombs.

\subsubsection{The 'Carinated Bowl' (CB) Neolithic}

More is known about this second strand of Neolithisation, which appears to have involved immigration by small farming groups from the far north of France (i.e. the Nord-Pas de Calais region) to large parts of Britain and Ireland between the 41st century and c 3800 BC. Within Scotland, this strand reached as far as Caithness in the north and Galloway in the south-west, but appears not to have extended as far as the Northern or Western Isles, or the north-west mainland (Figure 7). It is particularly strongly represented in north-east Scotland and it appears to follow major rivers, especially the Dee, Forth, Clyde and Nith; indeed, it may have spread rapidly from eastern Scotland to the south-west along the Forth-Clyde corridor and down the Nith. The farmers appear to have sought out and found areas of high agricultural potential, and proceeded to clear the forest in order to establish their settlements and farmland. (See Section 4.4 on the palaeoenvironmental record.)

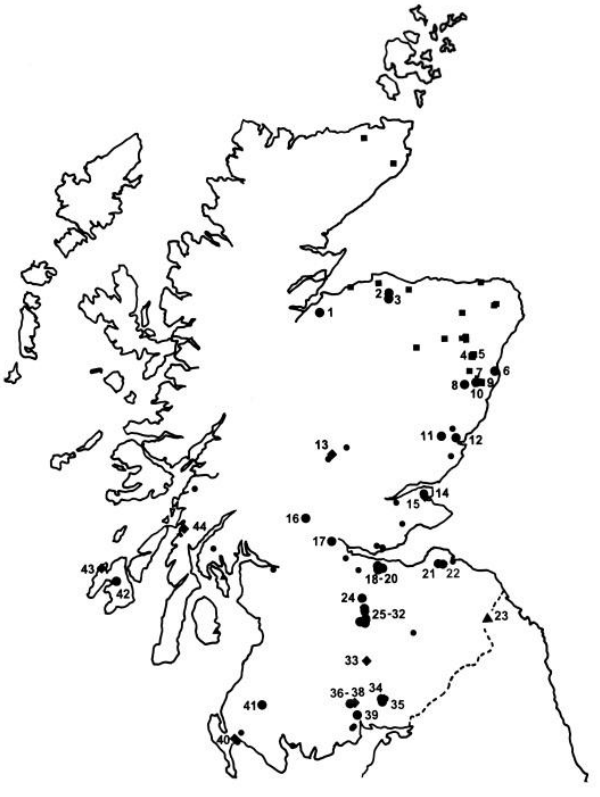

Figure 7: The 'Carinated Bowl Neolithic' in its early form, as manifested through pottery finds; information accurate to 2007. From Sheridan 2007b (where key to numbers can be found)

Recent Bayesian modelling of the available Scottish radiocarbon dates (Whittle et al. 2011, chapter 14) has claimed that it appeared in Scotland around $3800 \mathrm{BC}$, up to three centuries later than in Kent and the Thames Estuary, and as the result of secondary spread from south-east England. Whether that had indeed been the case is a moot point; both the use of Bayesian modelling (with its requirement to define an end-date to the phenomenon being modelled) and the assumption of chain-colonisation can be challenged and will continue to be debated. Be that as it may, it is clear that this strand of the Scottish Neolithic was indeed present in the parts of Scotland mentioned above by 3800 BC., appearing as a diaspora. Its key characteristics are as follows:

Economy (and see Section 4.1):

There is good evidence for mixed agricultural and pastoral farming. We know that bread wheat (and other varieties of wheat), barley and linseed were cultivated, and other domesticated plants may have been 
cultivated as well (Bishop 2009). Palaeoenvironmental evidence at Crathes Warren Field, Aberdeenshire (Tipping et al. 2009), suggests that cereals were cultivated in one or more field in the vicinity of a large house. Faunal remains (and indeed coprolites) show that domesticated cattle, sheep, goats and pigs were kept, and analysis of absorbed lipids in pottery has shown that dairying was part of this introduced subsistence practice, since milk fat has been found in 'traditional Carinated Bowl' pottery (Šoberl \& Evershed 2009). There is also evidence for the exploitation of wild resources, both plants (Bishop 2009) and animals. Hunting is demonstrated, for example, by the Rotten Bottom imported yew flatbow which, as argued in Section 5.3.2, is most likely to have been the possession of a farmer out on a deer hunt in the hills above Moffat. However, there is no evidence for the use of marine resources: Richards and Schulting's isotope analyses of early Neolithic human remains from coastal areas (Richards \& Schulting 2006) has shown no trace of a marine element in the diet. Even though the first farmers had arrived by sea, they had no tradition of eating fish or sea mammals.

\section{Domestic structures (see section 4.3)}

Image to follow

Figure 8: Selection of ground plans of ' $\mathrm{CB}$ Neolithic' dwelling structures: 1. 'Hall', Crathes Warren Field, Aberdeenshire (from Murray et al. 2009); 2. Smaller house, Garthdee Road, Aberdeenshire (from Murray \& Murray 200x); 3.
'Huts', at Auchategan, Glendaruel, Argyll \& Bute (from Marshall 1978)

These are mostly (but not exclusively) rectilinear and mostly plank, post-and-plank or post-built. There is a wide variety of sizes and durabilities, ranging from large houses the so-called 'halls', which are mostly found in East Scotland but are also represented at Lockerbie in the south west, and which are limited to the beginning of the Neolithic through smaller structures (e.g. the oval house at Garthdee Road, Aberdeen) and some flimsier, hut-like structures (including Auchategan on the slopes of Glendaruel, Argyll \& Bute: Marshall 1978). This diversity reflects both the process of becoming established as farming communities and the nature of subsistence activities. The fact that the large houses ('halls') belong only to the first few generations of the CB Neolithic suggests that these were the initial, communal living places of the first few generations of settlers, who lived together until they were sufficiently well-established to 'bud off' into individual family farmsteads. And the existence of the small, hut-like structures - analogous to the flimsy structures seen in north-east England (see 3.3.8) suggest that transhumance was practised as part of the overall subsistence strategy, at least in some parts of Scotland. Thus, the settlement pattern appears to show a basic pattern of year-round, house-based occupation with some seasonal settlement by a section of the community. 
1

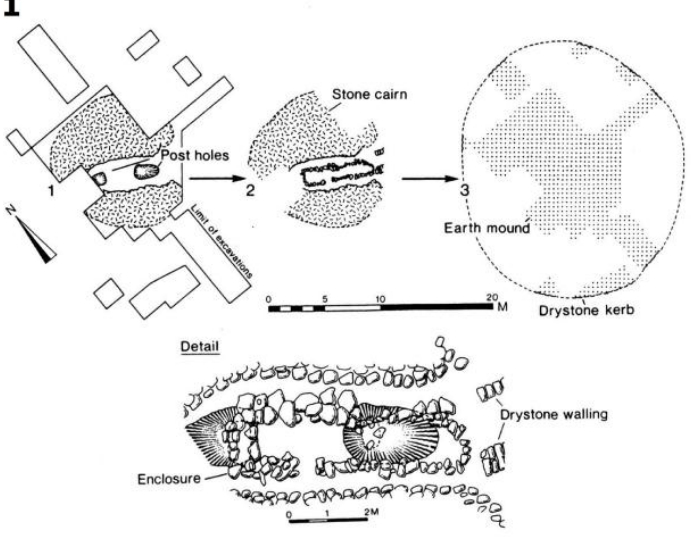

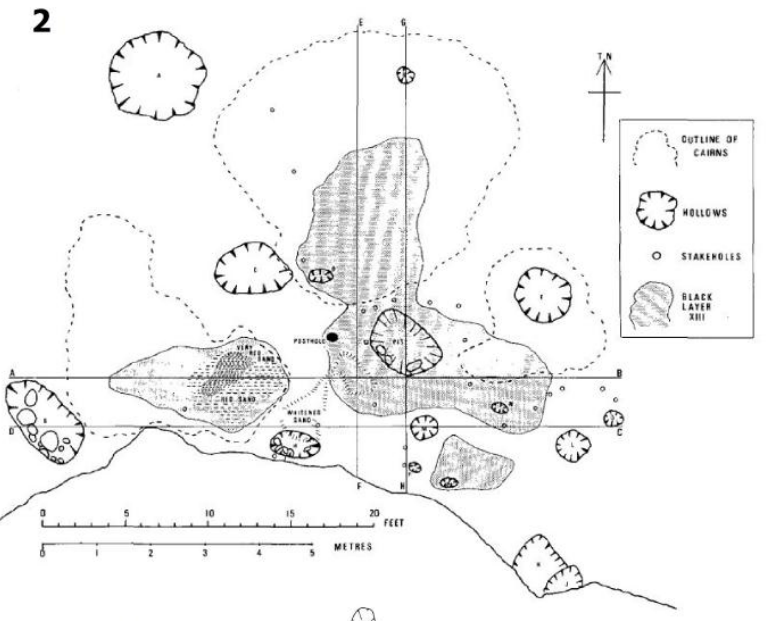

3

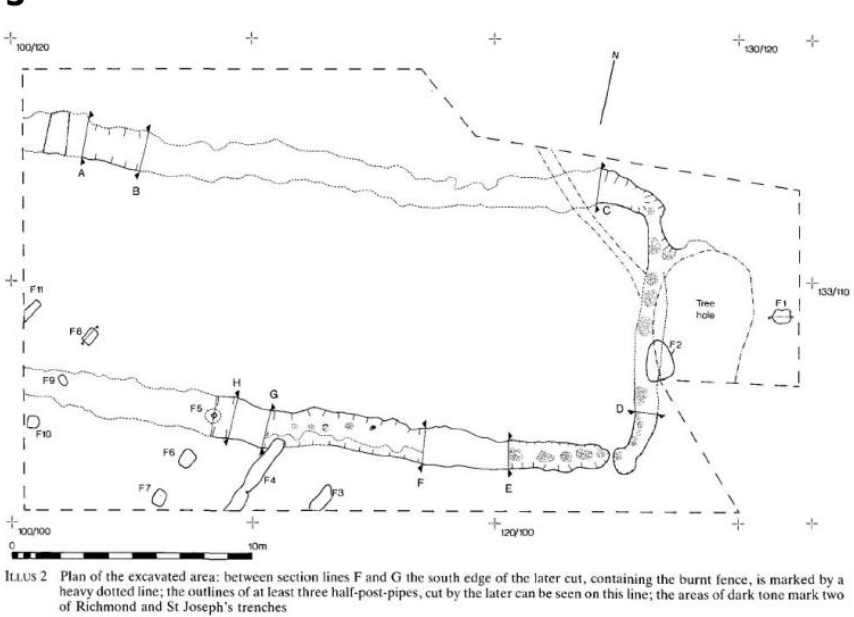

4

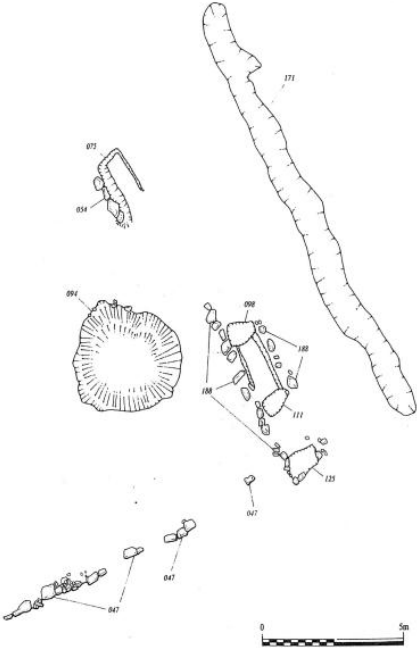

Figure 9: Examples of 'CB Neolithic' funerary monuments: 1. Pitnacree, Perth \& Kinross (from Coles \& Simpson 19xx); 2. Pyre covered by round mound, Boghead, Fochabers, Moray (from Burl 1984). 3. Mortuary enclosure, Inchtuthill, Perth \& Kinross (from Barclay and Maxwell 1991); 4. Eweford West, East Lothian (from Lelong \& MacGregor 2009)

\section{Funerary practices (and see Theme 6) :}

These feature the use of non-megalithic funerary monuments, followed by a translation of some of these into stone versions in parts of Scotland (as at Mid Gleniron and Cairnholy, for example). The non-megalithic monuments comprise:

i) 'linear zone' timber mortuary structures, which were usually burnt down and eventually covered by long (rectangular or trapezoidal) or round mounds of earth and/or stone;

ii) rectangular, post-built enclosures which are assumed to have been areas for the temporary or permanent laying-out of the dead (and see 3.3.1 regarding their dating); and

iii) cremation pyres, covered by round mounds (as at Boghead, Moray: Burl 1984, and see Sheridan 2010 b for a review of Neolithic round mound dating).

There is evidence, from Raschoille Cave and Carding Mill Bay Cave, Argyll \& Bute, for the use of caves for the deposition of human remains during the first half of the fourth millennium (Milner \& Craig 2009, tables 15.3, 15.4). This is consistent with practice attested in Ireland where, for example, skeletal remains were found at Kilgreany Cave, Co. Waterford, associated with CB pottery (Dowd 2008). 


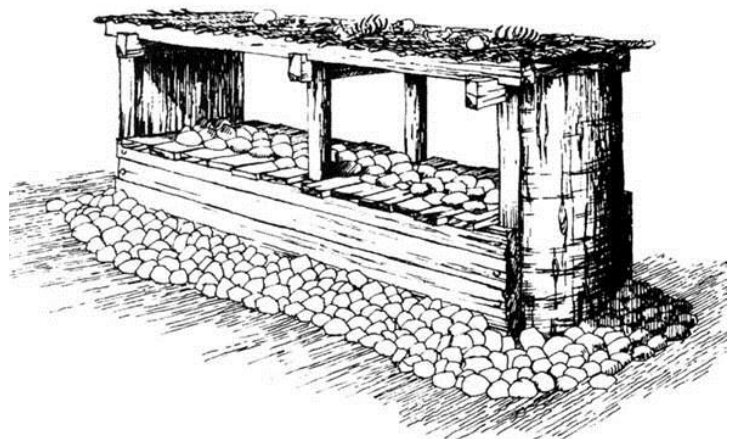

Figure 10: Reconstruction of 'linear zone' mortuary structure. From Ashmore 2006

Material culture (and see Theme 5): The Carinated Bowl pottery tradition, which gives its name to this strand of the Neolithic, originated as one of several regional groups of the Chasséo-Michelsberg ceramic tradition in northern France. It features carinated and Sprofiled bowls, uncarinated bowls and cups, and necked jars, mostly of fine fabric and including some very thin-walled vessels (c 4 $\mathrm{mm}$ ); decoration is absent, save for the occasional use of fingertip fluting. A process of 'style drift' from the initial, 'traditional $\mathrm{CB}^{\prime}$ style began in north-east Scotland within a few generations of the initial appearance of the CB Neolithic.

The associated lithics comprise:

- ground (and sometimes polished) stone axeheads, including fine, nonutilitarian axeheads of Alpine jadeitite, eclogite and omphacitite which had been brought over from France as old, treasured heirlooms of individuals or communities;

- leaf-shaped arrowheads, mostly of flint;

- plano-convex flint knives with extensive retouch

- flakes and blades of flint and other stone including pitchstone
- end and side scrapers of flint and other stone

and it is very likely that coarse stone tools, including saddle querns, would also have been part of the earliest CB Neolithic repertoire. Early Neolithic organic finds are extremely rare, but the yew flatbow from Rotten Bottom - which had probably been imported from Cumbria or Ireland, most probably Cumbria has already been mentioned.

Resource use and interaction networks:

The CB Neolithic lithics show that the early farming communities were not only making opportunistic use of locally-available resources but - as had been the case in the Middle Neolithic of northern France - were also targeting specific sources of good quality or 'special' stone from c $3800 \mathrm{BC}$ and were circulating items (and, in some cases, roughouts) made of these stone types over considerable distances. The stone types in question included Arran pitchstone (Fig. 9), tuff from Great Langdale in Cumbria (anf cf. the yew for the Rotten Bottom bow) and porcellanite from Tievebulliagh and Rathlin Island in Co. Antrim. (The Creag na Caillich source of calc-silicate hornfels does not seem to have been exploited until later during the $4^{\text {th }}$ millennium: Edmonds et al. 1991.) The creation of networks over which objects, resources, ideas and people travelled is a characteristic of the early $C B$ farming communities (and of their French forbears), and indicates that the immigrant communities would have sought each other out. The benefits of operating interaction networks would have included the maintenance of a viable pool of non-related partners - although whether this was a conscious choice, and/or articulated in terms of viable breeding populations, is a moot point. 


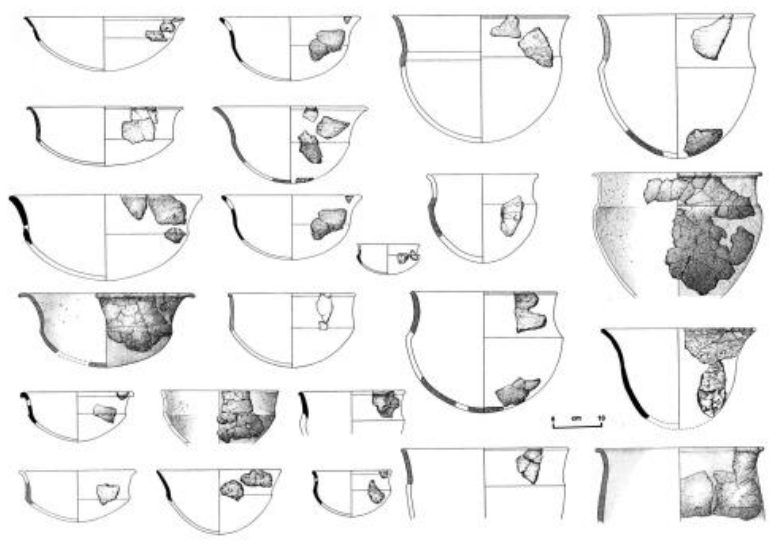

2

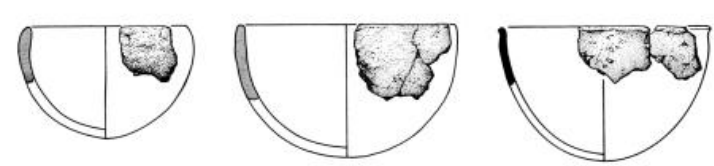

3
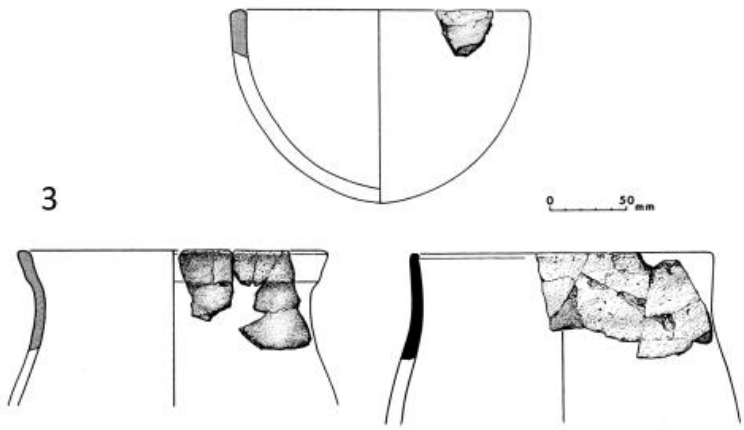

Figure 11: Carinated Bowl pottery: 1. Carinated and S-profile bowls; 2. Uncarinated bowls and cups; 3. Necked jars. From Sheridan 2007.

As for other evidence that may potentially relate to the CB Neolithic, it has been claimed that a causewayed enclosure may exist at Sprouston, Roxburghshire (Scottish Borders), but this needs to be tested through excavation.

As with the Atlantic, Breton Neolithic, the reasons for the appearance of the $C B$ Neolithic lie in the socio-economic dynamics of Middle Neolithic northern France. In this case, demographic pressure seems to be the root cause: an infilling of the Paris Basin, after a millennium of agricultural activity, seems to have resulted in an eastward and northward (and possibly westward) movement of people out of the Paris Basin during the late $5^{\text {th }}$ millennium), with these diasporic groups evolving a suite of regionally-specific pottery traditions - of which the regional variant that gave rise to CB pottery is one (Vanmontfort 2001; Crombé \& Vanmontfort 2007).

The question of the relationship of these putative north French incomers to the indigenous Mesolithic communities is a problem since, despite claims to the contrary (e.g. Thomas 2007), it is near-impossible to identify any sites or assemblages that demonstrate a process of acculturation.
Nevertheless, given the apparent disappearance of the Mesolithic way of life from Scotland around the beginning of the $4^{\text {th }}$ millennium, some process of acculturation must have taken place. It is not necessary to posit, as Thomas does, a 'population wipeout' as a consequence of the arrival of immigrant farmers; but exactly what happened remains a mystery. The paucity of Mesolithic human remains hinders attempts to identify introduced diseases, for example.

The main outstanding research questions relating to the $C B$ strand of Neolithisation are as follows:

1. Can the area of origin for the $C B$ Neolithic be pinpointed more specifically? And can the forerunner of every aspect of the CB Neolithic be identified there? This requires further fieldwork and survey in the Nord-Pas de Calais region, and adjacent areas.

2. The nature of, and any regional variability in, subsistence strategy, land use and settlement structure need to be clarified further. More and larger faunal assemblages need to be found as the existing dataset is relatively small. 
3. What was the nature of the relationship with pre-existing Mesolithic communities? How did the process of acculturation operate - and is there any evidence for the adoption of traditions associated with the Scottish Mesolithic by farming groups? (On present evidence, the answer to the last question is 'No'.) For how long after the appearance of the CB Neolithic did the Mesolithic way of life continue? Did it disappear because the farming way of life was perceived as preferable?

4. Is the Sprouston site a causewayed enclosure? And if so, does it date to the beginning of the Neolithic? (Cf. Whittle et al. 2011 on the dating of causewayed enclosures.)

\subsection{Subsequent developments during the Early and Middle Neolithic, c 3800-c 3000 BC}

A suite of developments, including a secondary expansion of farming communities and a process of regionalisation, can be identified for the period c 3800-3000 BC. It has become customary to call part of this period the 'Middle Neolithic', but its definition has tended to be nebulous and opinions differ as to where to place its notional start date. In fact, given the diversity of developments around Scotland and the absence of a clear horizon of generalised change, the use of this term is more a matter of convenience - as a way of breaking up a near-millennium of developments - than a marker of widespread change. Where used in the succeeding text, it will refer loosely (and arbitrarily) to the second half of the third millennium.

The principal developments during this $\mathrm{c} 800$ year long period can be characterised as follows:

\subsubsection{Expansion}

of 'the Neolithic', both in terms of an infilling of landscapes in the areas of earliest Neolithic activity and a spread of the 'Atlantic' (passage tomb-associated) Neolithic from western
Scotland to the Western and Northern Isles and the northern mainland. Indications are that this latter process may have taken place as early as the 38th or 37th century BC, and that farming and its associated traditions probably reached Shetland directly from western Scotland, rather than via Orkney. (See Theme 3 for details.) It is assumed that this relates to population growth but was not necessarily driven by that growth: in other words, it is unlikely that there would have been a land shortage on the mainland that occasioned a move out to the islands. Other factors probably informed the decision and the desire to explore new areas cannot be ruled out as a factor.

\subsubsection{Diversification and hybridisation in material culture, monuments and traditions.}

A process of regionalisation can be traced, as material culture, structures and traditions underwent 'style drift' with the passing of generations. (See Theme 3.) Thus, for example, the 'traditional Carinated Bowl' pottery of the $39^{\text {th }} / 38^{\text {th }}$ century became 'modified $\mathrm{CB}^{\prime}$ pottery, with the changes (in shape, decoration and manufacture style) occurring at different rates and in different ways in different parts of Scotland. Similarly, in south-west Scotland, over the course of the $38^{\text {th }}$ and $37^{\text {th }}$ centuries $B C$, one can trace the development of CB-associated funerary monuments from their non-megalithic beginnings, through simple stone translations (e.g. at Mid Gleniron and Cairnholy) to 'Clyde cairns' (see Theme 6). In the west, the development of passage tombs from the simple form as seen at Achnacreebeag, and the geographical expansion of this funerary monument tradition, can be traced. Other, regionally-specific styles of chamber tomb emerged elsewhere in Scotland (e.g. the stalled cairns of Orkney). Likewise, cursus monuments - which may represent an aggrandisement of Early Neolithic rectangular mortuary enclosures - emerged at some time between 3800 and 3650 BC (Cook et al. 2010) and are associated with 'modified CB' pottery; the few very long bank barrows in Scotland 
(such as the Cleaven Dyke: Barclay \& Maxwell 1998) may be alternative expressions of a similar concept. In eastern Scotland, the late fourth millennium re-emergence of large timber structures (e.g. at Balfarg Riding School) of similar size to the Early Neolithic 'halls', but not necessarily roofed, represents another aspect of regional diversity. Other expressions of diversity include variation in house building styles, with stone houses being constructed in areas that were relatively timber-poor (i.e. the Northern and Western Isles).

The hybridisation re ferred to above relates to the fact that the descendants of the two 'strands' of earliest farming communities that is, the 'Atlantic Neolithic' (for want of a better term) and the ' $\mathrm{CB}$ Neolithic' - must have interacted and shared design ideas. In western and south-west Scotland the trajectory of ceramic development shows a merging of the 'Atlantic' and CB traditions into what Jack Scott termed 'Beacharra' pottery, and the same specific variety of modified $C B$ pottery can be found in Clyde cairns (e.g. Glenvoidean) and a passage tomb (Achnacree) alike. Similarly, the chamber tomb of Clettraval on North Uist provides the clearest evidence for the incorporation of elements of both passage tomb and Clyde cairn design in the creation of some megalithic monuments in the Western Isles (Henshall 1968; Henley 2004). And on the northern mainland, in Caithness, we can perceive the appearance of the passage tomb funerary tradition and its interaction with the $C B$ Neolithic tradition (e.g. in the form of multi-phase monuments, where the long cairn format of the $C B$ Neolithic tradition was superimposed on passage tombs (as at Camster Long, Caithness: Figure 12).

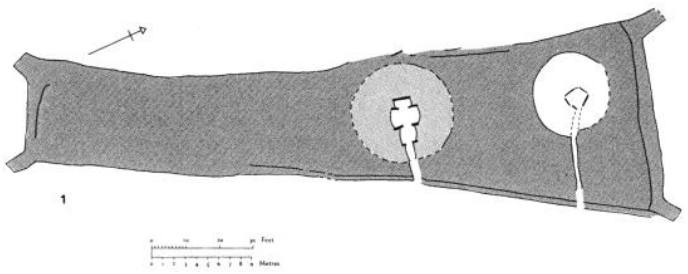

Figure 12: Multi-phase monument construction at Camster Long, Caithness, where a horned long cairn was superimposed on two pre-existing passage tombs with round cairns. From Henshall 1972

The particular trajectories of change that we can trace in different parts of Scotland - see Theme 3 for details - will have been influenced by the amount, kind and direction of interaction between different regions. With Shetland, for example, a marked regionalisation may well relate to a relative paucity of outside contacts over the course of the $4^{\text {th }}$ millennium, while in south-west and western Scotland, influences resulting from the development of an Irish Sea interaction network can clearly be seen in aspects of ceramic design. Likewise, in southern Scotland the emergence of Impressed Wares, possibly from c $3600 / 3500$ BC but certainly by 3300 $B C$, shows a sharing of design ideas both with northern England and (in the south-west) with north-east Ireland. And links between the northern mainland, Orkney and the Western Isles at some time between c 3600 and 3300 $B C$ are shown in the shared use of a specific type of pottery vessel known as the Unstan Bowl (fig $\mathrm{x}$ ).

[Fig 11 to go here]

\subsubsection{Social differentiation and strategies of competitive conspicuous consumption}

A process of competitive aggrandisement in chamber tomb construction can be identified, for example in the emergence of massive horned cairns in Caithness, Sutherland and Orkney (Figure 13) around 3600/3500 BC. These truly monumental long cairns - of which short versions also exist - were sometimes imposed on pre-existing passage tombs (as at the aforementioned monument of Camster Long, Caithness), and sometimes 
constructed from scratch (as at Point of Cott, Orkney). Given that they would have involved a considerable investment of effort to build, they can arguably be seen as statements of a group's - perhaps lineage's - power and authority.

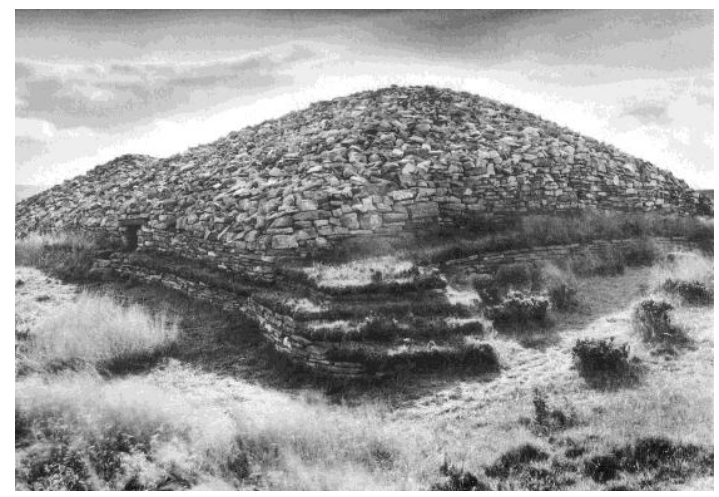

Figure 13: Massive horned cairn: façade of Camster Long, Caithness. Photo: Mick Sharp. From Davidson \& Henshall 1991

Other evidence for the same kind of process can be seen in Orkney, where aggrandisement can be traced not only in stalled cairns (with the massive example at Midhowe 'trumping' smaller versions) but also in passage tomb construction, with the emergence of Maes Howe-type passage tombs during the last quarter of the $4^{\text {th }}$ millennium representing a step-change from pre-existing Orcadian passage tombs (Schulting et al. 2010). The appearance of the latter is connected with the invention of Grooved Ware as a novel ceramic style, at some time between $3300 / 3200$ and $3100 \mathrm{BC}$, and relates to the emergence of a markedly inegalitarian society whose elite drew some of their power from what Mary Helms has termed 'cosmological acquisition' (Helms 1993). In other words, members of an emerging elite undertook long-distance sea travel to the major passage tomb cemeteries of the Boyne Valley in eastern Ireland - a centre of power during the Middle Neolithic and brought back ideas emulating the design of these tombs (including the use of cruciform chambers, of winter solstice solar orientation and of spiral designs on passage tomb stones: see Theme 3 and Schulting et al. 2010 for further details.)
Other hints at social differentiation elsewhere in Scotland come from the rare examples of jet and jet-like jewellery (i.e. 'monster beads') that probably belong to the second quarter of the fourth millennium, and the jet and jet-like belt sliders that probably date within the 3200-2900 BC bracket. (See Theme 5 for details.)

Further, and regionally-specific details of developments between c 3800 and c 3000 BC - including the opening of the flint mines at Den of Boddam, Aberdeenshire, towards the end of the $4^{\text {th }}$ millennium - are presented in Theme 3, along with the regionally-specific research questions. Meanwhile, the main outstanding research questions relating to this long period are as follows:

1. While we can sketch the outline of the principal developments, many questions remain as to their timing, tempo and trajectory. For example, did the 'Neolithic package' appear in Orkney from the northeast mainland, as seems quite likely, and did this happen as early as the late $38^{\text {th }}$ or $37^{\text {th }}$ century $B C$ ?

2. What lay behind the expansion of farming communities to the Western and Northern Isles?

3. Can we associate the regionalisation with any changes in subsistence strategy or in the design and construction of settlement structure? For example, isotope analysis of human remains from a communal Middle Neolithic cist grave at Sumburgh has indicated some consumption of marine resources, in contrast to the picture obtained from contemporary, earlier and later human remains elsewhere in Scotland (Melton \& Montgomery 2009). Was this a peculiarity of Shetland? And in Orkney, was the documented exploitation of marine resources for nondietary purposes? A further example: in lowland Scotland, many settlement sites dating to the second half of the $4^{\text {th }}$ millennium are represented only by pits and spreads of material; is this because the architecture of 
houses changed, so as to leave fewer traces in the ground, or can it be explained through taphonomy - since many of these sites are in prime agricultural land that has been worked over for millennia?And can we see any traces of the continuation of a purely 'Mesolithic' lifestyle over this period, or of 'acculturated hunter-fisher-gatherer' groups? (Perhaps yes, at West Voe, Shetland).

\subsection{Late Neolithic Scotland, c 3000-c 2500 BC}

Our understanding of developments within this half millennium is dominated by the spread - southwards from Orkney - of Grooved Ware use and associated practices, not just to other parts of Scotland but to Ireland and the rest of Britain. We are only now getting to grips with all that was involved in this phenomenon, and the picture is currently evolving thanks to the results of excavations at the Ness of Brodgar ceremonial complex (and indeed at Durrington Walls in Wessex, in the recent past), but the following scenario seems plausible:

The aforementioned process of competitive conspicuous consumption and hierarchisation that occurred in late $4^{\text {th }}$ millennium Orkney continued into the $3^{\text {rd }}$ millennium and had led, $3000 / 2900 \mathrm{BC}$, to the emergence of a specifically Orcadian version of a theocratic power system. This featured the use of Maes Howe-type passage tombs (Fig. 13) for housing the dead - and it is tempting to regard these people as members of dominant lineages - and for carrying out annual ceremonies at midwinter solstice, when the setting sun entered the passage and chamber. Perhaps there was a belief that this brought the ancestral remains back to life, thereby ensuring the well-being of the living for the next year.

[Fig 13 to go here]

The people who built and used these tombs also used Grooved Ware pottery (Fig. 14), and during the $30^{\text {th }}$ century they built the henge at the Stones of Stenness (Fig. 15) - with its stone circle surrounded by a single-entrance ditch and bank. (See Schulting 2010, 35-6 for a Bayesian model of the dates.) This would have been an open-air monument for the performance of ceremonies, forming part of a complex of special sites in this part of the Orkney mainland. The 'special' settlement at Barnhouse, also in this area, was superseded (or complemented), after $3100 \mathrm{BC}$, by the construction of the major enclosed ceremonial centre at Ness of Brodgar (Figure 14), with its massive buildings and two boundary walls. This reinforced the sacred status of the isthmus between what would have been marshy areas (now the Lochs of Stenness and Harray). Stone maceheads and other carved stone objects of various shapes (including balls) were used as symbols of power and as objects to be sacrificed ritually, by deliberate breakage, during ceremonies. Ceremonies also involved feasting.

[Figs $14-16$ to go here]

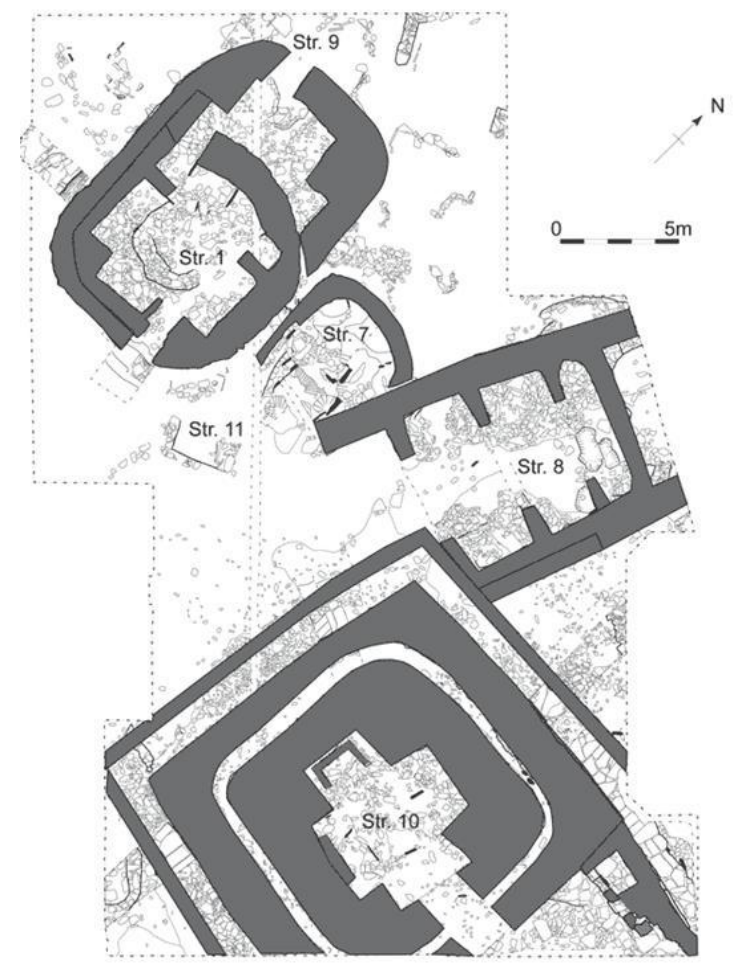

Figure 14: Large buildings at Ness of Brodgar, Orkney. Illustration: Nick Card 
It seems likely that this ceremonial centre in the heart of Orkney gained fame far beyond the archipelago, in the same way that the Boyne valley had previously been a ceremonial centre, attracting visitors from far and wide. Visitors to Orkney, and spread of its fame by word of mouth across the preexisting networks of contacts, would account for the rapid southwards spread of elements of its traditions - namely the use of Grooved Ware (which reached southern England and south-west Ireland), of various kinds of macehead, of carved stone balls (Fig. 17) (which were manufactured in large numbers in Aberdeenshire), of stone circles (and counterparts in timber, not currently/yet attested in Orkney) and, arguably, of singleand multiple-entrance, roughly circular henge monuments, including the 'anomalous' firstphase henge at Stonehenge. The adoption of these elements was selective, varying from region to region: for example, communities along the Atlantic façade of Scotland adopted the use of stone (and timber) circles and the use of Grooved Ware, although at Calanais stone circle on Lewis the latter is represented by just a single pot (Ashmore forthcoming; see also Sheridan 2004 on the nature and dynamics of this spread to Ireland.) Elsewhere, in Shetland, the only element that seems to have been adopted - apart from a single, and questionable, example of a Grooved Ware pot - was the cushion macehead. This type of macehead seems to have been made in Shetland (as well as elsewhere); it is likely that several of the examples of this macehead type found in England had been made in Scotland. (See Theme 5.)

Other evidence for the long-distance (and reciprocal) movement of ideas and objects (and people) includes the shared use of specific motifs - including the 'eyebrow' motif, as seen on a figurine from the Links of Noltland (see Theme 5), on a chamber tomb at Holm of Papa Westray South and on the Folkton 'Drums' in Yorkshire - and the northwards movement of fine oblique and petit tranchet derivative arrowheads of black flint (as seen in the passage tomb at Ormiegill, Caithness, for example: Figure 15).

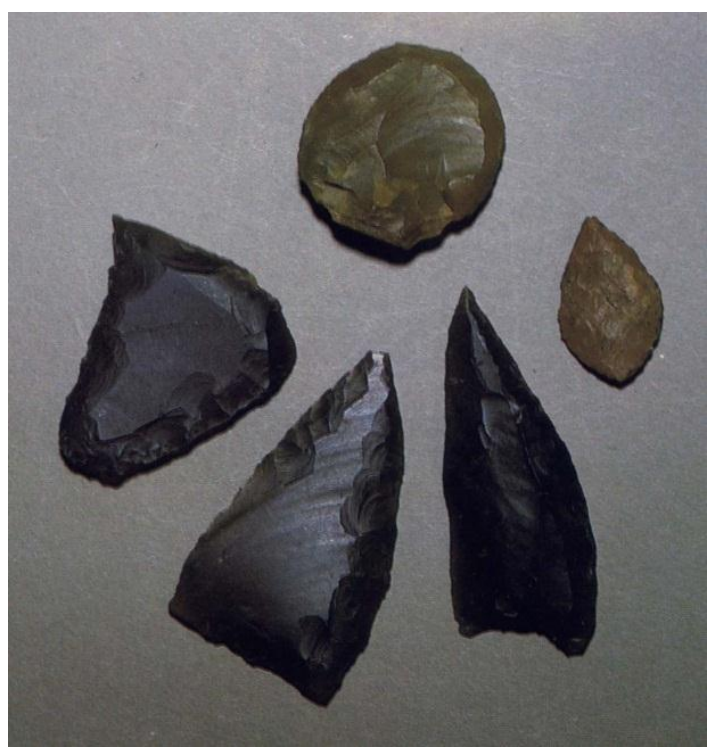

Figure 15: Late Neolithic oblique and petit tranchet derivative arrowheads of black flint, along with other (probably earlier) flint artefacts, from Ormiegill passage tomb, Caithness. From Clarke et al. 1985; photo NMS.

That long-distance contacts between Orkney and the south of England persisted until at least the $26^{\text {th }}$ century is suggested by a parallelism in the shape of houses at Durrington Walls and at Skara Brae (Parker Pearson 2007), and by continued sharing of some Grooved Ware styles despite the divergent regional trajectories in different parts of Britain and Ireland. Furthermore, it is well within the bounds of possibility that the Ring of Brodgar - which is by far the largest henge in northern Britain - was created for a member of the Orcadian elite who had visited Avebury and who wanted to recreate it as part of the Stenness-Brodgar ceremonial area. The dating evidence for both sites leaves much to be desired, but a date during or after the $26^{\text {th }}$ century $B C$ is consistent both with what we can say about the construction date of Avebury (Josh Pollard pers. comm.) and with the admittedly imprecise results of OSL dating at the Ring of Brodgar. 


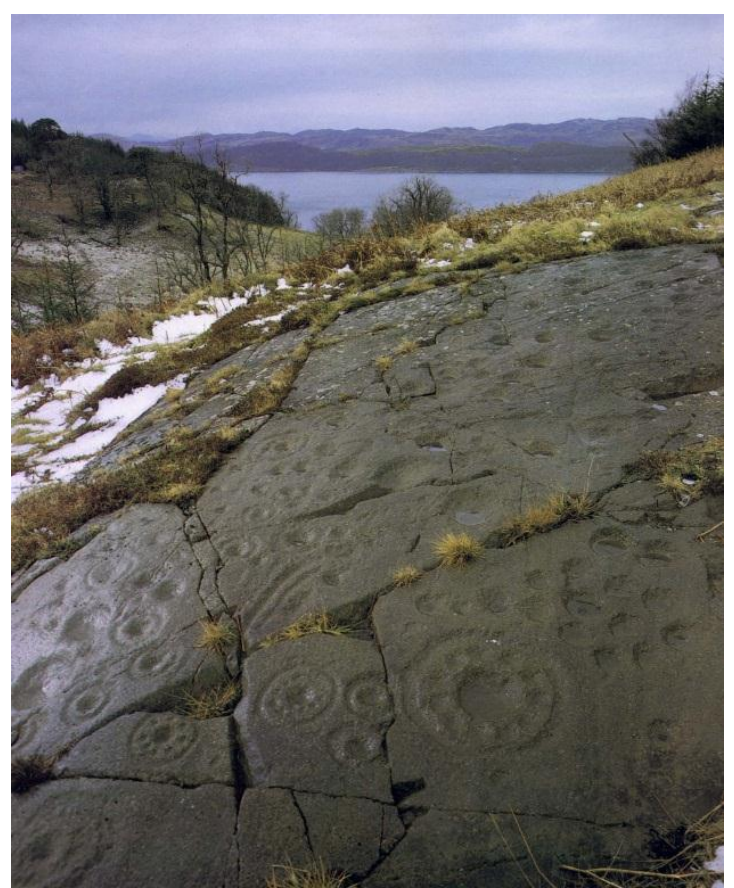

Figure 16: Bedrock adorned with 'rock art', Ormaig, Argyll \& Bute. From Clarke et al. 1985; (c Mike Brooks.

The phenomenon sketched above presents the most striking and obvious development during the first half of the third millennium, but it was not the only one. It now seems likely that most 'rock art', featuring cupmarks, cup-and-ring and other designs (Figure 16), was created during the first half of the third millennium BC (even though the earliest simple cupmarks probably date to the early fourth millennium, as suggested by a cupmarked slab from Dalladies funerary monument).

The nature of 'rock art' and its complicated relationship to 'passage tomb art' and Grooved Ware design is explored in Theme 6; and note that the creation of rock art on outcrops should not be confused with the much later re-use of some of these outcrops to create cist slabs during the Early Bronze Age, and stone settings during the Middle Bronze Age. Suffice it to say here that the overall distribution of 'complex rock art', featuring cup-and-ring and other designs other than simple cupmarks, extends beyond Scotland to other parts of Britain, Ireland and north-west Iberia. As Richard Bradley argued in 1997, the close similarities in designs and placement in the landscape in these different regions implies the existence of extensive Atlantic façade networks of contact (Bradley 1997). This accords with the evidence from the late fourth millennium major passage tombs of the Boyne Valley, where longdistance elite journeying as far as the Morbihan area of Brittany and south-west Iberia is attested (Eogan 1980; Stout \& Stout 200x).

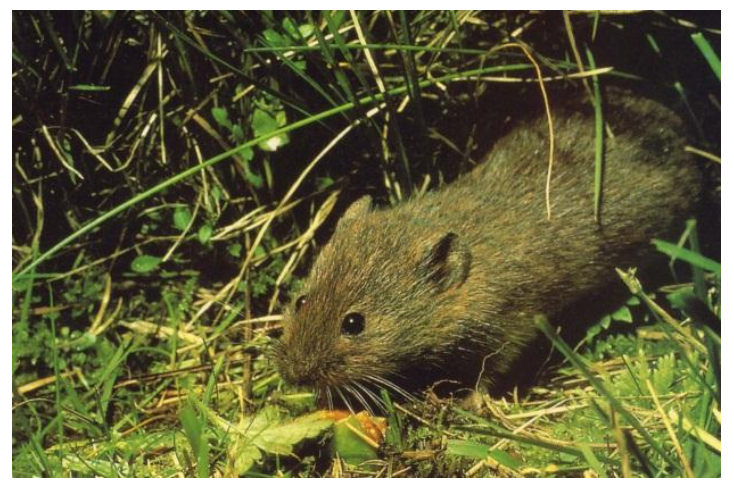

Figure 17: The Orkney Vole: a Continental arrival around or just before 3000 BC. Photo: (C) Dr Peter Reynolds

2008). It also accords with the genetic evidence for the arrival of the Orkney Vole in Orkney (Cucchi et al. forthcoming), which must have involved long-distance transport by sea from the Continent. Since Orkney Vole remains are present in Orkney by 3000 BC, their arrival may relate to long-distance journeying at that time. Therefore, while the Grooved Ware-associated traditions and practices involved interaction within Britain and Ireland, the evidence from rock art suggests the existence of more extensive networks of contact during the first half of the third millennium. 


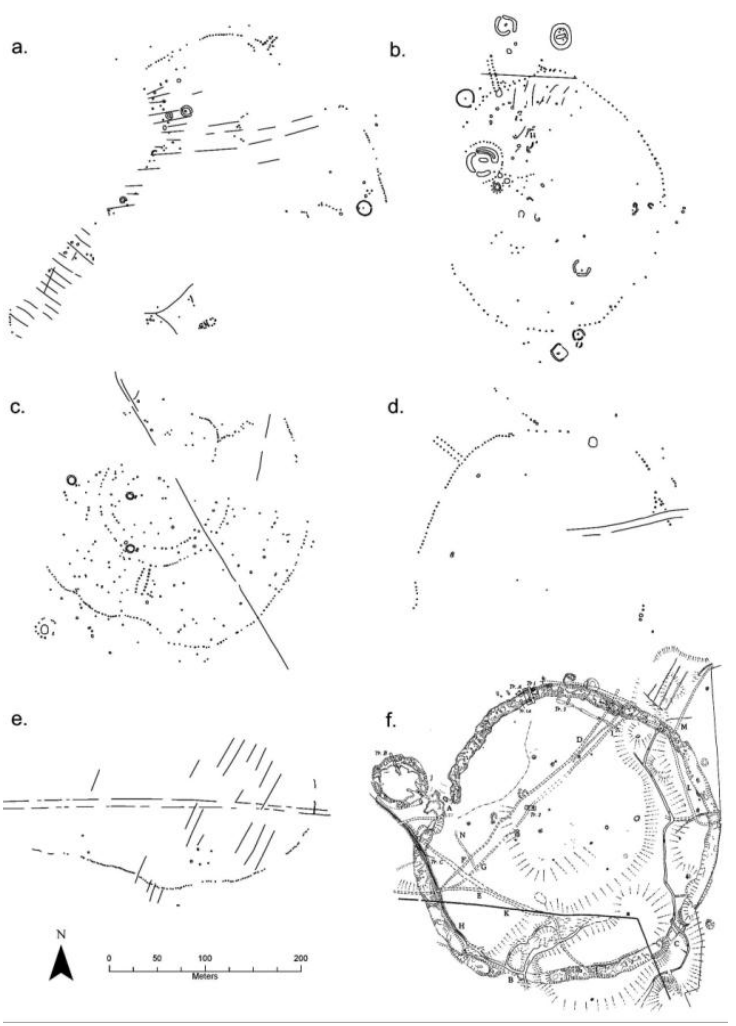

Figure 18: Late Neolithic enclosures in Scotland: a. Leadketty, b. Forteviot, c. Dunragit, d. Meldon Bridge, e. Kinloch (from Millican 2009), f. Blackshouse Burn. From Noble \& Brophy 2011b; drawn by Kirsty Millican

Other developments during this period include the emergence of large palisaded (and in the case of Blackshouse Burn, stone and earthen) enclosures in parts of southern and central Scotland (Figure 18) The example at Dunragit, Dumfries \& Galloway, may well be contemporary (and associated) with the use of Grooved Ware at the site; it, and the recently-excavated example at Forteviot, Perth \& Kinross (Noble \& Brophy 2011a and b), has produced radiocarbon dates indicating construction between the $29^{\text {th }}$ and $25^{\text {th }}$ century BC. The poorly-dated enclosure at Meldon Bridge, Scottish Borders, is closely comparable with the Dunragit and Forteviot examples and at least one further Scottish example is known from aerial photographs (at Leadketty, not far from Forteviot, in Perth \& Kinross: ibid.) Parallels can be drawn with the contemporary complex timber enclosure at Ballynahatty, Co. Down (Hartwell 2002). Timber structures featuring a central setting of four large posts - as seen at numerous sites in Ireland, and also in Wessex - have been found at Greenbogs, Aberdeenshire (Noble in press). Whether the Greenbogs examples had been special-purpose buildings for ceremonies (like the examples elsewhere), or houses, is unclear.

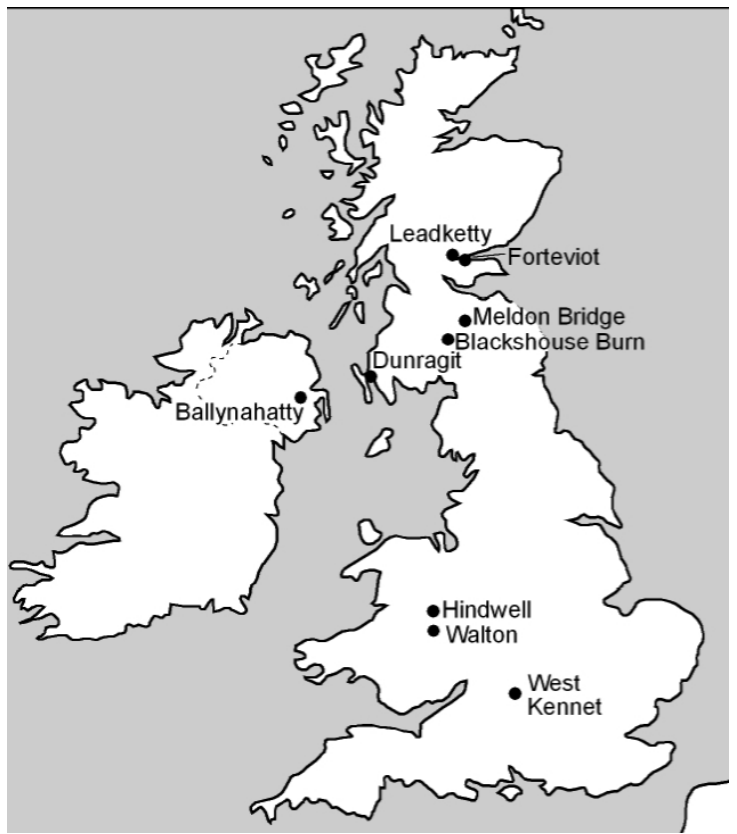

Figure 19: Location map for enclosures shown in Figure 18

Many research questions remain to be addressed, principally:

1. What was happening in those parts of Scotland that did not participate in the 'Grooved Ware phenomenon' as sketched above? And within Orkney, what were the social dynamics there between those who participated in the social system as sketched above, and those who did not?

2. Have we identified all the practices, traditions, types of structure and material culture associated with the 'Grooved Ware phenomenon'? (Our knowledge of Grooved Ware habitation structures outside Orkney is very poor, for example.) And to what extent was their spread due to long-distance travel (presumably by elites) as opposed to diffusion through networks of interacting communities? What was so attractive about the beliefs and rituals in Orkney that other people sought to emulate and adopt them? 
3. Were the Orkney-southern England links continuous between the $30^{\text {th }}$ and the $26^{\text {th }}$ century, or intermittent? This requires research at a pan-British level to find an answer. Also, to what extent were Orcadian practices adopted in Wessex? It could be argued that the inspiration for the first-phase monument at Stonehenge had been the Stones of Stenness. A comparative study of Grooved Ware-associated practices, traditions and material culture in Wessex and Orkney (and elsewhere in Britain) would be useful.

4. How does the creation and use of 'rock art' articulate with the practices and traditions associated with the use of Grooved Ware and associated monuments? The two overlap spatially and chronologically, but what accounts for the non-overlapping parts of their distributions?

5. Why were the large enclosures built? Were they centres for periodic ceremonial activity, and if so, how does their use compare with the use of Late Neolithic timber and stone circles and henges?

6. How, if at all, did subsistence strategies and settlement organisation differ from the preceding centuries in the various regions of Scotland? Does the abundant evidence for marine resource exploitationin Orkney (e.g.at Skara Brae) mean that these resources formed part of the diet?

\section{$2.5 \quad$ Endings}

Defining the end of the Neolithic has tended to be a matter for debate in the past, with discussion revolving around whether the appearance of metal, Beaker pottery use and other Continental novelties during the $25^{\text {th }}$ century BC occasioned the end of a 'Neolithic' lifestyle, or whether pre-existing traditions persisted alongside the novelties. The term 'Late Neolithic-Early Bronze Age' has been used by some as a convenient (if incorrect) way of describing the three centuries between the first appearance of metal and the beginning of bronze use during the $22^{\text {nd }}$ century BC. As argued in the Chalcolithic \& Bronze Age Panel report, the term 'Chalcolithic' is the most appropriate term to use to describe this period; but since the appearance of the 'Beaker package' clearly did not occasion an instant and widespread transformation of society in Scotland, it is useful to review briefly the principal developments during that period as they relate to pre-existing traditions and practices.

The novelties, which may well have been introduced by a small number of immigrants from the Continent (principally the Rhine delta and possibly also the Atlantic façade), before eventually being adopted and adapted by people in Scotland, comprise the following:

- the use of copper, and subsequently gold;

- the Beaker ceramic tradition, Continental in both design and manufacture;

- A funerary tradition featuring individual interment, initially in simple graves or in wooden cist-like structures, with gender-specific 'rules' regarding body position and statusspecific rules concerning grave goods; an emphasis on portraying some men as high status warriors/hunters; and the provision of food/drink for the journey into an envisaged afterlife;

- Novel archery accessories: barbed and tanged arrowheads, belt rings and wristguards, if not also composite bows;

- Continental dress fashion: the use of buttons as a dress accessory;

- Arguably the use of a fire-making kit comprising a flint strike-a-light and iron pyrites/ore;

- Potentially the use of oval houses (as seen in the Western Isles).

The reasons for their appearance could have been partly the undertaking of heroic, longdistance journeys by elite men and their retinues, as part of a widespread social 
practice in Continental Europe; partly a search for metal, particularly copper; and partly the straightforward exploration of new areas. The very widespread distribution of early, Continental-stlye Beakers (including as far north as Shetland, in the case of a worn sherd of All Over Cord-decorated Beaker from Stanydale) is consistent with the 'long distance journeying' idea.

Reactions to this appearance of exotic Continental novelties seem to have varied. In north-east Scotland they included the eventual construction of a range of nonContinental style monuments to honour certain individuals, with Beaker pottery featuring in the rituals: Clava ring cairns and passage tombs, recumbent stone circles and two-entrance, oval henges (Bradley 2000; 2005; 2011). The Clava passage tombs may represent a revival of the earlier, Neolithic practice of passage tomb construction.

Elsewhere, Beaker use did not really 'take off' in Orkney, where the social dynamics of the preceding centuries continued, with the use of the Ness of Brodgar continuing until 2300 $B C$. As noted above, the Ring of Brodgar may have been built after 2500 BC. Pre-existing chamber tombs of various types were reused; the infamous remains of the whitetailed sea eagles of the Isbister 'Tomb of the Eagles' (Figure 20) were deposited between 2450 and 2000 BC (Pitts 2006), as were the remains of dogs, deposited in the Cuween passage tomb (Sheridan 2005a). Humans were also buried in chamber tombs at this time; whether any chamber tombs were actually constructed in Orkney after 2500 BC remains to be demonstrated.

Figure 20: White-tailed sea eagle. From Pitts 2006; Photo: Nature Picture Library

In Shetland, Beaker pottery seems to have been adopted as a novel ceramic style, but its use was in a local idiom (e.g. in the Ness of Gruting house, built according to Shetland architectural tradition) and its development followed an insular trajectory. The same can be said for Beaker use in the Hebrides. Furthermore, in the Western Isles, it is clear that the chamber tomb inside the Callanish stone circle was built after the appearance of Beaker pottery, since worn sherds of an international-style Beaker were securely stratified in its lower cairn material (Ashmore forthcoming).

Elsewhere in Scotland, the question of how long Grooved Ware continued to be used after Beaker pottery appeared has not been satisfactorily answered. The latest dated Scottish Grooved Ware comes from Littleour, Perth \& Kinross (Barclay \& Maxwell 1998), with organic residues in two vessels having been dated to the second half of the third millennium BC; but the wide spread of dates from this assemblage suggests that there may be an issue with the encrusted organic residue on the pots that provided the samples, and re-dating of this assemblage is recommended. (See below, 3.3.1.3, for further details.) Similarly, the question of whether any Grooved Ware shows influence from Beaker pottery (or indeed vice versa) needs to be bottomed out. Presence of twisted cord impression on some Grooved Ware may not be a convincing indicator of Beaker influence.

Likewise, it is unclear whether other kinds of non-Beaker pottery were in use when the 'Beaker package' appeared. There is tentative evidence from Mye Plantation, Dumfries \& Galloway, where a pile from a putative pit-fall trap produced a date of $3913 \pm 39$ BP (2560$2240 \mathrm{cal} \mathrm{BC}$ at $2 \sigma$, UB-3882 (Sheridan 2005b). In between two pits in the line of pits were found sherds of what appears to be a hybrid between Grooved Ware and Impressed Ware pottery (See Theme 5). Whether this was contemporary with the dated timber is, however, uncertain.

Therefore, there remain many unanswered questions, prominent among which are the following: 
1. For how long did a recognisably 'Neolithic' way of life (however defined) continue after the appearance of the Beaker package? And what went on in parts of Scotland that were scarcely (if at all) touched by the Beaker phenomenon?

2. What were the other responses (apart from those listed above) to the appearance of the Beaker package? And what caused the demise of the Late Neolithic social system in Orkney, perhaps around 2300 BC?

3. Was Grooved Ware the only pottery type in use in the period immediately preceding the appearance of Beakers? If not, then what was used?

4. Basic information about the nature of settlement, land use and subsistence strategies needs to be gathered. The effect of the localised, intermittent episodes of forest regeneration as identified for the second half of the $3^{\text {rd }}$ millennium by Richard Tipping (1994) need to be explored: was there a shift in settlement? 
3. The Detailed Picture: issues

\subsection{Introduction}

This section addresses the evidence for the Neolithic in Scotland on a more detailed level than the 'overall Big Picture narrative'. Even at the 'Big Picture' level it is clear that the 'Neolithic' is not uniformly manifested, either in terms of character or chronology, across Scotland. This section consequently explores issues relating to finer levels of spatial and temporal resolution and identifies different scales of research question and narrative. At the heart of this are questions such as:

- How much variety is there in the character of evidence between the regions?

- How uneven is current knowledge and understanding of the Neolithic in different regions of Scotland?

- How does the character of the Neolithic vary across Scotland?

- What are the distinct regional developments in the Neolithic?

- What is the evidence for interregional interaction at different times?

- What are the reasons for the spatial and temporal variability?

- What is the best chronological resolution that we currently have, and can it be improved significantly through targeted dating programmes?

- Are there some periods for which we have a better resolution / understanding than others?

- What type of research questions and levels of narrative are possible with the spatial and chronological resolution currently available?

The detailed picture will be addressed through several subsections: the first will consider the nature and level of spatial and temporal resolution below the 'big picture' level; the second comprises regional

\section{of regional and chronological resolution}

summaries; the third will compare and contrast the results of these summaries in

terms of inter-regional variation, while a final subsection considers research priorities for achieving better resolution on the detailed picture.

\subsection{Levels of resolution and narrative}

Current analysis and understanding of the Scottish Neolithic is narrated on a number of different chronological and spatial scales, ranging from broad-brush 'grand narratives' (as offered in Theme 2), through regional accounts, to landscape-, site- and artefactlevel studies. How we can improve the articulation of these diverse scales of investigation and narrative-building is a key challenge.

For present purposes we shall focus on developing narratives at a regional level, since this approach provides a sufficient spatial resolution to identify broad patterns, while taking cognisance of levels of detail which get lost in the national picture. The regional level also allows us to examine what happened, when, at a greater level of detail than can be addressed through higher-level approaches.

\subsubsection{Spatial resolution}

As the 'Big picture' narrative of Theme 2 has made clear, following the initial appearance of two separate 'strands' of Neolithisation during the late $5^{\text {th }}$ to early $4^{\text {th }}$ millennium the one (the Atlantic façade, 'Breton' Neolithic) appearing on parts of the west coast of Scotland, the other (the 'Carinated Bowl' Neolithic) more widespread but essentially south of the Great Glen, except for parts of the Caithness coast - there followed a process of regionalisation, as traditions became reproduced and reinterpreted over time.

The fact that the Scottish Neolithic was regionally variable has indeed long been 
recognised, although the way in which Scotland has been divided into regions has varied. Piggott's $(1954,381)$ regional division of Scotland was essentially east vs. west, following his vision of two-strand Neolithisation and acknowledging that the Scottish Neolithic was part of a broader cultural tradition in Britain. More recent attempts to consider the regional nature of the Scottish Neolithic have focused on smaller areas, such as Orkney (e.g. A. Ritchie 2000), the Western Isles (Armit 2003) and SW Scotland (Thomas 2000), with Gordon Barclay arguing for the east Scottish lowlands (and particularly the lowlands of Aberdeenshire) as having a strong regional identity (Barclay 2000 - although note that some of the evidence for this distinctiveness - i.e. the recumbent stone circles and (two-entrance) henges - have since been shown to belong to the Chalcolithic and Early Bronze Age).

The definition of regionality between the late $5^{\text {th }}$ and mid- $3^{\text {rd }}$ millennium $B C$ is, however, problematic. As Niall Sharples noted (Sharples 1992), Scotland is not amenable to being divided into discrete Neolithic regions, since some traditions, monument types and styles of material culture transcend 'natural' geographical regions (as seen, for example, in the distribution of cursus monuments and bank barrows: Fig. 23) and since changing patterns of interaction altered the distribution of shared cultural traits over time. Furthermore, the concept of what defines a region is a slippery thing. While the topography of Scotland suggests certain natural regional divisions and an overall 'highland vs. lowland' differentiation, and while topography will have influenced routes and ease of travel and communication, it clearly did not determine cultural identity. One could, of course, attempt to define regionally-variable archaeological cultures, using David L. Clarke's concept of culture as 'a polythetic set of specific and comprehensive artefact-types [and, by extension, site-types and traditions] which consistently recur together in assemblages within a limited geographic area' (D.L. Clarke 1968, 232, with addition). However, the fierce debates of the 1970s and 1980s in British archaeology over the use (and utility) of the concept of archaeological 'cultures' highlighted the danger of such an approach, pointing out that a shared set of cultural attributes need not correlate with ethnic, linguistic or any other kind of cultural identity. Thus, in contrast to our Continental counterparts, we shall not be seeking to define 'cultures' as such (beyond the broadest level of 'the Carinated Bowl Neolithic', for example).

[Fig 23 to go here]

Other issues lurk behind the use of regionality as a concept. Firstly, as Gordon Barclay has pointed out (2000), by focusing archaeological endeavour and resources on a few regions with Orkney being the Scottish example he cites - this skews our knowledge of other parts of Scotland, so that we end up knowing a great deal about a few areas, and relatively little about others. To some extent, however, this issue has been mitigated by the strategic use of resources by Historic Scotland over the last 15 years, and by the impact of developerfunded archaeology (which has tended to follow the geography of infrastructural and commercial development). And in any case, issues of how we investigate different regions are incidental to the characterisation of regionality.

Secondly, our perspective may be skewed by our contemporary sense of regionality, which can often be defined by modern - and not-somodern - administrative boundaries (e.g. local authority areas and pre-1975 counties).

Thirdly, we need to acknowledge that the Neolithic perception of space and identity may not have included any concept of regionality at all - beyond an awareness that other people lived in other areas, some a long way away. Groups will indeed have had an identity, and this will have had a geographical aspect and there may indeed have been some sense of territorial ownership (at a local level); but what we are seeing, when we 
contemplate our distribution maps of site and artefact types, is the outcome of shared traditions, patterns of interaction and cultural choice.

Notwithstanding these considerations, the use of a regional approach does have heuristic value, for the reason given above - i.e. it allows us to investigate patterns of behaviour at a more detailed level than that of the 'Big Picture'. Furthermore, there clearly was regional variability during the Neolithic, even though the geographical characteristics of this variability will have changed over the centuries; this variability needs to be characterised.

A pragmatic approach has therefore been followed, whereby regionality is used as an analytical and narrative device. Scotland (and indeed neighbouring parts of England) has been divided into broad geographical regions for the purpose of describing material culture, monuments, traditions and practices, on the understanding that:

- these regions are a largely arbitrary division, albeit one in which shared intra-regional, and divergent interregional patterns can be perceived; and

- there will have been inter-regional interaction, differing in its extent and direction at different times during 'the Neolithic'.

After much discussion within the Panel, the regional divisions were delineated as follows (with relevant section numbers included; see Error! Reference source not found.):

\subsubsection{East and central Scotland, between the Great Glen and the Forth}

\subsubsection{South-east Scotland and north-east England}

\subsubsection{South-west Scotland}

\subsubsection{Western Scotland, south of the Great} Glen
3.3.5 The north-west mainland and the Hebrides north of the Great Glen

3.3.6 The north-east mainland (north of the Great Glen) and Orkney

\subsubsection{Shetland}

\subsubsection{Chronological Resolution}

Issues of chronological resolution can be considered from several perspectives: What level of chronological resolution is required (or desired) to achieve robust narratives at different scales? What are the limitations to the level of chronological resolution which can actually be achieved? What are the potential consequences of these limitations to our narratives?

Traditionally, many higher level narratives for the Scottish Neolithic have been related to a level of chronological resolution provided by a period-based system, in which 'the Neolithic' is divided, either into two (i.e. Early vs. Late) or three (Early-Middle-Late); the arbitrariness inherent in any periodisation has already been touched upon in Theme 2.

The problems with a period-based system have been widely recognised, yet such systems still persist in use. While these may, arguably, act as convenient short hand (shorter still would be N1, N2 etc!), the question remains: what defines these periods? In most cases, the definition / extent of a sub-period derives from recognition of the changing character of a range of archaeological evidence, frequently interpreted as reflecting or relating to other social or economic trends. Thus, the nature of any narrative will in part be defined by the degree of chronological resolution available.

Nowadays, with a growing body of reliable radiocarbon dates and the application of Baeysian modelling, the prospect of being able to identify developments over individual generations, rather than over centuries or 
quarter millennia (as had been the limitation in the past) is opening up (cf. Whittle et al. 2011). This means that we shall eventually be able to create finer-grained, more detailed narratives of what was happening, when, and to assess the speed of change. Of course, the vagaries of the radiocarbon calibration curve mean that there will always be some periods when our chronological resolution is poorer than others: within our time frame of interest, the plateau at $3500-3100 \mathrm{BC}$ is particularly frustrating (cf. Schulting et al. 2010). Unless a significant amount of dendrochronologicallydatable material is found, or ways of mitigating the problem of the calibration curve are discovered, then this will remain a challenge.

In the regional reviews that follow, we have chosen a pragmatic solution that enables readers to compare developments in different regions. We are making a fairly arbitrary division, as follows:

- From beginnings to $3500 \mathrm{BC}$ (which will go by the shorthand term 'Early Neolithic')

- 3500-3000 BC ('Middle Neolithic')

- 3000-2500 BC ('Late Neolithic').

The reason why this does not exactly follow the chronological divisions used in Theme 2 is that the separate sections on 'Beginnings' and 'Endings' were used there to highlight specific issues for the overall narrative. Having dealt with those, we can focus on what happened between the 'Beginnings' and the 'Endings'.

\subsection{Regional narratives}

This section will comprise narratives for the regions outlined above, starting with east and central Scotland and progressing roughly clockwise around the country. Research questions specific to each of the regions will be identified.

\subsubsection{East and central Scotland, between the Great Glen and the Forth}

This region includes the rich agricultural lowlands of Tayside and Fife, Aberdeenshire, Moray and the Black Isle - areas that are rich in Neolithic archaeology, but which have also seen millennia of farming, which has created a palimpsest of later activity and taken its toll on the Neolithic remains. Our knowledge of the Neolithic of this region owes much to research-based fieldwork, survey and synthesis, of which a considerable canon has grown up over the course of the $20^{\text {th }}$ and early $21^{\text {st }}$ century. Highlights include the following:

Research excavations and field survey:

- Early Neolithic timber 'halls' on either side of the River Dee at Crathes Warren Field (Murray et al. 2009) and Balbridie, Aberdeenshire (Ralston 1982; Fairweather \& Ralston 1993), and at Claish, Stirling (Barclay et al. 2002);

- Non-megalithic round mounds at Boghead, Moray (Burl 1984), Pitnacree, Perth \& Kinross (Coles and Simpson 1965) and Pitglassie, Aberdeenshire (A. Shepherd 1996);

- The Cleaven Dyke and the Littleour structure, Perth \& Kinross (Barclay \& Maxwell 1998)

- Stuart Piggott and Derek Simpson's excavations at Croft Moraig, Perth \& Kinross (Piggott \& Simpson 1971) and its subsequent reappraisal (Bradley \& Sheridan 2005);

- Alan Saville's excavations of flint mines at the Den of Boddam and on Skelmuir Hill, near Peterhead, Aberdeenshire (Saville 2008; 2011);

- The SERF (Strathearn Environs \& Royal Forteviot Project) excavations of the Middle Neolithic cemetery, Late Neolithic timber enclosure, timber circle and subsequent activity at Forteviot, Stirling (Noble \& Brophy 2011a; 2011b); and

- Aerial reconnaissance by RCAHMS and Aberdeenshire Archaeology (e.g. Shepherd \& Greig 1996). 
In addition to these, Richard Bradley's excavations of Clava cairns (Bradley 2000), recumbent stone circles (Bradley 2005; and cf. Welfare 2011) and small henges (Bradley 2011) in this region have served to demonstrate that these monuments actually post-date the conventional end-date of the Neolithic, belonging instead to the Chalcolithic and Early Bronze Age.

Synthetic reviews:

- Ian Kinnes' review of non-megalithic long mounds (Kinnes 1992a; 1992b) and non-megalithic round mounds (Kinnes 1979);

- Andrew Dunwell and lan Ralston's review of the archaeology of Angus (Dunwell \& Ralston 2008);

- reviews of the region's Early and Early to Middle Neolithic pottery by Audrey Henshall (Henshall 1968; 1983) and Trevor Cowie (Cowie 1992; 1993)

- Gordon Barclay's reviews of the archaeology of lowland Scotland (Barclay 1992; 1995; 1996; 2000; 2003)

Developer-funded (and other 'rescue') excavation has also played a major role in revealing the wealth of Neolithic sites in this region (Phillips \& Bradley 2004), as demonstrated for example in the excavations in the Balfarg and Balbirnie complex, Fife, led by Roger Mercer (Mercer 1981) and by Gordon Barclay and Chris Russell-White (Barclay \& Russell-White 1983); see also Alex Gibson's recent dating of the Balbirnie stone circle (Gibson 2010). Other important Neolithic sites revealed through rescue excavation include the complex of sites around Kintore, Aberdeenshire (Alexander 2000; Cook \& Dunbar 2008); others around Inverness, especially at Culduthel (Murray in prep.) and Raigmore (Simpson 1996); and the important Middle Neolithic site at Meadowend Farm, Clackmannanshire (Jones 2006; Jones \& Smith forthcoming).
It should be noted here that, as far as the archaeology of Aberdeenshire and Moray is concerned, a very great debt of gratitude is owed to the late lan Shepherd, Aberdeenshire Regional Archaeologist, who did so much to encourage and facilitate much of the work mentioned above in this part of Scotland.

\subsubsection{Early Neolithic, to 3500 BC}

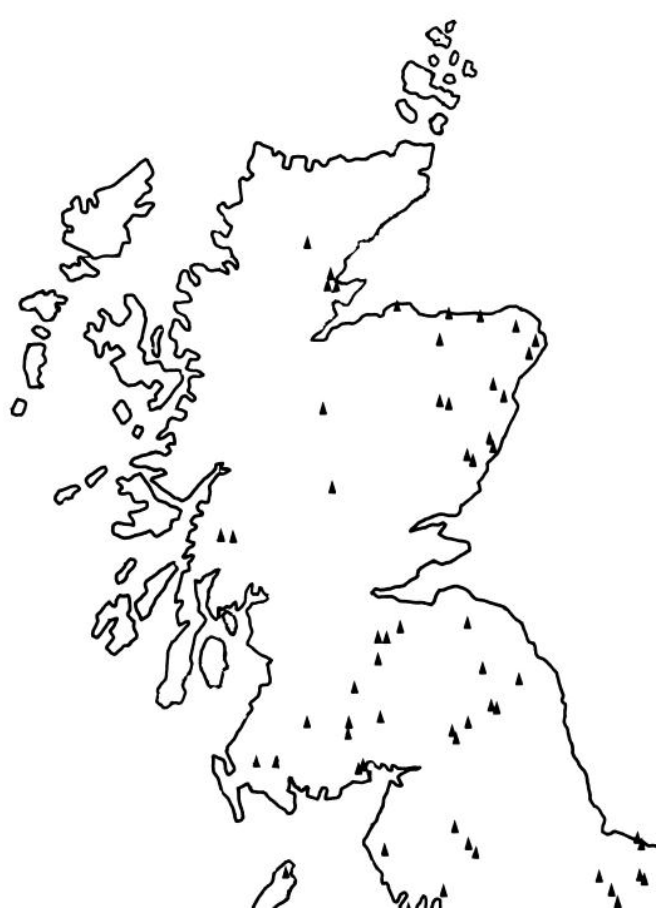

Figure 21: Distribution of non-megalithic long barrows in Scotland. Based on Kinnes 1992a, with addition; note that one mound (at Meadowfoot, Dumfries \& Galloway) may be a natural glacial mound

The Early Neolithic of eastern and central Scotland is marked by the appearance and subsequent development of the Carinated Bowl (CB) Neolithic, as sketched in Theme 2. Aberdeenshire is particularly rich in $\mathrm{CB}$ Neolithic sites, and these tend to cluster along major rivers and in areas which would have been favourable to mixed arable-pastoral farming (especially around Inverurie). This is shown, for example, in the distribution of $C B$ pottery (Figure 7), of Alpine axeheads (Figure 30) and of non-megalithic long barrows (Figure 21); cf. the distribution of nonmegalithic round mounds in eastern Scotland, Figure 22. 


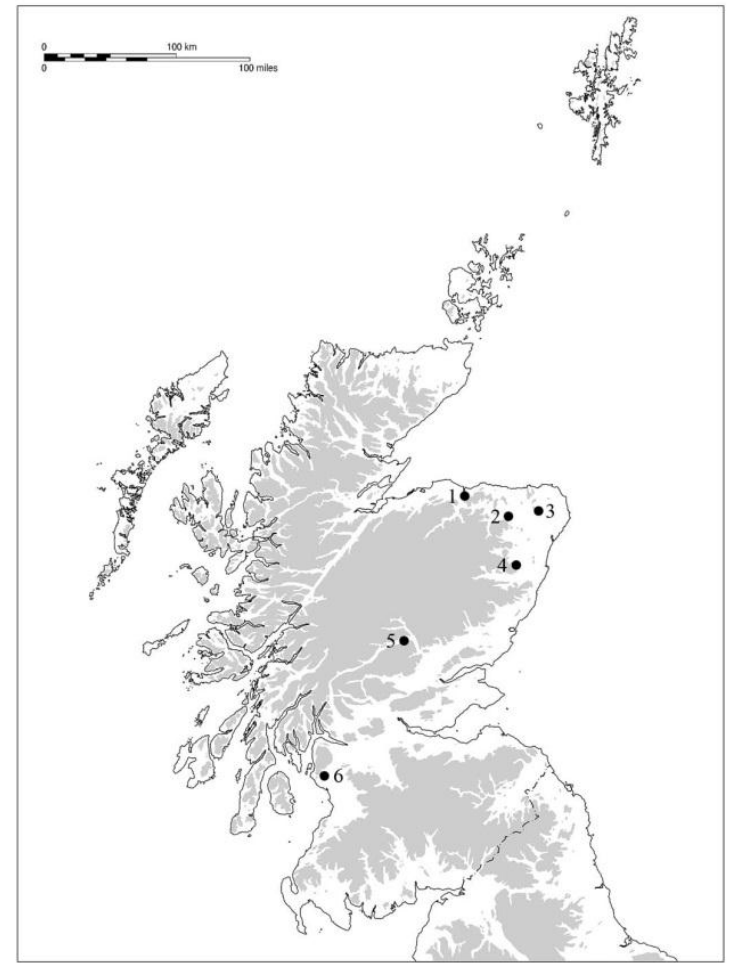

Figure 22: Distribution of non-megalithic round barrows in Scotland. From Sheridan 2010b

Indeed, that Aberdeenshire (and Angus) may have been an important landing place for our putative immigrant farmers from northern France is suggested by the large houses ('halls': Figure 23) at Crathes and Balbridie, on either side of the River Dee (with a further probable example known from aerial photography at Noranbank, Angus: Brophy 2007). These, together with the Claish 'hall' in Stirling, are among the earliest evidence for any Neolithic presence in this region and, as argued elsewhere (e.g. Sheridan 2010a and in press), these structures could well have been the communal houses for the first few generations of settlers, until they became sufficiently well established to 'bud off' into smaller, individual family settlements (at which point the 'halls' seem to have been decommissioned by being burnt down). The latter are represented, for example, by the houses (Figure 8) at Garthdee Road, Aberdeen, Aberdeenshire (Murray \& Murray 20xx); Pitlethie Road, Leuchars, Fife (Cook 2007); and, in a more truncated form, Deer's Den, Kintore, Aberdeenshire (Alexander 2000, illus 5) and Coul Brae, Mosstodloch, Moray (Gray \& Suddaby in press). Other Early Neolithic settlements are represented by pits and/or artefact spreads, as for example in the case of the pit with 'traditional CB' pottery at Hatton Farm, Elliot, Angus, dating to $4930 \pm 30$ BP, SUERC-24912 and 24913, 3780-3650 cal BC (Gray \& Suddaby 2010), and the pits at Blackhall Road, Inverurie, Aberdeenshire (Lochrie 2010a).

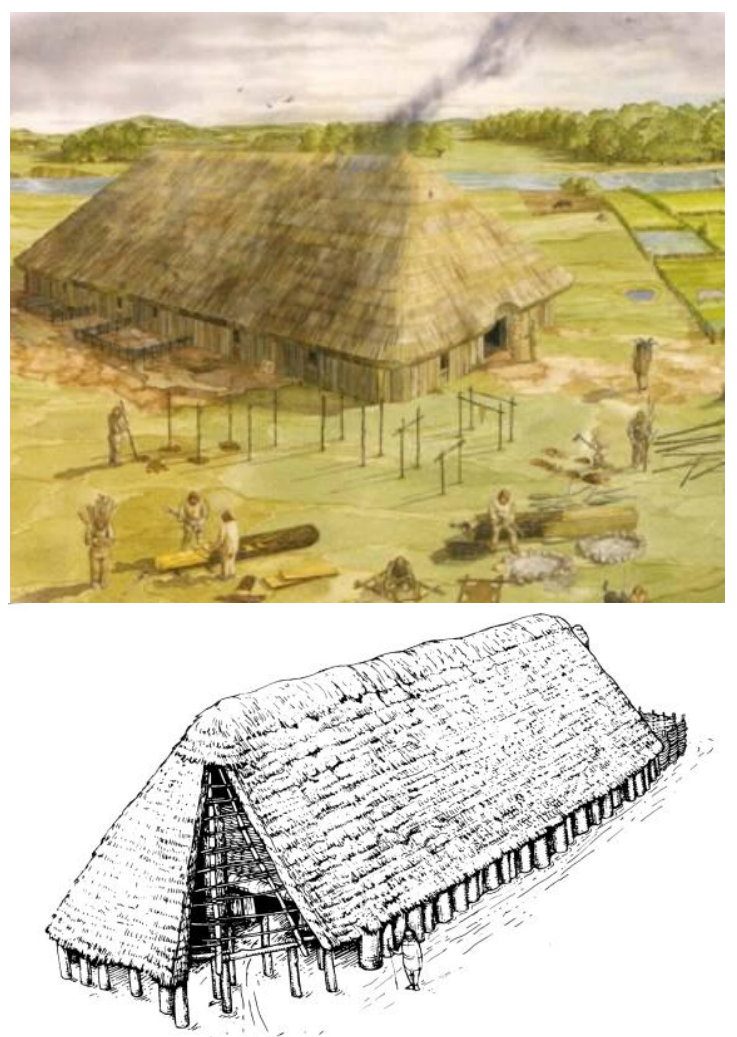

Figure 23: The 'halls' at Balbridie (top) and Warren Field, Crathes (bottom), both Aberdeenshire. Reconstruction drawings by David Hogg and Jan Dunbar with Hilary \& Charlie Murray. Reproduced by permission of Historic Scotland and Murray Archaeological Services

Bayesian modelling of the dates for the Crathes, Balbridie and Claish 'halls' has indicated that their currency spans between 3800-3705 cal BC and 3705-3630 cal BC (at 95\% probability) (Whittle et al. 2011, 832-3 and fig. 14.173), and modelling of the dates for the Garthdee Road house (ibid., fig. 14.157) has produced a near-identical range, suggesting that the 'budding-off' process started within a few generations of the initial 
arrival of the farmers. Furthermore, the presence of Arran pitchstone at Crathes (Warren 2009) indicates that the occupants participated in a network of contacts over which this material travelled a long distance from its source; this confirms that the process of establishing contacts between different groups of farmers started very early - thereby establishing a viable 'breeding population', apart from providing inter-group support.

In addition to housing several families, the large 'halls' would have constituted a powerful statement of identity and presence and, as noted in Theme 2, they would have constituted a very striking novelty, totally unlike any structure previously built in Scotland. Their Continental ancestry has been discussed elsewhere (most recently in Sheridan in press). That these were not just places of habitation, but were central to the belief system of their occupants, is suggested by the ceremony attending the construction of the Crathes 'hall', where the building of the structure was preceded by the erection of two massive, non-structual timbers along what was to become the long axis of the building (Murray et al. 2009, 37-40). These echo the split-trunk timbers used to frame the mortuary structures described below, and an analogy with totem poles has been drawn; at the very least, they indicate that wood/trees played a prominent role in the expression of beliefs (cf. Noble 2006).

As regards the susbsistence strategy of these early farming groups, palaeoenvironmental work around the Crathes structure has established that cereals were being cultivated in at least one field in the immediate vicinity (Lancaster et al. 2009), indicating settled agricultural habitation of the area, and at Balbridie, a particularly detailed impression of the crops grown was possible, largely thanks to a deposit of 20,000 carbonised grains found inside the structure (Fairweather \& Ralston 1993). Whether these represented a foodstore to tide the occupants over the winter, or else constituted a votive deposit at the time of the house's destruction by fire, is unclear.
The Balbridie evidence demonstrated the cultivation of the environmentally-demanding bread wheat, as well as emmer wheat, barley, oats and flax; all but flax were also found at Crathes (Lancaster et al. 2009). Both sites also produced evidence for the gathering of wild plants, including hazelnut and (at Balbridie) crab apple. While animal remains were poorly preserved at these (and other) large houses, lipid analysis of the Crathes pottery has revealed that the occupants' cattle (and/or sheep/goats) had been used for dairying, since traces of ruminant milk fats were found in them (as well as pig fat: Šoberl \& Evershed 2009). The human remains that survive from Early Neolithic eastern and central Scotland are either too small to permit isotopic analysis for obtaining dietary information (in the case of Dalladies) or else are not in a condition to permit such analysis, being calcined. The fact that large numbers of Neolithic arrowheads and other artefacts have been found on the sandhills of Tentsmuir in Fife and Culbin Sands in Moray (Clarke 2004) does not necessarily indicate activities connected with exploiting marine resources. The small size of many of the leaf-shaped arrowheads from these sandhills sites could as easily indicate their use in hunting birds as in shooting fish.

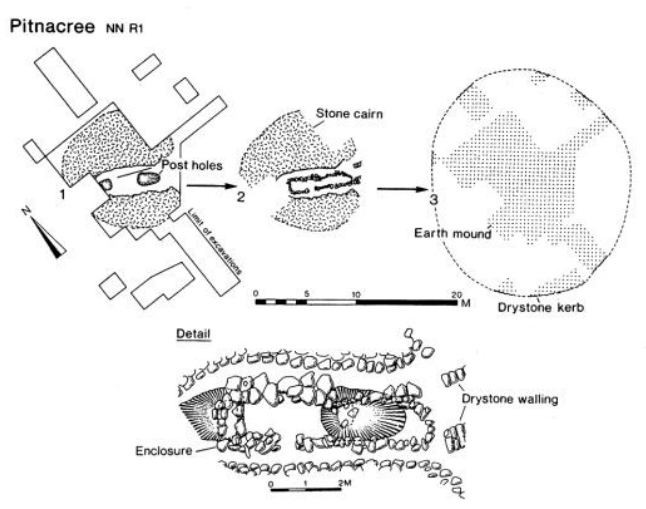

Figure 24: Plan of Pitnacree round barrow, Perth \& Kinross, showing the phases of construction and detail of the mortuary structure. From Kinnes 1992b

The funerary practices of these first farming communities in this region featured the use of non-megalithic structures (Kinnes 1992a, 
1992b). Rectangular 'linear zone' mortuary structures (Figure 10), of timber construction (rebuilt, at Dalladies and Pitnacree, using drystone walling), were probably used for the laying out (and possibly natural excarnation) of the dead. In addition to the two examples mentioned above, a mortuary structure is known from Fordhouse Barrow, Angus (Proudfoot 2008). After an interval - during which the latest versions of the mortuary structures and their contents were burnt these were covered over by earthen mounds, either long and rectangular or trapezoidal (as at Dalladies: Piggott 1972), or round (as at Pitnacree: Figure 24; Coles \& Simpson 1965). Distributions of these monuments are shown in Figure 21 and Figure 22.

Large, rectangular pit-defined and post-built enclosures (Figure 25) may also have been used for the laying out (and natural excarnation?) of the dead, as mortuary enclosures; examples include Inchtuthil, Aberdeenshire (Barclay \& Maxwell 1991); Cowie Road, Bannockburn, Stirling (Rideout 1997), Douglasmuir, Angus (Kendrick 1995 and see her illus 8 for further examples) and Castle Menzies, Perth \& Kinross (Halliday 2002). As will be seen below, however, there is a question mark as to whether these monuments formed part of the earliest Neolithic activity in the area.

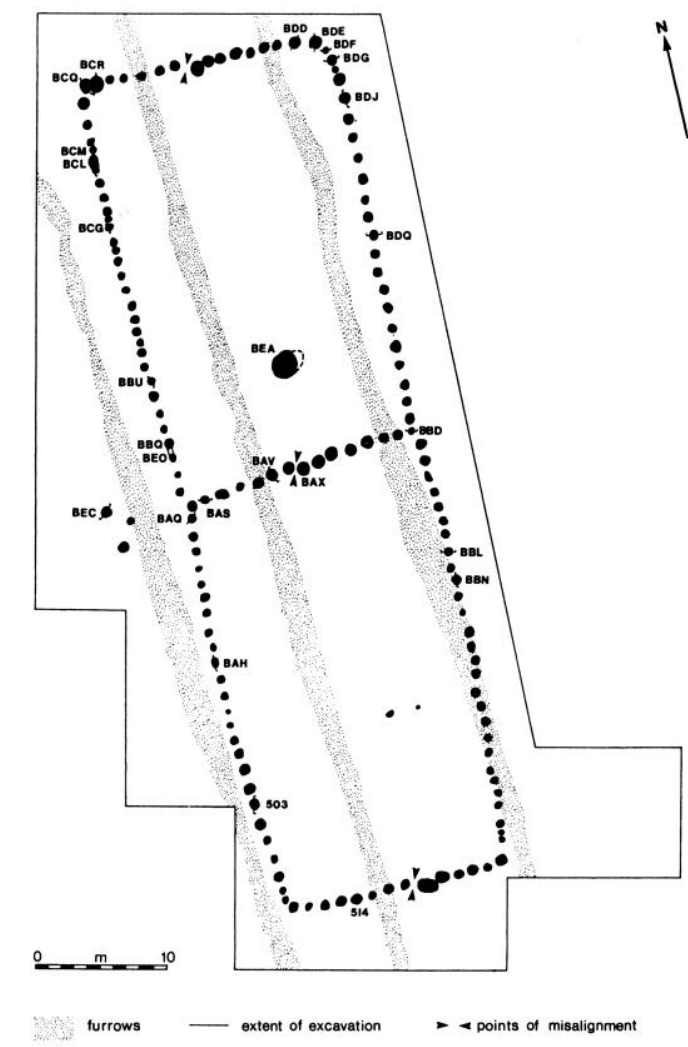

Figure 25: Rectangular timber-built mortuary enclosure at Douglasmuir, Angus. From Brophy 1998

In addition, the practice of cremation on an open pyre, followed by the sealing of the site by a round or long mound, is attested at several sites: those associated with round mounds are Boghead, Moray: Burl 1984; Midtown of Pitglassie, Aberdeenshire (Shepherd 1996); East Finnercy, Aberdeenshire (Sheridan 2010b) and the 'Pow Sod' cairn at Atherb, Aberdeenshire (ibid.), while those associated with long mounds are Knapperty Hillock (Kinnes 1992a, 85) and one of the Cairns of Atherb (Sheridan 2010b).

The use of long and round earthen mounds to cover pyres and mortuary structures indicates that these monuments were not intended for successive interment; rather, they would have stood as highly-visible monuments and as statements of identity (and possibly also land ownership) and would have endured as such long after the large 'halls' had been burnt down. Perhaps they were regarded as houses for the dead, and particularly of the founding ancestors. Indeed, with the 
exception of the Cairns of Atherb, the number of individuals whose remains have been found in these monuments is small; and at Dalladies, just one (unburnt) fragment of a child's skull was found. (Also present at Dalladies, but not associated with the bone, was a small slab with nine cupmarks, found over a posthole: Piggott 1972.Cf. a slab with two cupmarks from a putative Early Neolithic context at Raigmore, Highland: Simpson 1996, illus 9).

As for the dating of the long and round barrows, Bayesian modelling of the dates for the former (taking into account that many of the dates are from oak, with a possible old wood effect) has concluded that the earliest dated examples were built within the time range 3935-3750 cal BC (94\% probability), probably 3840-3775 cal BC (68\% probility), and the latest examples were built 3760-3620 cal BC (95\% probability) (Whittle et al. 2011, 828-9, fig.14.167). This indicates that they were built at least as early as the 'halls' and early smaller houses. As for the dating of the round barrows, this is problematic, due to the shortage of reliable and informative dates (Sheridan 2010b). Whittle et al have claimed (2011, 830-2) that they started to be built after the long barrows, but in fact the existing dating evidence does not allow us to determine either way (although they could have been constructed over the course of several centuries). The 'traditional Carinated Bowl' pottery at Pitnacree should be as early as any other example of this earliest form of ' $C B$ ' pottery in Scotland; it is particularly regrettable that the cremated bone associated with the primary use of this monument cannot be found (Sheridan 2010b).

Within the region, there are a handful of megalithic monuments (Henshall 1963, map 7), but these are all at the south-west and north-west fringes of the area in question and are understandable in terms of developments elsewhere in Scotland: the passage tombs around Inverness can be related to the passage tombs to the north of the Great Glen, while the Clyde cairn and 'unclassified' monuments in the south west, on the edge of the central Highlands, are outliers of a development that took place in western Scotland (see below). Human bone from one of these, the 'Clyde cairn' at Cultoquhey (Perth \& Kinross), has been radiocarbon dated as part of Rick Schulting's programme of dating Scottish chamber tombs and has produced a date of $4680 \pm 40$ BP (GrA-26922, 3620-3370 cal BC: Schulting pers. comm.; see Schulting et al. forthcoming for a discussion). This indicates that the use of this tomb did not fall within the earliest Neolithic in eastern Scotland.

A claim has been made for the existence of a (non-megalithic but stone-built) passage tomb in the complex, multi-phase monument at Fordhouse Barrow, Angus (Proudfoot 1998), but the structure bears an unmistakable resemblance to a keyhole-shaped corn-drying kiln, and until the full final excavation report has been produced, it would be unwise to speculate further.
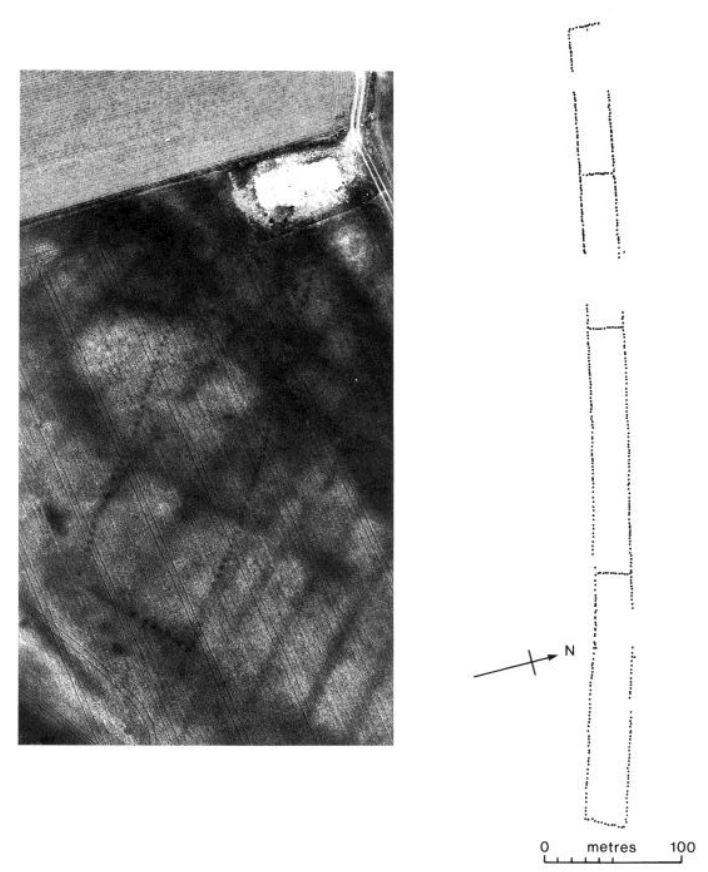

Figure 26: Aerial photograph and plan of cursus at Milton of Guthrie, Angus. From Brophy 1998; Crown copyright

Cursus monuments (Figure 26) and bank 'barrows' (Figure 27) (with the Auchenlaich example actually a cairn) need to be 
mentioned here, since at least some of these structures may have been in existence by $3500 \mathrm{BC}$, even though they do not belong to the earliest Neolithic.

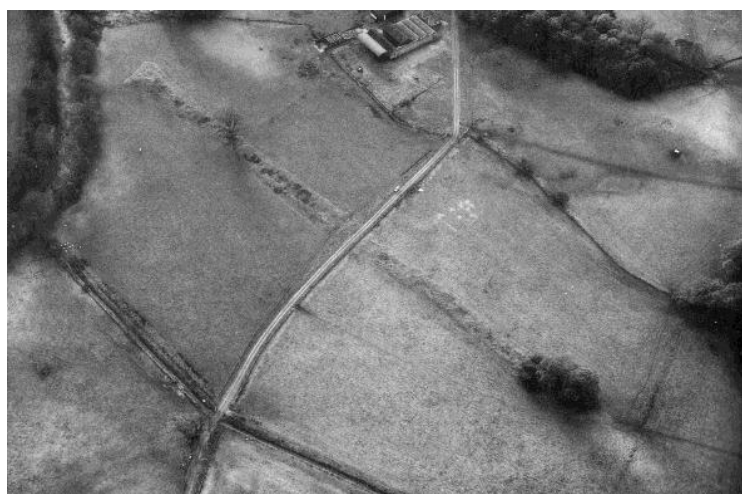

Figure 27: Auchenlaich bank 'barrow' (actually cairn). From Brophy 1998; Crown copyright

As discussed by Brophy (1998, 1999, 2005, 2006), these may represent aggrandised versions of the aforementioned mortuary enclosures and long barrows respectively; furthermore, it has been argued that the monument at Auchenlaich may have started its life as a Clyde cairn, with its mound subsequently elongated to an enormous 342 metres (Foster \& Stevenson 2002).As Fig. 32 shows, cursus monuments and bank barrows tend to cluster in Tayside (incidentally complementing the distribution of long barrows), but their distribution extends beyond east Scotland to include other areas of 'CB Neolithic' Scotland, with a cluster around Dumfries (Thomas 2007).

The chronological relationship between cursus monuments and mortuary enclosures has been explored by Whittle et al. (2011, fig. 14.170), who have Bayesian-modelled the currently available dates for the cursūs at Holm, Holywood North and Upper Largie (all outside the region under scrutiny here); and for mortuary enclosures at Douglasmuir, Castle Menzies, Inchtuthil and Cowie Road, Bannockburn. They have concluded that the latter might not have pre-dated the former by very long (if at all), and furthermore have argued that none of these monuments demonstrably pre-dates $3700 \mathrm{BC}$, seeing the most likely date 'in the middle rather than the early centuries of the fourth millennium cal $\mathrm{BC}^{\prime}$ (ibid., 830). As for the best-explored bank barrow - the c. $2 \mathrm{~km}$-long Cleaven Dyke (Barclay \& Maxwell 1998) - the date for its construction remains a mystery. The possibility that it may end with (or abut) a round mound requires investigation.

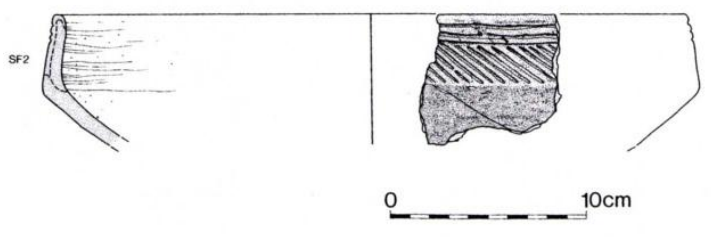

Figure 28: Unstan Bowl from Spurryhillock, Aberdeenshire.

The material culture associated with the Early Neolithic in eastern and central Scotland is explored in Theme 5; suffice it to note here that the process of 'style drift' from the 'traditional $\mathrm{CB}^{\prime}$ canon of pottery manufacture seems to have started very soon after this tradition of pottery appeared, to judge for the near-identity of the dates for the Crathes and Balbridie 'halls'. (The former's ceramic assemblage is of 'traditional $\mathrm{CB}^{\prime}$ ' pottery, the latter's, of 'modified CB pottery' in what Audrey Henshall has called the 'NorthEastern' style - henceforth 'CBNE'.) The trajectory of development includes some features that show clear continuity from the 'traditional CB' (such as the increased use of fingertip fluting, and of ripple burnishing, as a decorative surface finish: Fig. 33), and others that show a more marked departure. The latter include the use of lugged vessels (Fig. 34) and, at Balbridie, of two bipartite collared pots that appear to form the prototype of the 'Unstan Bowl' (Fig. 35, top). Intermediate forms between these and 'classic' 'Unstan Bowls' (as seen, for example, at Spurryhillock, Aberdeenshire) are known from Culduthel, Highland (Figure 28).

The small flaked lithic tools of Neolithic eastern Scotland have usefully been reviewed by Graeme Warren (Warren 2006), who concludes that they are consistent with early Neolithic assemblages elsewhere in Britain and Ireland, and are characterised by the use 
of a platform technology (with some bipolar technology use as well) and by the production of artefacts such as leaf-shaped arrowheads (Figure 82), serrated blades and flakes, convex scrapers and plano-convex knives. This industry stands in contrast with Mesolithic flaked stone industries.

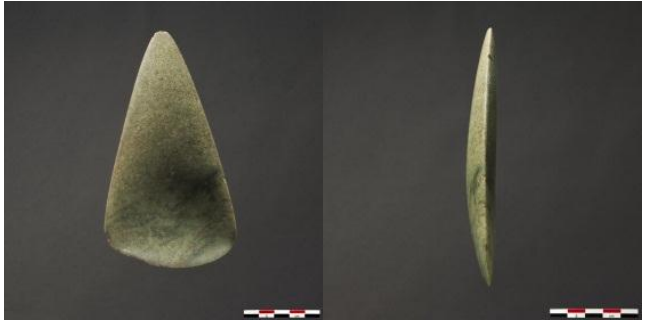

Figure 29: Jadeitite axehead from Garvock, Aberdeenshire (Nationalmuseet, Copenhagen, NM 12981). (C: Nationalmuseet

Other forms of Early Neolithic material culture in eastern and central Scotland include fine, non-utilitarian axeheads of Alpine jadeitite (and other Alpine rock), of which a cluster of examples are known from Aberdeenshire (Figure 29).

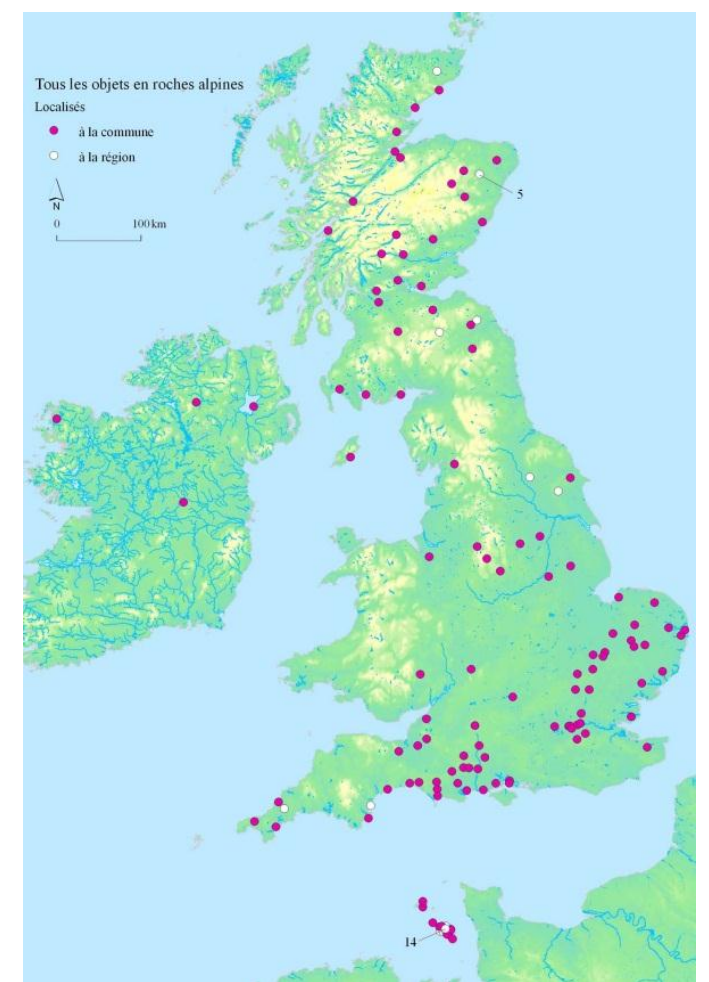

Figure 30: Distribution of Alpine axeheads in Scotland. Image: Projet JADE

By analogy with the Alpine axeheads from Cairnholy and from the Sweet Track in the Somerset Levels, these axeheads are likely to have been brought over by the immigrant farmers, as ancient and treasured possessions, and to have been deposited shortly thereafter (Sheridan et al. 2010). One fragment of such an axehead, from Inverness (Fig. 39), had been deliberately broken and burnt prior to its deposition close to the river.

Whether the equally fine all-over-polished flint axeheads (Figure 31) also belong to the pre-3500 period is unknown, since none has been found in a datable context. 


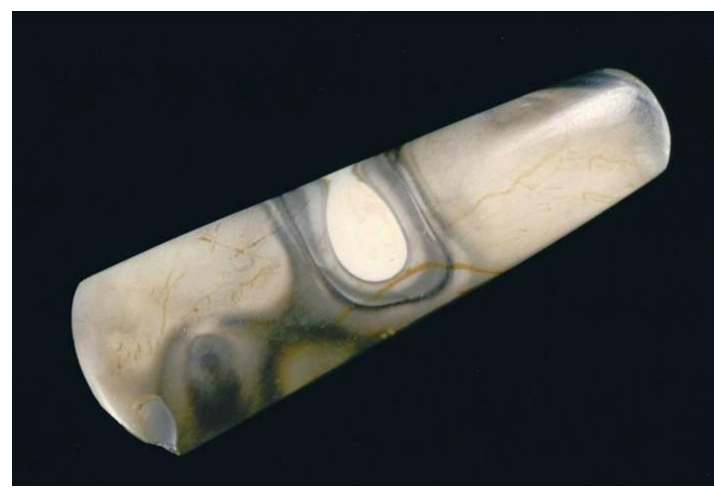

Figure 31: All-over-polished flint axehead from Bolshan Hill, Angus. CNMS

Similarly, it is uncertain whether the axeheads of Irish porcellanite that have been found in eastern Scotland (Figs. 41, and Figure 32) arrived prior to $3500 \mathrm{BC}$; it is possible, since the CBNE style of pottery shares features in common with that belonging to the second quarter of the fourth millennium in north-east Ireland (and indeed west and south-west Scotland). The Great Glen appears to have been a route used in travel between northeast Scotland and west/ south-west Scotland and beyond, as illustrated by the close similarity between one particular kind of CBNE pot and its counterparts in west/southwest Scotland (Fig. 43). The example of this kind of pot from Culduthel, on the outskirts of Inverness, is from a context dated to c 3600$3500 \mathrm{BC}$.

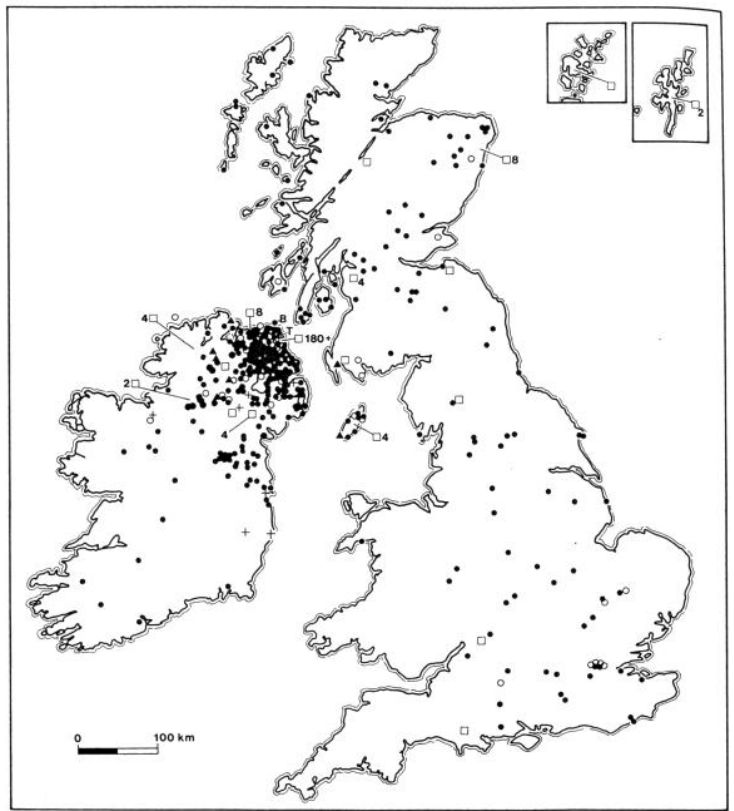

Figure 32: Distribution of Antrim porcellanite axeheads. From Sheridan 1986; note that many more are now known from Ireland

Other external contacts, this time with Yorkshire, are suggested by the fine necklace of Whitby jet 'monster beads' and amber beads, found with a Yorkshire flint axehead, at Greenbrae near Peterhead (Figure 64; Kenworthy 1977; Sheridan \& Davis 2002; and see below, see Section 5.2.5). The whole assemblage seems to have been imported from Yorkshire. A further 'monster bead', of locally-available material (probably a canneloid shale), has been found at Pitlethie Road, Leuchars, Fife (Sheridan 2007a). The dating of these beads is discussed in that publication and below; on currently-available evidence, a date within the second quarter of the fourth millennium seems likely. This jewellery suggests an interest in signalling status, and hence the existence of some degree of social differentiation, among the early farming communities of eastern and central Scotland.

\subsubsection{Middle Neolithic, 3500-3000 BC}

It is clear that the farming communities that had been established in eastern Scotland during the first quarter of the fourth millennium flourished and expanded during the second half of that millennium, since a 
number of settlements are known from that period. These include the following, to name but a few:

- Deer's Den, Kintore, Aberdeenshire (Alexander 2000)

- Midmill, Kintore, Aberdeenshire (Lochrie 2010b)

- Highfield, Inverurie, Aberdeenshire (Murray 2010)

- Alloa, Clackmannanshire (Mitchell et al. 2010)

- Balfarg Riding School (Barclay \& Russell-White 1993)

- Grandtully, Perth \& Kinross (Simpson \& Coles 1990)

- Dubton Farm, Brechin, Angus (Cameron 2002)

- Newton Road, Carnoustie, Angus (White et al. 2009)

- Drumoig, Fife (James \& Simpson 1997; Simpson 1997)

- Meadowend Farm (Upper Forth Crossing), Clackmannanshire (Jones \& Smith forthcoming).

Further assemblages are listed by Trevor Cowie in his survey of the pre-Late Neolithic pottery of eastern and central Scotland (Cowie 1992; 1993) and yet more, like the Meadowend Farm and Drumoig material, await publication. The latter include assemblages from Culduthel, Highland and Powmyre Quarry, Glamis, Angus.

The nature of the habitation evidence was usefully reviewed by Gordon Barclay (Barclay 2003). In most cases the evidence consists of pits - often clustered - and artefact spreads, but there are hints of structural traces (e.g. at Grandtully). The heavy truncation of all these sites, through millennia of ploughing, will have erased all but the deepest of the features, but at Chapelfield, Cowie, Stirling, remains of circular stake-built houses were found (Barclay 2003, fig. 8.5) while at Kinbeachie (Highland) on the Black Isle immediately outside our defined 'eastern Scotland' region but clearly related to east Scottish developments - traces of a rectangular house were found and radiocarbon dated to c. 3500-3100 BC (Barclay et al. 2001). Evidence relating to the subsistence strategy of the inhabitants is generally limited to traces of plant material (e.g. wheat and naked barley grains, fruit seeds and nutshells - e.g. Barclay \& RussellWhite 1993; White et al. 2009); bone preservation is generally very poor. As with the Early Neolithic material discussed above, it is clear that people were living in (or at least exploiting resources in) coastal areas, including sandhills - as attested, for example, by the assemblages of Impressed Ware from Brackmont Mill and Tentsmuir, Fife (Longworth 1967).

One striking feature of many of these Middle Neolithic settlements is that they are in areas with earlier Neolithic (and indeed Later Neolithic) traces of settlement as well. This is clearly the case, for example, at Deer's Den, Dubton and Balfarg. (See Gibson 2010, illus 3, for a recent graphical representation of the spatial relationship of the different phases of activity.) In other words, there is evidence for continuity of settlement, even if the different episodes occurred in slightly different areas and were separated in time.

Evidence relating to Middle Neolithic funerary practices is very sparse and, with the exception of the aforementioned unburnt human remains from the Clyde cairn at Cultoquhey and the cremated bone found at Leven, Fife (see below), is limited to the large timber structures (Fig. 45) from Balfarg Riding School, Fife and elsewhere (Barclay \& RussellWhite 1993, 76-88; cf. Gibson 2010) that are thought to be mortuary structures. As noted by Barclay and others (including Brophy 2007), they resemble the Early Neolithic 'halls' in ground plan and size, although it has been argued that, unlike the 'halls', these Middle Neolithic structures seem not to have been roofed (Barclay 2003, 76). Their presumed use has been for the laying out of the deceased, to allow excarnation by natural processes (e.g. bird scavenging). In addition to the two Balfarg examples, further examples were 
excavated at Littleour and at Carsie Mains, Perth \& Kinross (Barclay \& Maxwell 1997; Brophy \& Barclay 2004); part of another is suspected to have existed at Drumoig (Barclay 2003; Simpson 1997); and others are known from aerial photographs, in Tayside (Barclay 2003; Brophy 2007). As ever with regard to sites on gravel, unburnt bone will not have survived at these sites, although at Balfarg there are intriguing references to a deposit of calcined bone - presumed to be human, but sadly not identifiable now as mixed with another set of bone (Barclay \& Russell-White 1993, 77). There were also finds of calcined sheep bone, and even - remarkably - traces of fish (ibid., 88).

The aforementioned cremated human bone from Holly Road, Leven, Fife is of particular interest since it consisted of two deposits, one of which was found in a segmented, arcshaped ditch and dated to $4480 \pm 60 \mathrm{BP}$ (GrA-

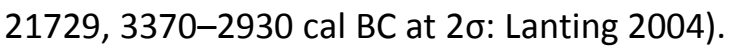
Contrary to the excavator's view that this ditch was an enclosure for an Early Bronze Age cist cemetery (Lewis \& Terry 2004), it appears that it was in fact a Middle Neolithic Age feature - hence the presence of the bone deposit, in a pit that had been cut into the ditch. A second deposit of cremated bone was found - as residual material - in one of the Early Bronze Age cists. This produced an earlier radiocarbon date (albeit one with a larger standard deviation) of $4760 \pm 90 \mathrm{BP}$ (GrA-21728, 3710-3360 cal BC at 20), suggesting some time depth to the Neolithic deposition of cremated bone.

As for other kinds of monument, as noted above, it is unclear whether the enormous bank barrow-cum-cursus, the Cleaven Dyke, was constructed during the second half of the fourth millennium; the possibility that the construction and use of other cursus monuments and bank barrows/cairn extended into this period can also not be ruled out.

Middle Neolithic material culture is well represented among the numerous pottery assemblages, and a trajectory of pottery development that moves progressively further away from the traditional CB pottery of the Early Neolithic can be traced. The 'modified CB' pottery of the Middle Neolithic (Fig. 46) is generally thicker and significantly coarser than the 'traditional $\mathrm{CB}^{\prime}$ ' repertoire, and the 'style drift' noted above included a decreasing use of carinated bowls and the use of other, novel vessel forms. This process can be seen, for example, at Balfarg Riding School (in cpmparing Cowie's 'Group 1' and 'Group 2' assemblages: Cowie 1993) The use of pottery decorated with various forms of impression (and sometimes also incision) - known by the general term of 'Impressed Ware' - can be regarded as part of the overall 'style drift'. The Impressed Ware assemblage from Dubton Farm, Brechin, Angus (Fig. 47), appears to represent an early version of this style of pottery and is associated, in one pit, with a date of $4735 \pm 40$ BP (GU-9094/AA-39948, 3630-3380 cal BC at 20: Cameron 2002; MacSween 2007). A similar (and probably similarly early) assemblage is known from the aforementioned settlement at Kinbeachie, Highland (MacSween 2001). From around $3300 \mathrm{BC}$ (or, at least, at some time between 3350 and 3000 BC, a variety of distinctivelyshaped vessels with narrow flat bases came into use as a major element in the ceramic repertoire (Figure 33).

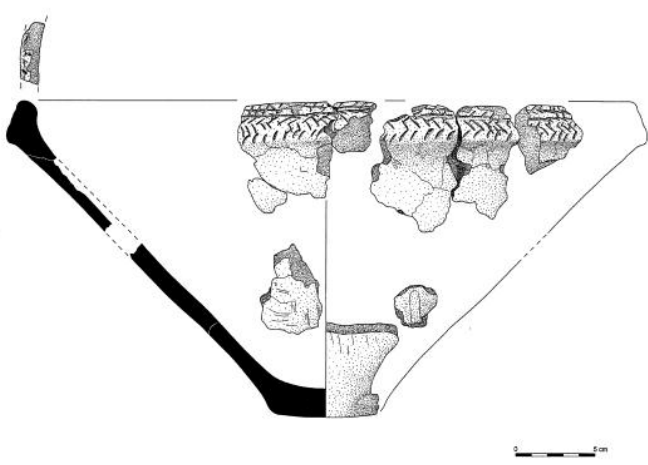

Figure 33: Example of truncoconic Impressed Ware bowl from Meadowend Farm (Upper Forth Crossing), Clackmannanshire. Reproduced courtesy of Headland Archaeology Ltd

Some of these were deep jars of various forms, others squat bowls, and most have a 
bipartite profile with a shallow upright neck. Rims can be heavy and club-like. Some vessels are undecorated, while others have profuse decoration on the rim and neck. Assemblages including this kind of 'Impressed Ware' include Deer's Den, Kintore, Aberdeenshire (Alexander 2000, illus 26), Brackmont Mill and Tentsmuir, Fife (Longworth 1968) and Meadowend Farm, Clackmannanshire (Sheridan 2011). This style of pottery was also used further south in Scotland (where it has been termed 'Meldon Bridge style' Impressed Ware: MacSween 2007) and in northern England; indeed, some of the large jars (e.g. Alexander 2000, illus 26, P49) resemble the 'Fengate ware' 'variant' of 'Peterborough Ware' in England.

As for other aspects of material culture, the use of leaf-shaped arrowheads and other Early Neolithic styles of small lithic tool seems to have continued (to judge, for instance, from the Kinbeachie assemblage: WickhamJones 2001). Similarly, pitchstone from Arran continued to be imported to eastern Scotland (e.g. at East Lochside, Angus: Ballin 2009,37), and links with Yorkshire continued - as demonstrated by the distinctively-shaped 'Duggleby adze' of flint found at Kemback, Fife (Fig. 49). Such objects are known to have been made in Yorkshire and recent dating of the eponymous find, from a grave in a round mound (Gibson 2009), has shown that they belong to the last quarter of the fourth millennium BC. Further evidence for links with Yorkshire during this period comes from Torben Ballin's recent analysis of flint assemblages: for example, he has observed that a significant proportion of the flint from Middle Neolithic pits at Midmill, Aberdeenshire, is likely to have been imported from Yorkshire (Ballin 2011, 58-60), while at East Lochside in Angus, a smaller proportion of the lithic assemblage is of grey Yorkshire flint (Ballin 2009, 37).

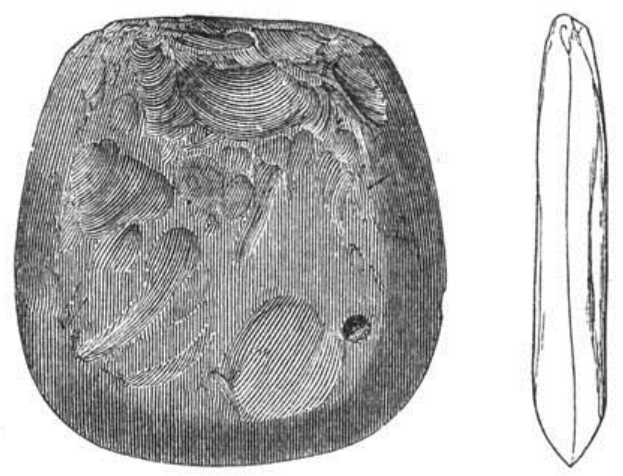

Figure 34: Discoidal flint knife, Pitforthie, Aberdeenshire.@ NMS

It is a moot point as to whether the (virtually) all-over-polished flint knife from Pitforthie, Aberdeenshire (formerly Kincardineshire; Figure 34) constitutes a further Middle Neolithic import from Yorkshire. A Yorkshire provenance seems likely given that it is known that such objects were being made in North Yorkshire by specialist flintworkers (Durden 1995). A finer, thinner version of this artefact type was found in Burial $D$ under the round mound at Duggleby Howe, Yorkshire, and the recent radiocarbon dating of this monument by Alex Gibson has concluded that the associated individual would have been interred shortly before the mound was raised at $2950-2775$ cal BC $195 \%$ probability: Bayesian-modelled date, Gibson 2009, 69). Whether this means that this particular variant of so-called 'discoidal' knives (Clark 1932) was in use before $3000 \mathrm{BC}$, or should be regarded as a Late Neolithic artefact type, is open to discussion. (See below, 3.3.1.3, for more circular discoidal flint knives.) 


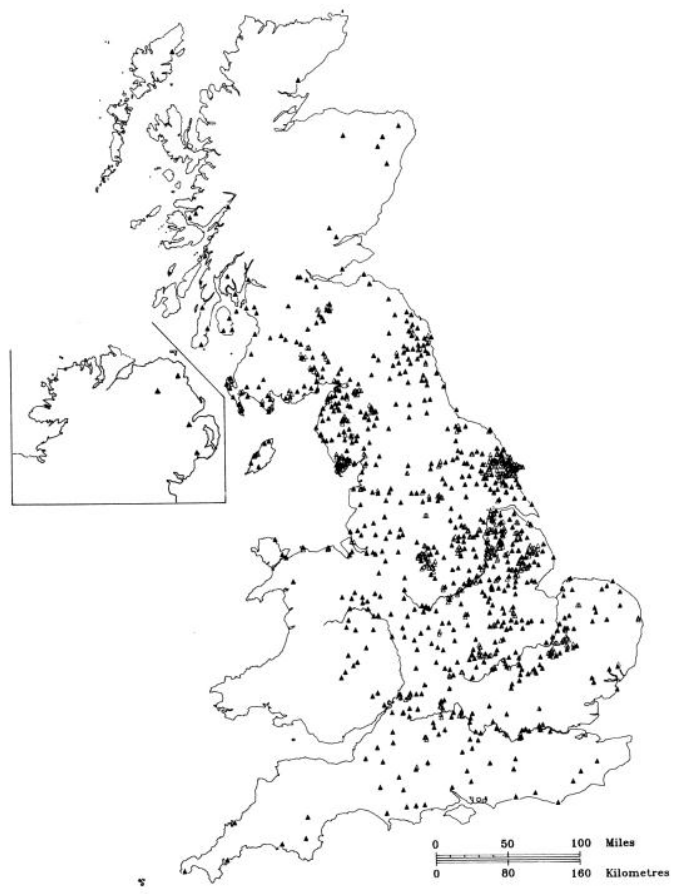

Figure 35: Distribution of axeheads of tuff from Great Langdale, Cumbria. From Clough \& Cummins 1988

It is likely that at least some of the axeheads of Antrim porcellanite (Figure 32), and the rather fewer axeheads of tuff from Great Langdale in Cumbria (Figure 35) found in eastern Scotland arrived during this period. Indeed, a fragment of a Great Langdale axehead was found in a Middle Neolithic context at Midmill, Aberdeenshire (Ballin 2011, 59). In other words, the inhabitants of eastern and central Scotland continued to interact with communities elsewhere, over networks of contacts that had been established long before.

To this period also belongs evidence for flint mining on the Buchan Ridge Gravels near Peterhead (Figure 36; Saville 2008; 2011); radiocarbon dating suggests that this activity probably occurred during the last quarter of the $4^{\text {th }}$ millennium BC. The flint cobbles are too small to have been used for the manufacture of large items such as axeheads; evidence for the use of a Levallois reduction technique suggests that at least some of the flint was used for the production of blades for chisel-shaped arrowheads. Because flint of the same geological origin occurs elsewhere in this part of Scotland, however, it is not possible to document the distribution of the mined flint.

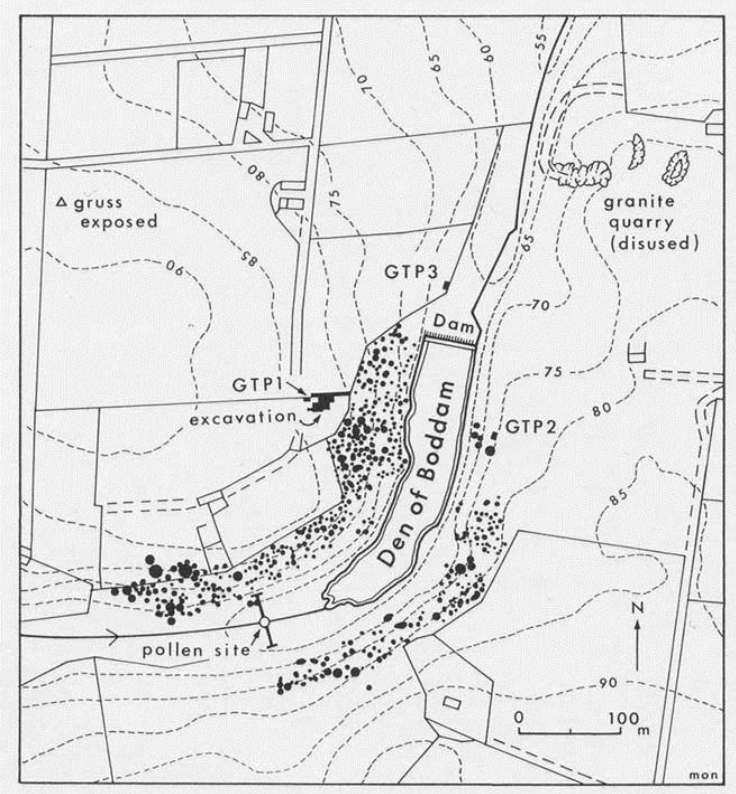

Figure 36: Plan of the flint mines at Den of Boddam, Aberdeenshire. From Saville 2008; plan by Marion O'Neil

\subsubsection{Late Neolithic, c 3000-2500 BC}

The widespread appearance of novel practices and novel material culture (including Grooved Ware pottery) around the beginning of the third millennium, as noted in Theme 2, is well attested in eastern Scotland. Finds of Grooved Ware have increased significantly since 1999, when only a dozen findspots from the whole of eastern Scotland were known (Longworth \& MacSween 1999; cf. Cowie \& MacSween 1999). Recent discoveries include the magnificent segment of a pot found in Powmyre Quarry, Glamis, Angus (Figure 83), along with large fragments from Midmill, Kintore, Aberdeenshire (Lochrie 2010b, illus 5), Inverurie Paper Mill, Aberdeenshire (Hilary Murray pers. comm.) and Mountcastle Quarry, Fife (inf Headland Archaeology Ltd). Such finds suggest a specific depositional practice - of placing large parts of individual vessels in pits, either singly or severally - that contrasts with the mode of deposition for earlier Neolithic pottery (whereby smaller sherds, and smaller portions 
of pots, generally tend to be found). In most cases - but by no means every case - Grooved Ware has been associated with non-domestic activity (e.g. in the Balfarg/Balbirnie complex).

The Grooved Ware finds from eastern and central Scotland include the assemblage from a pit at Littleour, Perth \& Kinross (Sheridan 1998), which is associated with the latest date for Grooved Ware in Scotland (as cited in MacSween 2007, fig. 33.4). Prima facie the dates (from organic residues inside three pots, plus birch charcoal from their pit) suggest that Grooved Ware continued to be made into the second half of the third millennium, thus overlapping with the use of Beaker pottery. However, the three organic residues (from Pots 2, 3 and 6 ) have produced disparate dates ranging between $4110 \pm 55 \mathrm{BP}$ (OxA-8992, 2880-2490 cal BC at 2 $\sigma$, Pot 6) and $3845 \pm 75$ BP (OxA-8993, 2550-2040 cal BC at $2 \sigma$, Pot 3$)$, and the birch has produced an even later date of $3750 \pm 50$ BP (AA-22906, $2340-1980 \mathrm{cal} \mathrm{BC}$ at $2 \sigma$ ). This spread of dates for material that was ostensibly deposited simultaneously is suspect, and re-dating, along with a critical review of the existing organic residue dates, is required.

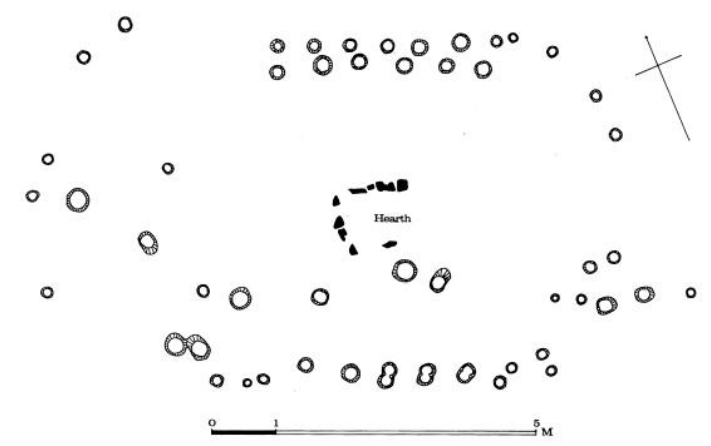

Figure 37: Ground plan of timber building at Stoneyfield, Raigmore, Highland. From Simpson 1996

Evidence for settlements is sparse and, once again, mostly takes the form of pits. A roughly rectangular post-built structure at Raigmore, Highland (Figure 37; Simpson 1996; 1999), could conceivably have been a house but its nature, date, and association with the Grooved Ware pottery found at that site are all debatable.
Elsewhere, circular timber structures featuring an internal setting of four posts (Figure 38) are known from Greenbogs, Aberdeenshire (Noble et al. in press) with several others in Angus and Perth \& Kinross known from aerial photographs - including a cluster of at least eight such structures at Chapelton, Angus (Noble et al. in press). The two Greenbogs structures have been radiocarbon-dated to between $2900 \mathrm{BC}$ and 2500 BC; a single sherd of Grooved Ware may have been associated. While these resemble Grooved Ware houses from elsewhere in Britain (including Trelystan in Wales and Beckton in Dumfries \& Galloway: ibid.), they also resemble Late Neolithic structures of ceremonial function (e.g. at Ballynahatty, Co. Antrim and Knowth, Co. Meath, Ireland) and others whose function could be either domestic or special purpose (e.g. at Machrie Moor and Durrington Walls). What is striking, however, is the similarity of form over large areas, together with the novelty of the design. Whether any of these structures evoked Late Neolithic structures in Orkney is open to debate, however. (These structures should not be confused with Iron Age structures featuring a square four-post setting, as seen for example at Grantown Road, Forres: Cook 2008.)

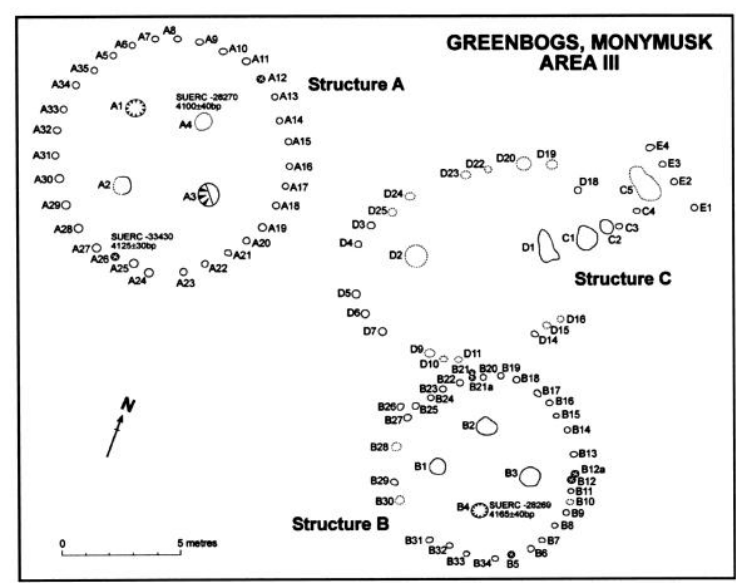

Figure 38: 'Four-poster' timber structures ( $A$ and B) at Greenbogs, Aberdeenshire. From Noble et al. in press

Evidence for funerary practices comes in the form of deposits of cremated bone. Recent 
dating of cremated bone that had probably been buried as foundation deposits in the sockets of the stone circle at Balbirnie, Fife (Gibson 2010) has shown that their deposition - and hence the construction of the stone circle - took place between the $31^{\text {st }}$ and $29^{\text {th }}$ century BC. At Orwell, Perth \& Kinross, one of two deposits of cremated human bone placed in the stone-hole of a standing stone - one of a pair - immediately after its erection has produced a date of $4180 \pm 35$ BP (SUERC18309, 2890-2630 cal BC at 20: Ritchie 1974, 8; Sheridan 2008, 201). At Forteviot, Stirling, a cemetery containing at least nine discrete deposits of cremated human bone, plus extensive scatters, has been radiocarbon dated to the first three centuries of the third millennium BC (Noble \& Brophy 2011a, table 1 - although note that not all the dates cited there have been calibrated to their $2 \sigma$ value). The discrete deposits were found in shallow scoops, and the excavators suggested that they may have been in wooden box-like containers. One of the deposits may have been marked by a standing stone. One contained a fragment of a burnt bone pin, another, sherds of an undecorated pot. This cemetery is reminiscent of that excavated at Cairnpapple, West Lothian (Piggott 1948) although it would appear that the Cairnpapple cemetery is a little earlier, dating to within the last three centuries of the $4^{\text {th }}$ millennium. (See below, 3.3.2.2.) At Raigmore, one pit contained the cremated remains of two adults, along with a petit tranchet derivative arrowhead (Simpson 1999). At Fordhouse Barrow, cremated human bone found in a putatively Beaker period pit (and quite possibly representing residual material) has been dated to $4340 \pm 35$ BP (SUEC-2726, 30902890 cal BC at 20: Proudfoot 2004). Finally, at Culduthel, two Grooved Ware pots (one a tall narrow jar, the other a small pot) found in a pit surrounded by 'satellite' features were thought, by the excavator, to have been a grave, but the burnt bone found in the pit has not been confirmed as being human (context inf. Ross Murray).
Much more is known about ceremonial (and other special) structures, thanks largely to the excavations in the Balfarg/Balbirnie complex and, more recently, the excavations at Forteviot. These structures consist of:

- At least one stone circle (at Balbirnie, and probably also at Balfarg; and see below)

- A pair of standing stones at Orwell (although whether these had originally formed part of a larger monument is unclear)

- Several timber circles - at Balfarg, North Mains and Forteviot, in each case associated with a bank and ditch henge constructed several centuries later

- Other henges

- A large timber enclosure with an avenue-like entrance at Forteviot, along with a timber circle.

Also of note is the stones marked with rock art (i.e. cupmarks and cup-and-ring marks), which are relatively abundant in Tayside and Fife but rarer elsewhere in the region under review.

Each of these will be discussed briefly below.

The dating of the relatively small, low stone circle at Balbirnie (Fig. 56) has provided valuable confirmation that this type of monument was indeed being built in eastern Scotland around the beginning of the third millennium BC. Despite its structural differences with the Stones of Stenness in Orkney (which is known to have been erected, complete with its surrounding henge, during the $30^{\text {th }}-29^{\text {th }}$ century $\mathrm{BC}$ ), it is conceivable that the inspiration for building the circle came from Orkney. This would accord with the fact that Grooved Ware was found in association with the circle at Balbirnie. (See Gibson 2010 for a discussion.)

Whether any other stone circles in eastern Scotland were constructed around this time is, however, a moot point, since the 
excavations of Richard Bradley at Clava cairns, recumbent stone circles and at the Broomend of Crichie henge (Bradley 2000; 2005; 2011) have demonstrated that all those monuments were erected after the conventional end-date for the Neolithic. (Indeed, in the case of Broomend of Crichie, the very concept that the stones had ever formed a circle has been convincingly dismantled: Bradley 2011, 75-80 and illus 2.9). Furthermore, his reconsideration of the Croft Moraig stone circles has concluded that the small oval setting (and, by extension, the numerous other oval stone settings in Tayside) was constructed during the second, or even perhaps the early first millennium BC (Bradley \& Sheridan 2005. As for the date of the earlier, SE-orientated stone circle, this is to be explored during fieldwork in 2012.

The evidence from Balfarg henge (Figure 39; Mercer 1981; Mercer et al. 1988; Gibson 2010) is more ephemeral than at Balbirnie, and it is not clear whether we are dealing with one stone circle, two, or some other form of stone setting. However, it has recently been argued (Gibson 2010, 72) that the stones were erected during the second quarter of the $3^{\text {rd }}$ millennium, possibly to replace one or more timber circle, for which a terminus post quem of the $29^{\text {th }}-25^{\text {th }}$ century exists.

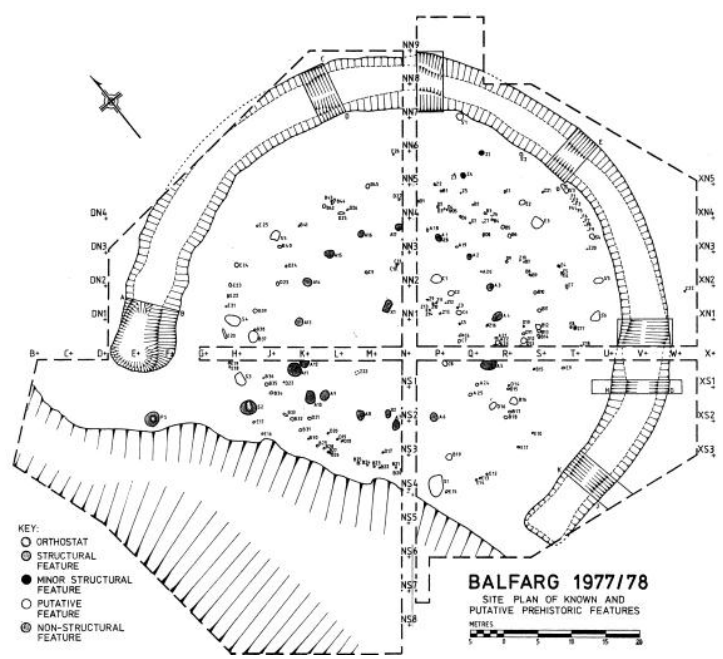

Figure 39: Plan of timber circles at Balfarg henge. From Mercer 1981

The pair of stones at Orwell, with the deposit of cremated bone in the packing of one, has already been mentioned; it is unclear whether this had originally formed part of a larger monument such as a stone circle, or whether these represent a class of Late Neolithic monument - paired standing stones. Elsewhere in Scotland, it is clear that short stone rows are considerably later, dating to the Middle Bronze Age.

At Balfarg (Mercer 1981) and North Mains (Barclay 1983), the timber circles consist of multiple rings, not necessarily contemporary with each other (although at Balfarg, it has been suggested that the outer rings may have supported wattlework screens, restricting the view of the inner, free-standing post ring: Mercer 1981). At both sites, the henge bank and ditch was constructed outside the timber rings and at North Mains, the the date of $3665 \pm 45$ BP (GrA-24007, 2200-1920 cal BC at $2 \sigma$ ), for cremated bone from burial $A$, under the henge bank, demonstrates that the henge was built several centuries after the timber circles (Sheridan 2003).

The timber circle at Forteviot (Figure 40; Noble \& Brophy 2011a) also predated the henge monument with which it is associated, but here the latter was constructed inside the timber circle. Both the circle and the henge surrounded the aforementioned cemetery of cremated remains deposits, and all these features were enclosed within the large 'palisade' enclosure discussed below. The radiocarbon dating of the circle (and the palisade) is based on oak charcoal but the excavators were careful not to use heartwood for dating, so with luck there should not be a considerable 'old wood' effect. The dates for the circle came out at c 2850-c 2450 cal BC (ibid., table 1) and are likely to post-date the cemetery; the dates for the henge (based on short-lived species charcoal) suggest that it was built between the $25^{\text {th }}$ and $23^{\text {rd }}$ centuries BC (ibid.). As for the 'palisade' enclosure, dates for its avenue-like entrance suggest that it was built between c 2900 and c 2450 BC (ibid.); Bayesian modelling would be necessary to produce a more precise estimate 
of the relative chronology and sequencing of all the structures here.

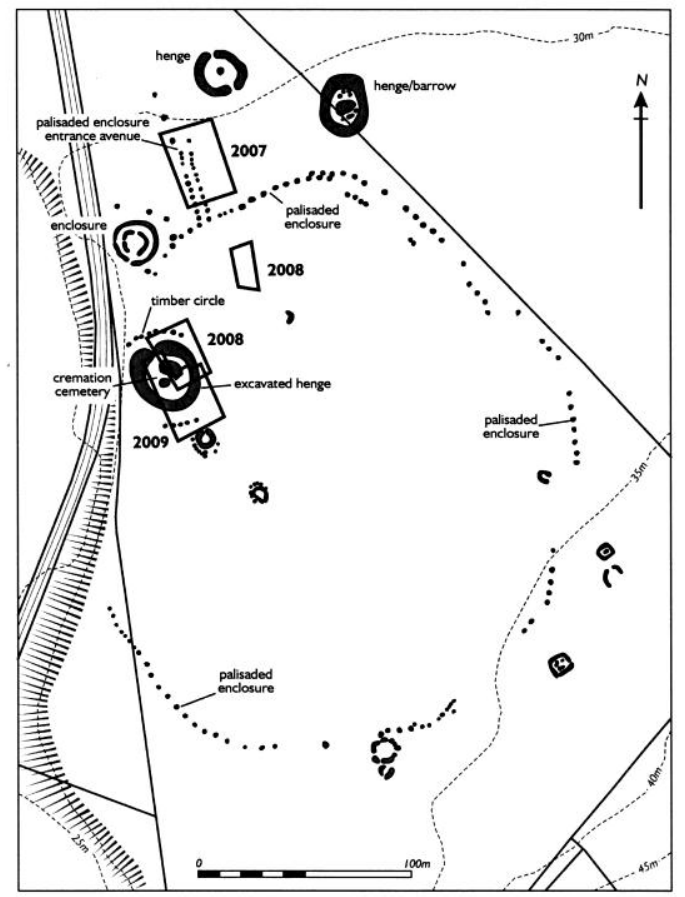

Figure 40: Timber circle (along with other prehistoric features including a massive Late Neolithic 'palisaded' enclosure) at Forteviot, Perth \& Kinross. From Noble \& Brophy 2011a

A further example of a timber circle of possible Late Neolithic date, once more associated with a henge, is known from Moncreiffe, Perth \& Kinross (Stewart 1985). It should be noted, however, that the 'Grooved Ware' from this site is much more likely to be Middle to Late Bronze Age 'flat-rimmed ware'.

Kirsty Millican's survey of the timber/pit circles of Scotland (Millican 2007) concluded that there are significant clusters along the southern edge of the Moray Firth and in Tayside and Fife. Whether all of these had been free-standing timber circles (as opposed to parts of round houses), and how many are of Late Neolithic (as opposed to Bronze Age or later) date, cannot however be determined without excavation.

The aerial photography record has also revealed the probable former existence of a number of henges in Tayside and Fife, in addition to the examples mentioned above
(Dunwell \& Ralston 2008, fig 9). These include a particularly large candidate at Westfield, Angus (Barclay 1999). Again, excavation is required to ground-test the evidence. It remains an open question, however, as to whether any henges in this part of Scotland were built prior to $2500 \mathrm{BC}$.

The large timber 'palisade' enclosure at Forteviot (Figure 18; Noble \& Brophy 2011a, fig. 2 ; 2011b) is one of a set of similar, Late Neolithic enclosures, the others of which are known from Dunragit, Dumfries \& Galloway; Meldon Bridge, Scottish Borders; Blackshouse Burn, South Lanarkshire (but in earthen form) and - from aerial photographs - Leadketty, Perth \& Kinross (Noble \& Brophy 2011b, fig. 2). The Leadketty enclosure is only $3 \mathrm{~km}$ away from Forteviot in Strathearn. The possible functions of these enclosures have been discussed (e.g. by Noble \& Brophy 2011b; Noble 2006; and Speak \& Burgess 1999); all agree that they will have involved a large amount of effort in their construction and will probably have served as gathering places for large numbers of people. Whether they had been the focus for ceremonial activity, foreshadowing the later large henge monuments in southern England (e.g. Durrington Walls), is a moot point.

Finally, the number of 'rock art' sites in eastern Scotland has grown, largely to the painstaking survey work in Tayside and Fife by John Sherriff (Sherriff 1995). A considerable number is now known in Angus, especially around the source of the Lunan Water (Dunwell \& Ralston 2008, fig 10).

The material culture record for Late Neolithic east and central Scotland - in addition to the Grooved Ware pottery mentioned above - is dominated by carved stone balls (Figure 60, fig 60) and maceheads (Figs. 61, Figure 59). Over $80 \%$ of all the $500+$ known carved stone balls have been found in north-east Scotland, and even though a few may have acquired an 'Aberdeenshire' provenance due to antiquarian collecting practices during the $19^{\text {th }}$ century, nevertheless this concentration 
seems genuine, and it is likely that they had been made using local, carefully selected erratic cobbles. Both these and the maceheads form part of the overall assemblage of Late Neolithic special-purpose and symbolically-significant items, which would have served as symbols of power and prestige, as well as perhaps having other functions.

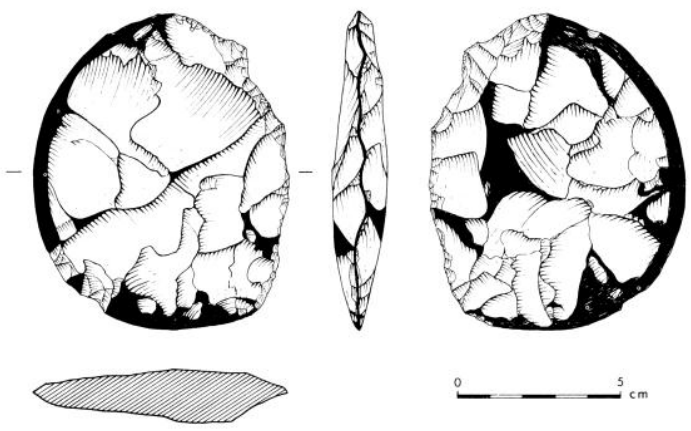

Figure 41: Edge-polished discoidal flint knife from near Huntly, Aberdeenshire. From WickhamJones 1987

As for other lithic items, while it appears that pitchstone was probably no longer being imported to this particular part of Scotland at the time (Ballin 2011, 3), the link with Yorkshire remained strong, with items such as the edge-polished discoidal knife found near Huntly, Aberdeenshire (Figure 41; WickhamJones 1987 and cf. Clark 1932) being probable imports. Grooved Ware pottery also shows that design ideas were being shared with Yorkshire (and indeed elsewhere in England) as shown, for example, in the near-identity (Figure 42) of a pot from Midmill, Aberdeenshire and one from North Carnaby Temple Site 2, Yorkshire (Manby 1974,fig. 18).

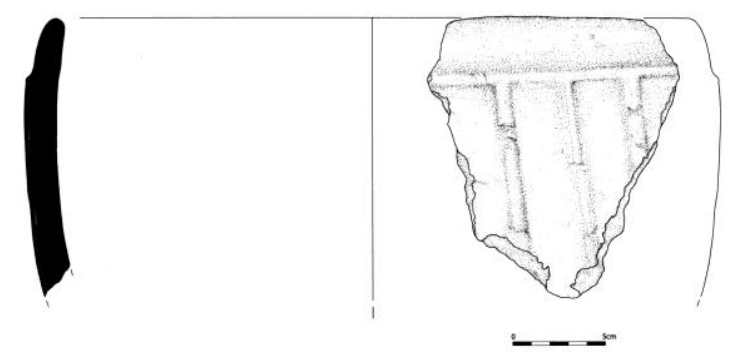

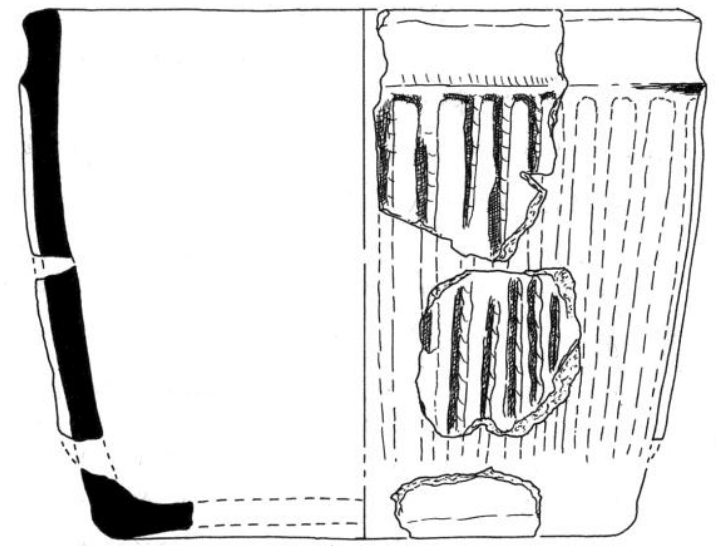

Figure 42: Very similar Grooved Ware pots found at Midmill, Aberdeenshire (top) and North Carnaby Temple 2, Yorkshire (bottom). Midmill reproduced courtesy of Murray Archaeological Services; North Carnaby Temple image from Manby 1974

\subsubsection{Research questions regarding Neolithic east and central Scotland}

The principal questions concern the need to improve our knowledge of the Neolithic in this part of Scotland, and to integrate all the strands of evidence reviewed above (and in Theme 4) into an overall narrative, as follows:

1. What is the overall pattern of settlement, land use and subsistence activity and how and why does it change? This will need the compilation of period-specific, GISbased distribution maps of all the evidence already available, and this will involve trawling through the grey literature.

2. What was the nature of Middle and Late Neolithic habitation structures? In other words, are we dealing with a change in building techniques, away from the Early Neolithic rectangular, post/post and plank-built construction (as the Late Neolithic 'four poster' structures suggest) - and were these structures used in a different way from Early Neolithic houses?

3. What can we say about the nature of, and changes in, society from the evidence currently available? Clearly 
this part of Scotland became involved in the larger social changes from $C$ $3000 \mathrm{BC}$ onwards, but did the nature of society change?Why was this region the epicentre for the production and use of carved stone balls? How exactly were the large 'palisade' enclosures used? And how does the practice of creating and using rock art articulate with other expressions of belief and ritual practice?

There are also more specific questions, including:

4. How many of the timber/pit circles and henges or henge-like sites known from the aerial record actually belong to the Late Neolithic?

5. We know relatively little about the use of animals in this part of Scotland, since bone assemblages do not survive well in the free-draining soils. We need to find many more, and larger, assemblages in order to improve our understanding of species exploitation and management techniques.

6. What prompted the initiation of flint mining on the Buchan Ridge Gravels? Could it have been a reaction to the existence of a flourishing specialist flintworking tradition in North Yorkshire?

7. The Littleour Grooved Ware assemblage needs to be re-dated, and the existing dates critically reevaluated; and there is a general need to round up all the existing dating information about all Neolithic pottery in this region, to refine our developmental sequence.

8. The dating of Neolithic non-megalithic round mounds needs to be improved, and unless the Early Neolithic cremated bone from Pitnacree turns up in the Duckworth Laboratory in Cambridge University, the only way to achieve this will be through excavation. The round mound at one end of the Cleaven Dyke would be a particularly interesting monument to explore, especially to examine its relationship (if any) with the Cleaven Dyke.

9. More examples of the 'four post' timber circle structures need to be excavated, to investigate their nature, use and relationship with other similarly-shaped structures elsewhere.

10. How many of the stone circles in this region date to the Neolithic? In particular, might the earliest stone circle at Croft Moraig be contemporary with Balbirnie?

11. Are paired standing stones a Late Neolithic phenomenon - and if so, is it restricted to Tayside and Fife?

12. The nature and date of the activities at Stoneyfield, Raigmore, need to be clarified through a programme of radiocarbon dating.

13. The use and significance of cursus monuments and bank 'barrows' needs to be clarified.

\subsubsection{South-east Scotland and north-east England}

This area stretches from the Forth to the Tyne, extending westwards as far as the source of the Forth but not extending as far as Clydesdale. It encompasses the rich agricultural lowlands and stretches of upland including the Cheviot Hills, and the inclusion of a part of north-east England recognises the cultural continuity of the Neolithic across this modern political boundary.

As with eastern and central Scotland - a region with which it shares many features of the Neolithic in common - this region is rich in Neolithic remains, and much has been learnt thanks to developer-funded archaeology over the last 20 years. Of particular note are:

- The excavations carried out in association with the upgrade of the 
A1 in East Lothian (Lelong \& MacGregor 2008) which, among other finds, uncovered two non-megalithic long barrows; and

- The major large-area excavations in advance of gravel quarrying at Cheviot Quarry and Lanton Quarry in the Milfield Basin, Northumberland which have significantly enhanced our understanding of Neolithic settlement (Johnson \& Waddington 2009; Passmore \& Waddington 2009; 2012; Waddington in press)

The latter complement the similarly largescale (and ongoing) research excavations elsewhere in the Milfield Basin, led by Roger Miket (Miket et al. 2009). These, along with previous Neolithic finds (e.g. at Yeavering, on the edge of the Milfield Basin: Hope-Taylor 1977; Harding 1981) make this one of the most intensively-studied foci of Neolithic (and later) activity in Britain.

Notable reseach-based excavations in southeast Scotland include Stuart Piggott's at Cairnpapple, West Lothian (Piggott 1948) the results of which have been re-assessed by Barclay (1999), Millican 2007, Sheridan (Sheridan et al. 2009, 214) and Bradley (pers. comm.) - and Brian Hope-Taylor's excavations at Doon Hill, East Lothian (Hope-Taylor 1980). Here, two timber 'halls' sharing virtually the same 'footprint' were found (Fig. 65); while Hall $B$ is clearly of first millennium $A D$ date, the presence of Early Neolithic pottery (of modified Carinated Bowl type) in association with Hall $A$, and the recent dating of encrusted organic residue on one such pot, confirming its early $4^{\text {th }}$ millennium $B C$ date, supports the argument that Hall $A$ is indeed of Early Neolithic date. The post-excavation work currently underway includes dating structural material from Hall A, so confirmation (or otherwise) of its Early Neolithic date is expected within 2012.

A further, and very important, source of information about the Neolithic in this region is RCAHMS' aerial photography survey, which has revealed the existence of three ditchdefined cursus monuments in Midlothian and East Lothian, and two pit-defined cursūs in the Forth Valley (Brophy 1999). This complements the geoarchaeological survey work undertaken in north-east England - especially in the lower Tweed valley and in the southeast Cheviots - by RCAHME and others (e.g. Passmore \& Waddington 2009; Topping 2008). Such work provides invaluable background information relevant to Neolithic landscape use.

Works of synthesis relevant to this region include lan Kinnes' publications on long mounds (Kinnes 1992a;b) and Miket and Edwards' gazetteer of Neolithic pottery from north-east England (Miket et al. 2009). Passmore and Waddington's two-volume publication (2009; 2012) on the archaeology of the Till-Tweed region offers a comprehensive review of the Neolithic (and other) evidence for this part of north-east England

The chronology for the Neolithic in the region is beginning to come into sharper focus with a good sequence of dates available for the early $4^{\text {th }}$ millennium, although dates for the later parts of the period are still underrepresented. Syntheses of most of the available dates for the region can be found in Lelong and MacGregor (2007) and Passmore and Waddington (2012).

The environmental evidence is currently rather limited but if future excavations employ comprehensive programmes of flotation on residues from hearth pits and midden pits in particular the amount of data should improve. There are virtually no faunal assemblages to speak of. The analysis of plant remains shows the importance of hazelnuts in the subsistence regime as well as the cultivation of emmer wheat, barley and oats. Pollen diagrams testify to small-scale clearance at this time with agriculture appearing to be focused around the settlement sites in fertile valleys and, no doubt, some coastal locales, on light easily- 
tilled soils safe from flood risk. There is activity in the uplands but the extent to which the uplands were used for small-scale cultivation, as may be the case on the baserich soils on areas of the Cheviot plateau, remains to be established. Other areas of upland, such as the Lammermuirs and the Fellsandstone escarpments of Northumberland, show little evidence for clearance until after the Neolithic and are most likely to have been used for grazing and hunting. Dating of large-scale alluviation events that form valley floor fills provides a proxy for tree clearance in the uplands and destabilisaion of the soil cover, presumably by cultivation. Preliminary work in Northumberland suggests catchment-wide alluviation events such as this first took place in the Beaker period in the centuries before 2000 cal BC (Tipping 2002) - that is, well after the end of the Neolithic.

\subsubsection{Early Neolithic, to $3500 B C$}

The story here, as in east and central Scotland, is one of the appearance of the 'Carinated Bowl Neolithic' by 3800 BC and the subsequent flourishing of the farming communities who were thus established.

A range of settlement evidence is known, with the Doon Hill timber 'hall' (Fig. 65) - strikingly similar in plan to Balbridie (Brophy 2007) constituting the largest structure. Its colocation with the $7^{\text {th }}$ century $A D$ hall is striking, and raises the question of how two structures separated by c 4500 years (if such be the case) could have come to be built in the same place; however, there is a parallel, at Lockerbie Academy, Dumfries \& Galloway, where an Early Neolithic 'hall' was found less than $500 \mathrm{~m}$ from an Early Historic hall (Kirby 2011). A further plausible candidate, beside the River Tweed at Sprouston, Scottish Borders, was pointed out by lan Smith (I. Smith 1991) but needs to be ground-tested through excavation (Figure 43). This example lies at the edge of a known Anglian settlement but differs from the Anglian houses in shape, instead being closely comparable with
Balbridie and Doon Hill A. Like Balbridie and Crathes, it lies close to a sizeable river; it is also situated close to what may be a very rare example of a northern British causewayed enclosure (ibid., illus 4 and see below).

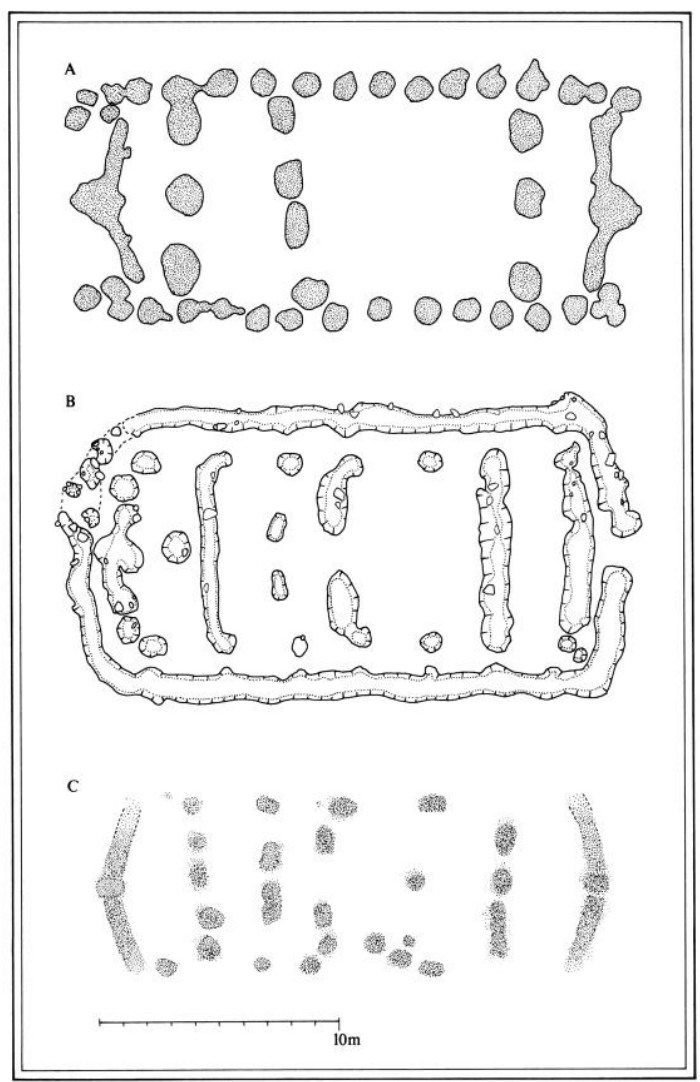

Figure 43: Comparative ground plans of known and putative Early Neolithic 'halls' at Doon Hill, East Lothian, Balbridie, Aberdeenshire and Sprouston, Scottish Borders. From Smith 1991

As for the smaller houses as discussed in section 3.3.1.1 for eastern and central Scotland, the evidence is fairly sparse, largely owing to the amount of plough-truncation in these rich agricultural areas. Traces of slots for a rectangular timber house, $9.5 \mathrm{~m} \times 4 \mathrm{~m}$, were found at Ratho, Midlothian (Figure 44; Smith 1995; Barclay 2003) and at Thirlings in the Milfield Basin, Miket et al. (2009) argued that a trapezoidal post setting could have been the central supporting element within a larger walled structure some $9.5 \mathrm{~m} \mathrm{x} 7 \mathrm{~m}$ in size. 


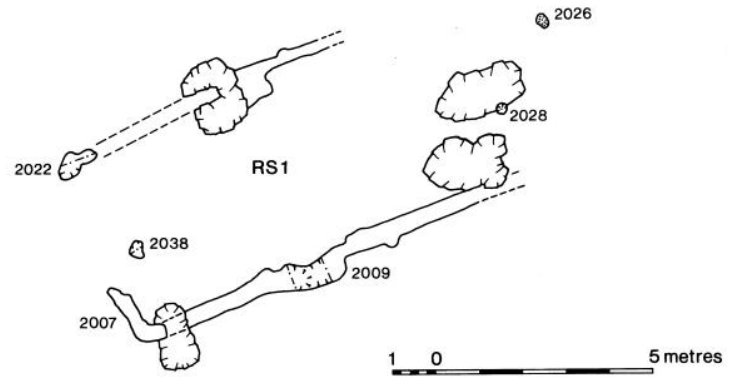

Figure 44: Plan of rectangular Neolithic house at Ratho, City of Edinburgh. From Smith 1995

An increasing amount of evidence has been coming to light to suggest that the range of Early Neolithic habitation structures included less substantial, flimsier constructions (Fig. 68), perhaps designed for seasonal or other short-term use (e.g. during transhumance or hunting). In north-east England these include the site at Bolam Lake interpreted as a triangular-based structure and a similar site at Whitton Park (Waddington 2003), at least seven triangular and irregular structures at Lanton Quarry (Waddington in press), and rectangular, circular and other irregular structures at Thirlings (Miket et al. 2009). In south-east Scotland, oval stake-built structures have been found at Chapelfield, Cowie, Stirling (Atkinson 2002) and at the Hirsel, Coldstream, during excavations of much later activities, Rosemary Cramp uncovered traces of at least one small, curvilinear, wattle-built structure associated with two Carinated Bowl pots (Cramp 1984 and in press). Such sites remind us that the lifestyle of these early farming communities probably involved not only sedentary occupation (necessary for cereal cultivation) but also temporary occupation, by certain individuals or small groups. (That said, it should not be assumed that all lightlyconstructed buildings had necessarily been for temporary use.)

The commonest manifestation of early Neolithic occupation, however, comes in the form of pits, groups of pits and associated spreads containing sherds, occasional flint tools and debitage, coarse stone tools and stone axe heads, together with burnt material including charred emmer wheat, and some barley and oats and on occasions some small fragments of burnt bone. Typical midden pit clusters include the sites at Yeavering (HopeTaylor 1977; Harding 1981), Bolam Lake (Waddington and Davies 2002); Coupland (Passmore and Waddington 2009), Thirlings (Miket et al. 2009), Cheviot Quarry (Johnson and Waddington 2009) and Lanton Quarry (Waddington in press), all in Northumberland; and Maybury Business Park, City of Edinburgh (Moloney \& Lawson 2006).

The discovery of Carinated Bowl pottery and leaf-shaped flint arrowheads in the sandhills at Hedderwick, East Lothian (Callander 1929, 67) indicates that here, as in east Scotland, Early Neolithic activities included those relating to the coast. The nature of these activities needs to be clarified, however. And in north-east England, the discovery of flint tools eroding from peat shelves in inter-tidal settings such as the Neolithic forest beds at Druridge Bay, Northumberland, remind us that some evidence for Early Neolithic activity will have been drowned by sea level rise.

One specific type of evidence not hitherto noted in this review of regional developments in Neolithic Scotland is the existence of at least one shell midden that may have been in use during the Early Neolithic, at Inveravon, West Lothian, on the southern shore of the Forth (Sloan 1984; see Canmore, NS97NE 18 for a list of the radiocarbon dates from this site). Here, as with the other Forth Valley shell middens, the dominant shell is oyster. Two such shells have produced dates of $5435 \pm 60$ BP and $5110 \pm 60$ BP (GU-1886-7), calibrating with a marine offset taken into account - to 3970-3660 and 3640-3360 cal BC respectively. These dates raise the question as to whether we may be dealing here with a very late survival of 'Mesolithic' communities, living entirely on wild resources, or localised, small scale use of marine resources by farmers in the area. (See below, 3.3.2.2 and 3.3.2.3, for further Neolithic dates from Forth Valley shell middens.) 
As for additional evidence for subsistence practices, lipid analysis of Carinated Bowl pottery from Cheviot Quarry (Stern 2009), Lanton Quarry, Doon Hill and the Hirsel (Cramp pers comm) have revealed evidence for ruminant dairy fat in some of the pots, suggesting the use of milk, as with Carinated Bowl pottery elsewhere. Plant macrofossils confirm that here, as elsewhere in the $C B$ Neolithic, wheat (including emmer) and barley were grown and hazelnuts were gathered (Johnson \& Cotton 2009)
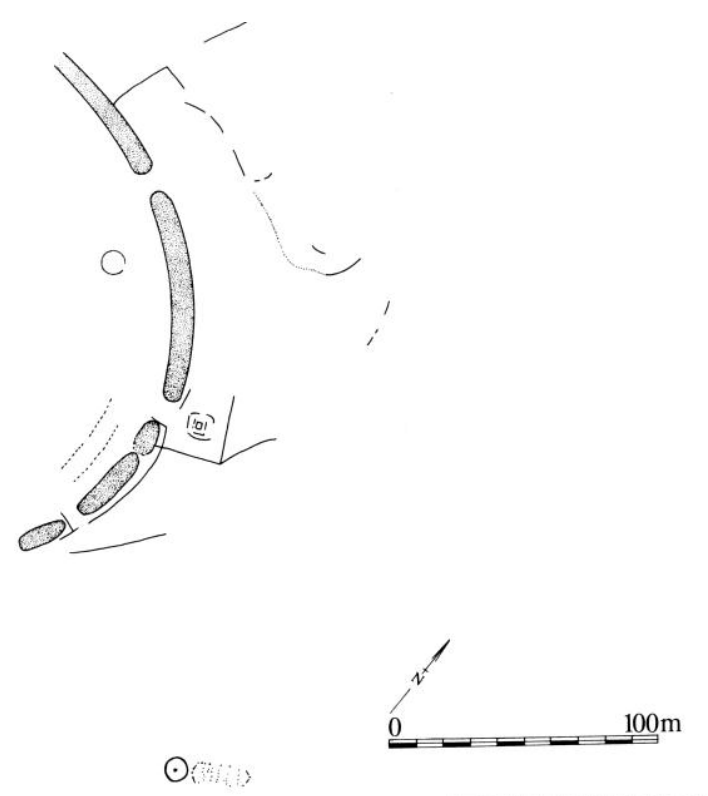

Figure 45: Possible causewayed enclosure at Sprouston, Scottish Borders; the possible Early Neolithic 'hall' is also shown at the bottom of the illustration. From Smith 1991

The possible existence of a causewayed enclosure - a type of site extremely rare north of the Wash - at Sprouston (Figure 45) has already been noted; others are suspected to exist at Hasting Hill, Tyne \& Wear(Newman 1976) and at South Shields, Tyne and Wear, below the Roman fort of Arbeia, where ditch terminals were excavated (Hodgson et al. 2001). (A further claimed example on Flodden Hill, overlooking the Milfield Basin, is considered to be unlikely given its position on a slope: Johnson \& Waddington 2009, 246.) Confirmation and dating of these sites would, however, require excavation.
The funerary practices of these early Neolithic farming communities match those already noted for eastern Scotland, with burnt 'linear zone' mortuary structures covered by long rectangular earthen mounds having been excavated at Eweford and Pencraig Hill, East Lothian (Figure 9; Lelong \& MacGregor 2007). Eleven long mounds of earth or stone, rectangular or trapezoidal in shape, are listed in Kinnes 1992a for this region, including the long cairns at Bellshiel Law, Devil's Lapful, Dod Hill and the Mutiny Stones in north-east England (Masters 1984; 1973) and the chambered long cairn at Dour Hill, Northumberland (Waddington et al. 1998) one of the few, or possibly even the only, megalithic tomb in the region.

The non-megalithic round mound at Broomridge, Northumberland (Greenwell and Rolleston 1877; Newbigin 1935), offers a close parallel for the monument at Boghead, Aberdeenshire, in having been the location of a cremation pyre, subsequently sealed by a mound; a large amount of Carinated Bowl pottery was found among the burnt remains, along with flint artefacts and a stone axehead. At least two other candidates for this kind of monument are known, at the Poind and his Man and at Shortflatt in north-east England (Davies 1995).

Some have interpreted the presence of burnt bone in two pits at Yeavering, associated with Carinated Bowl pottery, as evidence for individual interment in graves (Hope-Taylor 1977, 345, 354) but, as Miket et al. have pointed out $(2009,83-4)$, the bone has not been securely identified as human.

Three possible rectangular timber mortuary enclosures, analogous to the aforementioned examples in east and central Scotland, are known from north-east England from aerial photographs, at Ewart Park (Miket 1976), Milfield and Wark on Tweed (Johnson \& Waddington 2009, 246; 2012).

As noted above, a few cursus monuments are known in south-east Scotland, including a fine 
ditch-defined example at Inveresk, to the east of Edinburgh (Figure 46).

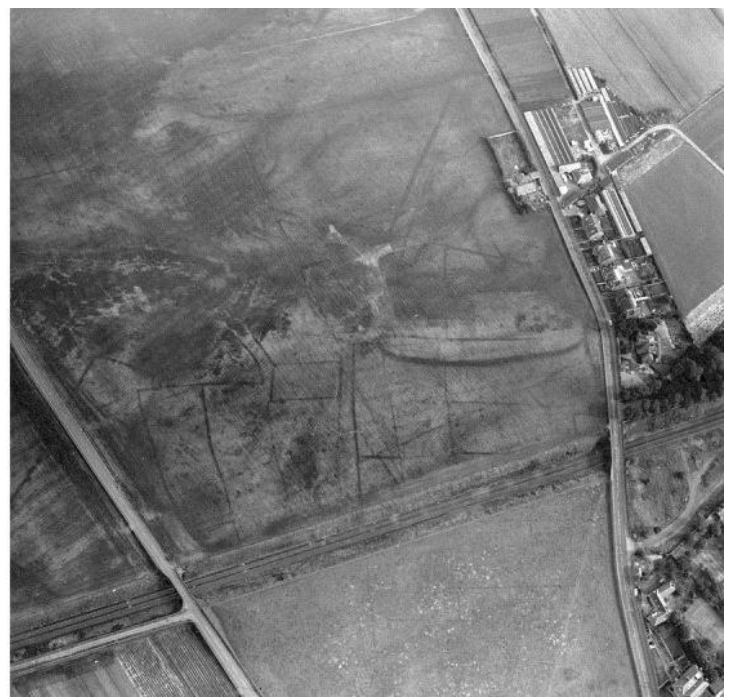

Figure 46: Aerial photo of cursus at Inveresk, Midlothian. ORCAHMS

The material culture associated with these early farming communities is strikingly similar (in its earliest manifestation) to that seen in eastern and central Scotland, with traditional Carinated Bowl pottery well represented (Sheridan 2007b; Miket et al. 2009; Waddington 2009). The evolution of 'modified Carinated Bowl' pottery through a process of style drift involved the kind of changes seen in Tayside and Fife, with a general coarsening of fabric and surface finish, less use of very thin, very fine pots, the use of heavier rims and more pronounced carinations/shoulders, the occasional use of lugs, and a drift away from the initial range of bowl and jar forms. The distinctive elements of the North-Eastern style of modificed CB pottery (e.g. the appearance of 'proto-Unstan Bowl' pots), seen further to the north, are not present - although there may have been an increase in the use of fingertip fluting as a decorative surface finish, as seen in the assemblage from Lanton Quarry (Figure 47).

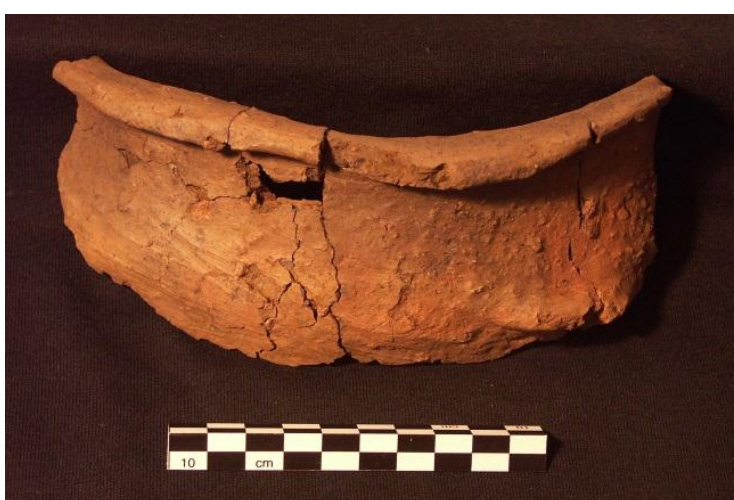

Figure 47: Bowl of 'modified Carinated Bowl' type from Lanton Quarry, Northumberland. Photo: Clive Waddington

The use of lithic resources, the style of knapping and the range of artefact types matches that seen in other Scottish CB assemblages (and indeed in other $C B$ assemblages further afield); the use of imported Arran pitchstone is attested at several sites, with examples beginning to be found in north-east England, in Coquetdale (Ballin 2011) and at Lanton Quarry. A specific characteristic of the flaked lithic assemblages of north-east England (e.g. Cheviot Quarry: Johnson \& Waddington 2009, 191) is that there is as yet no evidence for the use of locally available lithic raw materials. This is in direct contrast to Mesolithic practice which is characterised by the use of locally occurring beach flint, till flint, chert, agate and quartz. Instead much of the Neolithic flint is high quality nodular flint imported from the south (probably Yorkshire) or high quality glacial flint probably imported from the west coast. 


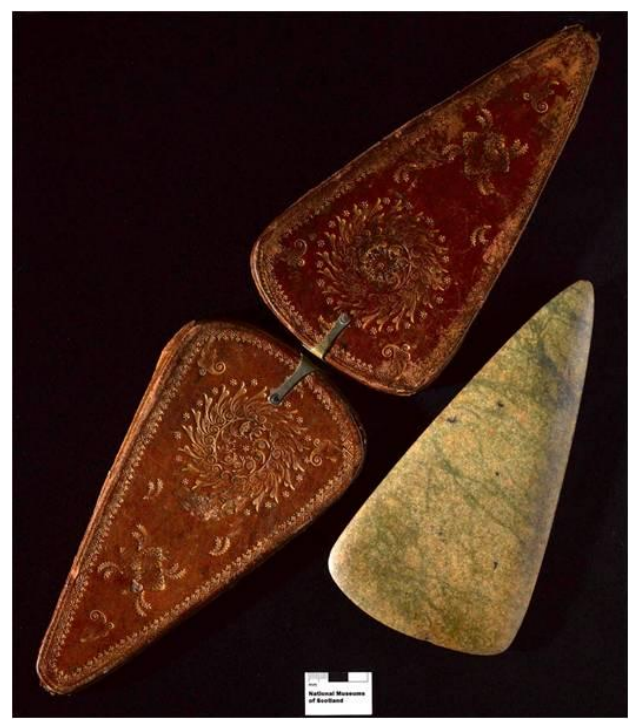

Figure 48: Jadeitite axehead from the Traquair Estates, Scottish Borders, along with its carrying case made C AD 1700. (C) NMS

Several axeheads of Alpine jadeitite (and other Alpine rock) have been found in this region, as elsewhere in the Scottish (and wider British) 'CB Neolithic'. These include the superb examples from Cunzierton and Greenlawdean, Scottish Borders (of which the former are shown on the 'cover' page of this document), and from the Traquair Estates the latter having been given its own carrying case by the Stuart family around 1700 (Figure 48; Sheridan et al. 2011).

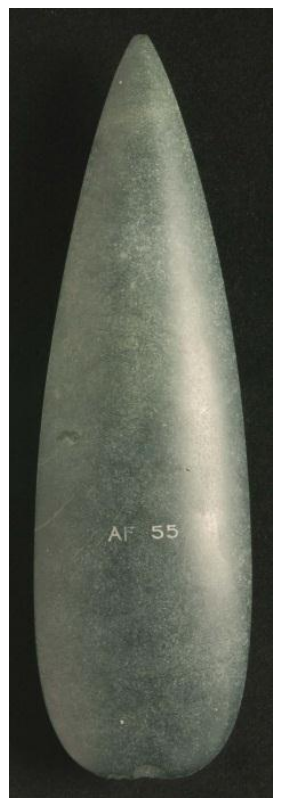

Figure 49: Axehead of Alpine omphacitite, said to have been found in a blacksmith's shop in

\section{Berwickshire. @NMS}

They also include a fine axehead of Alpine omphacitite, reportedly found in a blacksmith's in Berwickshire (Figure 49). As noted above, these are most likely to have been brought among the possessions of the immigrant farming groups.

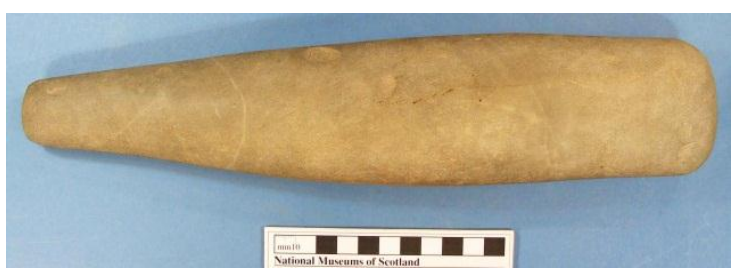

Figure 50: 'Cumbrian club' of Langdale tuff found at Upper Hindhope, Scottish Borders. CNMS

Other exotic axeheads, this time acquired through exchange across the rapidlyestablished interaction network, include numerous examples from Great Langdale in Cumbria - including a fine 'Cumbrian club' from Upper Hindhope in the Cheviot Hills (Figure 50). Such objects were probably not utilitarian axeheads, but symbols of power (whose production, during the first half of the fourth millennium (Davis \& Edmonds 2011) may well have been inspired by the ideology of Alpine axehead use). There is a notable cluster of Great Langdale ('Group VI') axeheads around the Tyne (Figure 35); indeed, Cummins and Harding's review of the stone axeheads of north-east England (1988) noted that over half of the 170 axeheads in this area are of Group VI rock. There are a small number of other 'exotic' axeheads, with three of Group 1 Cornish greenstone in northeast England; a small number of Group IX Antrim porcellanite axeheads (Figure 32 ) and of Group XXIV calc-silicate hornfels axeheads from Creag na Caillich near Killin (Figure 51; Edmonds et al. 1992); and a re-used fragment of a Group VII axehead from Graig Lwyd in north-west Wales, found on Cairnpapple Hill and most probably associated with the few sherds of Carinated Bowl pottery found there (Piggott 1948). Finally, all-over-polished flint axeheads are represented, e.g. at Craigentinny, City of Edinburgh. The source of the flint is unknown but would certainly be 
outside the region. These axeheads are discussed further in Theme 5.

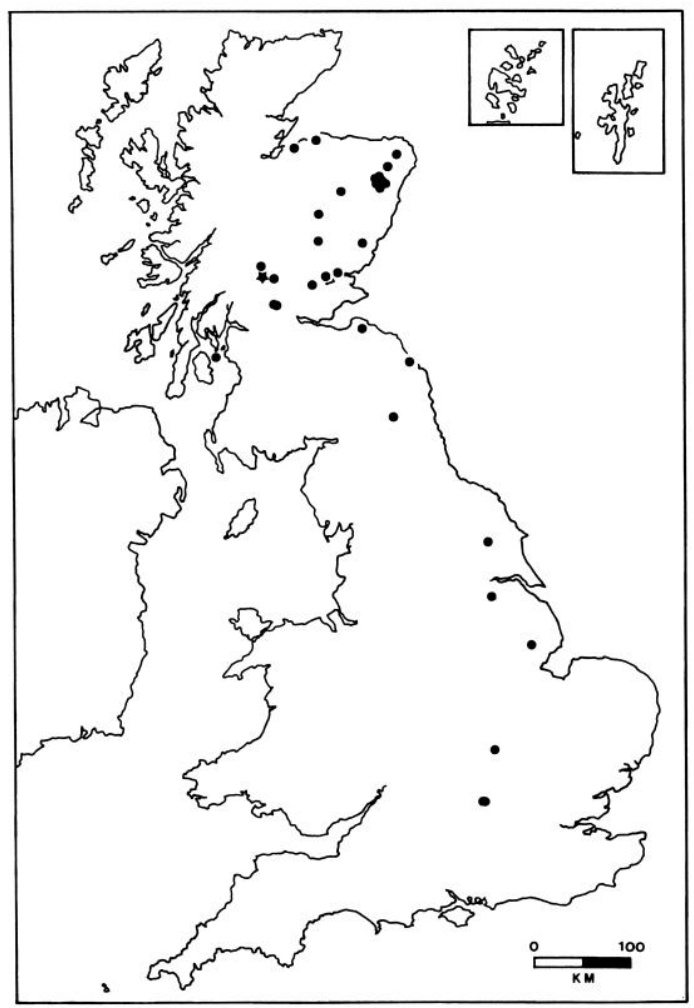

Figure 51: Distribution of axeheads of calc-silicate hornfels from Craig na Caillich (starred), near Killin, Perth \& Kinross. From Edmonds et al. 1992

As in eastern Scotland, early to middle Neolithic 'monster beads' are represented in this region, with a fine example in cannel coal or shale, emulating jet examples, having been found at Pencaitland, East Lothian (Fig. 77).

\subsubsection{Middle Neolithic, 3500 - $3000 B C$}

Evidence for settlement takes the form of pits and spreads containing Impressed Ware, for example at Thirlings and Cheviot Quarry, Northumberland (Miket et al. 2009; Johnson \& Waddington 2009) and Pencraig Wood, East Lothian (Lelong \& MacGregor 2007). At Overhailes, East Lothian, one such pit is thought to have formed part of a lightly-built, sub-circular or horseshore-shaped building, surrounded by a yard (MacGregor \& Stuart 2008). The individual pits and clusters of pits with Impressed Ware at Meldon Bridge,
Scottish Borders were interpreted by Speak \& Burgess as relating to ceremonial activity, on account of the fact that sherds of pots had been used to line the sides of two of the pits (Speak \& Burgess 1999, 104-5), but an alternative interpretation as settlementrelated pits is perfectly plausible. At Knowes Farm, East Lothian, Impressed Ware pottery was found associated with a rough line of 12 pits (Shearer \& McLellan 2008) whose function is uncertain: these could have related either to domestic activities or to 'special social gatherings', according to the excavators.

Other evidence that may relate to domestic activity comes from 'stray', or otherwise illdocumented finds of Impressed Ware pottery (e.g. at Dalkeith, Midlothian: Henshall 1966 and Ford, Northumberland: Kinnes \& Longworth 1985, 135 (Un 18:1-6); Miket et al. 2009, 84-5); as with Early Neolithic finds, Middle Neolithic activity of some kind is attested at the sandhills at Hedderwick, East Lothian (Callander 1929, 67-72 and Figs 512).

The shell middens of the Forth Valley have produced some dates suggesting Middle Neolithic exploitation of oysters (at Inveravon and Nether Kinneil, West Lothian: Sloan 1984 and see Canmore entries for date lists, with the calibrated versions taking into account a marine offset). Taking these and other dates at face value, this suggests a continuity of practice from preceding centuries, and the discovery of a handful of sherds of undecorated gritty Neolithic pot atNether Kinneil (Cowie 1993a, 38) provides evidence, however tenuous, that we are more likely to be dealing with a very rare instance of farming groups exploiting marine resources than of a very long-lived survival of Mesolithic groups.

Other evidence relating to subsistence activities includes the absorbed lipids surviving in two analysed Impressed Ware pots from Cheviot Quarry, which attest to the former presence of an animal fat/plant mixture, with beeswax also present in one of 
these pots (Stern 2009); while the use of cereals is attested by the presence of a broken saddle quern in a pit with Impressed Ware sherds at Thirlings (Welfare 2009; see also Bishop et al. 2009 for the organic evidence for wheat, barley and oat cultivation). At Overhailes, small fragments of mostly unidentifiable mammal bone (but including one pig bone) were found, and the use of wild resources is well attested by the remains of hazelnut shells.

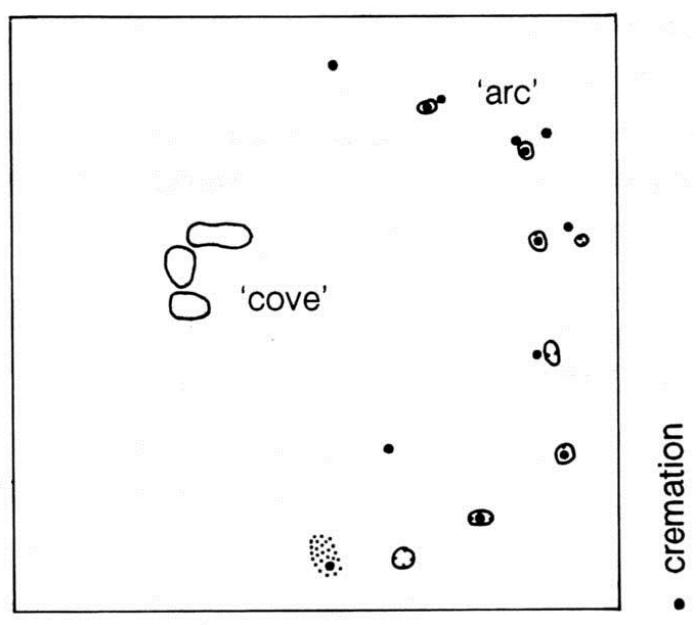

Figure 52: Middle Neolithic 'cemetery' of cremated remains, plus probably contemporary stone setting, at Cairnpapple. West Lothian. From Barclay 1999

In terms of funerary practices, the only clear evidence for this period in this region comes from two sites: Cairnpapple, West Lothian (Piggott 1948) and Whitton Hill, Northumberland (Miket 1985). At Cairnpapple, twelve deposits of cremated human bone were found (Figure 52), of which seven were found in and around a curving array of rock-cut pits that may or may not have held uprights; two settings of stones, forming what Piggott referred to as a 'cove', may also have been associated. (See Barclay 1999 for a critical review of these features.) A fragment of burnt bone or antler 'skewer pin' associated with one such deposit has recently been dated, as part of the NMS' radiocarbon dating programme, to $4470 \pm 35 \mathrm{BP}$ (SUERC25561, 3350-3020 cal BC at 20; Sheridan et al. 2009. Note that efforts to locate the cremated human bone have been unsuccessful).) By analogy with the dated henges of eastern and central Scotland, there is no reason to assume that the henge at Cairnpapple was in existence at this time; and see below, 3.3.2.3, for a discussion of the circular setting of 24 pits which surrounded this Middle Neolithic 'cemetery'.

At Whitton Hill, two 'cemeteries' were found, one being surrounded by a segmented ditch and the other with a penannular ditch. Both contained similar deposits of cremated human bone to those found at Cairnpapple, with the deposits in Site 1 being arranged in a rough circle around a sizeable pit, and those in Site 2 being arranged in an arc around a further sizeable pit. The pottery associated with these sites can now be appreciated as being of Middle Neolithic date (as suggested by Miket); radiocarbon dating of the cremated bone would help to confirm the date.

Evidence for other Middle Neolithic ceremonial sites in south-east Scotland and north-east England is notable by its absence unless the construction and use of the aforementioned cursus monuments extended beyond $3500 \mathrm{BC}$.

The material culture of the Middle Neolithic here is dominated by finds of Impressed Ware pottery, which shows affinities with contemporary assemblages further to the north (e.g. Meadowend Farm, Clackmannanshire) and to the south (among what used to be termed 'Fengate Ware'). The northern English-southern Scottish specificities of the shallow, highly decorated truncoconic bowls that form part of this repertoire was highlighted by Colin Burgess, who proposed to name it the 'Meldon Bridge style' of 'Peterborough Ware' (Burgess 1976; See MacSween 2007 for a discussion). The number of findspots of Impressed Ware in south-east Scotland and north-east England is relatively small, but the recent finds from developer-funded excavations suggest that more of this pottery remains to be found. 
In terms of lithics, strong links with Yorkshire are indicated in the use of imported Yorkshire flint to make items such as chisel arrowheads (of which a considerable number are known from Overhowden and Airhouse, Scottish Borders: Ballin 2009). These links are also echoed in the presence of three belt sliders in south-east Scotland: the example from Hallmyre, Scottish Borders (McInnes 1968, fig. 29.15), is of Whitby jet, while those from Balgone, East Lothian (ibid., 12) and 'probably south-east Scotland, are of cannel coal or shale (as identified by Mary Davis: see Sheridan \& Davis 2002 for details of the ongoing NMS project on the prehistoric use of jet and jet-like jewellery). As discussed in Theme 5, these objects probably date to 3200-2900 BC.

A single find of an artefact of Arran pitchstone at Meldon Bridge (Speak \& Burgess 1999, 89) may attest to the continuing importation of this material to this region during the Middle Neolithic, although since it was note securely stratified, an earlier date for this find cannot be ruled out.

\subsubsection{Late Neolithic, 3000-2500 BC}

Grooved Ware is known from a small but growing number of sites: Miket and Edwards (in Miket et al. 2009) list seven in their review of north-east English finds (although, as they note, the pottery from Milfield North pit alignment (Harding 1981) could be Early Bronze Age pottery), while Longworth \& Cleal (1999) recorded two finds in south-east Scotland. (A third claimed find, from Cairnpapple, can be rejected). To these can be added the finds from Eweford East and Eweford West, East Lothian (Lelong \& MacGregor 2008), found during the upgrading of the A1, and those from Lamb's Nursery, Dalkeith, Midlothian (Cook 2000). At Thirlings and Cheviot Quarry, Northumberland, it seems to have been used in a domestic context, while at Eweford East it had been associated with a timber circle and two roughly parallel alignments of posts - that is, monuments associated with ceremonial activity. Grooved Ware was also associated with a pit alignment at Ewart 1, Northumberland (Miket et al. 2009, 88).

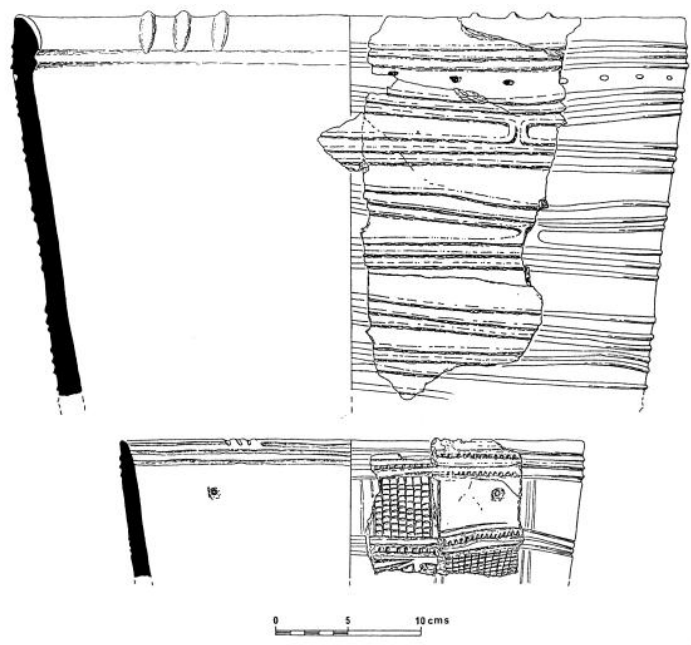

Figure 53: Grooved Ware from Yeavering, Northumberland. From Hope-Taylor 1977

At Yeavering, one find of Grooved Ware pots (Figure 53) may have been from a grave (although it is not stated whether the 'cremated' bone found in the pit in question had been human: Hope-Taylor 1977, 348-51, 354-5, figs. 121-2). As for the other finds (e.g. from the Hedderwick and Archerfield sandhills, East Lothian (Longworth \& Cleal 1999), it is hard to determine whether they related to everyday or special activities.

Our knowledge of the settlement and subsistence activities during this period in this region is therefore limited; analysis of absorbed lipids in the Grooved Ware from Cheviot Quarry (Stern 2009) revealed the presence of degraded animal fat/oil. The continued use of the Forth Valley shell middens (Sloan 1984; Armit \& Finlayson 1992) is suggested by dates from Nether Kinneil (see Canmore entry NS98SE 72); whether the Inveravon midden was also used at this time is unclear due to the large standard deviation of the dates in question.

Our knowledge of Late Neolithic funerary practices is similarly sparse, although Speak and Burgess had argued $(2009,26,104)$ for the presence of Late Neolithic deposits of 
cremated bone at Meldon Bridge, Scottish Borders. The radiocarbon dating is however unsatisfactory, with oak-and-hazel charcoal from Meldon Bridge having produced a date (GU-1059) calibrating to c 2900-2100 cal BC (Speak \& Burgess 1999, 103); once again, direct dating of the cremated bone is the only way to clarify matters. The uncertainty over the Yeavering bone has already been mentioned.

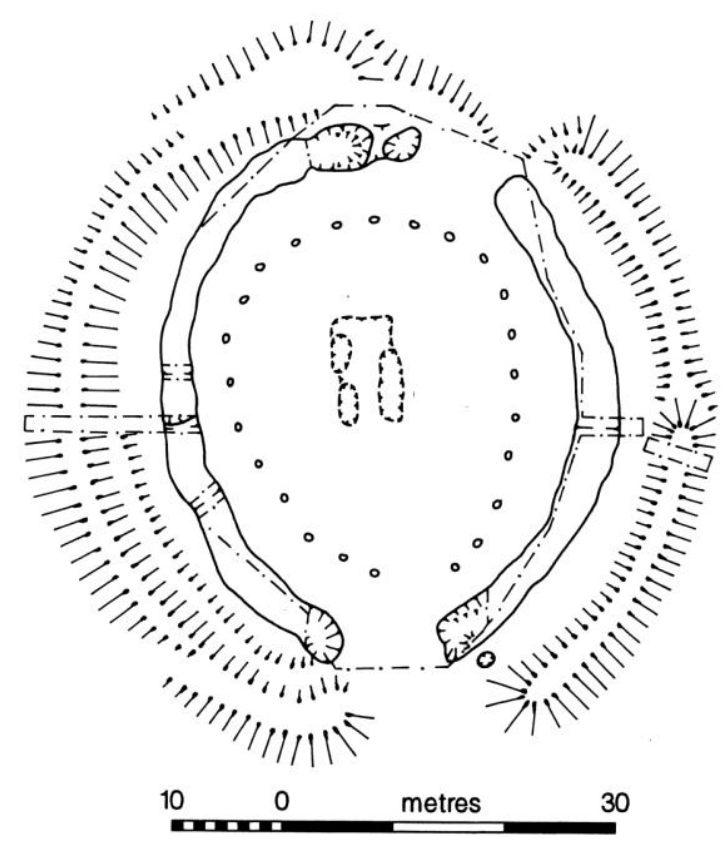

Figure 54: Stone (or possibly timber) circle at Cairnpapple, plus henge that was probably added centuries later. After Barclay 1999

As regards ceremonial monuments, in addition to the the aforementioned timber circle and paired alignment at Eweford East, and the pit alignment at Ewart 1, there is a possibility that the stone (or timber) circle at Cairnpapple (Figure 54), represented by 24 pits, was constructed during the first half of the third millennium BC. This feature has been variously interpreted in the past, with Piggott (1948) having argued for it being a stone circle, while Mercer (1981) argued for it having been a timber circle, a view subsequently accepted by Barclay (1999) and Millican (2007). Most recently, Richard Bradley has revisited and been impressed by Piggott's suggestion that the large stones forming the kerb of the late third millennium
BC cairn may have come from the putative stone circle (Bradley pers. comm.); these, plus some of the stones associated with the Beaker grave under that cairn, 'add up' in terms of the number of stones required for the circle. Irrespective of whether the circle had been of stone or timber, by analogy with other stone and timber circles in Scotland, a construction date within the first half of the third millennium seems eminently plausible.

It is also likely that the massive 'palisade enclosure', with its avenue-like entrance, at Meldon Bridge (Figure 18) was also constructed during this period, despite the absence of Grooved Ware from the site. This is based partly on the close formal parallel between this site and the timber enclosures at Forteviot and Dunragit, which have been dated to this period (Noble \& Brophy 2011a). The dating at Meldon Bridge leaves much to be desired, with very few of the radiocarbon dates relating directly to the enclosure, with oak (or unidentified charcoal) having been used, and with the standard deviations having been enlarged on advice from Patrick Ashmore. As a result, the four relevant dates (GU-1048, HAR-796-7 and SRR-648) give a hopelessly wide spread, albeit one in which a construction date within the 3000-2500 BC period is indeed possible.

Whether any henges were constructed in south-east Scotland/north-east England during this period is not known, although the concentration of Late Neolithic lithic finds around Overhowden Class I (single-entrance) henge, Scottish Borders, might point towards this site as a possible candidate (Atkinson 1950; Ballin 2011). The presence of Grooved Ware sherds in the upper fill of the henge at Yeavering (Miket \& Edwards 2009, 90) cannot be taken as a terminus ante quem for the henge's construction as they were redeposited. And at Cairnpapple, the fact that the oval, Class II henge is not concentric with the (probably) stone circle is consistent with Barclay's argument (1999) that the henge post-dates the circle, possibly by several centuries. All this should be viewed against 
the increasing amount of evidence to suggest that much henge construction occurred after 2500 BC (e.g. in the Milfield Basin: Harding 1981; Miket 1985; Passmore \& Waddington 2012)

One kind of Late Neolithic site that is very well represented, particularly in north-east England, is outcrops bearing cup- and cupand-ring 'rock art'. The Fellsandstone area of Northumberland is host to one of the largest concentrations of prehistoric rock art in Britain and there are over a thousand sites now known (e.g. Beckensall 2001). Many sites are also known in southern Scotland (Morris 1981), although there has been a lack of fieldwork to search for these kinds of sites in the Lothians compared to other regions. It has recently been shown that excavation of these sites can provide dating evidence, as well as sequencing of the carvings (Waddington et al. 2005; cf. Edwards \& Bradley 1999 on the Late Neolithic dating of rock art at Blackstone Beck on Ilkley Moor, Yorkshire), and excavation of such sites should form an important research priority.

As regards material culture, in addition to Grooved Ware pottery there is evidence for a significant importation of Yorkshire flint artefacts, with Torben Ballin's recent analysis of the assemblages from Airhouse and Overhowden, Scottish Borders, underlining this fact (Ballin 2011). The range of objects includes oblique arrowheads and edgepolished discoidal knives. This northern movement of material is complemented by the southern spread of carved stone balls and maceheads, the former probably from Aberdeenshire and the latter including at least some examples that may have been made in the Northern Isles, where maceheads are relatively abundant. Examples of both kinds of stone object are known from south-east Scotland and north-east England, albeit not in large numbers. A roughly spherical stone found at Cheviot Quarry has been published as a roughout for a six-knob carved stone ball (Johnson \& Waddington 2009, illus 12 and $179,182)$. This interpretation is not, however, universally accepted and another use as a hammerstone or ball-shaped grinder needs to be considered.

As in eastern and central Scotland, it appears that pitchstone was not being imported to this region at this time.

\subsubsection{Research questions regarding Neolithic south-east Scotland and north- east England}

The principal research questions are as follows:

1. Much more needs to be learnt about the nature, organisation and location of settlements, especially for the Middle and Late Neolithic. The Tweed Valley would make an excellent focus for targeted survey (including aerial reconnaissance) and excavation

2. Are the putative 'halls' and causewayed enclosures that are known from aerial photographs really Early Neolithic sites?

3. Our knowledge of funerary practices for much of the Neolithic in this region is very patchy: what was their nature and how did they change over time?

4. We know very little about ceremonial monuments during the Middle Neolithic.

5. Were any henges built prior to 2500 $B C$ in this region? In particular, when was Overhowden built?

6. Was the apparent use of shellfish in the Forth Valley a localised anomaly in terms of overall patterns of Neolithic susbsistence practices?

7. How was agriculture and the use of domestic animals organised? Our knowledge of the latter is particularly poor.

And more specific questions include: 
8. Can the dating of the 'palisade enclosure' and 'Neolithic' cremated bone deposits at Meldon Bridge be improved?

9. What is the relative dating of the circle and henge at Cairnpapple, and can we resolve the issue as to whether the ring was of stone or of timber? At present, the evidence seems to favour the 'stone' interpretation.

10. More rock art sites need to be investigated to enhance our dating evidence and help us to understand how they were used - and how their use articulates with other Late Neolithic ritual practices.

11. If possible, the calcined bone from yeavering should be revisited to check whether it is human or not.

12. The cremated bone from the two cemeteries at Whitton Hill needs to be radiocarbon dated.

\subsubsection{South-west Scotland}

This encompasses Dumfries \& Galloway, the mainland up to the southern mouth of the Clyde and Clydesdale. (We can also look across the Solway to developments in Cumbria - a region with whose inhabitants the farmers of south-west Scotland were evidently interacting.) Major contributions to our understanding of this region have been made by developer-funded archaeology, including pipeline and road work (which has, for example, uncovered several Grooved Ware-associated sites); by the work of Jack Scott (mainly on megalithic tombs), Bill Cormack and Jane Murray (on Dumfries \& Galloway); by the Biggar Archaeology Group and Lanark \& District Archaeology Society in Clydesdale; by Julian Thomas' excavations at Dunragit; and by Vicki Cummings and Chris Fowler's investigations of 'Bargrennan' chamber tombs.

The 'story' here is one of the appearance of the 'Carinated Bowl Neolithic' by, or around, 3800 BC followed by its regionally-specific development, with Impressed Ware pottery beginning to be used perhaps as early as $\mathrm{C}$ 3600/3500 BC and Grooved Ware appearing from c 3000/2900 BC. All these developments are echoed in Cumbria.

Early Neolithic evidence for settlement includes the 'hall' at Lockerbie, Dumfries \& Galloway (Kirby 2011) and various sites uncovered in Clydesdale, as on Biggar Common (Johnston 1996). It appears that Clydesdale and the Nith may have been key routes along which early farming communities rapidly spread. A presence on the sandhills of Glenluce is well represented (e.g. at Knocknab: Coles 2012). Early Neolithic funerary sites include the non-megalithic linear zone sites, covered by trapezoidal long mounds, at Lochhill and Slewcairn; a series of simple megalithic monuments (e.g. at Mid Gleniron and Cairnholy) seem to represent a translation into stone of the 'linear zone' idea. These form the basis for the emergence of a regionally-specific (and variable) tradition known as 'Clyde cairns', with clear links to very similar monuments in Ireland.

There is a cluster of cursus monuments around Dumfries (Thomas 2008).

A find of immense significance is the Rotten Bottom Bow, a yew longbow dating to c 3800 $B C$ and very probably the possession of a farmer out on a deer hunt. A few Alpine axeheads have also been found in this region - including a broken and burnt piece, found at Carinholy - and these will have been the possessions of the earliest farming communities in the region.

Middle Neolithic developments are represented at settlement sites on the Glenluce sandhills (McInnes 1964) and at Wellbrae and elsewhere in Clydesdale. Some large timber structures of Middle or Late Neolithic date may relate to similar structures seen elsewhere (eg at Balfarg Riding School).

Late Neolithic developments include the appearance of the large 'palisaded enclosure' at Dunragit. Finds of Grooved Ware at 
Alexandria (Suddaby pers comm) and Dreghorn, in addition to the finds at Dunragit and elsewhere, constitute significant additions to our knowledge. Publication of the major sites at Dunragit and Dreghorn will be important in allowing us to understand Late Neolithic developments.

A very unusual find dating to the Late Neolithic is the pitfall trap at Mye Plantation, near Glenluce, dating to the second half of the third millennium BC. Pottery which was found between two of the pits seems to show a mixture of elements between Grooved Ware and Impressed Ware.

Key research questions for this region are:

- When were the Bargrennan tombs-a regionally specific monument type (Murray 1992, Cummings \& Fowler 2007) built? Excavations have so far narrowed down the range to between c 3800 BC and C 1800 BC, but this needs to be narrowed, and the significance of these monuments needs to be bottomed out.

- When was the 'Twelve Apostles' stone circle constructed, and how does it fit in (if at all) with the Late Neolithic stone circles of Scotland?

- Overall land use patterns need to be explored. How were the uplands used? Was it only for hunting? How were the sandhills areas used?

\subsubsection{Western Scotland, the islands of the Clyde and the Inner Hebrides, south of the Great Glen}

The boundaries of this region have been drawn fairly arbitrarily, since there are many features of 'the Neolithic' that link it with areas to the north and south (and indeed, up the Great Glen, to north-east Scotland).

Our knowledge of the Neolithic in this region comes mainly from research-based activities, since there has been relatively little developer-funded archaeology (except on
Arran). Major contributions to our understanding of this region have been made by Audrey Henshall's and Jack Scott's work on the megalithic monuments and pottery of this region (Henshall 1972, Scott 1969a and b; 1977; 1978; 1989); by Graham Ritchie's (and his RCAHMS' colleagues') fieldwork, especially his excavation at Achnacreebeag (J N G Ritchie 1970); by Dorothy Marshall's excavations in Bute; and by John Barber's and Alison Haggerty's excavations on Arran. Most recently, the Discovering Bute Landscape Partnership Scheme, whose archaeological element has been led by Paul Duffy, has been providing an up-to-date statement of our state of knowledge of Bute archaeology (Geddes \& Hale 2010).

This region, characterised by its extensive coastline and by large stretches of upland, is very significant as including both strands of the earliest Neolithic - namely the Atlantic façade, Breton Neolithic (as attested at Achnacreebeag) and the 'Carinated Bowl (CB) Neolithic' (attested, for example, at Newton, Islay (McCullagh 1991). The earliest Neolithic can be characterised as the arrival of small groups of farming communities - the one having sailed up the Atlantic façade from Brittany at some time between c 4300 and $4000 \mathrm{BC}$, the other probably arriving as part of a westwards spread of the CB Neolithic, around $3800 \mathrm{BC}$ - and these people would have entered a landscape, parts of which were occupied by Mesolithic groups. However, the population levels may have been so low that the three groups may not have come into contact with each other for some time after the initial appearance of the farming groups. That the two farming groups did meet, however, is revealed in the architecture of megalithic monuments and in pottery. It appears that the farming communities and flourished: Achnacreebeag, for example, stands at the beginning of a complex process of passage tomb development in Scotland.

Early Neolithic settlement evidence is rare and none has yet been found that relates to 
the Atlantic façade, Breton Neolithic - but has been found, for example, in the form of pits and an artefact spread at Newton on Islay (McCullagh 1991), and as 'huts' at Auchategan, Argyll \& Bute (Marshall 1978). The latter, located on a plateau on a hillslope in Glendaruel, suggest that transhumance formed part of the Early Neolithic subsistence strategy. The CB pottery found at Auchategan includes one tulip-shaped vessel that would not be out of place among Michelsberg 'tulip beakers' on the Continent. The lithic material found at Auchategan - including Arran pitchstone and Langdale tuff - demonstrates that the inhabitants had already established a network of contacts over which such materials (and probably also people) circulated.

Funerary monuments consist of those in the passage tomb tradition - of which Achnacreebeag, with its closed megalithic chamber and simple passage tomb stands at the beginning, as mentioned above - and those in the CB regional tradition of Clyde cairns. The latter - probably constructed during the $37^{\text {th }}$ century, if not slightly earlier would have been built by the descendants of the earliest CB settlers, and demonstrate close connections with developments in south-west Scotland. A specific type of pottery - the so-called 'Achnacree bowl' found both in Clyde cairns (including Nether Largie in Kilmartin Glen) and a passage tomb (at Achnacree) - demonstrate close links with north-east Scotland, where an example of this specific pottery type has been dated, at Culduthel, to c 3600/3500 BC (Cook et al. 2010).

A cursus monument at Upper Largie in Kilmartin Glen (ibid.) represents a distant outlier to the overall distribution of this monument type, and demonstrates links with other regions of Scotland, especially the south west. It is a moot point whether at least one timber 'avenue' in Kilmartin Glen dates to this period. (See Cook et al. 2010 for a discussion.)
In terms of material culture, the pottery shows a hybridisation of the Breton and $C B$ traditions, and also reveals the adoption of the lugged plain jar from contacts down the Irish Sea. There is plentiful evidence for links with Ireland, not only in the importation of Antrim porcellanite axeheads and flint, but also in the export of Arran pitchstone to Ireland. Pirchstone was exploited from the earliest Neolithic, in a manner different from Mesolithic exploitation (Ballin 2011a), and was exchanged over long distances.

Middle Neolithic developments are not well represented, and it is unclear as to whether any passage tombs or Clyde cairns were built in this region after $3500 \mathrm{BC}$. Much more needs to be discovered about what was happening at this time.

Late Neolithic developments are better represented, with this region showing participation in the southward spread of ideas, practices and traditions from Orkney around $3000 \mathrm{BC}$ - as shown in the timber and stone circles at Temple Wood (Kilmartin Glen) and Machrie Moor, Arran, and in the rare finds of Grooved Ware pottery. It is also clear that rock art was being made in large amounts during the first half of the third millennium in this region.

Key research questions are:

- Much more needs to be understood about the Atlantic façade, Breton strand of the Neolithic: where and how did people live? How extensive was the initial appearance of this phenomenon?

- More needs to be understood about the relative chronology of the stone circles on Machrie Moor.

- The Middle Neolithic remains very poorly known: what was happening during this period?

- How does the rock art phenomenon articulate with the 'Grooved Ware' phenomenon? 


\subsubsection{The north-west mainland and the Hebrides north of the Great Glen}

As with western Scotland, most of our knowledge comes from research-based archaeology since there has been relatively little developer-funded archaeology in this region. Key contributions have been made by Audrey Henshall's study of the region's megalithic monuments (Henshall 1972); by Lindsay Scott's excavations (including at Eilean an Tighe, North Uist (Scott 1951); by Ian Armit's excavation at Eilean Domhnuill, Loch Olabhat, North Uist (e.g. Armit 2003); by Patrick Ashmore's excavations at Calanais in 1980 and 1981 (Ashmore forthcoming), along with Clive Ruggles' assessment of its archaeoastronomical aspects and by the Pontings'/Curtis' research in the area; by Derek Simpson's excavations at Northton, Harris (Simpson et al. 2006); and by the campaigns of the Universities of Sheffield and Cardiff on Benbecula and South Uist (Branigan \& Foster 2000; Parker Pearson et al. 2004; Parker Pearson 2012).

It appears that this region was first colonised by farming communities as part of a secondary expansion of 'the Neolithic': at any rate, there is no evidence for the early $C B$ Neolithic, and no firm evidence for the Atlantic façade, Breton Neolithic has yet been found - although examination of the simplest passage tombs in the region would be worthwhile. There are, however, elements of both of these Neolithic traditions, with passage tombs representing a development from the earliest form as seen at Achnacreebeag, and with North Uist megaliths - especially Clettraval - showing elements of both the passage tomb and the Clyde cairn traditions (Henshall 1972; Henley 2004). The date of 'the Neolithic's' appearance is likely to be during the late $38^{\text {th }}$ century.

Radiocarbon dating of developments over the $4^{\text {th }}$ millennium is particularly poor in this region, and so, although we know that stone(and probably turf)-built houses were constructed - at Eilean Domhnuill - details of the chronology of settlement and chamber tomb construction (and use of Hebridean Neolithic pottery) leave a lot to be desired. Furthermore, next to nothing is known about settlement on the north-west mainland of Scotland, even though the megalithic tombs form part of Henshall's 'Orkney-CromartyHebrides' grouping.

Armit's excavations at Loch Olabhat provided a fascinating insight into the pressures on land use during the Neolithic, although his model of a squeeze between rising sea levels and expanding blanket peat (Armit 2003) has not been universally accepted (see Chapter 4).

Evidence for agricultural activity, in the form of cultivation traces, has been found at Calanais and some sub-peat field walls are likely to be of Neolithic date, as at Barpa Carinish (Crone 2003).

That communities in this region maintained contacts to the south and the north is demonstrated in finds such as an Antrim porcellanite axehead in a haft at Shulishader, Lewis, and of finds of pitchstone - showing links to the south- and in the sharing of Unstan Bowls, which demonstrates contacts with Orkney and/or the north-east mainland.

As in western Scotland, our understanding of what happened between 3500 and $3000 \mathrm{BC}$ is not as clear as we would like, even though some of the Hebridean Neolithic pottery will certainly have been in use, as was the settlement at Eilean Domhnuill.

Late Neolithic developments are dominated by the construction of Calanais, in the first instance as a stone circle with a central monolith (Ashmore forthcoming), probably around 3000/2900 BC. This act - associated with a single Grooved Ware pot of a style closely comparable with Orcadian Grooved Ware - formed part of the southward spread of traditions and practices from Orkney. The lunar orientation of Calanais may have been planned from the outset, but was emphasised 
by the subsequent addition of avenues along the cardinal points.

Key research questions are:

- Our near-absence of evidence for Early Neolithic settlement on the north-west mainland needs to be redressed

- The dating of the appearance of 'the Neolithic' in this region needs to be clarified, as does the dating of subsequent developments

- To what date belong the plethora of small stone circles around the main ceremonial site at Calanais?

\subsubsection{The north-east mainland (north of} the Great Glen) and Orkney

This region encompasses part of the northern Highlands, the coastal lowlands of the northeast mainland and the archipelago of Orkney. As in the Hebrides, north-west and western Scotland, developer-funded archaeology has played a relatively minor role in producing evidence of the Neolithic, whereas researchbased archaeology has a long tradition, extending back to Alexander Rhind's excavations of chambered tombs in Caithness in 1853 and Petrie's (and others') investigations of various tombs in Orkney during the second half of the $19^{\text {th }}$ century (Henshall 1963, 45). More recently, the concentration of resources on studying Orkney's spectacular archaeology from the 1970s onwards has led to calls for a redressing of the balance (eg Barclay 2000) and this has largely been achieved, although further resources are required to continue initiatives such as the excavations at Ness of Brodgar. Orkney also has an unfortunate record of nonresourced and wholly unscientific excavation by landowners, with some finds never having made it into the public domain, despite the existence of Scotland's strict law of bona vacantia.

The recent radiocarbon dating and analysis of human remains from several Orcadian chamber tombs (Schulting et al. 2010 and forthcoming; Lawrence 2008) has greatly enhanced our understanding of the Neolithic inhabitants of Orkney, and the chronology of their monuments. Fascinating details of human palaeopathology have been obtained from an in-depth study of human remains from Isbister (where a high incidence of illness, and some cranial trauma, have been observed) and Quanterness, and the isotopic analysis of the bones has revealed that the diet was overwhelmingly terrestrial, despite clear evidence for fish bones and other marine resources at sites such as Skara Brae.

Parts of this region had been touched by the CB Neolithic during the early fourth millennium, since pottery of this tradition has been found as far north as Caithness, and there is even a small Alpine axehead known from Caithness. Expansion to Orkney did not, however, occur until the expansion, from the west of Scotland, of groups using passage tombs, probably around the $37^{\text {th }}$ (or late $38^{\text {th }}$ ) century BC. This brought the practice of building passage tombs to the north-east mainland as well, and a subsequent interaction between this tradition and the CBorigin tradition can be seen in the superimposition, possibly around $3500 \mathrm{BC}$, of massive long horned cairns over pre-existing passage tombs, as at Camster Long.

Settlement evidence for the earliest Neolithic presence in this region is sparse; best known are the stone buildings at Knap of Howar (A. Ritchie 1983), but remains of timber houses recently found as part of the Glasgow/Manchester University CuweenWideford project reminds us that timber houses were indeed used as far north as this.

The funerary monuments include the aforementioned 'Orkney-Cromarty-Hebrides' passage tombs; a peculiarity of this region, both in Orkney and on the mainland, is the stalled chamber format, which seems to echo the structure of houses. Details of the development of funerary monuments need to be clarified, but a clear process of competitive 
conspicuous consumption can be discerned from at least as early as $3500 \mathrm{BC}$, with the construction of massive horned cairns and the building of ever-larger and more elaborate stalled cairns and passage tombs (and indeed hybrid forms, as seen at Isbister. The emergence of Maes Howe type passage tombs at some point between $3400 \mathrm{BC}$ and $3100 \mathrm{BC}$ - the dating being hampered by the radiocarbon calibration plateau (Schulting et al 2010) - indicates a step change in the process of competitive conspicuous consumption.

The material culture of the early Neolithic in Orkney relates closely to that of the northeastern mainland, especially regarding pottery. The use of Unstan Bowls (and of associated undecorated and decorated pottery) seems to have spread from the mainland to Orkney, probably as part of the archipelago's initial colonisation by farming communities.

The best-known period is the Late Neolithic, when an apparently highly stratified society had emerged, probably basing its power on the claimed ability to interact with (and influence) supernatural forces. The particular expression of this had been informed by travel to the Boyne Valley, where a flourishing, hierarchical society had been building massive passage tombs. Elements of this theocratic society in Orkney include:

- The construction of Maes Howe-type passage tombs (although other types of chamber tomb may have continued to be built at the same time)

- The construction of the Stones of Stenness (including its henge) during the $29^{\text {th }}$ century BC (and, several centuries later, the construction of the Ring of Brodgar

- The emergence of the area around the Lochs of Stenness and Brodgar as a major centre for ceremonies, in which Maes Howe, the Stones of Stenness, standing stones, Barnhouse and the 'temple complex' at Ness of
Brodgar featured prominently. The associated rituals included the observation of the midsetting sun entering the chamber at Maes Howe during midwinter solstice, and the smashing of maceheads

- A variety of symbols of power, including various forms of macehead, carved stone balls and other unusual carved stone artefacts

- Grooved Ware.

The fame of this part of Orkney must have spread rapidly so that, as with the Boyne Valley, it appears that people came from far and wide to witness (and participate in) the celebrations and the monuments. This accounts for the rapid southward spread of the use of Grooved Ware and of timber and stone circles, as far as southern England (and with Grooved Ware now known from as far away as south-west Ireland).

Key research questions include:

- The need to refine the chronology so that the chronological relationship between the use of Maes Howe-type passage tombs and other tomb types, and of Grooved Ware and nonGrooved Ware, can be understood

- The need to enhance our understanding of early Neolithic settlement and subsistence practices

- There clearly was some long-distance contact between Orkney and southern England around 3000/2900 $B C$ - indeed, the first phase monument at Stonehenge might perhaps even have been inspired by the Stones of Stenness - and again around 2600 BC (when houses at Durrington Walls resemble Skara Brae houses, and when Grooved Ware once more shows similarities from one end of Britain to the other). But were there uninterrupted contacts throughout the first half of the third millennium? 


\subsubsection{Shetland}

The Neolithic of Shetland remains largely a mystery, since until recently, very little research or fieldwork had been carried out since Calder's, Henshall's and Roy Ritchie's surveys of the 1960s and 1970s. Critical review of the results of Whittle's excavations at Scord of Brouster (Sheridan 2012) has concluded that many of the structures are of post-Neolithic date. Recent advances have been made through Nigel Melton's excavations at West Voe, Sumburgh, which have uncovered Mesolithic and Early Neolithic middens; by his and Janet Montgomery's reanalysis of the human remains from the Sumburgh Cist; by Edwards et al.'s palaeoenvironmental work; by research into felsite exploitation by Torben Ballin, Gabriel Cooney and Will Megarry; by developerfunded excavation on the Hill of Crooksetter; and by the Nationalmuseet's Farming on the Edge project, which compares Shetland's Neolithic (and Neolithisation) with that of southern Scandinavia (Mahler 2011, 2012).

The story is one of the appearance of pottery - if not also of cereal cultivation and the use of domesticates - probably during the $37^{\text {th }}$ (or possibly late $38^{\text {th }}$ ) century BC. This seems to have arrived from western Scotland - perhaps the Outer Hebrides - as part of a secondary expansion of 'the Neolithic', and there is reason to believe that it did not arrive via Orkney, but instead came directly. Simple passage tombs such as the example on the Hill of Ronas, the highest point on Shetland, were probably built by these first Neolithic settlers. The West Voe site may represent a very rare example of where Mesolithic inhabitants selectively adopted elements of a Neolithic lifestyle; the few sherds of undecorated pottery found here may well be relatable to the undecorated component of the Hebridean Neolithic pottery tradition.

The subsequent history is one of marked insularisation punctuated by episodes of contact with the outside world. Thanks to a radiocarbon date obtained for short-lived charcoal from Modesty by the Nationalmuseet's Farming on the Edge project, we can now say that exploitation of the felsite sources (to make both axeheads and ground knives) was underway by the third quarter of the fourth millennium. The use of this strikingly attractive stone is distinctive: in addition to making small, utilitarian axeheads, large axeheads were manufactured (and, it seems, kept almost exclusively within Shetland) even though there would have been no substantial trees (R. Ritchie 1968; 1992; Ballin 2011b). Shetland knives are also a regionally-specific artefact type, perhaps used for skinning as well as cutting. A regionallyspecific pottery style, featuring undecorated bowls (some with grass used as a filler), had emerged during the second half of that millennium.

Shetlanders do not seem to have participated much in the competitive, hierarchical practices as seen in Late Neolithic Orkney and indeed the only candidate for a Grooved Ware pot in Shetland comes from a Late Bronze Age/Early Iron Age context, and is a little suspect. However, Late Neolithic contact with Orkney is demonstrated by the shared use of maceheads (pestle-shaped and cushionshaped); like Orkney, Shetland seems to have been a 'hot spot' for their use.

Outstanding research questions include:

- What is the sequence of funerary monument construction? A hypothetical sequence has been proposed by Sheridan (2012) but needs to be tested through fieldwork and dating

- What was the overall currency of the use of felsite, and how was exploitation organised?

- What was the Neolithic pattern of land use and subsistence practices?

- How was society organised, and how did this change over time? What were the social dynamics? 
- Were any of the maceheads found in southern England (especially in the Thames valley ) made in Shetland? 


\section{Lifeways and Lifestyles}

This theme considers aspects of the way in which people lived their lives during the Neolithic period in Scotland, starting with a consideration of the foods they ate (Section 4.1) and evidence for their diet as left in their bones (Section 4.2), and moving on to consider the structures in which they lived (Section 4.4) and ending with a consideration of the environment (including climate) in which they would have lived (Section 4.6).

\subsection{Food \& Drink}

\subsubsection{Introduction}

Human beings have highly complex relationships with their food and diet, as a diverse range of factors including personal identity, ethnicity and religion all strongly influence the choices people make about what they eat. Hence the subject is one of prime importance within prehistoric studies, particularly those of the Neolithic, which has long been defined, in part, as marking a shift from a hunting, fishing and gathering economy to the adoption of agriculture. Indeed, the question of how, when and why such economic change happened is the topic of considerable theoretical debate (e.g. Thomas 2003; Rowley-Conwy 2004)-and Scotland and other marginal European locations often feature prominently in these dialogues. Archaeological data from excavated sites, and the various palaeodietary proxies from the archaeological sciences, offer an increasingly detailed yet occasionally contradictory view of this complex problem. This contribution reviews these data, aiming to assess current state of knowledge of the subsistence practices, economy and the diet during the Neolithic period in Scotland.

\subsubsection{Archaeological evidence of diet and subsistence}

\subsubsection{Cereals and other plant foods}

Direct evidence for the use of specific foods is found in plant macrofossils and animal bones discovered during excavations of settlements. Plant foods, being organic, are highly prone to deterioration and unless their context of deposition is desiccated, frozen or waterlogged, plants will only survive if the remains themselves have undergone lowtemperature charring prior to deposition (Hillman et al. 1993). This situation leads to inherent biases in the archaeological record and an under-representation of plant foods in general, especially as the recovery of plant remains from archaeological sites is dependent on excavation methodology and, in particular, on the wet-sieving of soil samples (Jones 2000). Given that cereals are a strong indicator of arable agriculture, whereas hazelnuts are an indicator of the use of (presumably) wild food resources by Neolithic people, the economic and cultural implications of palaeobotanical data have been the subject of considerable debate in Scotland and elsewhere in northern Europe (e.g. Stevens 2007; Bishop et al. 2009).

In Neolithic Scotland, cereal remains have been identified from Balbridie (Fairweather \& Ralston 1993), Boghead (MacLean \& RowleyConwy 1984), Cowie Road (Holden 1997), Claish (Miller \& Ramsay 2002), Easterton and Eday (Boyd 1988), Isbister (Lynch 1983), Kinbeachie (Barclay et al. 2001), Knap of Howar (Dickson 1983), Lairg (Holden 1998), Scord of Brouster (Milles 1986 - although see above, 3.3.7, on the dating of the Scord of Brouster houses), Skara Brae (Dickson \& Dickson 2000), the Links of Noltland (Hastie 2011), the Stones of Stenness (MacLean 1978), Toft's Ness (Dickson \& Dickson 2000), Townhead and Unstan (both Boyd 1988; see also Jones \& Rowley-Conwy 2007 for further data and references). A number of recently discovered sites, including Crathes Warren Field (Murray et al. 2009), Broomhouses (Kirby 2006) and Station Brae (Addyman et al. 2004), have also produced cereals from their excavations, although full details of some of these are not available at present. Virtually all of these sites have also produced hazelnut shells and occasional remains of other wild 
food resources such as crab apple (Dickson \& Dickson 2000). Indeed, relative to later prehistoric and historic-period occupation sites, Neolithic sites tend to produce greater quantities of hazelnut fragments, hence implying that hazelnuts may have been relatively more important during the Neolithic than in later periods (Stevens 2007). It is clear, however, that cereal foods were present in Scotland from the earliest phases of the Neolithic, and their use continued throughout prehistory. Indeed, the Scottish data even suggest a pattern in the types of crop grown, with barley dominating samples from sites in the wind-swept and wet North, and wheat being more prominent in the sunnier and drier east of the country (Dickson \& Dickson
2000). However, given the interpretative difficulties associated with archaeobotanical data and cereals in particular, there is little consensus regarding the importance of cereal cultivation within the Neolithic economy (Jones \& Rowley-Conwy 2007; Bishop et al. 2009). Notwithstanding the degree of its importance, it can be said with some certainty that cereal agriculture was at least present throughout the Neolithic period in Scotland, and geographically widespread (Table 3). Furthermore, palaeoenvironmental research by Lancaster et al. at Warren Field, Crathes (2009) has indicated that one or more cereal fields or plots existed in the vicinity of the large 'hall' there.

Table 2: Dates for Neolithic cultivation from sites across Scotland; an example of collated data.

\begin{tabular}{|c|c|c|c|c|c|c|}
\hline Site & Start/End & $\begin{array}{l}\text { Dated } \\
\text { material }\end{array}$ & $\begin{array}{l}\text { Date } \\
\text { cal } \\
\text { BC }\end{array}$ & Date BP & $\begin{array}{l}\text { Lab } \\
\text { code }\end{array}$ & Author \\
\hline $\begin{array}{l}\text { Crathes, } \\
\text { Aberdeenshire }\end{array}$ & Start & $\begin{array}{l}\text { Club/bread } \\
\text { wheat } \\
\text { grain }\end{array}$ & $\begin{array}{l}3950- \\
3700\end{array}$ & $5015 \pm 35$ & $\begin{array}{l}\text { SUERC- } \\
10085\end{array}$ & Murray et al. 2009 \\
\hline $\begin{array}{l}\text { Crathes, } \\
\text { Aberdeenshire }\end{array}$ & End & $\begin{array}{l}\text { Naked } \\
\text { barley } \\
\text { grain }\end{array}$ & $\begin{array}{l}3820- \\
3650\end{array}$ & $4945 \pm 35$ & $\begin{array}{l}\text { SUERC- } \\
4034\end{array}$ & Murray et al. 2009 \\
\hline $\begin{array}{l}\text { Garthdee, } \\
\text { Aberdeenshire }\end{array}$ & Start & $\begin{array}{l}\text { Naked } \\
\text { barley } \\
\text { grain }\end{array}$ & $\begin{array}{l}3800- \\
3650\end{array}$ & $4950 \pm 35$ & $\begin{array}{l}\text { SUERC- } \\
8613\end{array}$ & $\begin{array}{l}\text { Murray et al. } \\
\text { forthcoming }\end{array}$ \\
\hline $\begin{array}{l}\text { Garthdee, } \\
\text { Aberdeenshire }\end{array}$ & End & $\begin{array}{l}\text { Naked } \\
\text { barley } \\
\text { grain }\end{array}$ & $\begin{array}{l}3780- \\
3640\end{array}$ & $4925 \pm 35$ & $\begin{array}{l}\text { SUERC- } \\
8607\end{array}$ & $\begin{array}{l}\text { Murray et al. } \\
\text { forthcoming }\end{array}$ \\
\hline $\begin{array}{l}\text { Powmyre } \\
\text { Quarry, Angus }\end{array}$ & Start/End & $\begin{array}{l}\text { Emmer } \\
\text { wheat } \\
\text { grain }\end{array}$ & $\begin{array}{l}3770- \\
3640\end{array}$ & $4920 \pm 35$ & $\begin{array}{l}\text { SUERC- } \\
30981\end{array}$ & Masser 2010 \\
\hline $\begin{array}{l}\text { Claish, } \\
\text { Stirlingshire }\end{array}$ & Start/End & $\begin{array}{l}\text { Emmer } \\
\text { wheat } \\
\text { grain }\end{array}$ & $\begin{array}{l}3790- \\
3620\end{array}$ & $4885 \pm 50$ & $\begin{array}{l}\text { AA- } \\
49461\end{array}$ & Barclay et al. 2002 \\
\hline $\begin{array}{l}\text { Balbridie, } \\
\text { Aberdeenshire }\end{array}$ & Start & Oat grain & $\begin{array}{l}3770- \\
3370\end{array}$ & $4820 \pm 80$ & $\begin{array}{l}\text { OxA- } \\
1767\end{array}$ & $\begin{array}{l}\text { Fairweather } \\
\text { Ralston } 1993\end{array}$ \\
\hline $\begin{array}{l}\text { Balbridie, } \\
\text { Aberdeenshire }\end{array}$ & End & $\begin{array}{l}\text { Emmer } \\
\text { wheat } \\
\text { grain }\end{array}$ & $\begin{array}{l}3700- \\
3360\end{array}$ & $4765 \pm 80$ & $\begin{array}{l}\text { GU- } \\
1421\end{array}$ & $\begin{array}{ll}\text { Fairweather } & \text { and } \\
\text { Ralston } 1993\end{array}$ \\
\hline
\end{tabular}




\begin{tabular}{|c|c|c|c|c|c|c|}
\hline $\begin{array}{l}\text { Eilean } \\
\text { Domhnuill, } \\
\text { Western Isles }\end{array}$ & Start & $\begin{array}{l}\text { Barley } \\
\text { grain }\end{array}$ & $\begin{array}{l}3710- \\
3520\end{array}$ & $4830 \pm 45$ & $\begin{array}{l}\text { OxA- } \\
9079\end{array}$ & Mills et al. 2004 \\
\hline $\begin{array}{l}\text { Eilean } \\
\text { Domhnuill, } \\
\text { Western Isles }\end{array}$ & End & $\begin{array}{l}\text { Barley } \\
\text { grain }\end{array}$ & $\begin{array}{l}2930- \\
2760\end{array}$ & $4265 \pm 30$ & $\begin{array}{l}\text { OxA- } \\
9159\end{array}$ & Mills et al. 2004 \\
\hline $\begin{array}{l}\text { Balfarg, } \\
\text { Fife }\end{array}$ & Start/End & $\begin{array}{l}\text { Barley } \\
\text { grain }\end{array}$ & $\begin{array}{l}3700- \\
3520\end{array}$ & $4830 \pm 40$ & $\begin{array}{l}\text { UtC- } \\
1302\end{array}$ & $\begin{array}{l}\text { Barclay and Russell- } \\
\text { White } 1993\end{array}$ \\
\hline $\begin{array}{l}\text { Culduthel, } \\
\text { Inverness- } \\
\text { shire }\end{array}$ & Start & $\begin{array}{l}\text { Naked } \\
\text { barley } \\
\text { grain }\end{array}$ & $\begin{array}{l}3650- \\
3510\end{array}$ & $4780 \pm 30$ & $\begin{array}{l}\text { SUERC- } \\
20229\end{array}$ & Murray, forthcoming \\
\hline $\begin{array}{l}\text { Culduthel, } \\
\text { Inverness- } \\
\text { shire }\end{array}$ & End & $\begin{array}{l}\text { Naked } \\
\text { barley } \\
\text { grain }\end{array}$ & $\begin{array}{l}3640- \\
3370\end{array}$ & $4725 \pm 30$ & $\begin{array}{l}\text { SUERC- } \\
27863\end{array}$ & Murray, forthcoming \\
\hline $\begin{array}{l}\text { Biggar } \\
\text { Common East, } \\
\text { Lanarkshire }\end{array}$ & Start/End & $\begin{array}{l}\text { Barley } \\
\text { grain }\end{array}$ & $\begin{array}{l}3650- \\
3100\end{array}$ & $4645 \pm 65$ & $\begin{array}{l}\text { AA- } \\
18155\end{array}$ & $\begin{array}{l}\text { http://www.historic- } \\
\text { scotland.gov.uk }\end{array}$ \\
\hline $\begin{array}{ll}\text { Skara } & \text { Brae, } \\
\text { Orkney } & \\
\end{array}$ & Start & $\begin{array}{l}\text { Barley } \\
\text { grain }\end{array}$ & $\begin{array}{l}3640- \\
3370\end{array}$ & $4735 \pm 40$ & $\begin{array}{l}\text { SUERC- } \\
3127\end{array}$ & Ascough et al 2007 \\
\hline $\begin{array}{l}\text { Skara Brae, } \\
\text { Orkney }\end{array}$ & End & $\begin{array}{l}\text { Barley } \\
\text { grain }\end{array}$ & $\begin{array}{l}3010- \\
2700\end{array}$ & $4270 \pm 40$ & $\begin{array}{l}\text { SUERC- } \\
3126\end{array}$ & Ascough et al 2007 \\
\hline $\begin{array}{l}\text { Westgate, } \\
\text { Aberdeenshire }\end{array}$ & Start & $\begin{array}{l}\text { Naked } \\
\text { barley } \\
\text { grain }\end{array}$ & $\begin{array}{l}3630- \\
3360\end{array}$ & $4675 \pm 30$ & $\begin{array}{l}\text { SUERC- } \\
31286\end{array}$ & $\begin{array}{l}\text { Murray et al. } \\
\text { forthcoming }\end{array}$ \\
\hline $\begin{array}{l}\text { Westgate, } \\
\text { Aberdeenshire }\end{array}$ & End & $\begin{array}{l}\text { Naked } \\
\text { barley } \\
\text { grain }\end{array}$ & $\begin{array}{l}3520- \\
3360\end{array}$ & $4660 \pm 30$ & $\begin{array}{l}\text { SUERC- } \\
31288\end{array}$ & $\begin{array}{l}\text { Murray et al. } \\
\text { forthcoming }\end{array}$ \\
\hline $\begin{array}{l}\text { Barnhouse, } \\
\text { Orkney }\end{array}$ & Start & $\begin{array}{l}\text { Charred } \\
\text { grain }\end{array}$ & $\begin{array}{l}3650- \\
3000\end{array}$ & $4590 \pm 75$ & $\begin{array}{l}\text { OxA- } \\
3499\end{array}$ & Ashmore 2005 \\
\hline $\begin{array}{l}\text { Barnhouse, } \\
\text { Orkney }\end{array}$ & End & $\begin{array}{l}\text { Naked } \\
\text { barley } \\
\text { grain }\end{array}$ & $\begin{array}{l}3330- \\
2880\end{array}$ & $4360 \pm 60$ & $\begin{array}{l}\text { OxA- } \\
2736\end{array}$ & Ashmore 2005 \\
\hline $\begin{array}{l}\text { Castlehill, } \\
\text { Inverness }\end{array}$ & Start/End & $\begin{array}{l}\text { Charred } \\
\text { grain }\end{array}$ & $\begin{array}{l}3520- \\
3100\end{array}$ & $4595 \pm 50$ & $\begin{array}{l}\text { AA- } \\
39809\end{array}$ & $\begin{array}{l}\text { http://www.historic- } \\
\text { scotland.gov.uk }\end{array}$ \\
\hline $\begin{array}{l}\text { Kinbeachie, } \\
\text { Black Isle }\end{array}$ & Start & $\begin{array}{l}\text { Barley } \\
\text { grain }\end{array}$ & $\begin{array}{l}3500- \\
3100 \\
\end{array}$ & $4575 \pm 45$ & $\begin{array}{l}\text { OxA- } \\
8204 \\
\end{array}$ & Barclay et al. 2001 \\
\hline $\begin{array}{l}\text { Kinbeachie, } \\
\text { Black Isle }\end{array}$ & End & $\begin{array}{l}\text { Barley } \\
\text { grain }\end{array}$ & $\begin{array}{l}3340- \\
2930\end{array}$ & $4455 \pm 40$ & $\begin{array}{l}\text { OxA- } \\
8206\end{array}$ & Barclay et al. 2001 \\
\hline $\begin{array}{l}\text { Meadowend } \\
\text { Farm, } \\
\text { Aberdeenshire }\end{array}$ & Start & $\begin{array}{l}\text { Naked } \\
\text { barley } \\
\text { grain }\end{array}$ & $\begin{array}{l}3490- \\
3120\end{array}$ & $4560 \pm 35$ & $\begin{array}{l}\text { SUERC- } \\
16835\end{array}$ & $\begin{array}{l}\text { Timpany et al. } \\
\text { forthcoming }\end{array}$ \\
\hline $\begin{array}{l}\text { Meadowend } \\
\text { Farm, } \\
\text { Aberdeenshire }\end{array}$ & End & $\begin{array}{l}\text { Naked } \\
\text { barley } \\
\text { grain }\end{array}$ & $\begin{array}{l}3340- \\
2930\end{array}$ & $4450 \pm 40$ & $\begin{array}{l}\text { SUERC- } \\
16894\end{array}$ & $\begin{array}{l}\text { Timpany et } \\
\text { forthcoming }\end{array}$ \\
\hline
\end{tabular}




\subsubsection{Faunal remains}

Bone assemblages allow the archaeologist to identify the various animals exploited (whether it be for food or other purposes) by humans at a given place and time; cut marks and fracture patterns inform on ways in which animals had been used, and mortality patterns can reveal stock-keeping strategies. However, due to the high soil acidity over much of Scotland, bones rarely survive, which means that discussion is restricted to a handful of sites, mainly in Orkney.

McCormick and Buckland (1997) and Dickson and Dickson (2000) have summarised the available evidence, and domestic sheep and cattle tend to dominate these bone assemblages in equal number, with domesticated pig, red deer, marine mammals, birds, fish and shellfish being of secondary importance in Orkney. This is true both of settlements (Skara Brae, Knap of Howar and Tofts Ness) and of burial monuments such as Ibister, Holm of Papa Westray and Quanterness - although it could be argued that the ritualistic aspect of the latter sites means that normal patterns of subsistence may not be represented here.

Papa Westray cattle are much larger than those typical of the Early Neolithic and may represent the presence of wild aurochsen, although cattle bones from other locations are within the normal size range for domesticated cattle (McCormick \& Buckland 1997). The very fragmentary remains from Scord of Brouster, Shetland seem to conform to the pattern of sheep and cattle seen in Orcadian sites (ibid.; although see also Section 3.3.7 on the dating of the remains from this site). At Northton, on Harris, the Minimum Number of Individual estimates for the site's small faunal assemblage suggested that sheep predominated over cattle; other species present comprised pig, red deer, seal, whale, fish and seabirds (Simpson et al. 2006). In short, it can be said with some confidence that domesticated livestock-especially cattle and sheep-were used throughout the
Neolithic period in Scotland. Red deer and aquatic mammals were exploited too, although it is not clear if this was primarily for their meat, or other products such as their hides, antler or blubber, of which the latter would have been useful as a source of oil for lighting, especially during the months of winter.

As discussed below, scientific analyses of human bones and teeth are invaluable indicators of aspects of diet, and these techniques can also be applied to faunal remains. Balasse et al. (2006) have performed a stable isotope study on sheep teeth from two Orkney sites (Holm of Papa Westray North and the Knap of Howar). Samples from Holm of Papa Westray indicate a partial reliance on seaweed as fodder at certain times of the year.

Fish bone assemblages are known from Knap of Howar, Skara Brae and Tofts Ness and a number of burial sites in Orkney, but these pose interpretative problems, partly because their recovery depends on excavation procedure, and their presence at sites (especially burial sites) may be the result of the activities of otters or birds, not humans (Barrett et al. 1999). In contrast to Mesolithic sites in the archipelago, Neolithic fishing activity seems to have been low-intensity, occurring throughout the year (Parks 2009).

\subsubsection{Artefacts}

The presence or absence of certain technologies, such as pottery, has implications for the cooking and food-storage capacity of past societies. Pottery in particular has considerable potential for the direct detection of food items in the form of impressions, residues and lipid analysis (e.g. Copley et al. 2005; Evans and Bick 1976). Cereal grain impressions are sometimes found on Neolithic pottery-an observation that implies pottery manufacture and cereal agriculture were coincident activities, although few examples of these have been securely dated (Gibson 2002; Brown 2007). Lipid analysis aims to 
identify certain fatty residues that become absorbed into the fabric of pottery as it is actually used. Lipids tend to become so wellpreserved within pottery that their extraction and identification is possible using gas chromatography and mass spectrometry. The analysis that has already been undertaken (by researchers working with Professor Richard Evershed of Bristol University) has shown that dairying seems to have been a component of Neolithic subsistence from the outset, as in Southern Britain. This implies the use of secondary products from cattle, a development that hints at sophisticated stockkeeping strategies practised by people from the Early Neolithic onwards (cf. Sherratt 1981). It also implies that the human population itself may have been either biologically or technologically adapted to this diet, as cows' milk is not easily digestible by human adults unless they are tolerant to lactose or the milk is further processed and refined.

Other artefacts provide information about the lifeways of Neolithic people; a number of flint tools have functional aspects related to subsistence, for example. Flaked stone bars are likely to have been used during the Neolithic, as later, as ard shares, while the use of spades and hoes is suggested by the marks they have left in sandy soils. (Cf. Section 4.1.2.4.) Querns, which are a key part of the tool-kit used to process cereals into digestible food, are somewhat under-discussed, perhaps because significant dating problems are presented by their simplicity of form, bulk and their tendency to appear out of context. Massive Neolithic saddle querns are known from Knap of Howar and Skara Brae on Orkney, and from Eilean Domhnuill on North Uist, where their association with domestic life is clear. As for the rubbing stones that would have been used with these querns, both slab rubbers and ball-shaped rubbers are known (e.g. at Eilean Domhnuill). Other coarse stone tools relating to food processing include some unusual tools found at Knap of Howar (Fig. x), which could have been used to pound a specific foodstuff (Ritchie 1983).

\subsubsection{Archaeological features and deposits}

At North Mains in Perth \& Kinross, cultivation ridges pre-dating an Early Bronze Age barrow were discovered by Barclay (1983). A study of soil chemistry and micromorphology suggested that an episode of cultivation, which probably involved intensive soil management techniques such as manuring, also pre-dated a subsequent episode of stockgrazing at the site (Romans \& Robertson 1983). The cultivation ridges were placed $2 \mathrm{~m}$ apart, comparable to "cord-rig" systems more widely known from Bronze Age and later contexts. Because so few surviving deposits of Neolithic palaeosoil have been analysed micromorphologically, it is difficult to establish whether the North Mains cultivation practices were more widespread. Future work could clearly benefit research of this kind; buried soils of Neolithic date are sometimes found, and they have often been used as termini post quos when dating a site's construction (Davidson \& Carter 1997).

Although quite rare, a few examples of Neolithic field systems are known; at Scord of Brouster in Shetland (Whittle et al. 1986) and a small number of sites on Arran (Barber 1997), although the dating of the latter is less secure and, as discussed in Section 3.3.7, much of the evidence that had previously been assumed to be of Neolithic date actually belongs to the Bronze Age. At Scord of Brouster, intact field systems were discovered preserved beneath peat, together with evidence of domestic dwellings and macroscopic remains of domesticated plants and animals. Similarly, the Arran field systems are associated with clearance cairns, small buildings and linear marks suggesting ard tillage. Ard and spade marks are also present at the Links of Noltand in the Late Neolithic period, where a ditch rather than a wall was used as a boundary (Clarke and Sharples 1985). A possible Early Neolithic boundary ditch is also known from Shurton Hill in Shetland (Whittington 1978). Collaborative proxy evidence of land clearance events exists 
in the form of pollen records (discussed elsewhere) and lake sediments, which reveal discrete episodes of soil erosion during the Neolithic, probably caused by land clearance and tillage for early agriculture (Edwards and Whittington 2001).

Outstanding research questions:

How much can we say about the diet land lifestyle) of people in the Neolithic? The synthesis of environmental information, pollen and excavated material is invaluable, but the development of lipid, isotopic and other forms of analysis that can shed light on diet, mobility, cooking and consumption will potentially offer an invaluable tool. What people ate is of course important (and has some bearing on the transition to the Neolithic) but the variability of food consumption based on age and gender may well become more apparent through further analysis of bone assemblages, pottery and even lithics from past excavations.

\subsection{Human remains}

\subsubsection{Biological anthropology}

Palaeopathological studies of human remains sometimes yield information on diet. Marks and irregularities on human bones and teeth can evidence metabolic diseases, which are caused by the absence of certain nutrients in the diet at discrete episodes during the life of the individual (Larsen 1997, 40-5; Roberts and Manchester 1995 166-80). Despite a significant quantity of human remains from Caithness, Orkney and Arran, relatively little of this kind of research has hitherto been undertaken, although major studies of the human remains from Isbister (Lawrence 2006) and Quanterness (Schulting et al. 2010) chamber tombs have been undertaken, with very interesting results.

Dental pathologies are directly related to diet. The presence or absence of dental caries is often cited as an indicator of carbohydrate richness. Among prehistoric populations globally, the teeth of agricultural populations are more frequently infected by caries than those of hunter-gatherers, for example (Larsen 1995). There are, however, many exceptions to this rule, including Scottish Neolithic sites, where caries is infrequently observed, occurring in $1 \%$ or less of teeth (Chamberlain and Witkin 2003; Chesterman 1979; McLaughlin 2008 see also Dommett et al. 2000). Such low rates of caries probably reflect a very abrasive diet and the absence of sugar-rich foods such as honey (Larsen 1995).

Dental wear can indicate the overall abrasiveness of diet although since it is also used as an indicator of age at death, its applicability is limited unless the ages of the individuals concerned can be controlled, which is currently very difficult with Neolithic material. Dental microwear analysis offers a more detailed view of food as an abrasive agent; quantitative analysis of microwear fabrics give an insight into the size of the particles and offer some idea about the foods that caused them. McLaughlin (2008) analysed human remains from sites in Orkney (Quanterness, Holm of Papa Westray North), Caithness (Tulach an t'Sionnaich and Tulloch of Assery A and B), Sutherland (Embo) and Arran (Clachaig, Torlin). The similarity of dental microwear fabrics of Scottish Neolithic individuals to those of samples from elsewhere in Britain and Europe suggests a wear agent that was common to the foods of the majority of these people. Given that Neolithic microwear patterns tend to be dominated by large, coarse scratches, the likely candidate to be this wear agent is grit from stone tools used to processes food such as cereal crops. Interestingly, samples from Neolithic sites on Arran also displayed fine scratches, which may be explained by the presence of fine-grained volcanic rocks nearby, if these were used as grinding tools. Hence dental microwear suggests tentatively that stone-ground cereal foods were an important dietary component in Neolithic Scotland (and elsewhere), although more work is needed to attempt to correlate the microwear patterns with artefactual evidence 
of food-grinding tools from Orkney, Arran and Caithness.

\subsubsection{Stable isotope analysis}

Stable isotope analysis investigates the composition of the protein component of human bone, hence ultimately the protein component in the diet of each human individual analysed in this way. Carbon-13 analysis can discriminate between the different types of plants that fix carbon from $\mathrm{CO}_{2}$ in the atmosphere or in water in different ways, thus providing a very useful indicator of terrestrial versus marine based diets. In addition to this, nitrogen isotopes can be used to investigate the tropic level of the food in the diet (e.g. meat versus plant consumption), although a sample of similarly dated herbivore and carnivore bones from the same area as the human remains are needed to fully interpret the results. Staple isotope analyses of Scottish Neolithic individuals has been performed on samples from Holm of Papa Westray North, Clachaig, Cultoquhey, Glecknabae, Haylie House, Rattar, Torlin and Embo (Schulting \& Richards 2002; 2009; Schulting n.d).

With the exception of Holm of Papa Westray North, all the Neolithic individuals analysed had terrestrial diets, with little detectable input from marine food resources. The Holm of Papa Westray North individuals do however show a slight contribution from marine protein in their diet, although this may be the result of consuming sheep whose own marine protein levels were elevated due to the consumption of seaweed as fodder ( $R$. Schulting pers. com.; cf. Balasse et al. 2006). Nitrogen isotope analysis suggests that meat or dairy produce, rather than plants, were the dominant sources of dietary protein (Schulting \& Richards 2002). One possible complicating factor in the interpretation of stable Nitrogen isotope data is the effect of manuring cereal crops, and the resulting enrichment of nitrogen-15 in the food (Bogaard et al. 2007), although the understanding of this phenomenon is still at an early stage. Work to assess its effect is currently underway.

The discovery that Early Neolithic individuals (and indeed most Neolithic individuals studied from Scotland, as elsewhere in Britain and Ireland) had a predominantly or wholly terrestrial diet, in contrast to the Mesolithic inhabitants of these islands, has been a major element in the debate about the nature of the Mesolithic-Neolithic transition, with Schulting \& Richards interpreting the sudden and radical dietary shift as evidence for immigrant farmers (e.g. Schulting \& Richards 2002); others taking issue with this (e.g. Milner et al. 2004) and rebuttals being made (e.g. Richards \& Schulting 2006). The evidence from coastal areas does, however, appear to support the idea of a radical change, and a 'turning of the back to the sea', even if, several centuries later, some farmers did choose to exploit marine resources.

\subsection{Conclusions}

Each indicator of Neolithic subsistence discussed above addresses a different aspect of diet or dietary behaviour on differing scales, thus each has inherent biases and weaknesses. Furthermore, each is dependent, to some degree, on the state of preservation of the material to be analysed. This situation can make it difficult to compare two or more proxies in a valid way and it is impossible, in most cases, for one proxy to be used as an independent check on another one. Bearing these issues in mind, it is still possible to make a number of conclusions based on these data.

Central to the question of Neolithic subsistence is the question of cereal cultivation. Cereals are known from a wide range of different type throughout the Neolithic period in Scotland, and continue to be discovered regularly. Their importance as a food is also suggested by dental work, and corroborative evidence exists in the form of field systems, indicators of soil tillage, and quern stones. Known examples of which tend 
to date to the later part of the Neolithic, introducing the possibility that cultivation practices were forced to respond to the centuries of damage caused by intensive agriculture and erosion in the earlier phases of the Neolithic. This may be stretching the available evidence to a considerable degree, but it highlights the central fact that cereal cultivation cannot be dismissed as a marginal activity, rather it probably played a pivotal role in the structure of society and economy, from the beginning of the Neolithic onwards-an hypothesis that future work will continue to test with AMS dating of the cereals themselves and stable isotope studies of manuring practices.

The patterns of cereal agriculture and domestic animal exploitation are markedly similar. Evidence for each is both as geographically widespread as the available data allows and occurs throughout the period of interest. Sheep and cattle were the most important animals in Neolithic Scotland (or rather Orkney and Harris, as data from elsewhere are largely unavailable), especially cattle when meat weight rather than bone frequency is considered. Pigs were apparently relatively unimportant, in contrast to sites in Southern Britain, perhaps reflecting the environment and lack of forest cover. Unlike sheep and cattle, pig farming does not involve the production of secondary products, so perhaps animal husbandry practices were deliberately structured in this way.

Wild food resources were exploited too, the evidence for this is irrefutable, particularly considering the abundance of hazelnut shells, deer, seal and fish bones and shells at a number of sites. Yet in coastal areas, as noted above, stable isotope studies of human bone is unable to detect much significant input from marine protein. It is not easy to understand why fishing and the rich food resources of the sea became so very much less important in the Neolithic. As Parks (2009) suggests, the lack of seasonality in Orcadian Neolithic fishing may be due to the fact that certain species are only abundant in the autumn, hence conflicting with the labour requirement of the cereal harvest.

It is clear that much of the above discussion is heavily geographically biased, especially towards Orkney. This is perhaps unavoidable at present. Future work with lipids and plant macrofossils has the potential to address this issue and provide a space-time model of subsistence practices in Neolithic Scotland that is not as geographically imbalanced. Indeed, a recently-completed major research project at the University of Bristol, 'Changing patterns of marine product exploitation in human prehistory via biomarker proxies in archaeological pottery' (NERC-funded), has been doing just that with its lipid analysis of a considerable number of samples of Neolithic (and later) pottery in various parts of Scotland.

\subsubsection{Outstanding research questions}

While our understanding of Neolithic diet and farming practices has increased significantly over the last two decades - especially through the application (over the last decade) of isotopic and lipid analysis - there nevertheless remain fundamental gaps, as follows:

- We know very little about the specific cultivation practices and herding strategies of these farming groups, and our list of cultivated plant materials may well be incomplete

- Flax has been noted at Balbridie, but to what extent was it cultivated, and was it principally a food crop (as opposed to a source of fibres for fabric manufacture and cordage)?

- How typical or atypical is the Orcadian evidence for subsistence strategies?

- How do deer fit into the equation? It has been suggested that they may have been deliberately introduced to the Orkney Islands, just as they had been introduced to Ireland, but do they constitute a partly-managed, partly-wild resource? How is the enigmatic evidence from the Links of 
Noltland - where a pile of deer carcases had been left, unscavenged and with a large fish on the top of the heap (Sharples 2000) - to be explained?

- To what extent were marine resources used as foodstuffs at different times and in different parts of Scotland?

- Is the elevated nitrogen isotope level that has been found in human remains in Orkney an indicator of the practice of manuring?

\subsection{Places to live and ways of living}

\subsubsection{Introduction}

One of the enduring questions we have about the Neolithic people who inhabited Scotland is: where were they living? On this face of it, this seems like a simple question, but underlying it is a complex range of evidence which suggests this question cannot easily be considered without recourse to thinking about wider economic and subsistence patterns. (See above.). Any research framework for Scotland's Neolithic has to answer this question, but also consider related issues (often downplayed in Neolithic studies): What was it like to live in the Neolithic? What happened on a daily basis? Can we identify the 'domestic' in the archaeological record, and what might it look like? In this section the range of evidence available for domestic structures and everyday life in the Neolithic in Scotland will be reviewed.

\subsubsection{The problem with Neolithic houses}

There is no doubt that people in the Neolithic of Scotland were living somewhere, but exactly where, and in what type of structure, has become a subject of some debate within Neolithic studies for Britain and Ireland as a whole (cf. Darvill and Thomas 1996; Gibson 2003). From the outset of Neolithic studies, there was an expectation in some quarters that Neolithic settlement in Britain and
Ireland would look rather like the timber longhouse settlements that defined the early Neolithic Linearbandkeramik of central Europe. A lack of any apparent traditions of timber building gradually eroded this confidence. For instance, in a wider review of prehistory in Europe, Piggott (1965) depicted Continental Europe as a farming economy defined by houses, fields and enclosures. However, his review of the Neolithic in England could depend only on ceremonial and burial monuments, structure associated with cult activity, not everyday life. Nonetheless, the expectation of a Neolithic of farmhouses, fields and sedentism continued to prevail until recent decades (Bradley 2003; Gibson 2003). The lack of buildings discovered in the archaeological record was explained in a number of ways (Darvill 1996). For instance, Kinnes (1985) suggested that virtually no Neolithic buildings had been found in mainland Scotland because the nature of these buildings may have left little or no traces in the archaeological record.

Despite the excavation of the unusual 'village' at Skara Brae, Orkney, little progress was made in identifying wider patterns of settlement in Scotland, in particular mainland Scotland (Barclay 2003). The excavation of a cropmark site, at Balbridie, Aberdeenshire in the 1970s (Fairweather \& Ralston 1993) offered some comfort for those looking for Continental-style longhouses in Scotland, although the nature and function of this and similar buildings is still disputed. However, with an absence of many other comparable structures in mainland Britain as a whole, and within the context of a new ideological model of the Neolithic developed in the 1980s, the absence of evidence gradually began to be taken as substantial evidence for absence. Subsistence models were developed that suggested that (early) Neolithic farmers were at least semi- (if not wholly) mobile, moving between temporary camps and monuments. This position was not viewed as being mutually exclusive with low level cereal farming and animal herding. This position became known as the 'mobile Neolithic 
hypothesis' and became something of an orthodoxy among some people by the mid 1990s (eg Thomas 1996; Gibson 2003 and see Barclay 2001). Within this context, use of 'loaded' terms such as 'farm', 'house' and 'domestic' were avoided, and replaced with more neutral terms such as 'building' and 'structure'.

More recently, evidence from developerfunded excavations (and to a lesser extent aerial reconnaissance) in both Ireland and Scotland has lead to arguments that a mobile Neolithic model may not be appropriate for Britain and Ireland (cf. Cooney 2003; Barclay 2001; Cross 2003; Smyth 2006). As we shall see, in Scotland a wide range of putative settlement sites and buildings have been identified, which suggest different degrees of sedentism may have been the norm in Neolithic Scotland, with clear regional variation (Brophy 2006). There is still a realisation that expecting to find wholly domestic activity may be inappropriate for Neolithic contexts, but also recognition that ritualised aspects of buildings, pit digging and deposition do not preclude their association with everyday life and daily routine. For the remainder of this section, then, evidence for a range of possibly domestic sites will be considered from across Scotland, from the unique to the typical.

\subsubsection{Island living, stone houses}

Scotland is fortunate to have world-famous and exceptionally well preserved houses built from stone. Unfortunately, these have a limited distribution, being found almost entirely in the Northern Isles. The study of stone houses and 'villages' contrasts sharply between Orkney and Shetland; while the former has been the focus of various high profile excavations, the resource in Shetland remains largely 'untapped'. There are also a series of important and distinctive Neolithic settlement sites in the Western Isles.

A number of Neolithic settlements have been excavated in Orkney. These are largely dated to the later Neolithic, although early Neolithic precursors to later house forms include Knap of Howar, Papa Westray (Ritchie 1983) and Wideford, Mainland (unpublished). The later Neolithic 'village' site of Skara Brae (Childe, 1931; Clarke 1976, 2003) is well known, but to this must be added an impressive list of other settlement sites that have been excavated on mainland Orkney - Barnhouse (Richards 2005), Stonehall, Crossiecrown and Ness of Brodgar (all as yet unpublished). Other island settlements excavated include Pool, Sanday (Hunter 2000), the Links of Noltland, Westray (cf. Clarke \& Sharples 1985) and Rinyo, Rousay (Childe \& Grant 1939). These clusters of buildings represent long-lived multi-phase settlements, and the stone construction of the buildings has facilitated a general understanding of the layout of the later Neolithic house in Orkney. The small buildings were arranged around a central hearth, with evidence for beds and storage space (e.g. 'dressers' and cupboard space) in some buildings. A series of atypical or specialist buildings - workshops, double houses, 'shrines' and large communal buildings - has also been identified at various sites. The houses within these 'villages' have different arrangements; at Skara Brae the houses were closely clustered and connected by low passages (semi-subterranean, surrounded by midden), while at Barnhouse the houses were slightly more dispersed and arranged around a central yard. Settlements were also characterised by long-term use, repairs and replacement buildings.

The survival of these buildings, either preserved beneath sand (Skara Brae) or in the ploughsoil (Barnhouse, Ness of Brodgar), has allowed some insight into their architecture. The buildings were typically constructed of local flags, with orthostats and slabs defining furniture. Buildings at some sites are embedded within midden material, giving a semi-subterranean effect. There is no indication of roof form or material, but the houses are presumed to have had pitched roofs, perhaps with timber supports and lined with turves, straw or seaweed. The nature of 
the buildings has generally been accepted as domestic; typical buildings would have housed a small family group. Richards (2005) has argued that these domestic spaces embodied a shared cosmology within their architecture that can also be recognised at the contemporary ceremonial and burial monuments of Orkney.

As with evidence for diet and subsistence, a disproportionate amount of information we have about Neolithic settlement in Scotland is based on Orkney. The potential for more buildings and settlements is clear, but perhaps a still greater untapped potential exists in Shetland. Calder (1950, 1956) initially highlighted a remarkable quantity of possible Neolithic stone buildings and associated fieldsystems across Shetland, obscured by peat and later settlement and farming - although, as we have seen in Section 3.3.7, many of these are more likely to be of post-2500 BC date. Calder identified 57 possible buildings, with a range of architectural forms. He also identified what he argued were related dyke / stone field boundary systems and clearance cairns, and he carried out basic excavations at a few sites. More recently, the Neolithic settlement at Scord of Brouster was excavated (Whittle et al 1986); once again, however, a critical reassessment of the evidence indicates that most of the evidence there is not of Neolithic date. (See 3.3.7.)

Although there is some variation in these structures, most are oval in plan (or 'heelshaped') with thick stone walls. There is little evidence for internal 'furniture' although some have central hearths and drains, while others have recesses arranged around the walls. Timber posts may have supported the roofs, with internal postholes found in some buildings. The most comprehensively excavated settlement, Scord of Brouster, consisted of three buildings, not all in use at the same time. Interestingly, not all buildings were of stone; Whittle et al $(1986,133)$ identified phases of timber building, 'flimsy transient shelters'. (Richards (pers comm) has identified early Neolithic timber round buildings at Wideford, Orkney mainland). There is still not a full understanding of the range of buildings identified, typified by enigmatic stone structures such as the Stanydale 'temple' (Calder 1950, Barclay 1996, 65-6), but such sites suggest that as with Orkney a range of specialist and perhaps ceremonial structures were constructed along the same lines as 'domestic' dwellings. One of the buildings at Scord of Brouster was interpreted as a pen or stock enclosure.

There is equal potential for settlement evidence in the Western Isles, in various forms, but often obscured (and preserved) both by machair and extensive later prehistoric and Norse settlement in the same locations (Armit 2003). Excavations have revealed very different looking settlements of Neolithic date. These include the remarkable site of Eilean Domhnuill, North Uist. This small islet was occupied within the time range 3650-2600 BC (ibid, 93) through a series of small rectangular buildings with stone foundations, probably turf walls, and central hearth, with associated animal pens, yards and surrounding palisade. This island could only have been occupied seasonally. On Harris, Neolithic / Beaker structures were excavated at Northton in 1965-66 (Simpson \& Murphy 2003; Simpson et al 2006); the house forms are similar to Eilean Domhnuill. A key characteristic of the Neolithic settlement sites known in the Western Isles is that they usually form only part of very long (several millennia) sequences of occupation, with Neolithic 'phases' at sites such as Alt Chrysal and Bharpa Carinish (ibid).

\subsubsection{Timber 'halls'}

Most Early Neolithic buildings in Britain and Ireland that could have had a domestic role were made of timber and were rectangular in form (cf. Darvill 1996; Smyth 2006; Brophy in prep). However, within this form, there is considerable variation in size, construction style and function, even within Scotland. 
At the larger end of the scale, a small group of rectangular timber halls have been identified as cropmarks by aerial reconnaissance since 1976. There are potentially as many as ten such sites known in the cropmark record, and four have now been excavated: Balbridie, Aberdeenshire (Fairweather \& Ralston 1993), Claish, Stirling (Barclay et al 2002), Warren Field, Crathes, Aberdeenshire (Murray et al.2009) and Lockerbie Academy, Dumfries and Galloway (Kirby 2011). These buildings share remarkable similarities, but it is by no means certain that they fulfilled a wholly domestic role. Balbridie for instance has been characterised as anything from a Europeanstyle longhouse to a cult house or feasting hall. All were in use at the very start of the Neolithic, c 3900-3700 cal BC, and were all burnt down (Brophy 2007).

The excavations of these sites have given a good impression of their scale, and the use of space within these buildings. Typically, these buildings have a ground plan in the order of up to $25 \mathrm{~m}$ in length and $12 \mathrm{~m}$ width, usually with slightly rounded ends. There is no evidence for roof height or form, but there is a suggestion that the roof could have had a maximum height of $8 \mathrm{~m}$ at Claish and Balbridie (Barclay et al 2002). The buildings were constructed from large oak posts; in the case of Balbridie these were set into a foundation trench. These may have been supplemented by wattle and daub outer layer, or turf (Loveday 2006), but there is no strong evidence for this. At Claish, there was a suggestion that the walls were repaired, with a few instances of post replacement. Roof support would probably have fallen on internal posts rather than the side walls, and internal divisions and large axial posts were found at all four excavated sites. Some of these divisions may have been in the form of continuous panel. Entrance to the buildings was typically through entrance gaps on one or both short end walls, although these entrances were often narrow, perhaps even awkward. An open 'yard' area may have existed at one end of Warren Field and Lockerbie Academy.
Little evidence was found within these buildings for what was going on inside them. Each was associated with Carinated Bowl pottery, although this in itself does not indicate domestic activity. Hearths, or at least burning pits, were found within all buildings, but floor surfaces were not recovered. Internal divisions suggest that space was ordered within each building, perhaps with 'rooms'. It could also be imagined that the roof space was utilised for storage, and perhaps an upper 'floor' was created. It is certainly possible to imagine an extended family (and perhaps animals) living in such a building, although it could also have been used for temporary accommodation (Brophy 2007) or even feasting (hosting up to 50 people (Ashmore 1996)).

However these remarkable buildings are viewed (and there are certainly a few other potential candidates in the cropmark record in eastern Scotland such as Noranbank, Angus and Sprouston, Borders) they seem to have been unusual, not typical, early Neolithic structures. As spectacular buildings, perhaps in wide woodland clearances (Lancaster et al. 2009), they would have been an enduring and imposing permanent presence in the landscape. Cross (2003) has argued that these 'halls' may have acted as a kind of equivalent of causewayed enclosures, permanent structures within a mobile and dispersed early Neolithic population.

\subsubsection{Camps and timber-built buildings}

If timber halls were unusual structures, perhaps nodal points in the landscape, and belonging to the very beginning of the 'Carinated Bowl Neolithic', where were the majority of people living? There is certainly evidence for smaller scale, less permanent and imposing structures, across mainland Scotland. In various reviews of the evidence, Barclay (cf 1996, 2003) has listed a range of light timber structures, mostly found during developer-funded excavations or through test-pitting lithic scatters. Although again 
there is little inherently 'domestic' about these structures, they seem the best candidates for where Neolithic people were living, eating and sleeping. When found, these buildings often take the form of a collection of post-holes, stake-holes, pits and possibly hearths, and sometimes an intuitive 'join-thedots' approach is required to make sense of this apparent disorder.

In some cases, these could be interpreted as no more than campsites (overnight or periodically used). Examples of these have already been discussed in theme 3 (e.g. at Auchategan, Argyll \& Bute). Slightly more sturdy structures have been found in greater quantities. The majority seem to be rectangular in plan, with light timber frames, such as Kinbeachie Farm, Highland (Barclay et al 2001) and Biggar Common, South Lanarkshire (Johnston 1997). A number of undated rectangular structures have also been tentatively interpreted as Neolithic houses, such as Kingarth, Bute (Mudie \& Richardson 2006) and Ratho Quarry, Edinburgh (Smith 1995). In themselves, this small group of negative features does not amount to a tradition, but suggests that there were light timber-framed buildings in Scotland in the Neolithic. Some are associated with central hearths, and most are in a range of $5 \mathrm{~m}$ to $10 \mathrm{~m}$ in length. There is little idea of the permanence or otherwise of these structures, but they conceivably could have held a small family group for a number of years, or at least been returned to seasonally. Several oval to round buildings have also been found recently, notably Beckton Farm, Dumfries and Galloway (Pollard 1997) and Cowie, Stirling (Atkinson 2002). In both cases, these later Neolithic settlements consisted of multiple phases of sub-circular stake-built structures, with palisade slots and central hearths. The double walls at Cowie may be associated with insulation or storage.

The paucity of evidence for 'everyday' houses and settlements is somewhat alleviated by a larger body of data in the form of pits. Pits in themselves are not indicative of settlement, and indeed can be interpreted as evidence for ritual activity. However, they also sometimes contain material which could be interpreted as domestic refuse, and are repositories of good environmental evidence. Developerfunded archaeology has allowed a wide range of Neolithic pits to be found across the Scottish mainland, often in isolation. In the period 1985-2005, over 50 Neolithic pits or pit groups have been found across Scotland (Brophy 2006, 22). Pits have been found that contain cereals, various types of pottery, polished stone axe fragments, smashed quern stones and so on. Although interpreting pits is difficult, there is little doubt that they offer a picture of a general low level of inhabitation of the wider landscape, sometimes found in association with the largest monuments, sometimes with the smallest 'domestic' timber buildings. Pits could be viewed as indicative of a range of behaviour and individual actions in the Neolithic, from the explicitly ceremonial to casual rubbish disposal; it is often difficult to differentiate the two in the archaeological record (Pollard 1997; Brophy 2006).

\subsubsection{Everyday life during the Neolithic}

There is currently a basic understanding, then, of the kinds of structures that people were living in during the Neolithic. This range of buildings reflects different temporal scales of settlement, from permanent houses to shortlived campsites. Aside from the buildings themselves, though, what other information have settlement sites provided about everyday life? Aspects of subsistence have been discussed above (Section 4.1). Although virtually no field systems have been associated with any houses or buildings outwith Shetland, much evidence for diet has been found associated with settlements. Other activities that might be imagined were being carried out at settlements - pottery manufacture, lithic knapping and other craft activities are covered elsewhere (theme 5), although again direct evidence for this is limited. It might also be naïve to expect to find evidence for such activities within 
houses; it may have been more appropriate for them to happen at arms' length from houses (Whittle et al 1986, 136) or in specialist buildings or areas of a settlement. One such structure has been suggested as a locus for knapping at Skara Brae, while the occasional presence of burnt lumps of potter's clay in settlements confirms that potting was carried out in the vicinity of dwelling structures, if not inside them.

Whittle (2003) has considered what he called the 'daily round', evidence for the kinds of activities Neolithic people were carrying out in and around settlements. In one sense, these routines are what most interest archaeologists, and yet are very difficult to get to through the archaeological record. For instance, outside of Orkney, there is virtually no evidence for sleeping arrangements or for a range of bodily functions, from eating and drinking (for food, see Section 4.1), to sleeping or expelling bodily fluids. Stone bed spaces have been identified at several Orkney settlements including Skara Brae and Barnhouse. These box-like beds are defined by orthostats and will have held organic bedding of some kind. A further model, based on post-medieval Scottish examples, could see such as space as being used for sleeping for a group of individuals, rather than one person as Childe imagined (1931). The socalled 'dressers' found within some Neolithic houses in Orkney seem to have served a storage or display function; this may though have been more subtle than displaying 'best Grooved Ware', and instead acted as a ceremonial focus (or shrine?) for the occupants of the house. No such furniture has been identified at any non-stone Neolithic building (or indeed any floor surfaces) in Scotland although the presence of possible box beds and furniture in some houses excavated beneath Durrington Walls henge, Wiltshire suggests that features are not impossible to find in timber structures (Parker Pearson 2007).

Evidence for toilet activities is still rarer. The usual environmental analysis of the fills of pits associated with, or near, settlements may not pick up traces of such activity, but pits may be one element of this aspect of everyday life. While a high quantity of organic material was found within Pit 1, Cowie, this feature was probably Mesolithic (Atkinson 2002); phosphate analysis of pit fills at Cowie has not been repeated at many other sites. Childe $(1931,18)$ argued that recesses in the corners of buildings within Skara Brae may have been used as 'privvies', although this idea has been dismissed by Richards (2005, 123; in contrast, see Clarke 2004). However, a complex series of drains discovered at Barnhouse led Richards to suggest that the inhabitants of the village had a specific concern with disposing of liquid waste, as well as channelling rain water (2005). Drains were also found at Skara Brae and Rinyo. Ultimately, such activities may have taken place in the woodlands that surrounded many Neolithic settlements in mainland Scotland (cf. Whittle 2003).

Activities and movement within buildings may be possible to identify in instances of exceptional preservation (e.g. hollows associated with squatting beside a hearth at Durrington Walls) but as yet no such evidence has been found in Scotland. Certainly, where floor surfaces or evidence survive, houses seem to have been arranged around firespots or hearths. Evidence for in situ burning in hearths in Orkney, as well as the so-called 'fire-pit' within Claish timber hall, suggest that these buildings may well have been smoky places. Logic dictates that opening in the roof or 'chimneys' were unlikely, and it is more likely that smoke would have been able to dissipate into roof spaces. Both wood and peat were burned within hearths at Scord of Brouster (Whittle et al 1986, 133) while there is also a possibility that some stone 'troughs' within Orkney houses may have been associated with heating stones for cooking. Interestingly, the discovery of 'hearths' outwith buildings at Barnhouse and Beckton Farm suggests that some activities based around fires - cooking, storytelling, crafts may have been communal in nature; the external hearth at Barnhouse for instance was 
very large and on the edge of the settlement (Richards 2005). Fires within houses may not have been used for cooking. Without the presence of lit fires, these buildings are likely to have been dark and cold places for much of the year, although presumably watertight. Fires would have served other roles as well; smoking and preserving food stored in the roof space, keeping insects at bay, ceremonial burning and so on.

The subdivision of space at a range of buildings - from timber halls to the Orkney houses suggests differential use of space within these structures, perhaps rooms. Topping (1997) has argued that such spatial divisions may have had social or ideological meaning, although there may have been more prosaic reasons for dividing up space (e.g. animals in the building). In a society where there probably would have been no clear divisions between ritual and domestic, houses may well have been a focus for routine and ritualised actions, non-domestic activities, deposition and ceremonial activities, activities which may have been private. Evidence for such activities has found at a range of Neolithic buildings in Scotland. The deposition of large quantities of grain at both Balbridie timber hall and Barnhouse house 8 have been interpreted as either offerings, or indicative of a grain storage role (and both are huge buildings). Pollard (1997) and Atkinson (2002) have both developed ideas of routine and ritual deposition and activity within a settlement context; the two may not have been distinct in the Neolithic. Further boundaries may have been eroded with the placement of human remains in 'domestic' contexts, attested to in various forms at Skara Brae, Beckton and Raigmore.

\subsection{Conclusions}

When everyday life in the Neolithic is considered, there are more questions than answers. The key outstanding research questions can be identified as:
- More better-preserved structures need to be found outside of the Northern Isles, in order to correct the current geographical imbalance in the evidence

- Within Orkney, the early timber buildings need to be understood more fully

- What range of structures were used for habitation at different times during the Neolithic, and how do these relate to overall patterns of land use and subsistence? Can any patterns relating to social differentiation be identified in the domestic arena?

- There is clearly a regional tradition of building with stone in areas where timber was scarce; but can other regional traditions be identified? To what extent was peat used as a building material?

- Can we identify any trends over time in either the shape and layout or construction of dwelling structures?

- Can activity areas and 'taskscapes' be identified with greater clarity?

- Can we identify socially meaningful and ritualised activities within settlements?

\subsection{Landscape, Environment, Climate}

\subsubsection{Climate and Climate Change}

Natural climate change is characterised by infrequent but rapidly initiated, short-lived but global or hemispheric excursions (Mayewski et al. 2004) which exceed anything within normal human experience (deMenocal 2001; Mitchell 2008). Events in prehistory were centred on c. 6200, 4000-3800, 22002000 and $1000-800$ BC. The beginning and end of the Neolithic period are bracketed by two of these.

Narratives are dangerous because of the absence of precise temporal correlations, so that cause and effect, cannot always be recognised, and because there may have been delayed responses in some systems. 
Nevertheless the following story, with time expressed as cal years BC, might be constructed. The period 5400 to $4000 \mathrm{BC}$ was 1-2 ${ }^{\circ} \mathrm{C}$ warmer than present in NW Europe (Davis et al 2003): temperature fluctuations within the Neolithic period are from a warm 'baseline'. NW European soils became wetter from around $5050 \mathrm{BC}$, more so after $4750 \mathrm{BC}$ (Hughes et al. 2000; Nesje et al. 2001; Spurk et al. 2002; Langdon et al. 2003; Blaauw, van Geel \& van der Plicht 2004; Magny 2004). Icerafting in the northern North Atlantic Ocean was earlier at $4700 \mathrm{BC}$ (Moros et al 2004) than the same effect off western Ireland at c. 4350 BC (Bond et al 1997), coincident with accelerated sedimentation and lowered seasurface temperatures in the southern Irish Sea and off Ireland (Keigwin \& Boyle 2000; Scourse et al. 2002; Marret, Scourse \& Austin 2004). Thermohaline circulation was possibly weakened (Broecker 2000; Oppo, McManus \& Cullen 2003; Thornalley, Elderfield \& McCave 2009).

The northern hemisphere cooled at $4500 \mathrm{BC}$ for c. 400 years (Karlen \& Larsson 2007), possibly principally felt in lower winter temperatures (Davis et al 2003). Increased frequency and intensity of westerly meridional winds by $4450-4400 \mathrm{BC}$ led to greater storminess around the North Atlantic Ocean, seen in loess and sand-sheet/dunebuilding around the North Atlantic Ocean (Noren et al 2002; Wilson et al 2004; Jackson et al 2005) and erosion in coastal archaeological stratigraphies (Peeters 2009), most noticeably after 4000-3800 BC (Keatinge \& Dickson 1979; Gilbertson et al 1999; Bjorck \& Clemmensen 2004; de Jong et al. 2006; Melton 2008, 2009). Geomorphological evidence for increased storminess contrasts, however, with biological evidence from western Scotland for quiescence at this time (Birks \& Williams 1983; Andrews, Gilbertson \& Kent 1987; Andrews et al 1987; Russell, Bonsall \& Sutherland 1995; Sugden 1999).

By 4350 BC soils were increasingly arid (Hughes et al. 2000; Nesje et al. 2001; Spurk et al. 2002; Langdon et al. 2003; Kalis, Merkt \& Wunderlich 2003; Blaauw et al. 2004). A c. $2{ }^{\circ} \mathrm{C}$ fall in mean July air temperatures at 4200 BC in northern Scandinavia (Grudd et al 2002; Helama et al 2002) might have lowered evapotranspiration rates, leading after 4100 $B C$ to wetter ground conditions. Temperatures ameliorated after c. 4100-4000 BC (Cheddadi et al 1997; Grudd et al 2002; Karlen \& Larsson 2007).

A lull of a few centuries in the rate or intensity of climatic change is suggested in some datasets. Relative aridity intensified after 3800 BC (Hughes et al. 2000; Nesje et al. 2001; Spurk et al. 2002; Langdon et al. 2003; Blaauw et al. 2004) as NW European air temperatures became very warm (Karlen \& Larsson 2007). $A$ fall in air temperatures in northern Scandinavia at $3700 \mathrm{BC}$, with a much steeper fall at 3650 BC (Grudd et al 2002; Helama et al $2002)$ is associated with wetter soils after $c$. 3650 BC. Dune building recurred at c. 39503700 BC (Gilbertson et al 1999; Bjorck \& Clemmensen 2004).

Atmospheric circulation in the North Atlantic had weakened by 3400 BC (Bond et al 1997, 2001) and became stable for a few centuries. However, around 3200-3100 BC was a cluster of dune-building events on coasts facing the northern Atlantic (Caseldine et al 2005; de Jong et al. 2006; Holmes et al 2007). Summer temperatures in northern Scandinavia continued to fluctuate, falling at $3200 \mathrm{BC}$ and recovering at 2900 BC (Grudd et al 2002), after which it became very warm (Karlen \& Larsson 2007). Major climatic variations in the later Neolithic to $c .2200 \mathrm{BC}$ appear fewer save for wetter soils after c. $2500 \mathrm{BC}$ and an increase in dune-building after c. $2300 \mathrm{BC}$.

\subsubsection{Knowledge gaps}

Some parts of the research community are making deterministic connections between climate and cultural change (Baillie 1995; Mayewski et al. 1996; Bogucki 1998; Sandweiss, Maasch \& Anderson 1999; 
Berglund 2003; Brooks 2004; Bonsall et al. 2002; Tipping \& Tisdall 2004; Gronenborn 2005, 2006; Turney et al 2005). It is essential to accept determinist arguments at their face value and to resist the impulse to reject them 'in principle'. At present the connections between climate and culture in prehistory are largely only temporal associations. Testable hypotheses need to be developed that can identify the physical, ecological, economic and social mechanisms driving change. Bonsall et al (2002) proposed an expansion in the late Mesolithic of opportunities for pastoral farmers as climate became drier but this change would also have benefited huntergatherers, making it hard to see why lifeways should change. Tipping (in press) and Tipping \& Tisdall (2004) suggested that climate change led to resource failure for late Mesolithic foragers, making the adoption of agriculture more tempting. There is little evidence so far for this (but there is little enough evidence for Mesolithic subsistence at all, let alone how it changed). The 'slighting of the sea' (Tauber 1981; Schulting 1998; Schulting \& Richards 2002; Milner et al 2004; Hedges 2004; Richards \& Schulting 2006) has been interpreted as a response to climatic stress in the North Atlantic Ocean (Tipping in press; Tipping \& Tisdall 2004) but its marked diachroneity across the Atlantic faćade (e.g. Lubell et al 1994) probably makes this unlikely. Changes in seasonality across Europe and through time need to be explored more (Davis et al 2003) because these will have affected the viability of crops in regions removed from south-west Asia as well as the availability of indigenous resources (Parks 2009). It cannot be assumed that present-day patterns existed in the Neolithic period.

Almost no palaeo-climatic data-set used above relates directly to Scotland, although each describes changes that will have impacted on Scotland. It cannot be expected that the archaeological community in Scotland should fund climatic reconstructions, but it can encourage the generation of highresolution proxy records readily achievable in Scotland such as reconstructions of summer temperature from Pinus sylvestris tree ring data (Grudd et al 2002; Helama et al 2002).

\subsubsection{Landscape and the Natural Environment}

Relative sea-level rise was either very slow or had effectively ceased by the Neolithic period (Shennan \& Horton 2002; Smith, Firth \& Cullingford 2002), making this factor unlikely to have influenced Neolithic communities in most areas (Armit 2003; Behre 2005).

Armit (2003) drew attention to the losses of land available to Neolithic farming communities through blanket peat spread. This is probably overstated (Mills et al (2003), although there are few localities in Scotland where blanket peat inception and spread have been systematically measured. Blanket peat inception seems to have occurred in the earlymid Holocene (Robinson 1987; Charman 1992; MacDonald et al 2006; Tipping 2008) and to have had climatic or pedogenic triggers. Once initiated, blanket peat continued to spread in and after the Neolithic period, but its spread does not seem to have accelerated within the Neolithic period. Blanket peat spread need not have confined human activities (Carter 1998; Tipping et al 2007). Behre (2005) argued that in north Germany early farming communities were confined by lowland raised mosses formed on marine mud as relative sea-level rise culminated but except for those in Aberdeenshire on older substrates (Tipping 2007) raised mosses cannot have significantly constrained human choice in Scotland.

The dominant vegetation cover of Scotland in the Neolithic period was woodland. Though present across much of the highlands by the Neolithic period, blanket peat seems not to have prevented tree growth in the way it can now, because it was still thin. Trees also in the main continued to live through the shortlived climatic fluctuations. There is currently no evidence that Scottish Calluna heaths developed via Mesolithic anthropogenic impacts in the ways suggested for English 
uplands (Simmons 1996). The distribution of major woodland types has been mapped at a broad scale by Bennett (1989), Tipping (1994) and Edwards \& Whittington (2003).

Rivers respond to landscape change. Analysis of data in Britain and Ireland has shown limited evidence for accelerated river activity at c. 4180, 3780 and 3590 BC (Johnstone, Macklin \& Lewin 2006): explanation of these is that they were climatic in origin. Disappointingly few catchments in Scotland have been investigated (www.aber.ac.uk/rivers/14c) but of these, few show extensive development of floodplains within the Neolithic period: an exception is the Carra Water in Kintyre (Tipping, Carter \& Haggart 1984). But it is clear that some rivers had floodplains as wide as today by the Neolithic, such as the Dee (Tipping 2007) and the Kelvin (Tipping et al 2008), providing the context for the possible burial of Neolithic landscapes beneath later alluvium (Howard \& Macklin 1999). Lacustrine sediments can also reflect landscape disturbance. The period 4000-3700 BC shows increased soil erosion (Edwards \& Whittington 2001) but Edwards (2004) advises caution in interpretation of this. Loch Olabhat is exceptional in the Neolithic period in showing such a phase from c. 3430 BC (Edwards et al 2000; Armit 2003; Mills et al 2003).

\subsubsection{Knowledge gaps}

It is important to know the pattern of relative sea level change after its peak at c. 4500 BC, to explain coastal settlement distribution patterns. There are two models, a steady decline to present sea level (Shennan \& Horton 2002) or a second period around $c$. 2000 BC of high relative sea level, the Blair Drummond Shoreline (Smith, Cullingford \& Firth 2000). New data suggest that this second event was the more important in some parts of Scotland such as Orkney (Dawson \& Wickham-Jones 2007) and Skye (Selby \& Smith 2007), but it is not yet clear whether relative sea level actually fell between c. 4500 and c. 2000 BC. As in riverine environments there is the potential in some areas for the burial of Neolithic archaeological landscapes, particularly in the Outer Isles, but at most places on mainland Scotland this is unlikely: for example, the Neolithic platform in the upper Forth Valley at Arnprior (Ellis et al 2002) which lies on but is not overlain by marine sediments.

There is almost no objective evidence from which to evoke the experience of living in or moving through a wooded landscape (Edmonds 1998, 1999; Evans, Pollard \& Knight 1999; Austin 2000; Brown 2000; Tipping 2003; Evans \& Hodder 2006). It is challenging to use palaeoecological techniques in reconstructing species compositions on spatial scales comprehended by people, or the canopy cover, or the spacing of trees and the extent of scrubby and thorny tangle. There are no 'fossilised' landscapes and no secure presentday analogues. The interplay between different techniques which inform on different aspects and scales of the woodland environment (Kreuz 2008), applied to the same landscape (e.g. molluscan assemblages (Dimbleby \& Evans 1974; Davies \& Wolski 2001; coleopteran assemblages (Robinson 2000; Whitehouse \& Smith 2004); on-site data on colluvial processes (Dreibrodt et al 2009)) will prove invaluable in the future, as might new palynological modelling approaches (e.g. Caseldine \& Fyfe 2006; Caseldine et al 2007) which create the spatial vegetation patterns that most plausibly explain pollen records. A related problem is intervisibility in a wooded landscape, ignored by most (Tilley 1994; Gaffney, Stancic \& Watson 1995; Gibson 2004) and circumvented by others (Cummings \& Whittle 2003), but which is critical in much archaeological conjecture relating to the cosmological and territorial concerns of ancient people. Knowledge of pollen recruitment now allows reconstruction in broad terms of the vegetation cover local to particular archaeological sites, but it is currently not possible to reconstruct tree density. A way forward might be to explore the spatial distribution of plant communities from soil pollen (e.g. Hannon et al 2008) 
because soil surfaces have the smallest, most local pollen recruitment areas, though care in identifying sealed contexts uncontaminated by more recent pollen is necessary (Tipping, Carter \& Johnston 1994).

Almost all deposition of alluvial sediments in Scottish rivers has happened since the Neolithic period. It therefore follows that in some environments there is a high probability of finding buried Neolithic archaeology and it must be a recommendation that this resource is explored in any archaeological strategy. It is, however, equally true that most erosion of pre-Neolithic fluvial terraces has occurred since the Neolithic and precautionary consideration of this in archaeological research strategies is also necessary. Localities where the present floodplain seems to have been the valley-floor in Neolithic times, such as the Rivers Dee (Tipping 2007) and Kelvin (Tipping et al 2008), need to be explored now. The critical interpretative problem in historical geomorphology remains the assignation of cause; whether autogenic, climatic or anthropogenic. The current paradigm, fed by metadata-sets, is that climate is the principal driver (Macklin, Johnstone \& Lewin 2005) but case studies are needed that draw on archaeological data and proxy data for the history of land use. More case studies are also needed that reconstruct the appearance of valley floors in the Neolithic period. As these factors are not yet known, experimental or phenomenological descriptions cannot be made upon any reliable basis, nor it is possible to describe how people used or negotiated riverine landscapes (Brown 2000). One model is that low-gradient rivers would naturally have been anastomosing systems with many thin channels threading their way between dense riparian woods (Brown \& Keough 1992): such reconstructions have very profound implications for seeing rivers as viable routes of communication.

\subsubsection{Changes in Woodland Cover and Composition}

More is known about what happened, and when, to the primary woodland than why. The possible impact of Mesolithic communities on these woods is unclear: if anthropogenic disturbance occurred at all (Tipping 2004) it was small in scale, localised, and was followed by complete tree regeneration, with perhaps a shift to hazel as the principal long-term effect (Turner, Simmons \& Innes 1993). At or near the Mesolithic-Neolithic transition there is evidence in southern and western Scotland that vegetation was less frequently burnt, the so-called 'charcoal fall': its is not known why.

New paradigms of climate change must affect any interpretations of vegetation change. In northern Scotland some populations of pine declined in the earliest Neolithic period, almost certainly through climatic impacts, though what these were is not known (Tipping et al 2008). The elm decline may be another example: its cause is not yet established and while disease remains for some workers the most plausible reason (Clark \& Edwards 2004), climate deterioration has emerged as increasingly relevant (Parker et al 2002; Edwards 2004). The elm decline no longer defines for most workers the beginning of the Neolithic period, because an anthropogenic cause for this is not currently widely supported. Nevertheless, statistical analyses of all ${ }^{14} \mathrm{C}$ dates suggest that the primary decline in Britain and Ireland began between 4393-4357 BC, very close to estimates for the adoption of agriculture. The decline ended, with elm trees probably being a rare component in woodland (Caseldine \& Fyfe 2006), at 3470-3340 BC (Parker et al 2002). The $c .1000$ year range means that individual elm declines need to be independently dated. Reductions in populations of oak trees commonly accompany elm declines as 'classic' landnam indicators but these need not be anthropogenic because precisely synchronous 'dying-off' events occurred in oak populations across north west Europe at 4350 and 3970 $\mathrm{BC}$, and later in the Neolithic period at 2820 and 2550 BC (Leuschner et al 2002). In parts of eastern and northern Scotland pine, elm 
and oak populations all died at the same time at the Mesolithic-Neolithic transition (Tipping \& McCulloch 2003)and the effect this had on Mesolithic perceptions of nature (Larsson 2003) needs to be considered.

People may have drawn on woodland resources without depleting them, with Rackham (1977) and Taylor (1998) arguing for Neolithic coppicing. No evidence has yet come from Scottish sites for woodland management but the use of split oak planks at Warren Field, Crathes (Murray, Murray \& Fraser 2009) demonstrates a very high level of skill in handling timber (see also Evans \& Hodder 2006).

Following Tipping's (1994) brief review of evidence in Scotland of mid-Neolithic woodland regeneration there has been no discussion from Scottish analyses and few new data that can add to the picture or test ideas such as those of Dark \& Gent (2001) concerning declining crop yields with time through disease. From Ireland, O'Connell \& Molloy (2001) noted widespread woodland regeneration, broadly synchronous from $c$. 3600-3200 BC, persisting until c. 2500 BC. No clear reasons were given by O'Connell \& Molloy (2001) save that regeneration may represent agricultural decline through declining soil fertility. There are few climatic changes at this time that might have deterred farming.

\subsubsection{Knowledge gaps}

Universal explanations are sought for what might have been highly contingent events, and it might be advisable to return to wellunderstood site-by-site interpretations. The elm decline, for example, was far more complex than the term implies, and multiple causes, each compounding the effect of others may be more realistic interpretations (Rackham 1980). The charcoal fall may have resulted from different causes depending on context. Edwards $(1988,1989,1998)$ saw this as possibly representing the cessation of Mesolithic manipulation of upland woods by fire as farming was adopted; Tipping \& Milburn (2000) found that the charcoal fall occurred in many environments and argued that fires were natural and ceased with the change to a wetter climate. New ways of understanding the detailed form of woodlands and of their management are needed: the Berglund model of contrasting changes in tree and non-tree pollen implies an adversarial relation between people and woods which is wrong.

It is striking how little recent attention has been given to mid-Neolithic woodland regeneration in Scotland: its potential significance, with its hint of agricultural failure, raises many questions.

\subsubsection{Proxy Data on the Earliest Agricultural Impacts}

Purported anthropogenic impacts on woodland may need to be re-interpreted because some landscapes may have been naturally open (Fenton 2008), clearings natural rather than anthropogenic (Brown 1997, 2000) and woods impacted by deteriorating climate. The critical observation must be in the recognition of positive indicators of land use and not in evidence for woodland loss, but all pastoral pollen indicators grow in natural grassland and their expansion in a pollen record may reflect only reductions in tree pollen. Microscopic charcoal alone is not an unambiguous indicator of human activity.

The least ambiguous indicator of agricultural activity is Avena/Triticum (oat/wheat) pollen, although Avena fatua is a wild grass. Hordeum type (barley type) and 'cereal-type' are ambiguous in what they indicate. Because elm declines can be of mid-Neolithic age, cereal-type pollen occurring before the elm decline need not be significant markers of either an 'invisible' Neolithic or precocious Mesolithic farming: all finds must in future be AMS ${ }^{14} \mathrm{C}$ dated. Cereal-type pollen continues to be reported, though outwith Scotland, from contexts immediately prior to $c .4400 \mathrm{BC}$ 
(O’Connell \& Molloy 2001; Innes, Blackford \& Davey 2003).

Excluding pre-elm decline examples, the earliest cereal type pollen record in Scotland currently known is of Avena/Triticum pollen at Achany Glen 2, Lairg (Smith 1998), from $c$. $4200 \mathrm{BC}$, but this is from a shallow and slowgrowing peat in which chronological precision is low. In general the earliest evidences come from the islands, on Orkney at c. $4100 \mathrm{BC}$ and c. 3950 BC (Bunting 1994, 1996) and c. 3950 BC near Skara Brae (de la Vega-Leinert et al 2007), on the Western Isles at c. 3950 BC (Mills et al 2003) and c. 3800 BC (Bohncke 1988). South of the Great Glen on the mainland, some oat/wheat pollen grains amongst many barley type grains at Warren Field, Crathes have a Bayesian-defined maximal age-range 3820-3700 BC (Tipping et al 2009), inseparable in age from the cache of carbonised grains at nearby Balbridie (Fairweather \& Ralston 1993) and within the age ranges defined by Brown (2007) from AMS ${ }^{14} \mathrm{C}$ dating of carbonised remains. These finds need not be the earliest even at the sites where they are recorded because cereal pollen has very limited dispersal, particularly in woodland, and there is a very high likelihood that single pollen grains will be missed in analyses where the temporal resolution is poor and the pollen sum is low.

\subsubsection{Knowledge gaps}

It must be borne in mind that pollen grains reported as of cereal type are from cultivated grasses. There have been strong criticisms of pre-elm decline cereal pollen from the potential for sample contamination, the imprecision of identification or incomplete reporting (e.g. Tipping 1995; O'Connell 1987; Bonsall et al 2002; Behre 2007; Brown 2007), which may have resulted in new finds being played down (Macklin et al 2000; Tweddle, Edwards \& Fieller 2005), as well as strong defences (Tinner, Nielsen \& Lotter 2007). Analyses must be more rigorous and the presentation of data much more comprehensive. Sediments must be analysed in thin, contiguous samples and to very high sums. 'Optimising' approaches wherein samples are scanned well beyond the total for all other grains (Edwards \& McIntosh 1988) is of uncertain value because this is a "seek and ye shall find" approach. Anomalously large grass pollen grains will eventually be encountered but does success really inform the debate? Multivariate statistical analyses of grass pollen grains might be useful (Tweddle et al 2005) although most finds will be of single grains, impossible to classify by such techniques. For individual finds, the medium in which pollen is embedded must be stated, the key/s used indicated, all size measurements reported, their preservation stated because size measurements are distorted by crumpling, photographs of grains published, SEM analyses of sculpturing perhaps standard, sediments directly $\mathrm{AMS}^{14} \mathrm{C}$ dated, and sufficient ${ }^{14} \mathrm{C}$ assays obtained to (a) identify anomalies and (b) apply wigglematched and/or Bayesian approaches to refining chronologies.

Stratigraphic approaches not using pollen might be pursued. A novel approach to the introduction of millet (Panicum miliaceum) in central Europe has used a species-specific lipid biomarker in lake sediments (Jacob et al 2009) but it may be telling that such lipid analyses suggest the same date of introduction as conventional plant macrofossil and pollen analyses. Ultimately, of course, some workers in the discipline may be attempting the 'fool's errand' of establishing an absence of evidence.

\subsubsection{The Scale of Neolithic Agriculture}

Arable agriculture originated in savannah and its translation across Europe (Colledge, Conolly \& Shennan 2005) probably required open ground (Bogaard 2004; cf. Edwards 1993). It is critical to define the spatial scale and duration of early Neolithic clearances (Buckland \& Edwards 1984). Vera (2000) argued that pollen data have seriously underestimated the amount of open ground in the early-mid Holocene created naturally by large 
herds of wild animal grazers, but this argument was successfully refuted by Mitchell (2005). O'Connell \& Molloy (2001) described extensive early Neolithic woodland clearance at some Irish sites, with the extent of woodland possibly halved. Caseldine \& Fyfe (2006), also in Ireland, suggested from new modelling techniques (below) that 'landnam' created a landscape in which overall at least $12 \%$ was open, but the best-fit suggested that individual openings were small and not necessarily intentional anthropogenic creations.

Pollen diagrams elsewhere are dominated by tree pollen for at least three reasons: (a) trees produce and disperse pollen much more abundantly than herbs and open spaces are undoubtedly significantly under-estimated by pollen analyses; (b) woodland clearance can lead to greater pollen production in remaining trees and their greater ease of transport to pollen sites; (c) many pollen sites are from large-diameter basins which receive pollen from enormous distances, making detection of open spaces nearly impossible (Edwards 1979). Tipping et al (2009) modelled pollen analyses at the early Neolithic timber hall at Warren Field, suggesting that the hall stood in a clearing some $2 \mathrm{~km}$ across containing scattered trees: this cleared area would not be detected in analyses from large diameter peat basins. There is no evidence for early Neolithic woodland clearance in Scotland to have been substantial or extensive. Kalis et al (2003) suggested for central Europe that this might only reflect the absence of extensive grazed grassland. In the Northern and Western Isles, woodland loss within the Neolithic may have been near-total but the cause of that woodland decline, climatic or anthropogenic, has not been established, and woodland gave way to heath (Edwards, Whittington \& Hirons 1995), which is not a direct product of agricultural activity.

The on-site evidence for agriculture is considered by Rowan McLaughlin (see also Rowley-Conwy 2004; Thomas 2004; Bogaard \& Jones 2007; Jones \& Rowley-Conwy 2007) but wider, landscape-scale implications involve, for example, the idea of shifting cultivation or slash-\&-burn farming to explain the apparently evanescent, suggested transient Neolithic settlement pattern in England (Edmonds 1999; Thomas 1999). Slash-\&-burn techniques are usually practised on infertile soils and the need for people to have resorted to such practices on the generally fertile soils of north-west Europe has been questioned (Rowley-Conwy 1981, 2003). Bogaard $(2002,2004)$ has also recently argued that fields were cultivated for long periods, and that farmers were sedentary. Comparable plant analyses need to be undertaken in Scottish contexts. It should perhaps be expected in addition that farmers would know how to amend or improve the nutrient status of cultivated soils. Neolithic examples of 'man-made' plaggen soils are known (Bakels 1997; Guttmann 2005) with Guttmann arguing for in situ cultivation of Mesolithic midden heaps at coastal sites, but how widespread such practices were remains unknown. The preservation of Neolithic domestic landscapes on Shetland (e.g. Whittle 1986) need to be revisited with the application of new scientific approaches.

DNA evidence indicates that all livestock, including cattle but with the exception, perhaps, of pig, were introduced into Britain (Bailey et al 1996; Bollongino et al 2005). In southern Scandinavia cattle were introduced from c. 4000 cal. BC (Price \& Noe-Nygaard 2009). There is no evidence yet in Scotland of wild cattle in Mesolithic contexts. It is possible that wild mammals were also introduced by people to, in particular, the outer isles, and Searle has argued for a surprising number of species in Ireland (Searle 2008). Stable isotope data indicate that cattle grazed on grass immediately upon their introduction whereas aurochsen and red deer grazed from the woodland floor (NoeNygaard, Price \& Hede 2005), although the influence of climate change on nitrogen cycling may affect these data. The scale of livestock-keeping is hard to estimate from 
archaeological finds from specific 'feasting' sites. Nor is it simple to compare quantities of surviving remains between robust species (cattle) and gracile species (sheep and pig) especially if dogs have been present on the site. Grazed grassland is recorded in most pollen diagrams, though seemingly insufficient to indicate extensive areas of pasture (cf. Kalis et al 2003) except in the areas where climate has induced less wooded circumstances in northern mainland, and the Northern and Western Isles. Noe-Nygaard et al (2005; Noe-Nygaard \& Hede 2006) argued for the creation of new grassland at the onset of the Neolithic through climate change, the collapse of woodland and the slowing of sealevel rise, all of which would be important in the climatically more vulnerable circumstances of Scotland (above). In some settings, as at Warren Field, cattle and crops appear to have been segregated (Tipping et al 2009), as they were in traditional shieling systems and perhaps for similar reasons (Kalis \& Zimmerman 1988).

\subsection{Conclusions: Research Questions}

- Tipping (1994) was critical of the lack of application of ${ }^{14} \mathrm{C}$ dating to Scottish vegetation histories. Almost all more recent analyses have dating controls, though often not enough, and no Scottish sequence has yet been ${ }^{14} \mathrm{C}$ dated with wiggle-matched or Bayesian precision, which will be needed if archaeological and palaeoecological data are to be compared.

- Simulation modelling (Bunting \& Middleton 2005), the approach used by Caseldine \& Fyfe (2006), Caseldine et al (2007) and Tipping et al (2009) (see also Caseldine, Fyfe \& Hjelle 2008), tries to estimate probabilistically the most likely distance from a pollen site that trees of different species grew, contrasting pollen production and dispersal characteristics to create some scenarios of tree distribution that are more likely than others. The future application of this approach has to be encouraged.

- Palaeoeconomic analyses must be directed far more explicitly to excavated and well-dated archaeological sites. Off-site analyses must be related to on-site data. Too many data are from analyses where human activities are secondary to ecological questions and unsuited to describe human activities. A focused approach, choosing pollen sites that describe landscapes at human spatial and temporal scales, linked as networks by independent dating, could test, for example, the balance between foraging and farming, differences in land uses between halls and houses, the spatial separation of ritual and routine, sedentism and mobility, agricultural success and failure.

More direct dating is needed of excavated crop remains and animal bones (Brown 2007; Price \& Noe-Nygaard 2009). Much more work is needed to be done towards understanding the balance of arable and pastoral activities. The abundance of cattle bone from some archaeological sites has meant an interpretative emphasis on their significance in Neolithic society (Edmonds 1999; Ray \& Thomas 2003), but the absence in the palaeoecological record for large or even modest expanses of grazed grassland in the Scottish mainland suggests limited exploitation of herded animals: this paradox needs to be explored. New work on using fungal spore assemblages as indicators of grazing pressure (Blackford \& Innes 2006) might provide insights, but currently such approaches cannot distinguish domestic from wild animals. Other approaches to defining the scale or intensity of agricultural activities might come from multi-disciplinary investigations of landscape change, such as at 
ScARF Neolithic Panel Report

Loch Olabhat (Mills et al 2003), with the caveat that such changes are not

unambiguous indicators of human intervention. 


\section{Material Culture and Use of}

\section{Resources}

Artefacts constitute the most abundant source of information about the way in which people lived their lives and expressed their identities and beliefs during the Neolithic. Here, the material is dealt with by broad material categories - ceramics (Section 5.1), stone (Section 5.2) and organics (Section 5.3). Because stone and organic remains tend to be approached by different specialists, in different ways, these two sections are further subdivided, as explained in the section introductions.

\subsection{Ceramics}

The study of Scotland's Neolithic pottery has a long history, extending back at least as far as the 1920s when Callander reviewed what was then known (Callander 1929). Studies of specific pottery types were to follow, with a somewhat confusing proliferation of style names (such as Jack Scott's 'Beacharra' ware and 'Rothesay Ware' (Scott 1969), along with 'Achnacree Bowls' and 'Unstan Bowls' (Henshall 1963; 1972). More recently, Scottish Grooved Ware was considered by Ann MacSween and Trevor Cowie in 1999, and MacSween revisited the dating of Grooved Ware in 2007, when she also considered the dating of Impressed Ware. The characteristics and dating of Carinated Bowl pottery (formerly known as 'Grimston Ware', or 'Grimston-Lyles Hill' pottery, and sometimes referred to as 'Bowl') were outlined by Sheridan in 2007, building on previous work by Audrey Henshall, who has made a major contribution to the understanding of Scottish Neolithic pottery (e.g. Henshall 1968; 1972; 1983).

However, with the exception of lan Kinnes' study in 1984 (which formed part of a broader assessment of the state of knowledge about the Scottish Neolithic), there has been no attempt to describe the overall nature and development of Scottish Neolithic pottery since Isla McInnes published her 'Scottish Neolithic pottery' study in 1961, in Scottish Archaeological Forum. This section of the ScARF document will aim to offer a summary statement of our current state of knowledge.

\subsubsection{Early Neolithic, to c 3600 BC}

Essentially, the story starts with the appearance of two north French ceramic traditions:

- a Breton tradition, featuring Late Castellic and related pottery, which appears in the west of Scotland (at Achnacreebeag) as part of the 'Breton, Atlantic' strand of Neolithisation and

- a North-French tradition, constituting one of a variety of regional styles of 'Chasséo-Michelsberg' pottery and which is known in Britain and Ireland as 'Carinated Bowl' pottery. (The justification for using this term to describe a tradition that encompasses non-carinated forms as well as carinated forms is explained in Sheridan 2007; and note that there is still variability in other people's use of terminology, with some still using the obsolete 'Grimston' or 'GrimstonLyles Hill' terms, or the over-vague term 'bowl (or Bowl) pottery'. This is to be discouraged as it leads to confusion.)

The origins of the Breton tradition lie in the Morbihan region of south-east Brittany, while the Carinated Bowl tradition is most likely to have originated in the Nord-Pas de Calais region of northern France, where excavations at Étaples have produced a close comparandum.

The distribution of these two traditions, in their initial form, does not overlap; the former is limited to the west of Scotland, while Carinated Bowl pottery use extends over much of southern and eastern Scotland, as far north as Caithness. As will be seen below, however, in its later variants there was 'cross- 
fertilisation' between the two traditions as potters shared design ideas. It should also be noted that there were parts of Scotland - the Outer Hebrides (and some of the Inner Hebrides), north-west Mainland, parts of western mainland Scotland and the Northern Isles - where pottery did not begin to be used until the late $38^{\text {th }}$ or $37^{\text {th }}$ century BC.

\section{Breton-style pottery}

The Breton tradition is characterised by the use of thin-walled, fine-textured bipartite bowls (of Late Castellic style) with distinctive decoration: the example from Achnacreebeag has a 'rainbow' motif above the carination and a fringe of short vertical lines below. Also present in the simple passage tomb at Achnacreebeag were sherds of two other pots of Breton style, more simply decorated with stab designs. The Breton parentage of this pottery is very clear, with comparanda, for example, from a simple passage tomb at Vierville, Normandy- a pot which represents the northward movement, either of the vessel itself or of the ceramic style, from Normandy (Cassen 2011) - and from the funerary complex at Locmariaquer in the Morbihan area of SE Brittany (ibid.). The development and dating of Late Castellic pottery is described in Cassen et al. 2011, from which it is clear that the assemblage at Achnacreebeag dates to between c 4300 BC and c 4000 BC. This is therefore the earliest pottery in Britain and Ireland, standing at the start of a tradition of using decorated bipartite bowls in the west of Scotland and in Ireland: later examples of this tradition, showing clear stylistic 'parentage' from its Late Castellic origins, are to be found in the Clyde cairns of SW Scotland (where Jack Scott termed them 'Beacharra Bowls') and in the court tombs in the north of Ireland (where Humphrey Case called them 'Ballyalton bowls': Case 1961). The longerterm development of this particular ceramic style has been traced by Sheridan (1995; 2003), where its persistence in Ireland to around the $36^{\text {th }}$ century BC can be traced.
Petrological thin-sectioning of sherds from the Achnacreebeag pots (by Gwenaëlle Hamon, for Alison Sheridan), and comparison with Breton Late Castellic pottery, has unfortunately proved inconclusive in determining whether the former had been actual imports to Scotland; the fabric is so fine that there are too few lithic inclusions to allow a consideration of origins on that basis. However, further work on examining local clays may help in this enquiry. It seems likely, however, that it was the know-how to make this pottery, rather than the pots themselves, which moved from Brittany to Scotland. This will have been a totally new technology in late $5^{\text {th }}$ millennium Scotland, and the skill with which the Achnacreebeag assemblage had been made means that it can only have been made by a skilled and experienced potter/s.

It should be noted that the objections that have been raised to the idea of a Breton ceramic tradition having been introduced to Scotland (Whittle et al. 2011, 808ff) are based on a misunderstanding of the ceramic sequence in Scotland, with the later versions of this pottery type (e.g. at Beacharra) being assumed to be the 'parent' of the Achnacreebeag pots. This is an error (as explained in Sheridan 2012), and in any case no plausible alternative explanation for the appearance of an entire ceramic tradition has been offered.

\section{The Carinated Bowl tradition}

This tradition features the use of carinated and uncarinated vessel forms, all undecorated (save for the occasional use of decorative finger fluting). Sheridan has made a distinction between the earliest manifestation of this ceramic tradition, which she has called 'traditional Carinated Bowl [henceforth CB]', and subsequent developments, called 'modified (or developed) CB' (Sheridan 2007; note the importance of using capital letters to distinguish between the tradition and the vessel form). 'Traditional $\mathrm{CB}^{\prime}$ pottery is markedly consistent (in fabric, form and finish) over a wide area in Britain and Ireland, 
whereas 'modified $\mathrm{CB}^{\prime}$ shows regional variation as the process of 'style drift' led to changes, in different ways, at different rates, in different areas.

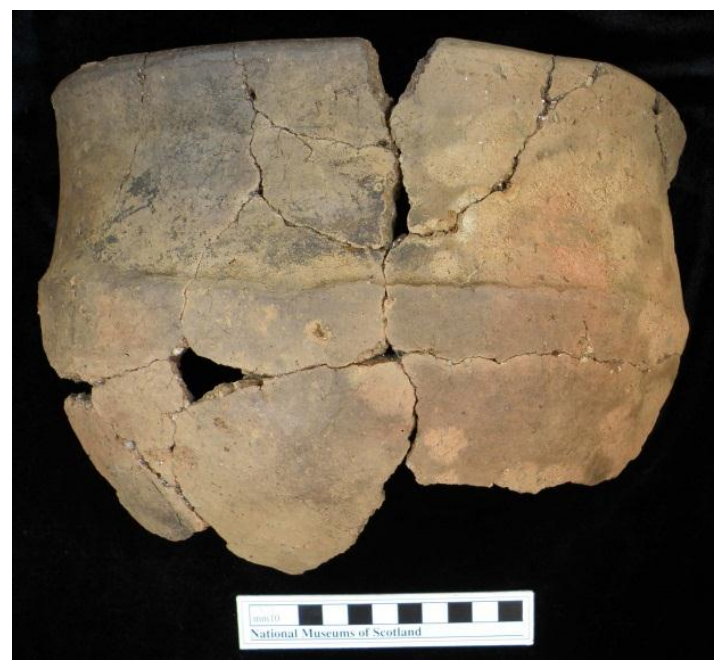

Figure 55: Large Carinated Bowl pot from Knocknab, Glenluce, Dumfries \& Galloway. Photo: Alison Sheridan

'Traditional Carinated Bowl' pottery features carinated bowls in a variety of sizes and shapes, mostly (but not exclusively) finetextured, and mostly thin-walled. Some are extremely thin - as thin as $4 \mathrm{~mm}$ in some cases - and the whole tradition is the product of skilled potters with over a millennium of experience in making pottery. As with the Breton tradition, its appearance in Scotland, probably during the $39^{\text {th }}$ century $B C$, represents a wholly alien technology, and the skill with which this pottery was made shows that it was made by people who were used to making pottery, and who followed conventions in the 'recipe' and techniques of pot construction as well as in the shapes to be made.

The carinated forms range from broad, shallow bowls to deep-bellied bowls; one of the latter, from Auchategan, Argyll and Bute, is of classic Michelsberg 'tulip beaker' form while others would seem 'quite at home' in Chasseo-Michelsberg assemblages from northern France. Carinations are generally gentle, and in some cases the pots are Sprofiled. The uncarinated forms comprise generally roughly hemispherical bowls and cups, and also large necked jars, with a deepbellied, S-shaped profile. With all the pots, surfaces have been carefully smoothed, and in some cases the exterior (and sometimes interior) have been polished to a low to medium sheen, or even burnished to a high sheen. Lithic inclusions are sparse, often less than $3 \%$ in density, and often feature the use of crushed granitic stone, with tiny mica platelets giving the surface a slight glitter. Widespread technical details of manufacture include the marked thinning of the neck just above the carination, which is particularly prevalent on the wide shallow bowls; while this weakened the vessel - with many pots having broken at this point - it nevertheless helped in achieving the desired vessel shape. Once more, the widespread occurrence of this feature points strongly to $C B$ pottery having been introduced by potters who shared the same ceramic tradition.

While some have accepted Andrew Herne's suggestion that carinated bowls had a special, ceremonial function, the evidence does not substantiate such a view. There is abundant evidence for the use of some carinated (and a few uncarinated) bowls for cooking, but they would also have been used for serving, and larger vessels for storage. This pottery has been found in the full range of contexts, from the domestic to funerary and other monuments.

The subsequent development of this tradition is, as indicated above, a story of regional diversification, with a process of style drift having operated in different ways, at different times, in different areas. In north-east Scotland, as Henshall had observed as long ago as 1983, a regional style emerged early on, featuring the increased use of fingertip fluting and of ripple-burnishing; the addition of lugs; and the addition of new forms, including baggy lugged bowls. This 'North East Carinated Bowl' (NECB) pottery finds echoes in the developed Carinated Bowl pottery of northern Ireland (in what Case called 'Lyles Hill ware: Case 1961), and this is no coincidence, as there are documented links 
between NE Scotland and NE Ireland, via the Great Glen (e.g. in the use of porcellanite axeheads from Co. Antrim). The early date at which this 'style drift' occurred is indicated by the assemblage from the so-called 'hall' at Balbridie, Aberdeenshire: built within a generation or so of the near-identical 'hall' at Warren Field, Crathes, just across the River Dee, its assemblage is of NECB pottery, whereas that at Crathes is 'traditional Carinated Bowl'. The Balbridie assemblage includes sherds from two sharply carinated bowls with decoration on their collars: these constitute the beginnings of what was to become the Unstan Bowl, and it is assumed that this represented innovation in pot design.

Other regional versions of 'developed Carinated Bowl' pottery include a general coarsening and thickening of the vessels, the occasional addition of lugs, and shape deviation from the earliest carinated forms.

In the west and south-west of Scotland, a fusion of the Breton and Carinated Bowl traditions can be seen, with decorated bipartite bowls occurring along with developed CB forms to constitute Scott's 'Beacharra' tradition, with its regional variability. Into this mix was added the use of deep baggy lugged bowls; as argued elsewhere (e.g. Sheridan 2004), this may well represent the adoption of a south-west English style of pottery (formerly known as 'Hembury Ware', thanks to north-south interactions within the Irish Sea area from the c $37^{\text {th }}$ century. Some sharing of styles between NECB pottery and that found in $W$ and SW Scotland is clear from the distinctive pots formerly known as 'Achnacree Bowls' (and as part of 'Rothesay Ware'): these have long, vertical necks, heavy, hooked rims and shallow bellies, and are decorated with vertical lines of either ripple burnish or incision. Examples have been found at Culduthel, near Inverness, in a domestic context; in the passage tomb at Achnacree; in the Clyde tomb at Nether Largie in the Kilmartin Glen ; and in Clyde tombs in Bute . The example at Culduthel comes from a context radiocarbon dated to c 3600-3500 BC and this provides a reasonable estimate of the date of this pottery.

A recent attempt to use Bayesian modelling to characterise the dating of modified Carinated Bowl pottery in Scotland has been made by Whittle et al. (2011), but this has failed to take into account that defining an end to this process is difficult, since ceramic traditions tend not to end abruptly; instead, we can trace a gradual process of style drift as conventions change and as new design ideas are adopted, through local innovation and through links with other areas. For this reason the use of Bayesian modelling is flawed. (See Sheridan 2012).

The spread of pottery using to the Outer Hebrides and the Northern Isles

It was this fusion of Carinated Bowl and Breton-origin pottery that spread to the Outer Hebrides, parts of western Scotland and north-west Scotland, probably during the late $38^{\text {th }}$ or $37^{\text {th }}$ century BC. Jack Scott (1966) has termed this pottery 'Hebridean Beacharra', and examples can be seen from sites such as Northton (Simpson et al. 2006), Calanais (Ashmore forthcoming), Eilean Domhnuill (Armit 2003) and various chamber tombs (Henshall 1972). The repertoire includes both undecorated and highly decorated vessel forms, in a variety of shapes. The former include simple uncarinated bowls, bowls with flanged rims and deep lugged jars (with their 'Hembury/South-Western pottery' affinities) and the latter include large ridged jars and Unstan Bowls - a type of vessel shared with Orkney and north-east/east Scotland, and almost certainly adopted in the Hebrides thanks to contacts with Orkney and/or the north-east mainland. Decoration is almost exclusively by incision. The dating of this 'Hebridean Neolithic pottery' tradition leaves much to be desired, with the existing dates suggesting an implausibly long currency from around the $37^{\text {th }}$ century (or even possibly late $38^{\text {th }}$ century) until the early third millennium. 
Improvement of the dating is a key research priority.

As far as the earliest Neolithic pottery in Orkney is concerned, this too contains an undecorated and a decorated component, with Unstan Bowls possibly being present from the beginning. Close ceramic links with the north-east mainland are in evidence, and it may be that the farming communities who pioneered farming in Orkney came from the north-east Mainland. The widespread use of the term 'Unstan Ware' offers a misleading impression of consistency among the pottery associated with Unstan Ware, and should be avoided. Key assemblages for understanding the early development of pottery include the Knap of Howar (Ritchie 1983) and Pool (Hunter 2007).

The earliest pottery in Shetland consists of a handful of very small, undecorated, slightly coarse sherds from West Voe. While these are too small to be diagnostic, they are most likely to resemble the plainware component of the ceramic tradition of the Hebrides and western mainland.

\subsubsection{Middle Neolithic developments}

Some idea of the regionally-diverse ceramic developments has already been presented in Theme 3. Essentially, in eastern, south-east and south-west Scotland we are dealing with the evolution of the Carinated Bowl tradition, with Impressed Ware beginning to be used possibly as early as c $3600 \mathrm{BC}$ and becoming the dominant tradition thereafter, until the adoption of Grooved Ware from Orkney around 3000 BC. Regional and chronological variation in the Impressed Ware tradition can be traced, with clear links between the variant seen in south-west Scotland and its congeners in north-east Ireland (Sheridan 1995), and with a southern Scottish-northern English style clearly evident. Vessels featuring very narrow flat bases are one characteristic of this style, and some pots that have clear affinities with English 'Fengate Ware' have been found at several sites (e.g. Deer's Den, Culduthel, Highland and Overhailes, East Lothian).

In Orkney, details of the development of plain and decorated non-Grooved Ware pottery still need to be clarified. It appears that there may well have been some chronological overlap with the use of Grooved Ware but the duration of this is unclear, partly because of the radiocarbon calibration plateau between 3400-3100 cal BC.

In Shetland, it appears that an insular style featuring fine and coarse, undecorated, mostly hemispherical vessels emerged during the second half of the fourth millennium (Sheridan 2012).

\subsubsection{Late Neolithic developments: Grooved Ware}

The key development is the emergence of Grooved Ware - a phenomenon that occurred in Orkney, with the Pool ceramic sequence offering the key to its origins (MacSween 1992, 1999, 2007). As indicated above, the precise date of its emergence remains a little obscure, but Schulting et al. (2010) have concluded that it was very probably in use by 3200 BC. Its emergence seems to be related to the social dynamics of Late Neolithic communities in Orkney, where a system of competitive conspicuous consumption operated. The key features of Orcadian Grooved Ware have been defined by MacSween and Cowie (1999) and Sheridan (1999), and the very close similarities between some Grooved Ware from Orkney and far-flung Grooved Ware from southern England have long been recognised - indeed, in the original use of the term 'Rinyo-Clacton' ware.

That Grooved Ware in different parts of Britain and Ireland followed different (and sometimes convergent) trajectories is clear, but many more high-quality dates are required in order to define the nature of these trajectories in detail. 


\subsubsection{Conclusions and outstanding questions}

**Text to follow**

\subsection{Stone}

As indicated in the introduction to this theme, research into stone artefacts (and other uses of stone) has tended to be undertaken in different ways by different specialists, with some focusing on small, knapped lithics, others on axeheads and similar objects, some on coarse stone tools, etc. With knapped small lithics, the emphasis has tended to be on identifying the châine opératoire and working tradition for the various kinds of stone used, while stone axehead studies until the advent of Projet JADE on Alpine axeheads - have been dominated by issues of provenancing the raw material. Relatively little use-wear analysis has been undertaken in order to establish how various kinds of stone artefact had been used. The study of stone used in building houses and monuments has not received much attention until recently, when Colin Richards has sought to identify the quarry areas used for the stones in the Ring of Brodgar and Calanais stone circles.

For these reasons, this section is divided into several sub-sections dealing with the different kinds of stone artefact, as follows:

\subsection{1 small knapped tools (such as} scrapers and blades)

5.2.2 axeheads (plus adze heads and chisels)

5.3.2 so-called 'coarse stone tools' (e.g. querns)

5.2.4 'special' artefacts (such as maceheads and carved stone balls - although this is not to deny that some axeheads definitely fell within the 'special' category)

5.2.5 stone as used for personal ornamentation
5.2.6 stone used as a building material, and for interior fittings

5.2.7 'miscellaneous' stone (including haematite and ochre)

\subsubsection{Small knapped tools}

The study of small stone tools has much to tell us about the nature of Neolithic society, by revealing patterns of raw material procurement, traditions of working, and the networks of exchange over which materials and finished objects travelled. Much of this work is best undertaken in close collaboration with geologist colleagues, but the research questions that it can address can only be answered by integrating the results of lithic analysis within broader models of (and approaches to) Neolithic society and its material culture.

\section{Neolithic Raw Materials}

A large number of lithic raw materials were exploited during the Scottish Neolithic, and in recent time research has shown that raw materials traditionally associated with the Mesolithic were also used in the Neolithic. Staffin baked mudstone and Rhum bloodstone, for example, were not only used in the Mesolithic, but through the Neolithic and well into the Bronze Age.

The following types of stone raw materials were widely used in the Scottish Neolithic, some more widely than others:

for implements of all kinds -

- Flint (coastal, Buchan Ridge, Antrim (both directly imported and beach derived on western coasts) and Yorkshire flint);

- Chert;

- Quartz and quartzite;

- Arran pitchstone;

- Rhum bloodstone;

- Staffin baked mudstone;

- Lewisian mylonite;

and for axes -

- Cumbrian tuff;

- Porcellanite; 
- Creag na Caillich hornfels;

- North Roe felsite;

- Various Aberdeenshire axe-head materials (Groups XXXII and XXXIII).

These materials all inform on Scottish Neolithic territoriality, and they may be grouped in several ways. Some, for example, were used for everyday smaller tools (the list's first seven raw materials), whereas others were used mainly for the production of axe-heads (the list's last five raw materials see also section 5.2.2). In considering the general territorial structure of Scottish Neolithic societies, the above raw materials may also be grouped according to their inclusion in various exchange networks, where some appear to have been used locally without being exchanged at all (eg, quartz and chert); others were exchanged within relatively small territories (eg, baked mudstone, bloodstone and mylonite - possibly also coastal flint and Buchan Ridge flint); whereas some were exchanged over extensive distances (eg, pitchstone, Antrim flint and Yorkshire flint). The way these raw materials were exchanged obviously also reveals how much, and possibly in which way, they were regarded, thereby informing us about beliefs and ideology.

\section{Extraction}

In Scotland, Neolithic extraction sites relating to different raw materials have been investigated, such as: several groups of chert quarry pits from the Scottish Borders and South Lanarkshire (some probably dating to the Mesolithic period, others to the Neolithic); a worked quartz vein from Lewis (Cnoc Dubh); a hornfels quarry in Perthshire (Creag na Caillich); a complex of flint quarry pits in Aberdeenshire (Den of Bodham and Skelmuir); and the massive felsite quarry complex in North Roe, Shetland. Some raw materials were probably largely procured from pebble deposits along the Scottish coast (eg bloodstone), some from exposed coastal veins (eg pitchstone), whereas the procurement of other raw materials are as yet unexplored (eg mylonite). The procurement of 'imported' raw materials, such as Yorkshire flint and porcellanite, have been discussed in a number of English and Northern Irish papers.

The analysis of procurement sites allows a number of questions to be discussed, such as technical matters (eg, were the raw materials hammered out of the bedrock, was firesetting used, scafolding, etc.); organizational matters (eg, operational schemas, spatial organization of the various processual steps, etc.), and ideological matters (was work at the procurement sites ritualized to any degree, as known from ethnographic cases).

\section{Key Issues}

The analysis of Scottish Neolithic territorial structures and exchange networks ought to focus on a number of specific topics, tasks and questions. They include:

Lithic and stone quarries; this point is obviously of importance to the definition and understanding of exchange networks, as the quarries form one end of chains of exchange. At present, practically no Scottish lithic and stone quarries have been analysed and published.

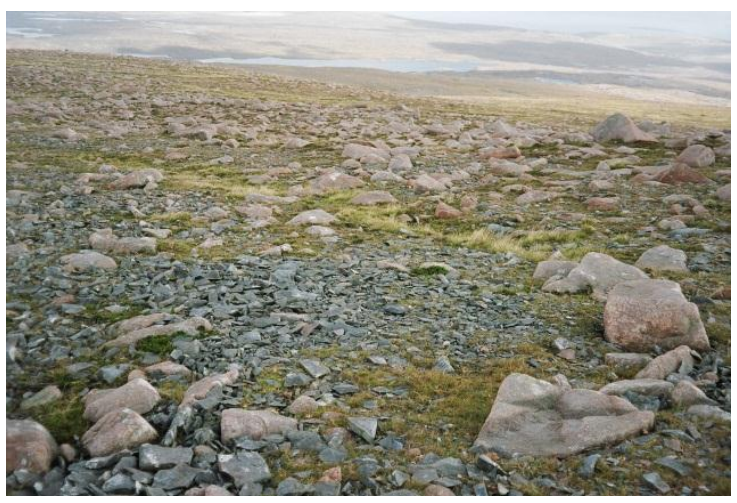

Figure 56: Felsite workshop within the Neolithic quarry complex at Midfield, North Roe, Shetland. A scatter of knapping debris is seen within a circle of boulders - large pieces of waste to one side, finer waste to the other. Probably a workshop for the combined production of felsite axeheads and Shetland knives (photo: T.B. Ballin). 
Production of distribution maps (simple plots, contour maps, Thiessen polygons, fall-off curves, etc.) to define the geographical extent of territorial units, as well as the character of the associated exchange networks (eg, did the exchange involve any form of redistribution?). This ought to involve the production of catalogues and databases of assemblages which include artefacts in bloodstone, etc., the way the distribution of Arran pitchstone has recently been analysed (Ballin 2011).

Some individual raw materials are very poorly understood, which clearly affects the interpretation of the exchange between various regions. Most notably, a banded form of rock found in practically all later Neolithic and Bronze Age assemblages along the Lewisian west-coast has been defined as practically every possible fine-grained metasedimentary rock - by geologists (!) - which has as a consequence that the associated exchange network would either link the Lewisian west-coast with that island's eastcoast (if it is mylonite) or with the Isle of Skye (if it is baked mudstone, as recently suggested). The solution is to consult geologists as to how this particular conundrum may be resolved, and to seek to locate the actual sources/outcrops/quarries on the ground. If the raw material is Lewisian mylonite (as one might expect, if one applied Occam's Razor), the sources are likely to be within a limited part of the faultzone running along the Lewisian eastern seaboard.

In addition to informing us on Neolithic territoriality and exchange networks, stone raw materials may carry information on ideology in general. Ethnographic sources suggest that practically all lithic raw materials were associated with non-functional (for example totemic) values. This topic ought to be explored by analysis of how different raw materials were used for different tool forms, or how they were used in different associations or contexts (domestic, burial, ritual). Where particular raw materials were used for specific tools, but not for others, it should be asked whether this could have a functional explanation (it is, for example, the writer's view that the lack of serrated pieces in pitchstone - despite the fact that pitchstone was mainly exchanged throughout Scotland in the Early Neolithic - was due to the brittleness of the raw material), and it is well-known that crushed quartz (despite the fact that it was not treasured enough to be exchanged) was used to cover certain burial and ritual monuments.

Traditions of working, and range of artefacts produced

There appear to be differences in the way raw materials (and particularly flint) were worked during the Neolithic, as opposed to during the Mesolithic. This includes the introduction in the Early Neolithic period of invasive retouch, and in the Late Neolithic period (Impressed Ware and Grooved Ware periods) of highly diagnostic Levallois-like technique.

Uni- and bifacial invasive retouch allowed the production of a series of new artefact forms, such as sophisticated projectile points and cutting implements, whereas it is thought that the Levallois-like technique may have allowed broad flakes for chisel-shaped and oblique arrowheads, discoid knives, and slender blades for cutting implements, scrapers, etc. to be produced from the same parent cores. Particularly the latter technique needs further investigation, and it is suggested that a chronologically unmixed, statistically suitable Late Neolithic flint assemblage be selected for refitting. This should allow a standardized operational schema to be produced for this approach, shedding light on the steps involved and the blank types produced.

The range of small lithic artefacts includes leaf- and lozenge-shaped (EN) as well as chisel-shaped and oblique (LN) arrowheads (which contrast with Mesolithic microlithic armatures); plano-convex and scale-flaked knives with extensive invasive retouch; polished axeheads and knives (blade and discoidal forms); finely serrated pieces and 
saws; strike-a-lights; scrapers and piercers; as well as many simpler forms, such as notched, denticulated and edge-retouched pieces. It is generally thought that burins disappeared at the Mesolithic-Neolithic transition, but dating late burins more precisely to investigate whether burins may also form part of the toolkit in the earliest part of the Early Neolithic period should be attempted.

Due to the flaking properties and varying toughness/brittleness of the raw materials used in the Neolithic, some tool types have a special affinity for, or avoid certain raw material types. It is, as stated above, likely that the brittleness of pitchstone is the reason why no serrated pieces are known in this material.

The distribution patterns and assemblage compositions of, for example, pitchstone and Yorkshire flint indicate that some raw materials may have been perceived differently, and subsequently used differently, in different parts of Scotland. Pitchstone may have been perceived in emblematic terms on the source island, Arran, defining people there as 'those who use and control pitchstone' while on the immediate mainland, it may have been an important exchange object, tying together a number of kinship-related groups. Further afield, where pieces are usually found in ones and twos rather than whole assemblages, they may be highly valued exotica.

Yorkshire flint, which in the Late Neolithic dominates southern Scotland completely, may have been perceived here mainly in functional terms, while further afield, where assemblages may contain as much as $50 \%$ Yorkshire flint, it may have gained in value due to its exotic character. It should be noted, however, that (as shown on Orkney) where central sites in a territory may contain $50 \%$ Yorkshire flint, more peripheral sites may contain none at all.

The distribution patterns, and perceptions, of Early Neolithic pitchstone and Late Neolithic
Yorkshire flint suggest that important changes took place around the Early/Late Neolithic transition with the former probably representing a tribal society, organisation, and belief system, and the latter one of budding chiefdoms.

\section{Exchange/movement of lithic materials and/or finished artefacts}

Depending on whether the raw materials were perceived mainly in a functional or in a stylistic light (i.e., as a means of group identification or differentation), they were exchanged, either within smaller geographical areas or territories, or across large areas, possibly across numerous territories.

Following Clark's (1975) territorial definitions, the raw material exchange of the Scottish Neolithic may be summarized in the following manner:

- techno-complexes - quartz, chert

- inter-regional social networks pitchstone, Yorkshire flint; Antrim flint

- social territories -baked mudstone, bloodstone, mylonite

- local sources of importance - pebble flint, Buchan Ridge flint, agate/chalcedony, chalcedonic silica, quartzite

- local ad hoc supplements - jasper, basalt/dolerite

In the north, the west and the Highland zone quartz was used throughout prehistory, but probably not exchanged to any great extent. Chert dominated southern Scotland in the early Neolithic, but continued to be used to a lesser extent through the Late Neolithic period. This raw material was probably exchanged very little either, but used near the ubiquitous outcrops.

Arran pitchstone was exploited throughout prehistory on Arran itself (and probably in southern Argyll and Bute), but on the mainland the exchange of pitchstone is mainly associated with the first half of the Early 
Neolithic, followed by a trickle into Impressed Ware times. The importation of Yorkshire flint may have started as early as 3600 BC (Greenbrae hoard), and went on to dominate raw material use completely through the Late Neolithic period, and dropped to a trickle in the early Bronze Age. The dating of the Antrim flint exchange is less certain, but the Auchenhoan and Portpatrick caches suggest dates in the middle and later Neolithic. The importation of Antrim flint, probably from $37^{\text {th }}$ century BC if not earlier, is fairly certain. However, the understanding of the associations and context of Antrim flint in Scotland would definitely benefit from more attention.

Extensive exploitation of Buchan Ridge flint in Aberdeenshire is associated by virtue of the technological attributes of its manipulation (widespread use of Levallois-like technique) with the later Neolithic. Work on these finds is presently ongoing. The remaining raw materials known from Scottish Neolithic contexts generally appear to have been used throughout prehistory, but all these raw materials are in need of more attention to increase our understanding of their general use, distribution and exchange patterns, as well as of how they were perceived in prehistory society.

\section{Research questions:}

- How strong is the contrast between Neolithic and Mesolithic lithic traditions: and is it possible to identify a process of acculturation or mutual influence between them? To what extent does the structure of technologies compare to the possible North French progenitors for the earliest Neolithic in Scotland? It might be one thing to copy a lithic type, but to change the whole structure is very different.

- How and when did reduction techniques change during the Neolithic? Debate still exists about the timing of the appearance, for example, of bipolar techniques. Our understanding of core technologies, percussive techniques etc, are limited in terms of understanding both spatial and temporal variation; not least in terms of considering this across the range of materials exploited.

- Organisation of the reduction sequence across space: how was the chain of events from procurement to deposition structured across the Scottish landscape? Can we identify any largescale artefact production, akin to the specialist Middle and Late Neolithic flint artefact production on the Yorkshire Wolds?

- Typo-chronology: can definitive typologies for formal stone tools be generated for the Scottish Neolithic, establishing a clear technical vocabulary and a sense of changes over time? To what extent does typology allow us to identify links to other areas within or without Scotland? What is the date of the Campbeltown hoard of Antrim flint axeheads and flakes? This will require a review of the current dating evidence of a) the same type of flint axe-head elsewhere and b) the same reduction pattern for flake production in Ireland

- Function: what contribution does use wear and/or residue analysis have to understanding the use of stone tools during the Neolithic? These practices have revolutionised our understanding of stone tools (cf. Van Gjin, for example) and preliminary work in Scotland (Finlayson, Hardy, Barton, Warren) shows promisealbeit mainly on Mesolithic sites. How does function change over time? Where? Why? How does this relate to other evidence for the nature of the landscape and the function of sites - e.g. palaeoenvironmental and plant macrofossil evidence etc.

- Deposition: how and why were stone tools deposited in the ground in the 
Neolithic? Arguably, if we can't answer this, we can't begin to answer many of the other questions we are asking... This in turn is clearly related to:

- Belief: How do attitudes to flaked stone reflect on attitudes to stone more generally?

- What is the source of the black flint as used for many of the Late Neolithic ripple-flaked oblique arrowheads?

\subsubsection{Axe-heads (plus adze-heads and chisels)}

It has been estimated that around 4000 ground stone axe-heads - and a far smaller number of adze-heads and chisels - have been found in Scotland, of which only around 130 are of flint (and those include examples where grinding is limited to the blade area). There being no known ground stone axeheads of Mesolithic date in Scotland, and very few indeed that have been found in postNeolithic contexts, it is, therefore, assumed that the vast majority of these date to the Neolithic.

Most of the research on axe-heads and related objects has been focused on addressing the question: 'Where did the stone originate?', and there is a history of provenancing research that extends back to the earliest stages of this field of study in the 1930s (with the work of the Petrology Committee of the South Western Group of Museums \& Art Galleries: followed by the work of the Council for British Archaeology's Implement Petrology Committee (IPC) - now continuing its existence as the independent Implement Petrology Group (IPG): http://implementpetrology.org/). Much of this provenancing was by petrological thinsectioning and the publication, in 1988, of the IPC's listing of petrologically-identified specimens from Scotland (and the rest of Britain: Clough \& Cummins 1988) marked a watershed in our understanding of the movement of material.
Work by Roy Ritchie (the IPC Reporter for Scotland) on the stone extraction sites on Creag na Caillich, near Killin, Perth \& Kinross (MacKie 1972; Ritchie \& Scott 1988) and at the Beorgs of Uyea in Shetland (Ritchie 1968; 1992) paved the way for subsequent investigation of these source areas. The former site was excavated by Mark Edmonds et al., on behalf of National Museums Scotland, in 1989 (Edmonds et al. 1992), and the Beorgs of Uyea and other felsite sources in Shetland are currently the subject of field research by Torben Ballin, Gabriel Cooney and Will Megarry (Ballin 2011; Cooney et al. in prep.).

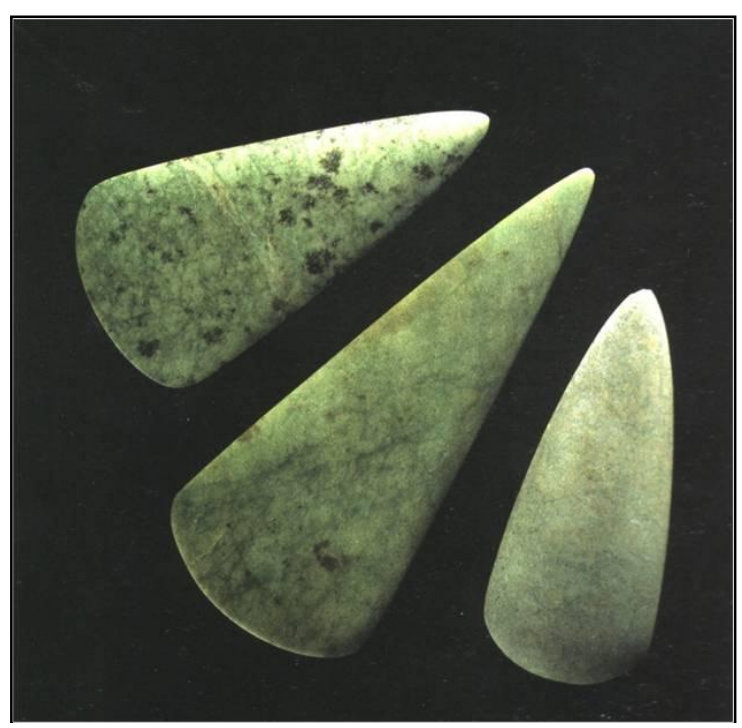

Figure 57: Projet jade - INSERT caption

Since 2006, Projet JADE - a major international research project, led by $\mathrm{Dr}$ Pierre Pétrequin (CNRS and formerly of the University of Besançon) - has revolutionised our understanding of the c 30 axe-heads of Alpine rock (i.e. jadeitite, eclogite and omphacitite) in Scotland - see boxed text. This project has focused not only on the (nondestructive) sourcing of the raw material, but also on axe-head shape, on the chronology of different types of Alpine axe-head, on the biography of individual axe-heads, on contexts of deposition, and on the social and ideological significance of these very special axe-heads across the whole of Europe 
(Pétrequin et al. 2008; 2012 (with extensive bibliography); Sheridan et al. 2011; 2012).

The sourcing of flint axe-heads has been more problematic, although morphology has offered clues, with the hoard of 'mint condition' flint axe-heads (and other flint objects) from Auchenhoan, near Campbeltown, pointing strongly towards Co. Antrim as the source area (Saville 1999), while the presence of a handful of distinctively shaped, waisted 'Duggleby axe-heads' and 'Seamer adze-heads' (e.g. at Biggar Common: Johnston 1997) unequivocally point towards Yorkshire (as does the slightly earlier flint axehead found, together with a necklace of Whitby jet and amber beads, at 'Ardiffery', Cruden, Aberdeenshire: Kenworthy 1977; cf. Manby 1979 on Yorkshire flint axe-head typology). The recent dating of human remains associated with a 'Duggleby adze' at the eponymous site (Gibson 2011) has confirmed that this particular object type belongs within the period 3300-3000 BC. Scottish flint seems only to have been used for a handful of flint axe-heads, and the flint mines on the Buchan Ridge will not have been used for making axe-heads, as the nodules are unsuitable for this purpose.

\section{: Sheridan 1992; Saville 20xx; Pailler 20xx)}

The source of the exquisite, often marbled flint used to make a distinctive kind of flint axehead - the All-Over-Polished variety - is unknown, although it is of the same kind as is found in Jutland, Denmark, and there has been much speculation in the past as to whether these are axeheads imported from Denmark. (Essentially, the Danish axeheads dating to c $3600 \mathrm{BC}$ - have broader side facets and none has the glassy polish as seen on the finest British examples and so, unless the latter represent material specially made for export, a Danish origin seems unlikely.) The markedly east coast distribution of AOP flint axeheads, extending as far as Folsetter in Orkney (where a slightly atypical example was found), suggests that wherever the source was- and the bed of flint runs under the
North Sea from Denmark to eastern England the axe-heads had travelled by sea, along the coast. Research by Yvan Pailler on similarlyshaped (but in many cases less highly polished) flint axe-heads in England - Pitts' 'Crudwell type' (Pitts 1996) - has suggested that the large, highly polished examples are a subset of a larger production.

The result of all the provenancing studies is that it is clear that a considerable number of axeheads found in Scotland come from preferred sources - the term 'axe factory' is avoided since it has overtones of modern industrial production. Of these, the bestrepresented in Scotland is Great Langdale in Cumbria, whose tuff (named 'Group VI' in the IPC scheme) had been extracted and exchanged in the form of axe-heads from the very beginning of the Neolithic (Edmonds 2011). Indeed, there is evidence (from Dumfries \& Galloway) that some people may have travelled across the Solway Firth and acquired roughouts, as well as finished axeheads.

The axeheads acquired from this source over the course of the fourth (and early third?) millennium comprise both 'workaday' examples (many with characteristically faceted sides) and a larger, distinctivelyshaped, probably special-purpose implement, 'the Cumbrian Club' the dating of which needs to be clarified, but is assumed to fall within the second half of the $4^{\text {th }}$ millennium (Edmonds 2011). There is a very good chance that the exploitation of this greenish-grey rock, obtained by means of a perilous climb up a steep mountain, had been motivated by the desire to reproduce the 'magic mountain' experience of Alpine jadeitite exploitation (Pétrequin et al. 2008 and see boxed text).

The same desire may have lain behind the exploitation of stone from other mountainous or otherwise 'liminal' sources, including Creag na Caillich, the source of calc-silicate hornfels (Group XXIV) and Tievebulliagh and Brockley (on Rathlin Island), Co. Antrim (the sources of 
porcellanite (Group IX). Research by the Irish Stone Axe Project (Cooney \& Mandal 1998) has revealed that this stone was used for over half of all the c 22,000 axe-heads found in Ireland. The Scottish distribution of porcellanite axe-heads from these two sources in north-east Ireland

(Error! Reference source not found. overlaps ith that of Great Langdale axe-heads but, as Jack Scott pointed out, the latter predominate in Dumfries \& Galloway while the former are more common further to the north, thereby reflecting the predominant patterns of interarea contact during the Neolithic. The presence of a few porcellanite roughouts in Scotland (Sheridan 1986) might indicate that some people were travelling to the source, rather than acquiring finished axe -heads from contacts in Co. Antrim. The distribution of porcellanite axe-heads (Sheridan 1986; Sheridan et al. 1992) also reflects patterns of contacts and movements within Scotland, travelling northwards up the Atlantic façade and north-eastwards, up the Great Glen, to Aberdeenshire. There are even two examples from Shetland, and these could have arrived as part of the secondary expansion of 'the Neolithic' to Shetland from western Scotland during the $38^{\text {th }}$ or $37^{\text {th }}$ century BC. The Atlantic movement included one porcellanite axehead (Figure 58) that was found, still set in its haft of rosaceous wood, at Shulishader on the Isle of Lewis, (Sheridan 1992). The haft has been radiocarbon-dated to $4470 \pm 95 \mathrm{BP}$ (OxA$3537,3490-2910$ cal BC at $2 \sigma$, calibrated using OxCal 4.1).

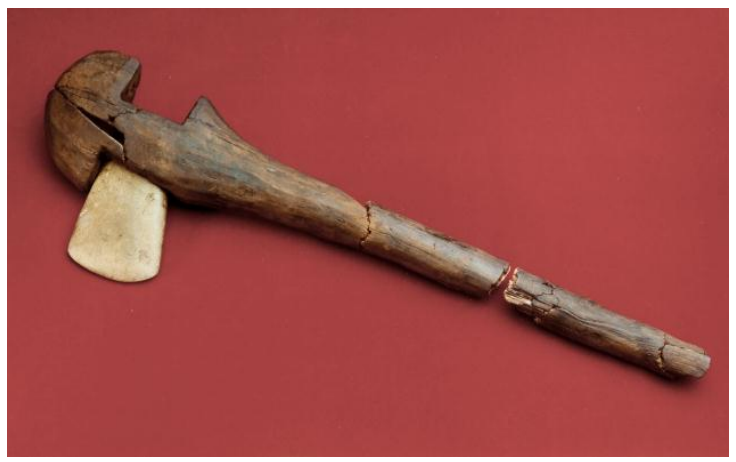

Figure 58: Neolithic axe, with Antrim porcellanite axehead, from Shulishader, Lewis, (C) NMS
The source on Creag na Caillich does not seem to have been as intensively used as Great Langdale or the porcellanite sources; fewer than 40 axe-heads (plus at least two cushion mace-heads) are known to have been made of this material, and the overall distribution is curiously scattered, with one example being found as far south as Buckinghamshire. Dating evidence is sparse, but a Middle to Late Neolithic date is suggested by the radiocarbon dates (Edmonds et al. 1992) and by the fact that it had been used to make cushion mace-heads.

The axeheads and distinctive polished knives of Shetland, made using the visually-striking riebeckite (and other) felsite, are remarkable in several respects. As pointed out by Roy Ritchie (1992), the axe-heads include many that exceed $140 \mathrm{~mm}$ in size, even though there will have been very few trees on Shetland. This is in stark contrast to the situation on Orkney, where the axe-heads tend to be diminutive. Only a handful of objects made of Shetland felsite left Shetland, and in one case, a knife that had been thought to come from 'Lanark' was found (by Noel Fojut) to have come from Lerwick, the label having previously been mis-read. A particularly valuable piece of evidence relating to the chronology of felsite exploitation has just been obtained for the Copenhagen Nationalmuseet's project, Farming on the Edge: this is a radiocarbon date of $4580 \pm 35$ BP (SUERC-37997, 35003110 cal BC at $2 \sigma$, calibrated using OxCal 4.1) from Maloideae species charcoal associated with a hoard of felsite axeheads and knives found in a knoll at Modesty, Shetland; fragments of steatite vessels were also found (Kinghorn 1895). The field investigation planned by Cooney et al. (in press) should provide additional dating evidence.

A few other sources of stone were preferentially used in Scotland (see Ritchie \& Scott 1988 for details), but only to a small extent. Other 'ungrouped' axe-heads have been made using locally-available stone 
(including, in some cases, river cobbles); it should be relatively easy to establish a rough estimate of the percentage of Scottish axeheads made from such material.

Overall, the information already available indicates that axe-heads from various sources were being exchanged around Scotland, some from a very early stage during the Neolithic (e.g. at Carzield, Dumfries \& Galloway: Sheridan 2007) - when the establishment of networks of contacts between farming communities was an important way of maintaining community sustainability. The various models of 'down the line' (etc.) exchange developed in the 1970s (Clough \& Cummins 1979) are now regarded as having taken insufficient cognisance of the social value of these objects, as well as any utilitarian value. A particular instance of this is the Alpine axe-heads of jadeitite and other Alpine rocks. These do not seem to have been 'exchange' items within a British and Irish context, but instead are more likely to have been brought over by the immigrant farming groups from northern France, as treasured (and supernaturally-charged) heirlooms, at some time between 4000 and 3800 BC (Sheridan 2007; Pétrequin et al. 2008). That some axe-heads of other rocks had also been accorded a special social value is suggested by the large or otherwise distinctive Cumbrian clubs, the All-Over-Polished (AOP) flint examples, and the Yorkshire flint, and the Shetland felsite types. As the work of Projet $J A D E$ has shown, it would be limiting to regard these simply as symbols of power, although they could indeed have had that role. Their significance may well have extended beyond that and one other aspect that reflects upon their importance is the fact that copies of a type were made in different kinds of stone. Several imitations of the 'Durrington type' Alpine axe-head form are known from Scotland (especially in Aberdeenshire: Sheridan et al. 2011), and there is one instance known where a Seamer axe-head of flint was copied in Langdale tuff. It is clear that much remains to be discovered about the social significance of these objects.
The outstanding research questions facing stone axe studies are as follows:

- The chronology of production and distribution needs to be clarified further for the 'preferred' sources, and in particular the currency of distinctive types of axe-head (such as the Cumbrian club) needs to be placed on a firmer footing.

- More specifically, what is the date of AOP flint axe-heads - the only type other than jadeitite axe-heads to have received a glassy polish - and where were they made?

- While most axe-heads seem to have been located as unassociated 'stray finds', can any patterns in deposition practices be discerned?

- What kind of additional information be gleaned from updating the IPG records for stone axe-heads in Scotland - for instance, by collating information about examples (and fragments thereof) from excavations since 1988 ?

- There is a possibility to investigate the use of axe- and adze- heads through the study of patterns of damage, curation and re-use that could suggest how long individual examples had been used before discard? Do axe-heads of a particular rock decline in length with distance from source - i.e. indicating that they were kept for longer (and thus re-sharpened more) than others made from more local rocks? (Roy Ritchie argued that this is not the case with porcellanite axeheads.)

- How widespread was the practice of imitating specific axe-head types in other kinds of stone?

- How does our understanding of resource use, as based on the study of stone axe-heads, compare with the picture obtained from studying other kinds of Scottish Neolithic resource use? 
- $\quad$ How many of the axe-heads known are actually either fakes (of which numbers are known to have been made during the $19^{\text {th }}$ century) or recent ethnographic manuports? The work for Projet JADE, together with a recent case where a Shetland implement in a museum in England had been confused with a Polynesian example collected by Captain Cook, highlights the need for those who study and curate stone axe-heads to develop their knowledge of material from elsewhere in the world and of fakes.

\subsubsection{Coarse Stone Artefacts from the Neolithic}

The term 'coarse stone artefact' is used in archaeological discussion as a blanket description for what is really a wide and disparate range of tools and objects. Many potential functions are represented including butchering tools, grain processors, craft tools of all types, agricultural implements and sculpted pieces. Widely different types of rock were selected and some artefacts were deliberately shaped prior to use whilst others, particularly the cobble tools, were used for jobs which left distinctive task-specific wear traces. These artefacts had many and varied roles to play in prehistoric lifeways and for this reason they must be a valuable component of any research framework.

Most work on stone tools in Scotland has been confined to recording their presence in excavation reports; even that is patchy with no recognised terminology and little discussion of context. Scholarly attention has been paid to individual tool types such as flaked stone bars and ard points from the Northern Isles with attempts to classify them by shape and to date their use (Rees 1979, Rees 1986a, Rees 1986b, Hedges 1986). With the exception of a recent work of synthesis from the Northern Isles (Clarke 2006 and see below) stone tools have never had a role in regional or national discussions of material culture.
Nature and development of the repertoire of stone artefacts over time

Research into use of stone tools in Neolithic Scotland is heavily biased towards the Northern Isles and this is because of the number of research-led excavations, particularly since the 1980s in Orkney, that have produced large assemblages of stone tools from all prehistoric periods. These factors allowed research into the use of stone tools from the Neolithic to the end of the Iron Age which demonstrated how changes in the composition of stone tool assemblages occurred at specific points (Clarke 2006). For example, in Orkney, cobble tools dominated Early Neolithic assemblages whilst flake tools and a narrower range of cobble tool types were more common in Later Neolithic contexts. Various types of ground stone tools were also in use. In contrast, at the same period in Shetland agricultural stone tools such as flaked stone bars and ard points were dominant but these did not appear in Orkney until after the Grooved Ware occupation.

We therefore have clear differences between the material cultures of these two island groups during the Neolithic that have never been addressed - particularly because the emphasis of research on Grooved Ware sites has, in my view, skewed archaeologists' view of the Neolithic. Recent work on St Kilda has demonstrated the presence of flaked stone bars and other stone tools which are dateable, by comparison with assemblages from the Northern Isles, at least to the Bronze Age and possibly earlier (Fleming 2005a and b). This offers a tantalising glimpse of maritime communication routes from the Neolithic onwards.

Elsewhere in Scotland we have very little detail about the use of coarse stone tools. The assemblages are mostly composed of various types of cobble tools and quern stones but we do not know how their use may have changed or developed through time.

Recent excavations of Early Neolithic contexts in Ayrshire indicate the presence of some 
types of coarse stone tool within Early Neolithic deposits that were also in use during the Late Mesolithic elsewhere in Scotland (Clarke 2008). This raises the question of just how far into the Neolithic these Mesolithic processing strategies continued.

\section{Raw materials and manufacture}

A very wide range of raw materials was used for stone tools across Scotland and this reflects the diversity of the local geologies (Clarke 2006). The issue of just where the rock came from and how it was collected has barely been addressed in the literature. A cobble source for many of the tools would suggest local access to beach or river gravels. At a more organised level specific quarries of sandstone have been recorded in Shetland (Calder 1956, 356) and on St Kilda prehistoric quarrying of dolerite was investigated by excavation (Fleming and Edmonds 1999). Also in Shetland evidence for shale quarrying has been identified near Sumburgh (Turner 1998, 32). These were most likely raw material sources for flaked stone bars and probably some other tool types. There is no clear dating evidence to indicate whether these quarries were used in the Neolithic or Bronze Age and there is as yet no demonstrated link between these extraction areas and the tools found on occupation sites. What is apparent is that around the end of the Neolithic and the beginning of the Bronze Age there appear to be different choices made in the use of stone accompanied by some changes in manufacturing methods and a range of new tool types in Orkney and Shetland (Clarke 2006).

Manufacturing was not just confined to the flaking of a blank to shape. For other stone tools grinding was significant, particularly in Orkney.

\section{Use}

Though functional terms are given to most prehistoric tools, in reality we cannot say for certain just what exactly they were used for. In order to investigate the myriad functions of these stone tools, particularly the cobble tools, we need to reproduce the wear traces experimentally and until now there has been no sustainable programme of such work in Scotland. Skaill knives have been assessed for their practicability in butchering (Clarke 1989) and the characteristic wear traces on stone ard points were investigated to determine their function (Rees 1979) but these are isolated instances.

Analysis of wear traces through experimental reproduction is, if done properly, a lengthy scientific process. Key questions need to be formulated before designing the programme and in order to do this we first need to know the range of stone tools present and how they have been deposited - this information is clearly lacking not only in the Neolithic but across the span of prehistory in Scotland

\section{Key Issues}

Not much is known about the use of coarse stone tools across mainland Scotland and the Inner and Outer Hebrides and we need to know what we have got before we can take full advantage of their potential. A nationwide synthesis of coarse stone tools from the Mesolithic to the end of the Iron Age would provide a valuable corpus of information from existing collections. With this method we can overlap the boundaries of the 'Three Age System' - these are points at which there are significant changes in the production and use of coarse stone tools e.g. Late Mesolithic/ Early Neolithic; Early Neolithic/ Late Neolithic; Late Neolithic/ Early Bronze Age. There is a too much focus on Grooved Ware at the expense of the rest of the Scottish Neolithic research excavations directed towards the Neolithic of Shetland, Caithness and St Kilda would illuminate the Neolithic of northern Scotland. A programme of experimental archaeology at postgraduate level could attempt to address the range of craft and processing activities that involved these stone tools. 


\subsubsection{Special' stone artefacts (e.g.} carved stone balls and maceheads)

This category covers a variety of Middle to Late Neolithic objects, such as mace-heads and carved stone balls, which were not workaday utilitarian artefacts and may have had a special, ceremonial, significance in Neolithic society (e.g. as symbols of power). Also included in this category is a variety of odd-shaped stone objects from Late Neolithic Orkney, mostly but not exclusively from Skara Brae, whose function and significance are uncertain; and finally the figurine found recently at the Links of Noltland is considered here, along with its comparanda.

\section{Maceheads}

This class of artefact is united by having a perforation, often neatly parallel-sided, indicating that it was designed to be mounted on a haft. (A handle of willow from Skara Brae has been suggested as a macehead haft. Another common feature is that many have been made from visually striking types of rock, usually glacial erratics (cf. Fenton 1988 on the choice of stone for Early Bronze Age battle-axe heads). Several types have been defined (principally by Fiona Roe, who proposed a Britain-wide typology in 1979). The principal types are ovoid, pestle-shaped and cushion maceheads, with a knobbed, slightly oval macehead from Skara Brae constituting a kind of hybrid between maceheads and carved stone balls .

Within the ovoid class is a sub-group of decorated maceheads, of flint or other siliceous stone, known as 'Maesmawr-type maceheads'; and the pestle-shaped maceheads comprise some examples with straight/-ish sides (formerly known as 'Orkney Pestles') and others with concave sides (formerly known as 'Thames Pestles', this nomenclature has been dropped since it is clear that many examples found in Orkney are waisted).

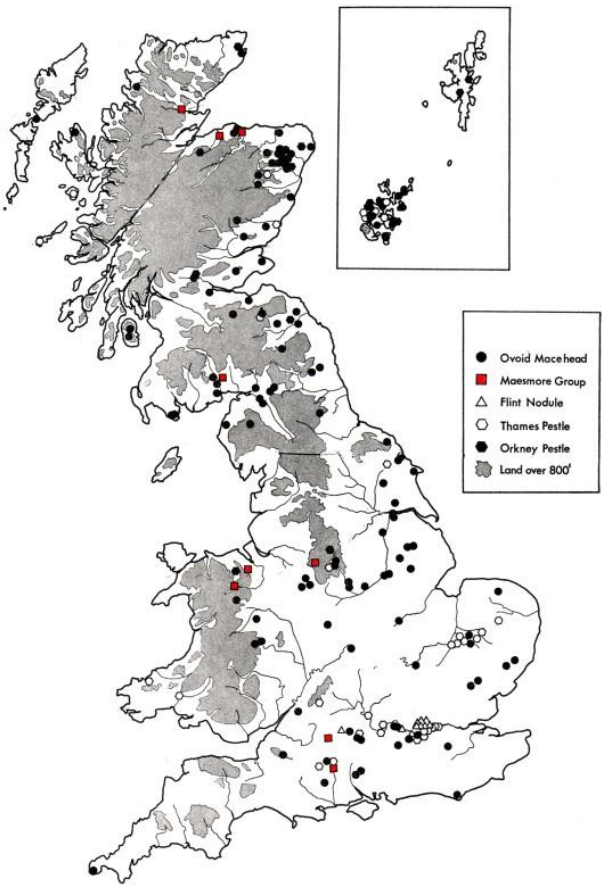

Figure 59: Distribution of maceheads (Roe 1968)

Cushion-type mace-heads which are often of green or greenish stone. These were first studied systematically by Gibson (1944), who pointed out that several are of virtually identical size and shape. However, they are made of various materials, including calcsilicate hornfels from Creag na Caillich (as confirmed by thin-sectioning of the example from Knock, Lewis, for instance), which suggests that they were not all made in the same location.

Macehead distribution in Scotland is uneven (Figure 59), with a marked concentration of all of the main types of macehead in Orkney (but none of Maesmawr type), a smaller but nevertheless important cluster in Shetland, a scatter around the northern, western and south-western coasts and islands of Scotland, and a fair representation in the rich agricultural lowlands of north-east and southeast Scotland (Roe 1967; 1968; 1979; Simpson \& Ransom 1992). The knobbed example from Skara Brae is without parallel in the rest of Neolithic Britain and Ireland. 
Most of these maceheads are likely to have been made using cobbles collected from glacial deposits or riverbeds. The flint/flint-like Maesmawr-type maceheads may well be an exception, and even though an unfinished example was found in the River Tay, the source of the raw material is unknown.

By analogy with battle-axe heads, where experimental replication by Malcolm Fenton (1984) has revealed how long each stage in the manufacturing process would have taken. The most time-consuming part of mace-head manufacture would have been the boring of the perforation, which may well have been done using a wooden drill bit, with plenty of sand and water. The most labourconsumptive type of macehead is the Maesmawr type, where not only would the drilling of the hole have been a risky business (as siliceous stone is prone to breakage during perforation), but the decoration would have involved much painstaking grinding, particularly in the production of the lozengeshaped 'network' design on one or both ends. Such mace-heads were probably made by specialists; they are are scattered widely (but thinly) around Britain and Ireland, and include the famous spiral-decorated example from one of the passage tombs under the largest mound at Knowth, Co, Meath. (The fact that the spiral design on the Knowth macehead is more similar to spirals found in Scotland than those found in Ireland has led to speculation that that macehead may have been made in Britain, possibly even Scotland, even though the stone had probably not come from Scotland: Sheridan 2004.) Also possibly made by a small number of specialist stoneworkers are the cushion maceheads.

The function of these objects has been debated (Roe 1966; 1968; 1977). In theory, all could have been weapons, as they would have been effective in delivering blunt force trauma. However, in addition (or alternatively), they were probably weapons of social exclusion, owned only by the elite, to judge from the care and time expended in their manufacture. Microwear analysis is unlikely to be able to demonstrate whether any had been used for both (or indeed either) purpose. That some had featured in Late Neolithic ceremonies is indicated by the high incidence of mace-heads that have been deliberately broken across their middle, found on the strip of land separating the Lochs of Stenness and Harray between the Stones of Stenness and the Ring of Bookan. This ritual breakage finds echoes in the potlatch ceremonies of north-west America and Canada, where valuable objects were ceremonially broken, to dedicate them to otherworldly forces and to show off the donors' wealth and power. Given that, in Late Neolithic Orkney, we seem to be dealing with a ranked society that was engaged in acts of conspicuous consumption in its monument building (Schulting et al. 2010), it seems likely that mace-heads were also part of the 'vocabulary of esteem', and featured in competitive displays. Indeed, this might partly account for their diversity of shape as ranking markers.

Find contexts include the 'temple complex' at Ness of Brodgar; the settlements at Skara Brae, Barnhouse, Toft's Ness and Rinyo; and chamber tombs, including Taversoe Tuick, Orkney and Tormore, Arran . At Tormore, the mace-head will have represented secondary use of the monuments; it may well have been deposited at the same time as a Grooved Ware bowl, around 3000-2900 BC (Henshall 1972, 305).

The available dating evidence from Britain and Ireland suggests that mace-head use (including the use of antler mace-heads - see section $\mathrm{x}$ ) probably began during the Middle Neolithic, at some time between 3300 BC and $2900 \mathrm{BC}$ - the precise dating being subject to a plateau in the radiocarbon calibration curve - and continued into the Late Neolithic, encompassing the period when Grooved Ware use became widespread (from around $3000 \mathrm{BC}$ ). It should also be pointed out that pestle mace-heads had a second period of use during the Early Bronze Age, as shown by one example found in a cache of objects (including 
a V-perforated button of albertite) deposited on the outside of Isbister chamber tomb, Orkney (Simpson \& Ramson 1992, no. 7), and another, miniature, example, found in a child's grave alongside a Food Vessel at Doune, Perthshire (McLaren 2004). While the Isbister example might represent the collection and re-use of an ancient object, the Doune miniature could have been made during the Early Bronze Age.

That ovoid and pestle mace-heads (along with antler mace-heads) were the earliest types to be used is suggested by the presence of one of each type in the large passage tomb mound at Knowth in the Boyne Valley, with the Maesmawr-type example in the eastern tomb and a fragment of a pestle-shaped mace-head in the western tomb. Recent radiocarbon dating of cremated bone at Knowth will shed new light on the probable date of both mace heads (Schulting et al. forthcoming). The fact that mace-heads also featured in miniature form, as pendants, in several Irish passage tombs including Tara also suggests that they were in use between 3300 BC and 2900 BC. The presence of both a pestle and a cushion mace-head at Barnhouse (Clarke 2005, fig. 14.2 ) is consistent with this date range; recent Bayesian modelling of the $\mathrm{C} 14$ dates (Schulting et al. 2010, 34-5) suggests a start date of $3300-3110 \mathrm{cal} B C$ and an end date of c 2900 cal BC for the use of Barnhouse.

As for the dating of cushion mace-heads more generally, the current dating evidence for the Ness of Brodgar offers a somewhat broad overall bracket of c 3100 BC-c 2300 BC, but this may well become narrowed as more phases of activity are dated. Cushion maceheads found with cremated bone in southern England, at Stonehenge, Wiltshire and at Dorchester-on-Thames, Oxfordshire (in association with bone 'skewer' pins) are likely to date to the early third millennium BC.

The knobbed macehead found at Skara Brae, is dated to between $3100 \mathrm{BC}$ and $2600 \mathrm{BC}$. A pestle macehead, and a small fragment of a cushion macehead, were also found at that site; the former is an old find, with no provenance details, while the latter was from a late context (the uppermost midden).

The main outstanding research questions concerning the contexts and use maceheads are:

- Can the dating - especially of the end of the Neolithic use of mace-heads, and of specific sub-types - be refined?

- Where, and on what scale, were maceheads made? More specifically, where were Maesmawr mace-heads made, and where was the flint/flint-like stone obtained?

- It seems likely that some movement of mace-heads took place (as suggested, for example, by the scatter of finds along the western seaboard of Scotland). Can this be substantiated on petrological grounds, and if so, can the direction and extent of movement be traced? In particular, can movement be traced from Orkney, where many mace-heads seem to have been made and used?

- Were the Knowth maceheads imported from (or via) Scotland?

- Were any used as weapons, and can microwear analysis confirm this?

\section{Carved stone balls}

These internationally esteemed and objects of Scottish prehistory have been the subject of much speculation. Mathematicians have claimed that they represent Platonic solids and many other disparate functions having been suggested (e.g. as throwing weapons, ref). The fact that they are frequently described as 'mysterious' is unhelpful. Stuart Piggott declared 'Their use is wholly unknown' and thus emphasised the need for them to be studied and understood against the background of what we now know about Late Neolithic Scotland (cf. Edmonds 1992).

Over 400 examples of these balls are known, with over $90 \%$ having been found in northeast Scotland, where most are likely to have 
been made. The map of recovery emphasises the absolute dominance of Aberdeenshire finds (although it should be noted that, during the $19^{\text {th }}$ century when much antiquarian collecting occurred, an Aberdeenshire provenance seems to have been desirable, so it may be that a few balls found elsewhere have acquired this as a provenance). The rest of the distribution shows as a smaller concentration within Orkney (where the variety of styles is the broadest), plus a thin scatter around the coast of Scotland, and into northern England and north-east Ireland. One ball has even been found in Norway, but this must have been a Viking period find, taken to Norway as a curio or amulet. Notwithstanding the obvious difference in the densest concentration of finds, the distribution maps for carved stone balls and mace-heads share features in common, (the thin scatter around the Scottish coast and beyond) attesting to a network of contacts operating in Late Neolithic Scotland.

Most of these balls are around $70 \mathrm{~mm}$ in diameter, and some - including the famous ball from Towie, Aberdeenshire (Figure 60) have been decorated with spiral and/or other designs that clearly reference Irish (and Orcadian) passage tomb 'art'. Detailed descriptions and excellent drawings can be found in Dorothy Marshall's corpus (Marshall 1977), which lists the number of balls with four knobs, six knobs, etc.. By far the commonest type is the 6-knob variety, which would have been the simplest to lay out.

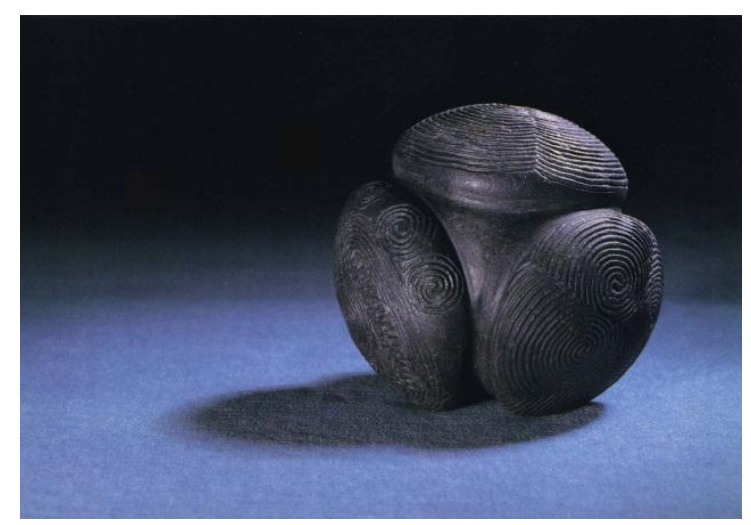

Figure 60: Carved ball from Towie, Aberdeenshire CNMS

As with mace-heads, the makers of carved stone balls sought out stones that are visually and/or texturally striking, likely to have come from glacial deposits and/or river beds. Experimental replication (by David Jones) has suggested that the makers would have selected cobbles that were not too different in size and shape from the desired final product. The shaping and decoration would have taken at least 50 hours, and an estimate of well over 100 hours can be suggested for the highly-skilled manufacture of the Towie ball, with its finely-pecked/incised, intricate decoration.

While the Towie ball represents the peak of the stoneworker's skill, akin to the Knowth Maesmawr-type macehead (with which it shares the use of a spiral design), not all carved stone balls were equally skilfully made, and there are examples that show design faults, with knobs 'squeezed in' to the overall pattern. A few appear to be unfinished.

The most plausible explanation of the function of these balls is that they were symbols of power rather like the orb in the historical symbols of regal power, showing off the status of their owner; some, like the Towie ball, bear symbolically-significant symbols that explicitly evoke decoration also deployed in elaborate passage tombs. Like maceheads, they may well have been 'fancy' weapons; and indeed they could have been mounted as maceheads, with lashing passing through the spaces between the knobs. Alternatively, like the ethnohistoric bolas of 
South America, which they resemble, they could have been throwing weapons, or used at close range, on a short leash. Again, like maceheads, they would have inflicted blunt force trauma if applied to a skull (or any other part of a body). Carved stone balls make sense when seen as one of a suite of fancy weapons used as symbols of power, operating in a society where competitive elite display was an important aspect of the 'vocabulary of esteem'. The fact that the epicentre of their manufacture lay outside Orkney, in Aberdeenshire, reminds us that Orkney was not the sole centre for innovation during the Late Neolithic: to some extent we are dealing with regional centres of 'fashion' in the design of symbols of power. Furthermore, their overall distribution attests to the widespread nature of contacts at this time. They may also serve as a reminder of how significant Aberdeenshire may have been in the course of developments nationally at this period, and how relatively little is known of this significance.

Their dating to the centuries around $3000 \mathrm{BC}$ (i.e. the Middle to Late Neolithic) - at least for their manufacture - is suggested by the fact that beads resembling miniature 6-knobbed stone balls have been found at Knowth, in the tomb under the main mound (Sheridan, in press); like the miniature mace-head pendants, these show that personal jewellery was reinforcing the international 'symbols of power message' among the elite. Again, the recent dating of deposits inside the main mound will shed light on the specific date (Schulting et al. forthcoming). (Note also that several Irish passage tombs contain smooth versions of carved stone balls; these may constitute an Irish variant of the 'carved stone ball' idea, and indeed may have been the source of inspiration for using the ball shape).

Another pointer towards the $c 3000 \mathrm{BC}$ date for manufacture is the fact that the spiral and other designs on some balls so closely evoke the complex, 'plastic style' passage tomb 'art' of the Boyne Valley, which will have been created during the last few centuries of the fourth millennium BC. The presence of carved stone balls at Skara Brae suggests a date bracket for its use between 3100 and 2600 BC.

The key outstanding research questions relating to carved stone balls can be suggested as follows:

- What was their overall currency? When exactly did they begin to be used, and did they continue to be used throughout the Late Neolithic?

- Does the dating of Irish smooth stone balls permit the suggestion that they could have provided the design inspiration for the Scottish carved stone balls?

- Are there any signs of blunt force trauma on human skulls of the period that could have been caused by a blow from a carved stone ball (as opposed to a macehead or club)?

- Might microwear examination reveal any use-wear traces?

\section{Variously-shaped carved stone artefacts}

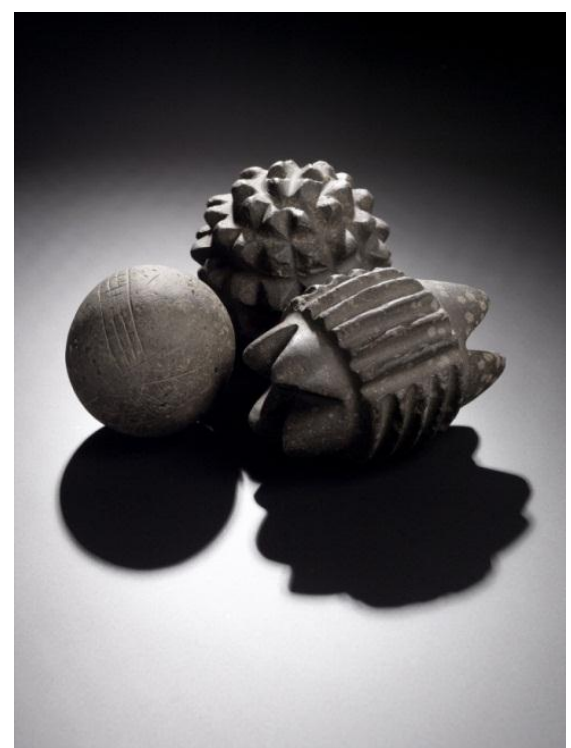

Figure 61: Carved stone objects, Skara Brae CNMS

Mace-heads and carved stone balls form part of a broader range of carved stone objects that belong to the late fourth and/or early third millennia BC. The other, variously- 
shaped objects have all been found in Grooved Ware-associated contexts in Orkney (or as stray finds there), and these include the famous objects from Skara Brae: the hand grenade-shaped item (Figure 61) and the three-pointed object (Figure 62). Similar objects have been found in the Maes Howetype passage tomb at Quoyness and the Ness of Brodgar 'temple complex' has produced a further type of object that falls within the same conceptual grouping, in the form of roughly rectangular, solid, polished blocks of visually-attractive stone .



Figure 62: Three pointed object, Skara Brae CNMS

In every case these objects can be considered as fancy weapons, which could have been carried in a fist (rather like the spiked 'meanies' of some native American tribes) or else, in some cases (e.g. the Ness of Brodgar blocks), mounted as a mace. Like the carved stone balls and maceheads, these could all have delivered a painful, indeed lethal, blow. These seem to have been the products of a society where authority could be enforced through violent means, if necessary, and where the elite competed with each other in having novel shapes of weapons. Again, an analogy can be drawn with the ethnohistoric record of North America, where weaponry (including tomahawks and maces) shows a wide variety in design.

Among the odd-shaped stone objects from Skara Brae and elsewhere are some which could, theoretically, have had a more prosaic function. These include the knobbed spike from Skara Brae, with a parallel from Rinyo while this could indeed have been one of the fancy weapons, it could also have been used as a fish gaff, a seal club or to despatch animals, since a blow to the skull would fell a cow or ox instantly. A cattle skull from Skara Brae has a roughly circular hole between the eyes that could, theoretically, have been caused by a blow from this kind of object. Similarly, the relatively thin, hatchet/cleaverlike object could have been just that. The starshaped object that is covered under section 5.2.7 could equally be regarded in this category - i.e. as a utilitarian object which, because of its unusual shape, has tended to be lumped in with the more obvious fancy weapons.

Research questions relating to these objects are:

- What is the overall range of forms of 'fancy weapons'? No overall corpus exists.

- How might one tell whether an object had been a utilitarian item as opposed to a symbol of power? (There may be a false dichotomy here, since innovation in design need not be restricted to prestige items.). Enhanced micro-wear study?

- What is the overall chronological currency of use of these objects?

- Are any comparanda known from outside Orkney?

- Do any human skulls show wounds that could have been caused by these objects? And might use-wear analysis shed any new light on their use?

The figurine from the Links of Noltland 


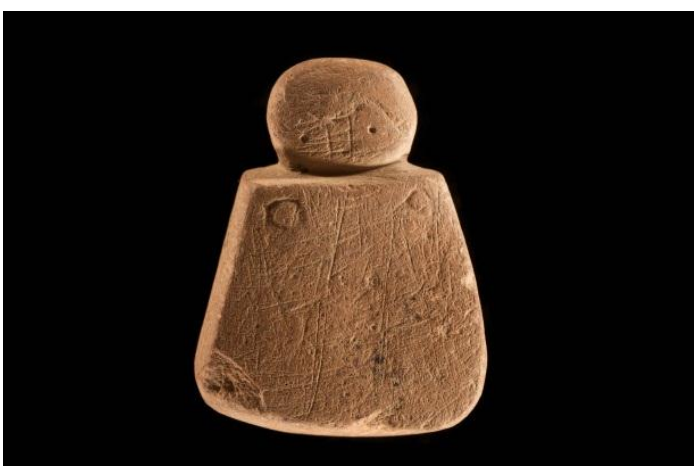

Figure 63: Links of Noltland figurine CHistoric Scotland

This small anthropomorphic figurine (Figure 63 ), only $41 \times 31 \times 12 \mathrm{~mm}$, was found in 2009 at the Late Neolithic settlement at the Links of Noltland on Westray (Goring 2011) and has since become internationally known as the 'Orkney Venus' (http://www.historicscotland.gov.uk/orkney-venus.pdf), or the 'Westray Wifie' (http://en.wikipedia.org/wiki/Westray Wife), replicated in popular biscuit form by local bakers WFM Brown, and also in Warholesque artwork by a local artist.

Probably made from a beach cobble, it has been shaped so as to depict a figure - either human or divine - with a round head, angular eyebrows and rectangular nose. The body appears to be wearing a cloak; two circular hollows at the shoulder have been suggested to be breasts, although an alternative interpretation as garment fasteners (e.g. the heads of large pins) is possible. To judge from the recently-obtained radiocarbon dates from the Links of Noltland (Moore \& Wilson 2011, $38-9)$, the figure may well date c 2900-2600 BC.

This has been hailed as the earliest representation of the human form in Scotland, and it is of particular significance because the 'eyebrow motif' is also found pecked into a structural stone at the Holm of Papa Westray South chamber tomb nearby (Davidson \& Henshall 1989, plate 24), and on the chalk 'drums' from Folkton, Yorkshire (Longworth 1995), suggesting that it had a particular significance in Late Neolithic cosmology. This is what has given rise to the idea that the figure may depict a deity, perhaps an ancestor. How the object was used, remains a mystery.

It is not, however, the only such object to have been found in Late Neolithic Orkney; a second figurine, in baked clay, was found at the Links of Noltland in 2010, and one or two other possible examples are known. The discovery, in 2011, of a segmented, baked clay anthropomorphic phallus at Ness of Brodgar hints at variability in Late Neolithic representational objects.

The key research question to be answered is:

- What is the significance of this figurine? Was it a sacred object, used in rituals? Or might it have had a more prosaic function - even perhaps as a toy? - The contextual background of both finds at the Links of Noltland needs to be probed to investigate whether these can shed light on its function.

\subsubsection{Stone used for personal ornamentation}

Beyond Orkney there is relatively little evidence for the use of jewellery or dress accessories, of any materials, in Neolithic Scotland. However, stone - in the form of jet, cannel coal and oil shale - does feature in the visually striking, so-called 'monster beads' of the Early to Middle Neolithic, and in the belt sliders of the Middle Neolithic; and there are also a few stone beads other than 'monster beads'. 


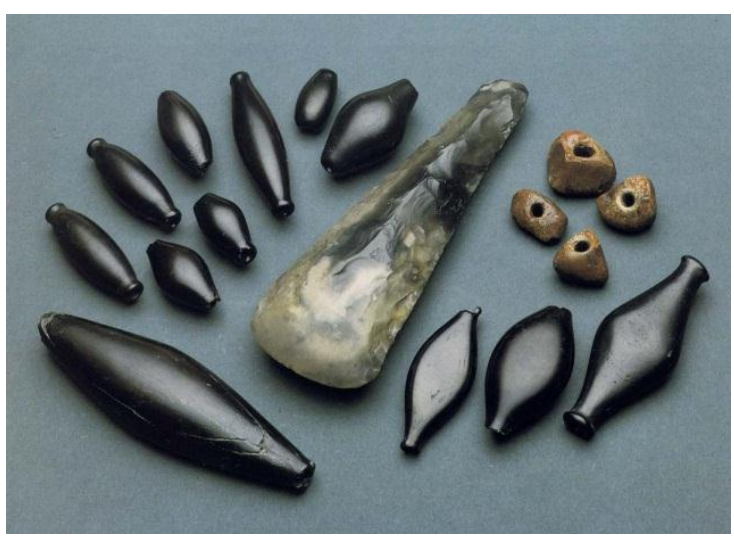

Figure 64: Necklace of jet and amber beads, and associated flint axehead, from Greenbrae, Cruden, Aberdeenshire. (C) NMS

'Monster beads' are large, oval beads up to $115 \mathrm{~mm}$ long (in the case of a cannel coal example from Watch Hill, Skene, Dumfries and Galloway). Some have collared ends. They are of a type of jewellery that is widespread in Early to Middle Neolithic Britain, with examples known as far away as Devon; in Scotland the distribution extends as far north as Greenbrae, near Peterhead, Aberdeenshire, where an entire necklace was found in 1812 (Figure 64; Kenworthy 1977). The 12 beads here are of hard Whitby jet, and the necklace had also included four beads of amber, representing pieces that had been collected from the shore - probably in Yorkshire - and simply perforated. The necklace was accompanied by a flint axehead, and the whole assemblage is likely to have been imported from Yorkshire. The objects are reported to have been found in a mound, and it is possible that this had been a grave for a significant individual. Jet may well have been believed to have magical properties, as a stone that is warm, that floats, that can be burnt and that is electrostatic (Sheridan and Davis 2002). One relatively recent find is a bead from a house at Pitlethie Road, Leuchars, Fife, and its publication (Sheridan 2007) reviews the finds from Britain although two others have since been found in England.

Beads and other ornaments made from materials other than jet are likely to have been made in Scotland, using locally-available jet substitutes, such as oil shale and cannel coal in order to emulate the jet ones.

The date of these beads has been reviewed by Sheridan (2007), who suggests that while they do not belong to the earliest Neolithic, a currency within the $38^{\text {th }}-35^{\text {th }}$ or $34^{\text {th }}$ century $\mathrm{BC}$ seems possible. The question of the lower end of this date range is a matter for debate, hinging upon the currency of the specific type of blade-polished flint axe-head (as found at Greenbrae) in Yorkshire.

It is not known whether the use of 'monster beads' was gender-specific.

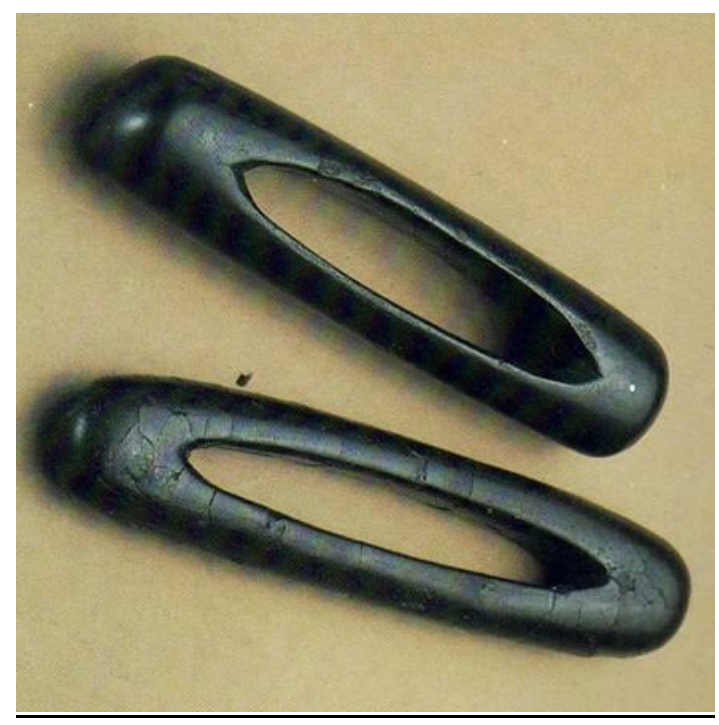

Figure 65: Belt sliders from (top) 'Skye' and (bottom) Beacharra, Argyll \& Bute. CNMS

Belt sliders (Figure 65), like 'monster beads', were prestigious possessions, again made of jet and substitute jet-like materials. They are slightly later than 'monster beads', being of Middle Neolithic date and with a currency within the 3300-2900 BC bracket. The distribution map (Figure 66) shows that these are widely distributed in Britain, with a concentration in Yorkshire, the source of the jet; within Scotland, there is a bias towards the south, with the alleged findspot of 'Skye' having been challenged (Clarke et al. 1985, 238). Again, emulation of jet examples in local materials took place, with the 'Skye' example of cannel coal or shale, while the example 
from the Clyde cairn at Beacharra is of Whitby jet.

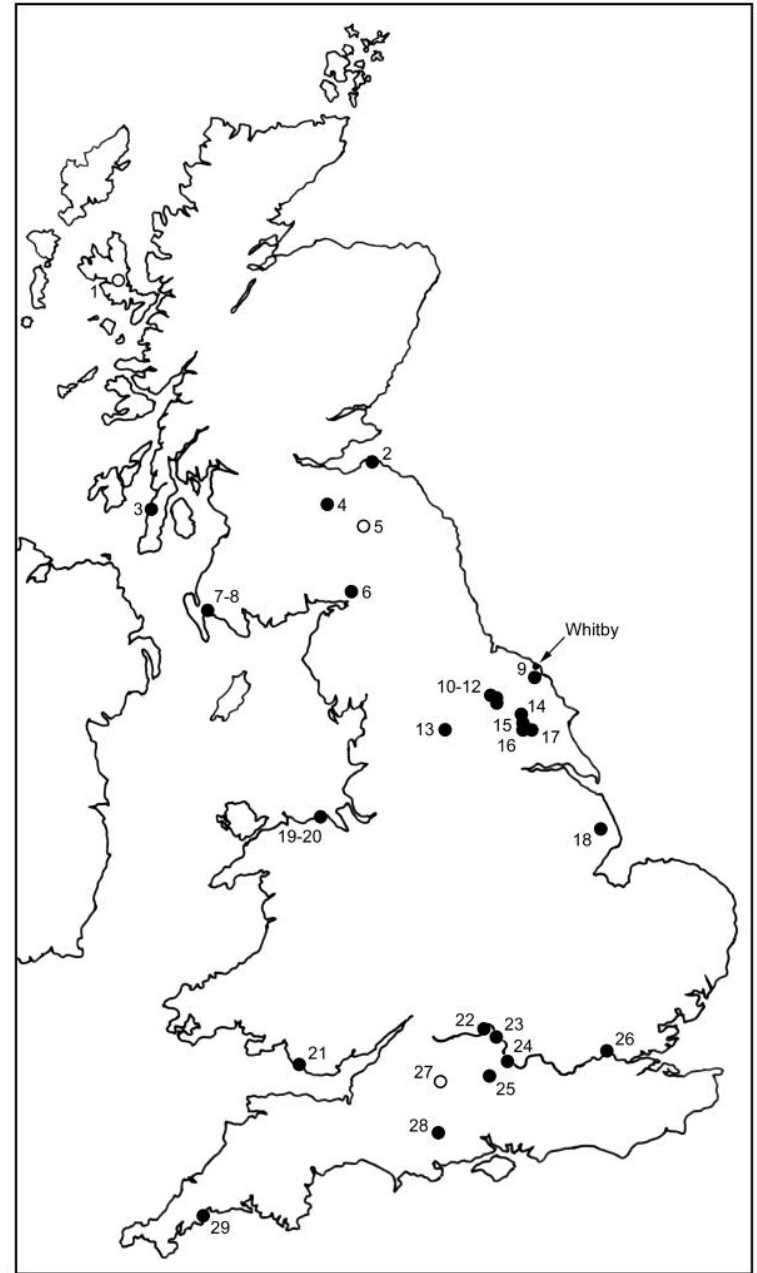

Figure 66: Distribution map of belt sliders CNMS

These have tended to be found in funerary contexts, where (in English findspots) they are associated with single graves (under round or oval barrows, and/or within a ring ditch) of individual adult men. At Beacharra, the presence of the slider indicates secondary use of an already centuries'-old chambered tomb.

Miscellaneous stone beads: these include five black stone beads from Skara Brae, which Childe had assumed to be jet but which have been shown, by XRF analysis by Mary Davis, to be made of a stone other than jet (probably of Orcadian origin). A few other stone beads were found at Skara Brae.
A Late Neolithic bead of lead ore, found in Quanterness passage tomb, should be mentioned here. Needless to say, the use of this material does not imply any knowledge of metal during the Late Neolithic; instead, we should see it as the use of an attractive, locally available stone, distinguished, and possibly lent liminal power, by its weight.

There may be one or two other stone beads from Neolithic contexts in Scotland and it would be useful to undertake a thorough search. The globular jet bead found in a chamber tomb at Cairnholy is not Neolithic, but instead relates to an Early Bronze Age secondary reuse of the monument.

\section{Outstanding research questions}

- Refinement of the dating of 'monster beads' would be useful, by getting reliable AMS dates for the contexts of any such beads found in the future, and by paying attention to any dates that are acquired for the specific type of edge-polished axehead that accompanied the Greenbrae beads.

- It would be useful to 'bottom out' the question of whether the 'Skye' slider had indeed been found there; this is a matter of trawling through antiquarian documentation (since this is a very old find), although it is quite possible that no relevant information exists. 
5.2.6 Stone as used as a building material, and for interior fittings

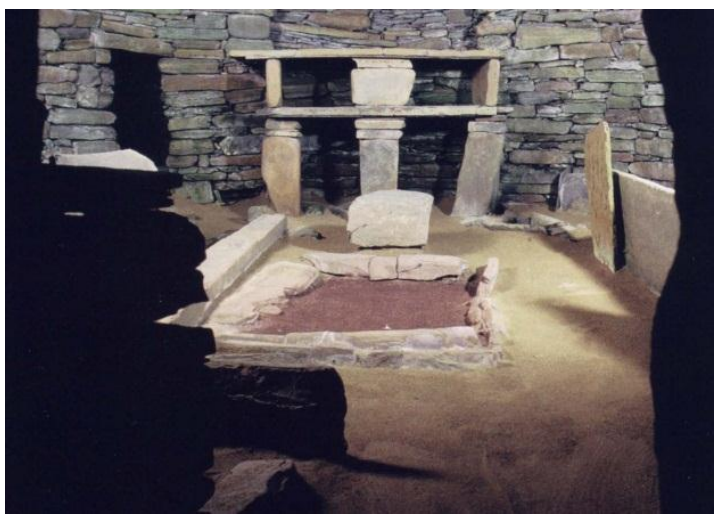

Figure 67: Interior of a 'house' at Skara Brae @

Stone was used to construct monuments over large parts of Neolithic Scotland, and in the Northern Isles, where wood was scarce, it was used extensively in the construction of houses and their internal fittings - which is why Skara Brae has survived as northern Europe's best preserved settlement (Figure 67). (In the Western Isles, where wood was equally scarce, stone does not feature in domestic architecture as prominently, but this is probably because greater use was made of turf there, and also the stone may not have been as easy to work as the tabular Orkney flagstone.)

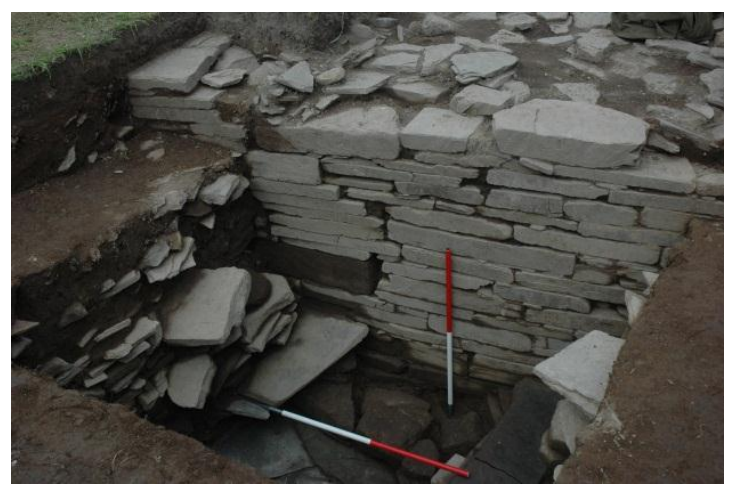

Figure 68: The Lesser Wall of Brodgar revealed to its full surviving height CORCA

The skill of the Neolithic stoneworkers is obvious from the Ness of Brodgar, which has produced some of the most accomplished examples of drystone wall construction in the whole of prehistoric Europe. The aesthetic and ideological significance of stone is clear from examples such as the arrangement of flags to form a design similar to that seen on Unstan bowl collars at Unstan chamber tomb (and elsewhere in Orkney) (Figure 69): verily the tomb was used as a 'vessel for the ancestors' (cf. Sharples \& Sheridan 1992).

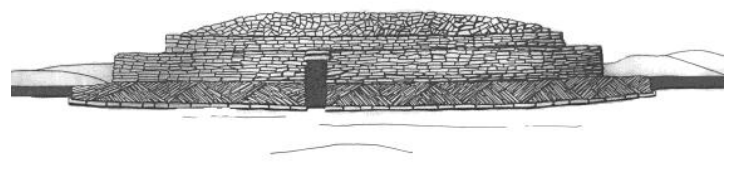

Figure 69: Unstan chambered tomb @check

Until recently, however, relatively little attention was paid, in Scotland, to the sourcing of structural stone, to its working, or to the reasons behind the use of specific types of stone. However, Colin Richards' work on seeking the source of the stone used to create the Ring of Brodgar in Orkney, and the Calanais monuments on Lewis, has directed attention to questions of stone quarrying and movement, while work by Lekky Shepherd (2000) on the decoration of structural stone and internal fittings at Skara Brae has led the way in exploring how stone could be used to express identity.

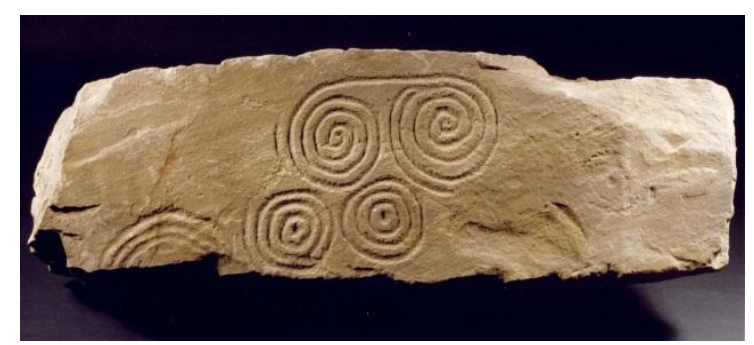

Figure 70: Eday Manse IA 2

This work continues in the current research by Antonia Thomas, who is reviewing all decorated stone in Neolithic Orkney and in particular the adornment of stone - not just by incising designs but also by painting, at Ness of Brodgar. Other adornment of stone takes the form of the designs - some relatively simple, others complex - found on Maes Howe-type passage tombs in Orkney . 


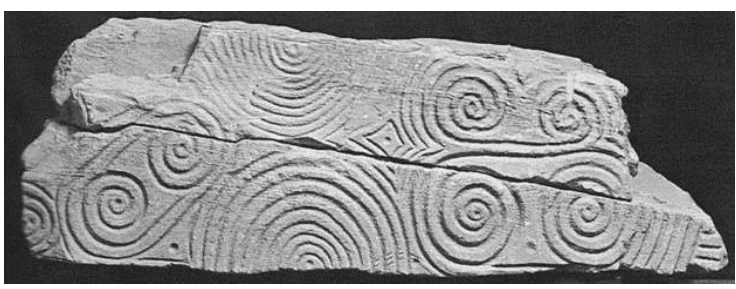

Figure 71: Pierowall stone henshall book

Furthermore, John Barber's experimental reconstruction and collapsing of a chamber tomb has explored issues of the architectural and engineering aspects of building in stone (following his earlier work on the construction of the Point of Cott (Barber 1997) and on the construction of chamber tombs in general (Barber 1992), and it has also shown what happens when a structure collapses. This has provided invaluable insights into the movement of chamber tomb deposits as a result of structural collapse.

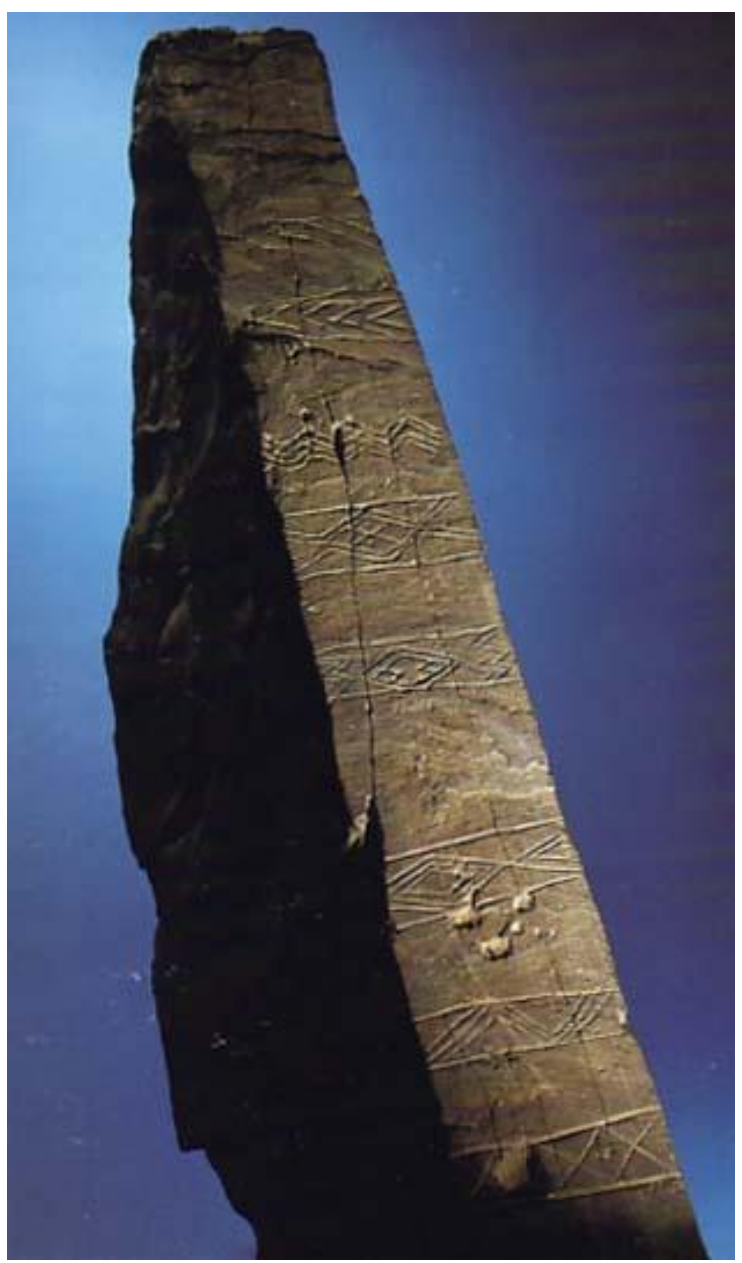

Figure 72: Brodgar stone
Other aspects of stone use have, however, received relatively little attention, and in the light of recent research by others such as Richard Bradley, David Trevarthen, and Emmanuel Mens on monuments in Scotland and elsewhere, the following research questions could usefully be addressed:

- To what extent was colour, texture or other properties of stone a factor in the selection of particular stones for use, and their specific positioning, in monument construction? The use of quartz, for example, may well have had particular significance, especially given its later use in some recumbent stone circles, and given the practice of ritually smashing quartz. The importance of colour selection has been highlighted by Richard Bradley's work on the Chalcolithic or Early Bronze Age Clava cairns (Bradley 2000).

- Can the châine opératoire of monument construction be reconstructed, using the principles of 'virtual refitting' as used to such striking effect by Emmanuel Mens in his examination of the construction of Carnac in Brittany? If so, how were outcrops exploited, and was there any significance in the choice of which face of the rock (i.e. quarried, vs weathered) was used in a particular position in a monument?

- Continuing the research of Colin Richards, how far was stone moved in order to create specific monuments? Is there any patterning in its use by monument type? Was the stone brought from various locations as 'tribute' from differing social groups?

- Can particular traditions in the architectural use of stone be identified (other than the fine use of Orkney flagstone in Orkney)?

\subsubsection{Miscellaneous uses of stone}

This category encompasses the types of stone, and types of use, that are not covered within 
the previous categories. The evidence is dominated by Late Neolithic Orcadian finds.

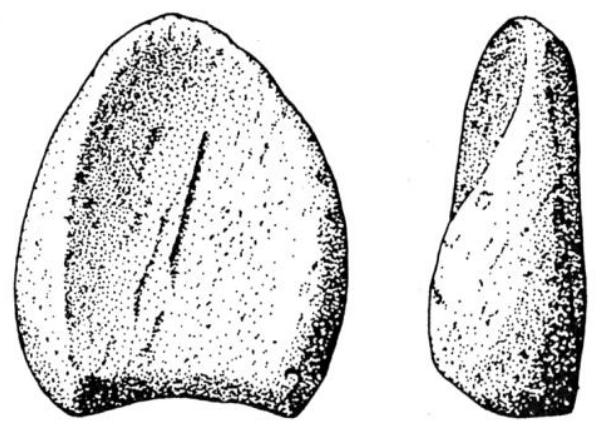

Figure 73: Used piece of pumice from Skara Brae CNMS

There is evidence, from the Northern and Western Isles (e.g. at Skara Brae, the Links of Noltland and Ness of Brodgar on Orkney, at Eilean Domhnuill, Loch Olabhat, North Uist and at Northton, Harris), that pumice (produced by volcanic eruptions probably in Iceland and washed ashore in Orkney and the Western Isles) was collected from the shore and used as an abrasive (e.g. for smoothing and sharpening bone objects, such as the large fine pins as found at Skara Brae) during the Neolithic (Figure 73).

It has not been found on sites lying over 10 $\mathrm{km}$ from the coast, however, suggesting that its use was opportunistic rather than systematic. The pumice is datable to specific eruptions by means of the tephra it contains; Peter Ditchfield, at the Oxford Laboratory for Art and Archaeology, is currently researching this matter, and samples from Northton have been taken for this purpose.

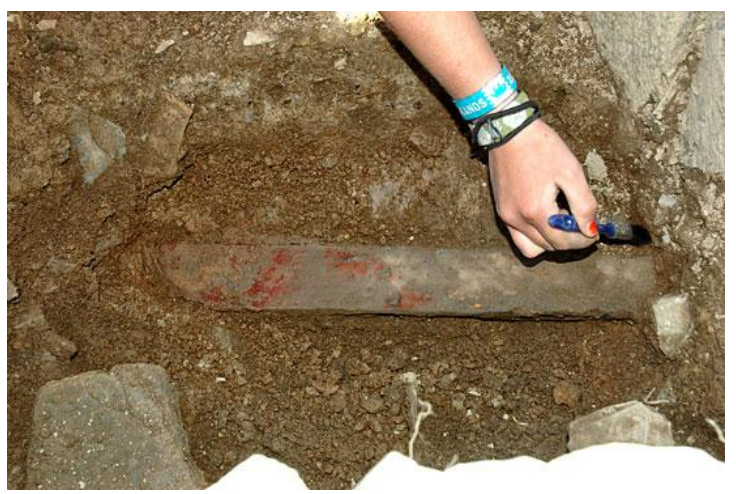

Figure 74: Painted slab discovered in Structure
Eight under excavation at the Ness of Brodgar CORCA

Ochre (hydrated iron oxide, limonite) was used as a colourant in Late Neolithic Orkney where it is readily found as a loose, earthy stone - and the spectacular recent discovery of painted stones at Ness of Brodgar demonstrate one of the uses of this substance, which produces yellow and brown colours. Small containers of stone, whalebone, fired clay and limpet shell, used for grinding small spherical lumps of ochre (which must have been mixed with some kind of binder, possibly fish oil or blubber), are known for example from Skara Brae, where Childe described them as 'paint pots' (Figure 75 and Figure 77).

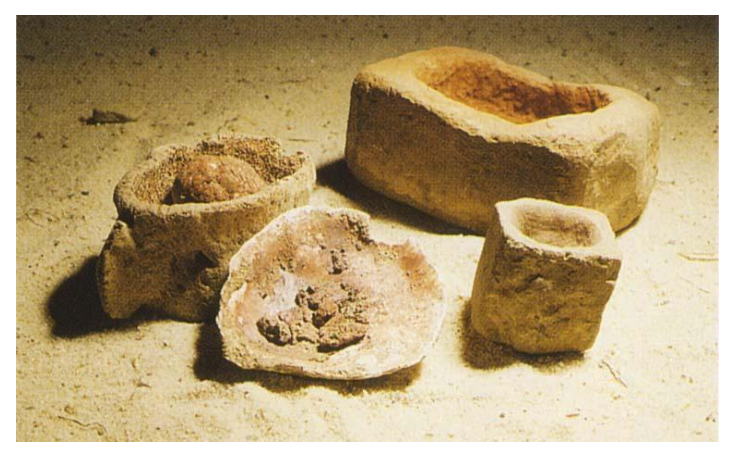

Figure 75: Ochre grinders, Skara Brae @NMS

Haematite (the mineral form of iron oxide) is also known to have been used in Late Neolithic Orkney, with lumps and traces being found, for example, at Skara Brae and Crossiecrown and, most spectacularly, as painted pigment on stones at Ness of Brodgar (Figure 74). 


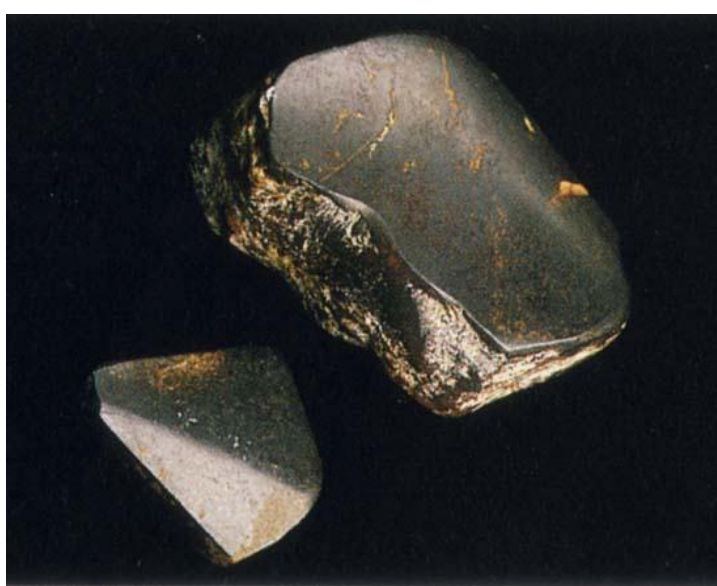

Figure 76: Haematite, Skara Brae @NMS

This mineral (Figure 76), which occurs as solid nodular lumps, probably had two functions: firstly, as a producer of red and red-brown pigment (as indicated by the Ness of Brodgar painted stones, and demonstrated experimentally by Arlene Isbister (Isbister 2000)); and secondly, as a polisher for hides (although this function has not been demonstrated, and the many cattle astragaloi found with rub-wear at Orcadian Late Neolithic sites may have additionally, or alternatively, served that purpose). Haematite could have been used in two ways to create pigment: it could have been powdered and mixed with water (as seems to have been the case, for example, with the whalebone 'paint pot' from Skara Brae in Figure 77).

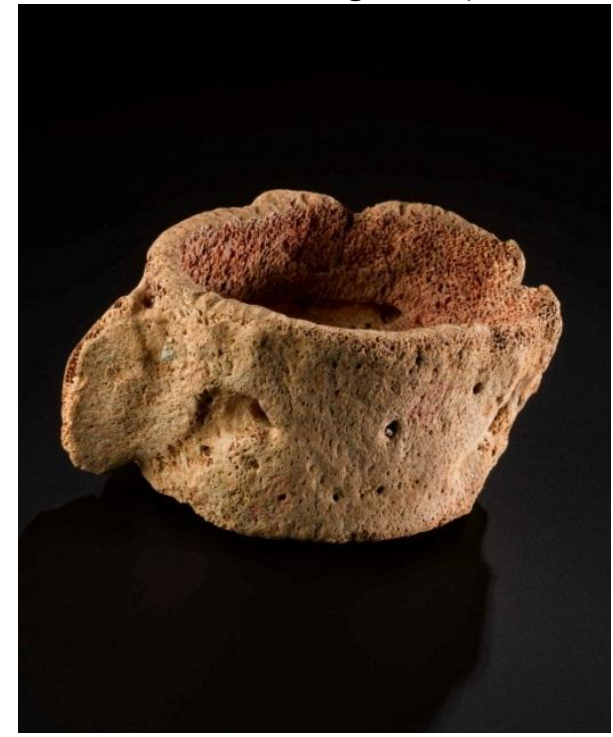

Figure 77: Whalebone 'paint pot' for ochre CNMS

Alternatively, Isbister's experimental work has shown that the distinctive facets seen on many lumps of haematite could have been produced by pulling a nodule along a carved groove, to fill the groove with pigment. That other substances in addition to ochre and haematite had been used in Late Neolithic Orkney to produce pigments is suggested by George Petrie's observations of finding masses of red and white pigments at Skara Brae, along with 'a small piece of red pigment, which had apparently been partially rubbed down' (Petrie 1867, 210).

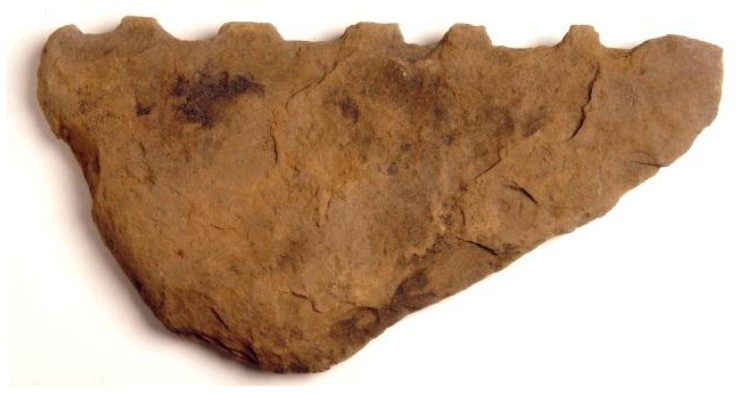

Figure 78: Crenellated flagstone, Skara Brae CNMS

The other stones included in this section come under the heading of 'mystery items', whose function is uncertain, and comprise:

i. a star-shaped plaque of shale or shalelike stone from Skara Brae (Figure 79), which could have been used as a kind of bobbin, for storing or winding cord; a similar object is known from Taversoe Tuick, Rousay and

ii. ii) a sizeable slab of sandy flagstone with a deliberately crenellated upper edge (Figure 78), again from Skara Brae (with a parallel from Ness of Brodgar and one other Orcadian site).

There is an echo, in the design of these stones, of the devices used in the recent past elsewhere in the world for scutching flax, although in the absence of evidence for flax cultivation in Late Neolithic Orkney (although evidence does exist elsewhere in the UK, including Balbridie, Aberdeenshire), this cannot be put forward as a strong suggestion. In theory these slabs could have been used for threshing cereals, but other uses are possible, and indeed these need not have been utilitarian objects. (cf. some of the 
'special stone objects' described above, which may have had a utilitarian function.)

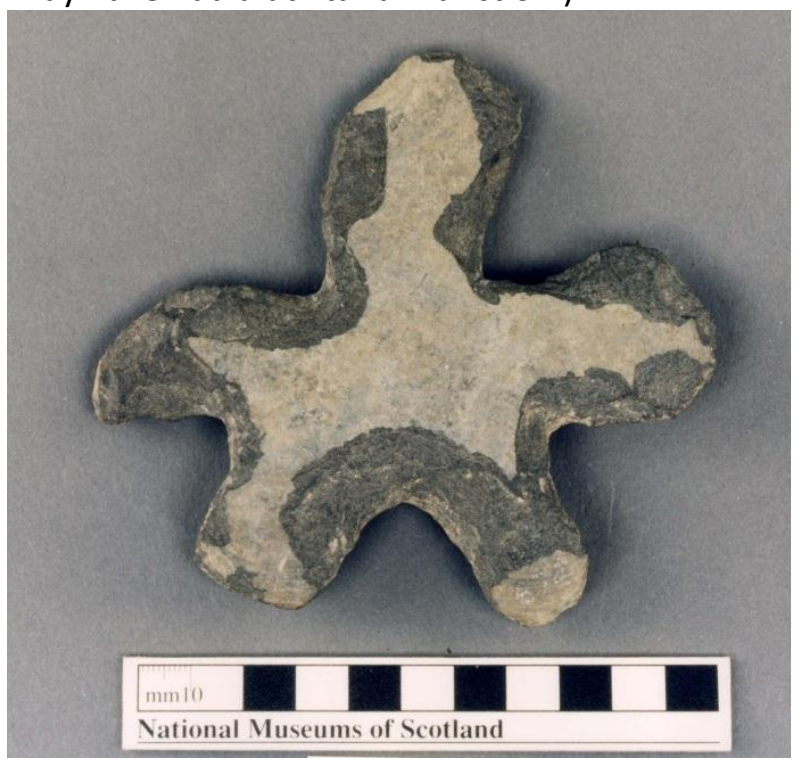

Figure 79: Star shaped plaque of shale or shale like stone, Skara Brae. CNMS

The research questions surrounding all the stone covered in this section are as follows:

- Is the use of colouring agents in Neolithic Scotland limited to Late Neolithic Orkney? Researchers need to check for traces of pigment in artefacts and structures (and indeed on bones). Restraint is required in the initial cleaning of artefacts as recovered from the ground.

- What use was made of pigments, other than to decorate structural stones?

- What was used instead of pumice as an abrasive in inland sites? Was it sandstone or sand? Microwear analysis of artefacts might be able to shed light on this.

- What was the function of the 'mystery objects'? If the crenellated stones had been used for threshing, how would this work?

\subsection{Organics}

Despite the fact that Neolithic people will have relied on organic materials for all aspects of their life - from clothing to tools, containers, ornaments, structures and fittings, boats etc - organic artefacts (and organic remains in general) in Neolithic Scotland are, for most of the country, very rare indeed due to the adverse preservation conditions. In many areas, the record consists solely of fragments of charcoal from hearths or burnt structural timber. However, one important exception is the sandy parts of Orkney, from where several sizeable assemblages of artefacts of bone, antler and marine mammal ivory (plus small assemblages of wood and plant material artefacts) have been excavated (e.g. at Skara Brae and the Links of Noltland: Clarke 1976; 1989). Bone and antler objects have also been found in Neolithic contexts in the sandy areas of the Hebrides (e.g. at Northton on Harris: Simpson et al. 2006) and in both of these archipelagos, bone will have been used as a substitute for wood, which would have been in short supply. Wellpreserved organic remains were also encountered in the waterlogged levels of the Neolithic crannog-like settlement at Eilean Domhnuill, Loch Olabhat, N. Uist (Armit 2004), but because of the cost of retrieving and conserving such finds, these were left in situ for the benefit of future generations.

Scotland's Neolithic organic artefacts will be dealt with in three parts: bone, antler and marine ivory (5.3.1) - and shell will be included with these, even though technically it is inorganic; wood and other plant material (5.3.2); and textiles and animal skins (5.3.3).

\subsubsection{Bone, antler, marine ivory and shell} The record for the use of these materials is wholly skewed towards Late Neolithic Orkney, where large assemblages have been excavated at Skara Brae and the Links of Noltland, and smaller assemblages at Pool, Toft's Ness, Rinyo, Knap of Howar and Ness of Brodgar (inter alia). Small assemblages are also known from elsewhere in Scotland, 
mainly in the Hebrides and notably at Northton, where a crown antler mace head had been found (Simpson et al. 2006, 74, fig. 2.34.15). This object will be considered further below.

Some idea of the amount of material found at the Orcadian sites is provided by Andrew Foxon's doctoral research (1991; available online from Glasgow University: http://theses.gla.ac.uk/1157/) into the assemblage excavated at Skara Brae by Gordon Childe in the 1920s and 1930: this comprised some 6270 individual items. Several thousand more were excavated by David Clarke during his 1972-3 and 1977 excavations (Clarke in prep.).

The Skara Brae material and the other Scottish Neolithic assemblages demonstrate that bone, antler, marine ivory and shell were used extensively, skilfully, and in a varied manner: as with other resources, Neolithic people were well versed in making the best use of the materials available to them. (For example, many piercing tools were made using cattle and sheep metapodials, whose solid exterior could easily be shaped into strong points.) In the case of Orkney and the Hebrides, the shortage of wood meant that some objects that are likely to have been made of wood elsewhere (e.g. cups and containers) were made of whale bone, or of other materials. Bone and antler would indeed have been 'the plastic of prehistory'.
As regards the procurement of the raw materials, bones from cattle, sheep and other domestic species would have been available through normal slaughtering for food. Antler appears to have been both collected as shed antler and obtained through butchery; nonshed antler and deer bone could have been obtained by hunting (although it has been suggested that Orcadian Neolithic deer were introduced by man to the islands and were probably a semi-domesticated species; and see Sharples 2000 on the special role of deer in Orcadian Neolithic society). Boar's tusks would have been obtained through hunting. Bones and ivory from marine creatures would probably have been obtained in an opportunistic manner, as they became stranded or embayed; there is no evidence for the deliberate sea-borne hunting of such creatures. The use of walrus ivory, killer whale tooth ivory and sperm whale tooth ivory is attested. Fish would, however, have been obtained through fishing, and the large size of some of the Neolithic fish at Skara Brae suggests deep-water long-line fishing. Shellfish/shells would have been gathered from the shore. The working of these materials on site is attested by the abundant evidence for bead- and pendant manufacture at both Skara Brae and the Links of Noltland.

The range of objects made of these materials, at Skara Brae and the Links of Noltland, can be summarised as follows (and see Figs. $X-X$ for examples):

Table 3: INSERT CAPTION

\begin{tabular}{l|l|l|l|l|l|l|l|l|l}
\hline Object & $\begin{array}{l}\text { Domestic } \\
\text { mammal } \\
\text { bone }\end{array}$ & Antler & $\begin{array}{l}\text { Deer } \\
\text { bone }\end{array}$ & $\begin{array}{l}\text { Boar's } \\
\text { tusk }\end{array}$ & $\begin{array}{l}\text { Marine } \\
\text { ivory }\end{array}$ & $\begin{array}{l}\text { Whale- } \\
\text { bone }\end{array}$ & $\begin{array}{l}\text { Fish } \\
\text { bone }\end{array}$ & $\begin{array}{l}\text { Sea } \\
\text { shell }\end{array}$ & Other \\
\hline $\begin{array}{l}\text { Structural (eg } \\
\text { roofing) }\end{array}$ & & & & & $\mathrm{X}$ & & & \\
\hline Scapula shovel & $\mathrm{X}$ & & & & & & & & \\
\hline Mattock & $\mathrm{X}$ & & & & & & & & \\
\hline Adze & $\mathrm{X}$ & & & & & & & & \\
\hline $\begin{array}{l}\text { Adze sleeve/ } \\
\text { other socket/haft }\end{array}$ & & $\mathrm{X}$ & & & & & & & $\begin{array}{c}\text { walrus os } \\
\text { penis }\end{array}$ \\
\hline Slice/knife/chisel & $\mathrm{X}$ & & & & & & & & \\
\hline Pick & & $\mathrm{X}$ & & & & & & & \\
\hline Whistle & $\mathrm{X}$ & & & & & & & & \\
\hline
\end{tabular}




\begin{tabular}{|c|c|c|c|c|c|c|c|c|c|}
\hline $\begin{array}{l}\text { Polisher/ } \\
\text { smoother }\end{array}$ & $x$ & & & & & & & & \\
\hline Spatulae & $X$ & & $X$ & & & & & & \\
\hline $\begin{array}{l}\text { Fabricators (for } \\
\text { working lithics) }\end{array}$ & $x$ & $x$ & & & & & & & \\
\hline $\begin{array}{l}\text { Container (cup, bowl } \\
\text { etc) }\end{array}$ & & & & & & $\mathrm{X}$ & $x$ & $x$ & \\
\hline Awl/borer/point & $x$ & & & & & & & & Bird bone \\
\hline Needle & $x$ & & & & & & & & \\
\hline pin & $x$ & $x$ & & & & $x$ & & & Bird bone \\
\hline Bead & $x$ & $x$ & $x$ & & $x$ & $x$ & $x$ & $\mathrm{x}$ & $\begin{array}{c}\text { Dom. } \\
\text { animal } \\
\text { tooth }\end{array}$ \\
\hline Pendant & $x$ & $x$ & & $x$ & $x$ & & & & \\
\hline 'dice’ & $x$ & & & & & & & & \\
\hline other/indet & $x$ & & & $x$ & & & & & \\
\hline
\end{tabular}

Clearly, then, bone and the other materials played an important part in several aspects of everyday life, providing the raw material for tools, containers, structures and items of personal adornment (including the large pins, used to fasten garments, some of which have perforations or bulbs to help prevent them from slipping). Regarding the latter, containers made from scallop shell - like their counterparts in bone and stone - were used as dishes for grinding ochre, a colourant. The huge number of beads found at Skara Brae contrasts markedly with Grooved Ware contexts outside of Orkney, where beads are extremely rare.

The antler 'mace head' from Northton - if indeed it had been used as a ceremonial object, rather than as a hammer (for which there is no clear evidence) - represents a type of object that is widespread in Middle to Late Neolithic Britain. Initially reviewed by Derek Simpson in 1996 (and found to comprise 58 examples from Britain, most (41) coming from the Thames and its tributaries), this class of objects was subjected to a radiocarbon dating programme during the early 2000s (Loveday et al. 2007) and found to date mostly to between 3300 and 2900 BC; the Northton example was not directly dated, but had come from the same general level as the bulk sample of animal bone that produced a C14 date of $4411 \pm 79$ BP $(3350-2890 \mathrm{cal} \mathrm{BC}$ at $2 \sigma$, BM-705).

The principal outstanding research question is:
- To what extent is the evidence from the Northern and Western isles atypical, vis-à-vis the use of these resources in Neolithic Scotland? Is it right to assume that marine resources would not have been used inland, and that in areas rich in wood, some object types (e.g. containers) would have been made of wood.

In order to answer this question, there needs to be excavation of well-preserved organic material, and this cannot generally be planned (although the waterlogged levels at Eilean Domhnuill, Loch Olabhat, North Uist) might shed further light on the use of these materials in the Hebrides.

Other research questions are more specific, and include:

- What is the full range of species used in Late Neolithic Orkney? A recent reexamination of some of the Skara Brae jewellery suggests that the range may be wider than previously suspected.

\subsubsection{Wood and other plant material}

Artefacts (other than the burnt or decayed remains of structural wood, or wood used in fires) of these materials are much rarer than those of bone, antler and ivory, and in some cases they exist only in the form of 
impressions left in pots (and in daub), or as skeuomorphs (in pottery). However, the few wooden artefacts that do survive include two of major national (and indeed international) importance, namely: i) a flatbow of yew from Rotten Bottom, Dumfriesshire (Fig. $x, y$; Sheridan 1992; 2007) and ii) an axe haft, of rosaceous wood, from Shulishader, Lewis (Figure 80; Sheridan 1992). Both were found in peat and had probably originally been deposited in pools; their waterlogging has preserved the wood. Both are on display in the National Museum of Scotland.

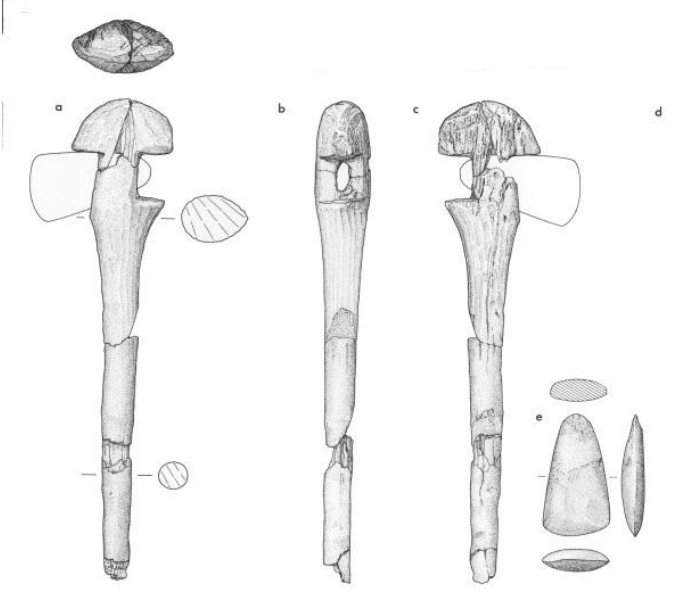

Figure 80: The Shulishader axe. Drawing by Helen Jackson for NMS

The Rotten Bottom bow, radiocarbon dated to $5040 \pm 100$ BP (4040-3640 cal BC at 2 $\sigma$, OxA3540 ), is the oldest bow in Britain and Ireland and belongs, formally, to the Early Neolithic. Skilfully made from a single stave of yew, it now measures $1.36 \mathrm{~m}$ but would originally have measured $1.74 \mathrm{~m}$, having broken in use, at full draw, almost certainly during a deer hunt. Its estimated draw-weight of 35 lbs $(15.86 \mathrm{~kg})$ for a $28^{\prime \prime}(71 \mathrm{~cm})$ arrow indicates that it had been designed as a hunting bow, for use at very close range (10-15 m). It was found near the end of an upland valley in the hills above Moffat, in a position which would have been ideal for hunting deer (since the animals, having been driven along the valley towards the precipice, would have wheeled round at this point). Having broken, this precious possession could not have been mended, although its string would have been removed for re-use. It had probably been imported to Scotland since yew did not grow in Scotland at this period (except perhaps for one or two tiny areas in the south); it is most likely to have come from Cumbria, across the Solway Firth, but an alternative is Ireland. The early farming communities in Scotland were in contact with both of these areas, importing axe-heads of tuff and porcellanite, and Antrim flint. Even though the bow was found in a hunting context, it is most likely to have been the possession of a farmer, given these links and the early Neolithic farmers' lifestyle would have included exploiting wild resources. 


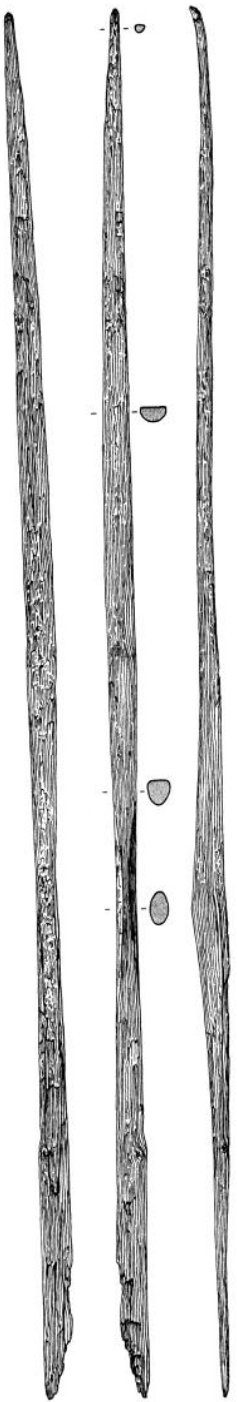

Figure 81: The Rotten Bottom bow, shown with its broken limb at the bottom of the illustration Drawing: Marion O'Neil for NMS.

Yew is the best wood for making bows, being strong yet supple. This object shows that the early Neolithic inhabitants of Britain had a sophisticated knowledge of the properties of different woods and used these to their best effect. Furthermore, the small number of knots in the Rotten Bottom bow indicates that the growth of its parent branch had probably been managed. Bows are extremely rare in Neolithic Britain and Ireland, with only two others known (namely Meare Heath and Ashcott Heath, Somerset, both radiocarbon dated to c 3600-3100 BC. The earliest bow in Ireland post-dates the Neolithic, being radiocarbon dated to 2399-2042 cal BC (Barrysbrook, Co. Offaly: Murray 2004).

Neolithic arrow shafts are also extremely rare in Britain; one example, from Fyvie, Aberdeenshire (fig. x; Anderson 1876), is of viburnum and has a leaf-shaped arrowhead still in situ, along with traces of the mastic used to fix it in position. It may be that, as with other Early Neolithic examples found in the Somerset Levels, birch bark tar had been used to fix the arrowhead in position (Aveling \& Heron 1998); only analysis can demonstrate whether this is indeed the case.

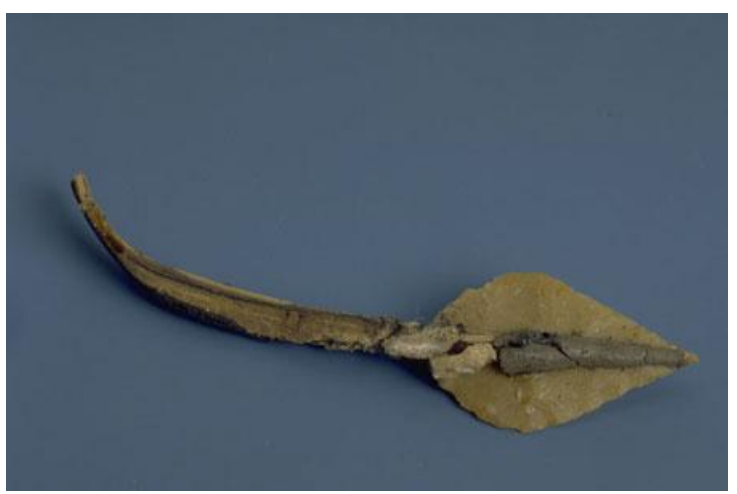

Figure 82: Leaf-shaped arrowhead with traces of shaft of viburnum, from Blackhillock, Fyvie, Aberdeenshire. Photo: Marischal Museum (C) University of Aberdeen

The Shulishader axe haft, which was found with its imported Antrim porcellanite axehead in position, represents an equally rare artefact type in Britain and Ireland. It has been radiocarbon dated to $4470 \pm 95 \mathrm{BP}$ $(3490-2910 \mathrm{cal} \mathrm{BC}$ at $2 \sigma, 0 x A-3537)$ and is thus of Middle Neolithic date. It had been deposited complete but peat-digging had removed its butt part; its extant length is $\mathbf{4 8 0}$ $\mathrm{mm}$ and it will have been made from a piece of round wood at least $160 \mathrm{~mm}$ in diameter. Of the rosaceous woods, it is most likely to have been made from hawthorn. Most of its surface is covered with adze facets, which may have been left deliberately as a decorative feature. The haft swells towards the top, but has an unexplained deep square cut where the back of the axe-head would have sat, thereby weakening the haft - a 
sacrifice possibly made to allow the display of the quality of the axe blade. When this axe was published in 1992, only nine other Neolithic axe hafts were known to have survived in Britain and Ireland (with a few others known from documentary references); since then, there may have been one or two additional finds, but these objects remain very rare, despite the fact that they would have been very common during the Neolithic, as a vitally important tool (and also a display item, as has been suggested, for this object).

The only other wooden implement known from Neolithic Scotland is a finely-worked fragment of a handle, of willow, found at Skara Brae (Clarke 1976). In an Orcadian context, where wood was scarce, this would probably have been a valued object; it has even been suggested that it could have been a mace haft. Other pieces of wood were found in the waterlogged levels at Skara Brae in David Clarke's 1972-3 excavations, including twigs, fragments with tool marks and pieces of spruce - reminding us that driftwood would have been a valuable resource in the Northern and Western Isles, being washed across the Atlantic from virgin forests in North America.

A fragment that may have come from a decorated early Neolithic wooden bowl was found at the 'hall' at Warren Field, Crathes (Crone 1999), but this was so small that its identification must remain tentative.

The artefacts described above suggest that tree and shrub growth had probably been managed - as is clearly the case elsewhere in Neolithic Britain where, for example, the Somerset Levels have revealed evidence for Neolithic trackways (Coles \& Coles 19xx). Woodland management is certainly implied by fragments of willow withies, used for building (eg as wattle and daub - as attested, for example, at Girvan Distillery: Sheridan 2009) and basketry. Fragments of probable withies were found in the waterlogged layer at Eilean Domhnuill, Loch Olabhat, and it has been argued that the design of some Grooved
Ware pots - especially where vertical applied cordons are concerned - may constitute a skeuomorph of wicker baskets (Figure 83). The illustrated example from Powmyre Quarry, Glamis, Angus, is a reasonably convincing skeuomorph (or at least evocation), complete with the cross-hatching between the vertical ribs.

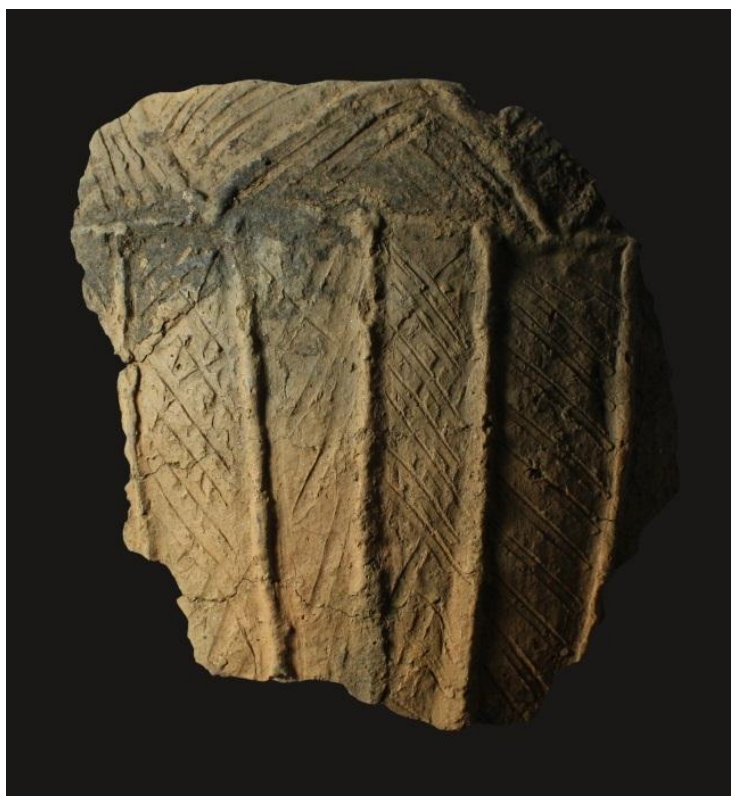

Figure 83: Large part of Grooved Ware pot from Powmyre Quarry, Glamis, Angus, showing basketry skeuomorphism. Photo: Headland Archaeology.

Wood was, of course, used to a major extent for building domestic, funerary and ceremonial structures throughout the Neolithic in Scotland (cf. Noble 2006), and people clearly possessed the skills to fell trees, split them and work and join timber. The construction of the large Middle to Late Neolithic enclosures at Meldon Bridge, Dunragit and Forteviot (Brophy \& Noble 2011) would have used large numbers of oak trees, as would the construction of post-defined cursus monuments (Thomas 2007). The construction of rectangular houses of various sizes (including the so-called 'halls') would also have required significant amounts of wood, and several of these show evidence for the use of planks. At Warren Field, Crathes, two large trunks appear to have been erected 
prior to the construction of a 'hall', and it has been suggested that these may have had a special symbolic significance (Murray et al. 2009); at any rate, they are reminiscent of the split trunk terminal posts used in Early Neolithic timber mortuary structures (i.e. Kinnes' 'linear zone' structures: Kinnes 1984, 1992). While the evidence for these structures consists of postholes and/or charcoal, extant wooden structures are extremely rare (although the waterlogged layers at Eilean Domhnuill, N Uist constitute an unexcavated example). One such structure - a hastilyconstructed platform, perhaps used as a fowling/hunting hide - was excavated in 1999 at Parks of Garden, overlooking the Carse of Stirling in the Forth Valley (Ellis et al. 2002). This was made from roundwood trunks and planks, mainly of oak and alder, with birch brushwood and produced radiocarbon dates between c 3350 and 2900 BC, placing this structure within the formal Middle Neolithic (ibid., 250). A trackway found nearby during the $19^{\text {th }}$ century could have been contemporary, and there may well be other Neolithic structures among the wooden structures listed in the Scottish Wetland Archaeology Database (SWAD: http://xweb.geos.ed.ac.uk/ ajn/swad/search es.html).

A final example of the structural use of timber is provided by the posts that had been set into pits and almost certainly used as a pit-fall trap at Mye Plantation, near Glenluce, Dumfries \& Galloway (Sheridan 20xx). First excavated in the 1920s (Mann 19xx), this site was further investigated in the 1950s by Richard Atkinson and Roy Ritchie, but never published; a waterlogged post from one of the pits was radiocarbon dated in the 1990s and produced a date of $3913 \pm 39$ BP $(2560-2240$ cal BC at $2 \sigma$, UB-3882). Although this places the site within the Chalcolithic period, pottery found between two of the pits shows elements of both Impressed Ware and Grooved Ware affinities. Atkinson \& Ritchie had argued that the posts had been sharpened and set into the pits with the sharpened ends upright.
As is clear from the above, a variety of wood species were used in a skilful and knowledgeable way. It is highly likely that all parts of a tree would have been exploited, with bark usable to make containers and bast usable to make cordage, etc. However, direct evidence for this in Scotland is still lacking, even though examples are known from later periods (e.g. a birch bark cover for an Early Bronze Age log coffin from Dalrigh, Oban: Sheridan 2002).

Plants other than wood were indeed used, with mosses and rushes providing the raw materials for cordage and matting. A fragment of heather rope, exactly like recent Orcadian 'simmons' rope, was found at Skara Brae while the cord impressions frequently found on Middle and Late Neolithic pottery (e.g. from Glenluce) may attest to the use of some kind of plant material; analysis would be necessary to determine the full range of materials used, and to see whether wool and sinew had been used.

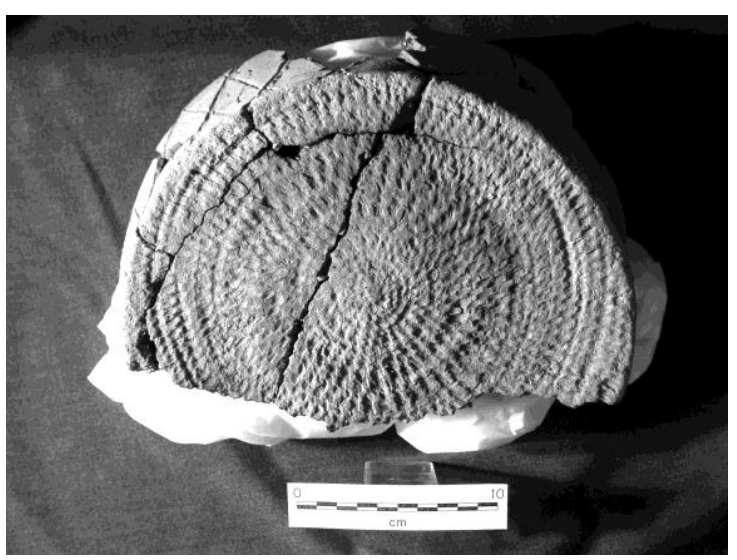

Figure 84: Matting impression on the base of a Grooved Ware pot (V275) from Forest Road, Kintore, Aberdeenshire, (C) AOC Archaeology

There are a very small number of examples of basketry or (perhaps more likely) matting impressions on Neolithic pottery, all of it of Grooved Ware type. The clearest example is from Forest Road, Kintore, Aberdeenshire (Figure 84: MacSween 2008), where a large flat pot base shares the same centre as the mat on which it had been placed; the impression could have been formed while the pot was being constructed, with the mat 
permitting the pot to be rotated. The spiral structure of the matting's construction is clearly visible.

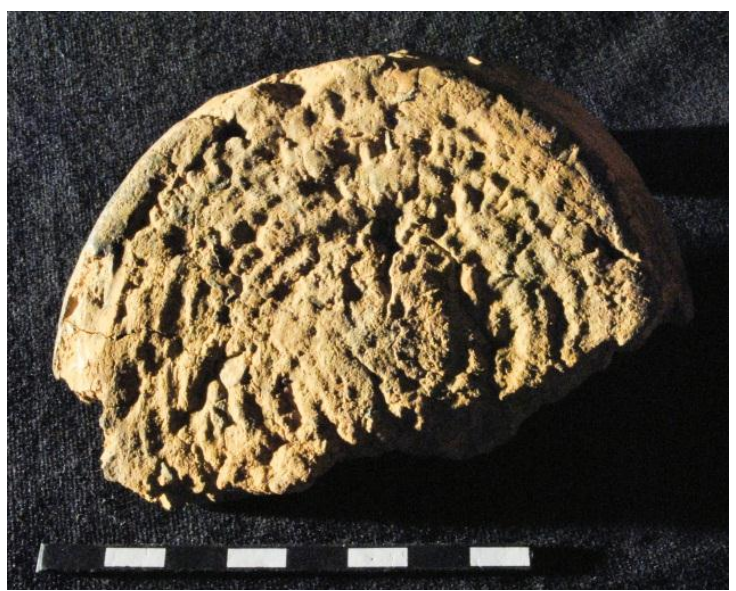

Figure 85: Matting impression on the base of a Grooved Ware pot from House 3, Barnhouse, Orkney. Photo by Lynda Aiano, Orkney Museum.

A smaller Grooved Ware pot from Barnhouse, Orkney, also appears to have an impression of matting, again showing spiral construction (Figure 85; Richards 2005, fig. 4.17, no. 1890); and Gordon Childe had also observed a matting impression on the base of a Grooved Ware pot from Rinyo (Childe \& Grant 1948, 34, pl. X,9). Among the Balfarg Riding School, Fife, assemblage of Grooved Ware, five pots bore faint traces of 'row upon row of unevenly twisted twine [sic], generally 4-5 mm thick' (McLellan 1993), on the lower wall and base of large, relatively thin-walled vessels. It was suggested that the pots may have been supported in a basket while being built up; re-examination by a basketry specialist should be able to determine whether that had indeed been the case.

Finally, although not strictly artefactual as such, the discovery of fragments of ten puffballs in the waterlogged levels at Skara Brae suggest the deliberate collection of this fungus and its possible use as a styptic, to staunch the flow of blood. This reminds us of the various medicinal uses of plants which are bound to have been exploited during the Neolithic in Scotland.
The research questions arising from this review of the available material are as follows:

1. Are there other Neolithic structures or artefacts represented in the SWAD database? (This can only be addressed through fresh fieldwork and dating).

2. What material was used for the cordage whose impressions are found on Middle and Late Neolithic pottery? Were a variety of materials used, and do these differ from those used in later periods?

3. How faithfully do Grooved Ware designs echo the design and construction of basketry? (This is easily addressed, and would build on past research by Linda Hurcombe in the University of Exeter.)

4. Were the Balfarg Riding School Grooved Ware vessels made inside baskets, as has been claimed?

5. What range of organic material was exploited at Eilean Domhnuill Neolithic settlement? (This can only be addressed through excavation, appropriately resourced)

6. Do any other examples of Neolithic artefacts or structures made of wood and other plant materials exist among unpublished (or indeed published) excavation assemblages, or in museum (or other) collections?

7. (Not so much a question, more an observation) Much more direct evidence is needed regarding organic artefacts and structures of all kinds: while we can see that organic resources were skilfully used, we only have a tiny snapshot of the full range of materials and uses. For example, we suspect that curragh-like boats had been used to transport the first farmers and their resources to Scotland, and that logboats had been used for onshore and inland water transport, but so far the earliest dated example of a logboat is Early Bronze Age (from Catherinefield: Mowat 19xx). 


\subsubsection{Textiles and animal skins}

Direct evidence for Neolithic textiles and animal skins seems to be lacking entirely; once again, these would have been ubiquitous and important elements of Neolithic material culture, especially as items of clothing. Instead, we have to rely on indirect evidence, in the following forms:

- Carbonised seeds found at the 'hall' at Balbridie, Aberdeenshire (Fairweather \& Ralston 1993), demonstrating that flax was cultivated from the earliest Neolithic in Scotland, thereby raising the possibility that linen could have been used (as a thread, if not also as woven fabric - the plant could, however, be used only for its nutritious oils).

- One impression of woven cloth, found on a sherd of Impressed Ware from Flint Howe, Glenluce, Dumfries \& Galloway (Henshall 1969) and likely to date to between 3500 BC and 2900 BC. According to Audrey Henshall, 'The textile was a plain weave cloth, with one system of threads much closer together than the other system; the latter would have been hardly visible and they have not registered in the impression. There were about 32 threads per inch in the close-set system, and about 10 threads per inch in the wide-set system. The direction of spin of the former was $S$ ( $z$ on the impression)....The Luce Sands textile seems to have been almost a repp.' [a fabric with prominent rounded crosswise ribs].

- Dress accessories: i) bone pins, used to fasten garments (see above, Skara Brae). The examples are all from Late Neolithic Orkney. We cannot tell, however, whether such pins were designed for use with animal skin garments or with fabric garments; ii) Middle Neolithic belt sliders of jet and jet-like materials, which imply the use of belts (of various widths, but generally below $50 \mathrm{~mm}$ ) to constrain garments.

- Borers (mostly or wholly of bone), which could have been used to pierce animal skins; bone needles (from Skara Brae), for sewing; knives (of stone) to cut skins; scrapers (of flint, other stone or bone) to remove fat from skins; and haematite blocks, which could have been used to smooth and polish skins.

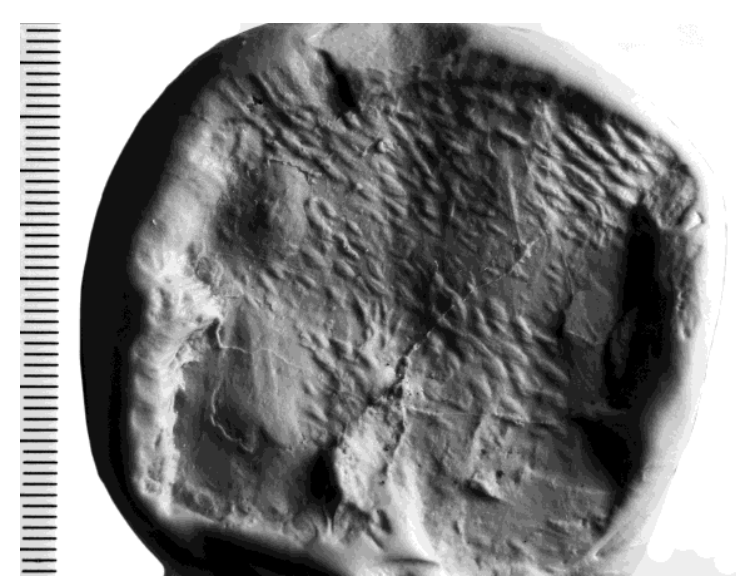

Figure 86: Photo of 'mould' made after laserscanning the Flint Howe sherd, showing the texture of the woven fibres. Photo (CArchaeology Department, Exeter University, courtesy of Dr Linda Hurcombe.

The Glenluce sherd is especially important as it demonstrates that weaving was undertaken in Neolithic Scotland. There is no other evidence for weaving from this period - no spindle whorls, no loomweights, etc - and the Glenluce impression is too small to allow one to determine exactly how the item had been woven (although further research, including experimentation, may well shed light on the matter: cf. Hurcombe 2008).

As regards the use of animal skins, it should be noted that there is no evidence for the use of leather - i.e. skins that have been processed in a specific manner, involving tanning - until the Roman period in Britain. 
The outstanding research questions are as follows:

1. Was the Glenluce fabric made of wool? This is an important question, as it would shed light on sheep breeding and management at this early period: it is believed that the species of sheep extant in Neolithic Britain would not have produced good quality wool, suitable for use in textiles, having instead a 'deer-like coat' (Ryder 1995). Examination of the Glenluce sherd by Linda Hurcombe (University of Exeter) has revealed that the fibre was a dense material, but experimental replication would be needed to determine whether it was a plant fibre (Hurcombe 2008). Such work is planned as part of $\mathrm{Dr}$ Hurcombe's ongoing research into prehistoric textiles, cordage and basketry.

2. How can we increase the body of direct evidence for the use of textiles and animal skins in Neolithic Scotland? Targeting of wetland areas (and in particular, Loch Olabhat on N. Uist) would seem to offer the best possibility. 


\section{Neolithic Society and Belief Systems}

This theme deals with the less tangible aspects of Neolithic life: how society was structured, and how people made sense of the world.

The nature of life and death, ceremony and religion, funerary practice and monumentality has dominated British Neolithic studies for over a century. The vast majority of Neolithic sites and monuments we have in Scotland are of a non-utilitarian character, or seem to have been associated with the dead. Yet paradoxically very little is known about such aspects of life and death in the Neolithic.

\subsection{Society}

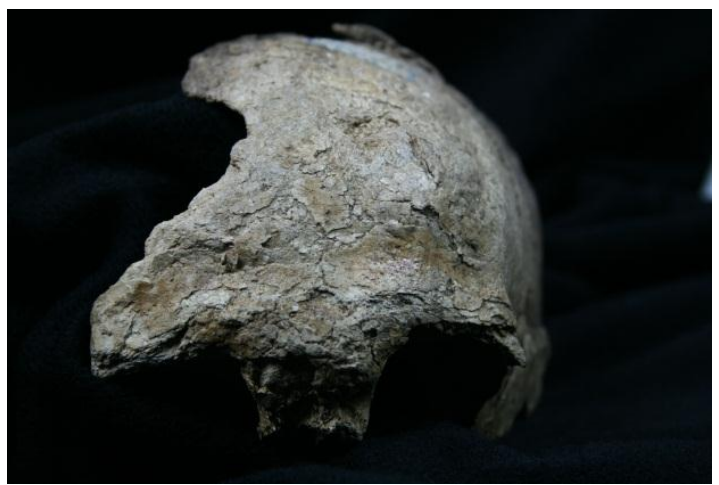

Figure 87: One of five crania from the Orcadian chamber tomb of Cuween Hill. (C) R Crozier

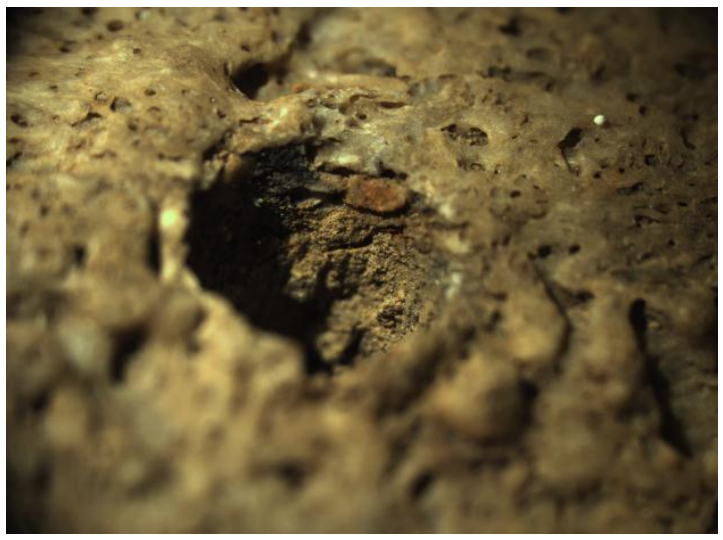

Figure 88: Drill holes identified on a fragment of sternum from the Orcadian chamber tomb of Quanterness, Mainland. Whilst their purpose is unclear, they suggest a much more complex relationship between the living and the dead. (C) $R$ Crozier

The nature and organisation of society in the Neolithic period is little understood. We do not, for instance, even know how many people lived in Scotland during that time. Renfrew $(1973,149)$ used a calculation of, 'two to twenty acres of effective arable land per head' to suggest the population of Neolithic Arran was between 600 and 1200, and that of Rousay less than 650. (Renfrew acknowledged these figures looked high.) Around the same time as Renfrew made these calculations, Brothwell $(1971,79)$ suggested that the population of the British Isles as a whole in the Neolithic was between 10,000 and 40,000, probably a little low. Such calculations, based on mortuary data and / or available arable land result in widely varying figures and are based only on partial data and good deal of guesswork. Recently, Darvill (2010, 124) has suggested a reasonable population figure for the British Isles in the Neolithic would have been something in the order of 200,000; perhaps at this stage then it is safest to say the population of Scotland at this time would probably have numbered in the tens of thousands. Yet this may not have remained static. Models of population levels in LBK Europe have been constructed using analysis of the distribution and quantity of radiocarbon dates (Shennan \& Edinborough 2007). This suggests a rapid increase of population with the arrival of farming, followed by a plateau, then collapse. This study concludes that 'radiocarbon dates can be used as proxies for population history' (ibid, 1344), and there is potential for such analysis (but perhaps with very different results) for Scotland. There is a general sense population increased throughout the Neolithic (cf. Ashmore 1996, 42) which is more of an assumption than a tested scenario. Great communal monumental projects could attest to this, but declining settlement and burial evidence does not support this hypothesis, and so the jury remains out on this, as with most population issues. 
How was society organised? There is a general assumption that the basic unit of society was kin-based, with, for instance, families inhabiting one building. The floor spaces of Neolithic houses in Ireland suggest they could have accommodated a 'family size' group of perhaps 5-12 people (Grogan 2002, 520). Larger communal buildings (from Balbridie to Barnhouse) suggest gatherings of these small groups rather than huge domestic units (and see Theme 4). The wider organisation of these groups is unclear. There has long been a general view of Neolithic society as having some kind of 'tribal' basis, although what this meant in reality is unclear, and nowadays the less loaded (but fuzzy) terms 'communities' or 'small-scale group' are favoured. Generally, family is viewed as the basis for community identity and cohesion (where this is even discussed, which is rarely and superficially, usually with some anthropological or ethnographic model in mind). Some sense of hierarchy is hinted at by selective deposition of human remains in tombs and barrows, the notion of a 'directing mind' behind monument construction and perhaps also the control, or procurement, or resources. An enduring model in this context is that of territories, with certain parcels of land 'belonging' to different groups. This idea was fleshed out by Renfrew (1973) who argued that chambered tombs were indicators of territoriality on Arran and Rousay, with each 'community' having one chambered tomb and access to a series of key coastal and inland resources (illus). This model has been much criticised, but not adequately replaced. Renfrew suggested a chiefdom model of social hierarchy for the Neolithic of Britain. Arguments for a shamanic or priest-like ruling class (e.g. MacKie 1977) are difficult to sustain. By way of contrast, the 'communal' nature of early Neolithic burials is often taken as evidence for an egalitarian society (although not everyone was buried in this way). In sum, until towards the end of the Neolithic, there is 'very little evidence for ranking' (Darvill 2010, 124).

In Scotland there are hints of ranking (e.g. in the use of jet and jet-like jewellery during the Early and Middle Neolithic); and in Late Neolithic Orkney, a highly hierarchical, theocratic society appears to have existed, with diverse symbols of power in use (including various styles of macehead).

Outstanding research questions:

- What was the population of Scotland in the Neolithic, how were people distributed, and how did this change through time?

- Can evidence for kin-based organisation of society be extrapolated from human remains?

- Who were the people whose remains were sealed under non-megalithic long and round barrows during the Early Neolithic? Were they special members of the community?

\subsection{Belief systems}

\subsubsection{The natural world and landscape}

One of the most natural things that people in the Neolithic seem to have incorporated into their belief systems was the landscape that was all around them. The environment provided a whole range of resources, opportunities and challenges, and would have impacted hugely on everyday life. (The exploitation of natural resources, and the nature of the environment, are covered elsewhere in this document.) Yet it seems increasingly likely that people in the Neolithic had more than an economic and passive relationship to the natural world around them. Archaeologists have argued over the past few decades that natural places and features within the landscape may have been symbolically important, and formed important aspects of the social life and world view of the first farmers (cf. Bender 1992; Tilley 1994; Bradley 2000). Specific features in the landscape may have inspired monument form and location, given power to material culture, 
and even wholly 'natural places' may have taken on special significance.

The properties of natural materials, it has been argued, have some bearing on the way people viewed and utilised them in the Neolithic. For instance, anthropological studies of the significance people around the world hold for wood / trees, and stone, have impacted on the study of timber monuments, megaliths and stone tools. The role of trees and the woodland world may have led to the creation and treatment of timber monuments, for instance (cf. Noble 2006) (illus). The very different nature, source and temporality of stone as a building material from timber may have played an important role in the British Neolithic (Parker Pearson \& Ramilsonina 1998). In particular the sourcing of stone was likely not only a practical consideration but also one where the source of the stone may have been a special place redolent with social meaning. For instance, Jones (1999 has suggested that the two main stone types reflected at Machrie Moor stone circles (red sandstone and white/grey granite) literally represented the dominant geologies of north and south Arran. More recently, the idea of sourcing standing stones has gained in popularity, with Richards (2010) identifying and investigating quarries associated with the Stones of Stenness and Calanais. Thus also have the sources of stone axes and other lithics been re-evaluated in light of Bradley's suggestion that stone remains imbued with symbolic values of the source, with axes for instance being 'pieces of places' $(2000$, and see theme $\mathbf{5}$ ).

The very nature of monumentality may also have been shaped by the landscape. For instance it has been argued that henge monuments in Orkney represented microcosms of the wider landscape (Richards 1996). Associations have also been made with rivers / water and cursus monuments in Scotland (Brophy 2000). Cummings (2002) has argued that chambered tombs in SW Scotland were situated within specific locations in the landscape to facilitate views of both coast and mountains (illus). As with alignments on the sky (see Section 6.3.2.), such properties of monuments may have been but one aspect of their meaning to those who built and used them.

Although Neolithic beliefs are very difficult to demonstrate, current research suggests certain landscape locations and the properties ascribed to them may have been important, even before monuments were built on them. Places such as rivers, mountains, woodland clearances, caves and watersheds may have been significant aspects of the Neolithic worldview.

\section{Outstanding research questions}

- Is it possible to identify more closely the source of megalith building materials? This level of analysis has been undertaken for very few sites at anything other than a very general level.

- How much more can we say about the wood used in timber monuments? More work is needed on the type of timber, but also where this might have been sourced from.

\subsubsection{Neolithic cosmology}

There is a common popular perception that people people in the Neolithic and Bronze Age spent a good deal of time trying to make sense of the movement and position in the sky of the sun, moon and stars, and building monument to capture this knowledge. However, despite this, archaeologists have paid 'archaeoastronomy' scant attention as a serious line of enquiry until relatively recently. However, proposing connections between monuments and the sky have a long tradition in Scotland. (NB Alignments associated with recumbent stone circles, multiple stone rows and Clava cairns will be dealt with in the Chalcolithic and Bronze Age document.)

Interest in the cosmological significance of the design and use of Scottish Neolithic 
monuments began with the work of Sir Norman Lockyer (1909) who, fresh for his work at Stonehenge, sought to extend his observations to the avenues and circles of Calanais, Isle of Lewis, and the recumbent stone circles. As well as identifying specific alignments on the sky, Lockyer conceived the idea that if astronomical alignments could be tied to the observation of particular celestial bodies, then the movement of those bodies over time would allow calculations to be made that would reveal the date of construction of the monument. So for instance he concluded, "that the Aberdeen circles are more than a thousand years younger than those of Cornwall and the West coast" (1909, 408). (Bradley (2005) has demonstrated, this was a good estimate, albeit arrived at erroneously.) Lockyer's work at Calanais was quickly followed by additional surveys by Captain (later Admiral) H. Boyle Somerville. His survey of Calanais is the first accurate plan of the monument to be produced; he noted the main stone avenue here aligned true north, and he was the first to observe the lunar alignments at this site (Somerville 1912, 1923).

Calanais subsequently inspired another nonarchaeologist-surveyor, the engineering Professor Alexander Thom (who had first encountered Calanais, and the Pole star, on a sailing holiday (Thom 1996)). From the 1930s to 1980s, Thom carried out surveys of hundreds of megaliths in Scotland (as well as elsewhere in Britain and in Brittany); he actively published his results from the 1950s onwards with a generally negative reception from the archaeological establishment (his key works being Thom 1967, 1871, Thom \& Thom 1978). Thom had a very high opinion of the technical, scientific and astronomical skills of prehistoric people (unlike many of his contemporaries) and established some classic, if flawed, ideas pertaining to the construction and organisation of megalithic monuments. These included the concept of a standardised unit of measurement used in the European Bronze Age (the 'megalithic yard', 2.72 feet), an idea which has largely been dismissed (cf.
Heggie, 1981, Ruggles 1999, 83, Burl 1991, 125-6). More pertinently, Thom believed that the layout of megaliths revealed the alignment of elements of the structure that in association with prominent/distinctive features of natural or man-made origin on a skyline at some distance enabled the recognition or the forecasting of particular solar, lunar or even stellar events that were of crucial calendrical significance. Often these relationships were incredibly accurate, and would have depended on occupants of Neolithic and Bronze Age Scotland to have been aware of at least the rudiments of Pythagorean mathematics and capable of carrying out and recording observations over cycles sometimes running for many years.

Thom's work was largely sidelined (or ignored) by mainstream archaeologists, with concerns raised about issues such as the methods and accuracy of Thom's work, and the lack of context of the sites with which he worked. (For a full summary of the pros and cons of Thom's work, see Heggie 1981; Ruggles 1999.) Thom's super-accurate alignments and calculations came under further scrutiny in light of the work of Aubrey Burl (1976, 1976a, 1981, 2006) and Clive Ruggles (1998, 1999, Ruggles \& Barclay 2000) in the 1970s and 1980s. Burl for instance noted for recumbent stone circles that the coincidence of lunar movement with the recumbent placements meant that it would have been possible to determine the arrival of a period of full moon and its monthly risings and settings using rather rough and ready markers. Burl and Ruggles were the advance guard of what one could term the 'nonprecisionist school'. Their contention was that the precise, observational hypothesis of Thom that sought evidence for an advanced mathematical, Pythagorean capacity in early farming culture, was not well-founded.

Some support for Thom within the archaeological community was forthcoming however. Euan Mackie (1977) published his polemic 'Science and Society in Prehistoric Britain' in which he set out his experimental 
excavations at Kintraw, Argyll (illus), and observations at the site of Ballochroy, Kintyre and the reinterpretation of excavations at Cultoon on Islay which he felt were, in their different ways, 'blind tests' of Thom's observational theories. He described Thom's theories in far more accessible terms and attempted to place the expertise that Thom postulated within a feasible Neolithic society by creating the notion of astronomer priests, an exclusive group, highly privileged for which he garnered evidence and attempted to place this group and its cognate society on an ethnographically informed scale (but see Theme 6.2). And any consideration of Thom's legacy must include an appreciation of the immense body of survey material he collated throughout his career, still a valuable resource today. The subsequent work by Heggie, Ruggles, Burl and others was in no small part inspired by Thom, even if only by the desire to check the veracity of Thom's work.

Heggie's (1981) analysis of all of Thom's observations allowed him to quite quickly dispose of the significance of complex geometry and mathematics that Thom hypothesised. In the same year lan Thorpe (1981) examined the ethnographical record where he saw the almost universal interest in constellations and the lunar cycle among human societies. Where calendrical schemes have been created they are almost always uncomplicated. Such work re-enforced the idea that highly accurate alignments were neither likely, nor necessary, in prehistory. Therefore a less complex relationship with the sky has been postulated for the Neolithic, something archaeologists have become increasingly comfortable with.

There are a number of 'classic' examples of monumental associations with lunar or solar events that are by and large accepted by archaeologists as being part of the experience of those monuments. Perhaps the best documented example is the midwinter sunset alignment along the Maes Howe chambered tomb passage (illus), first reported by Magnus Spence, an Orcadian, in 1894. This remarkable phenomenon mirrors that at Newgrange. Importantly this phenomenon required some degree of monumental accuracy, but did not have to be millimetre perfect for the effect to work. And the lighting up of the back of the chamber for a short time each day for a week or so on either side of the solstice worked looking into, not away from, the monument (Burl 1981, 251; MacKie 1997; Richards 2005 and see www.maeshowe.co.uk). Loveday has argued that the cursus monuments at Holywood, with a near north-south axis, may have drawn on a general association with the constellation Orion, which would have been low in the southern sky in the Neolithic (2006, 139-42). Ruggles $(1998,1999)$ has suggested that general alignments such as this, which could be easily planned without a great deal of accuracy or specialist knowledge, should be viewed as part of the experience of monuments, but not the only reason for their construction. Alignments on, and drawing attention to, phenomenon in the skies was but one aspect of the world view of people in the Neolithic. And the ability to 'stagemanage' such other-wordly experiences may have been a source of power and legitimacy (Bradley in Barrett et al 1991, 56).

We know that people in the Neolithic must have had an interest in the sky. At a practical level knowledge of the position in the sky of the sun, moon and stars would have been invaluable for navigation and wayfinding, as well as managing the agricultural cycle, the seasonal round and 'measuring' time. Debate continues as to how precisely these heavenly bodies were understood, and to what extent the sky was a factor in the religious life of people in the Neolithic, as well in everyday tasks. Thom suggested: 'We do not know the extent of Megalithic man's knowledge of geometry and astronomy. Perhaps we never shall' (Heggie / Thom 1981, 235).

\section{Outstanding research questions}

What firm evidence do we have for people in the Neolithic monitoring and recording the position and movement of the moon, sun and stars? Did this change through time? (For 
instance, was there more of a focus on the sun in the later Neolithic?)

Can we recognise significant astronomical alignments embedded in monuments? Is it possible to identify appropriate methodologies and datasets for establishing this? (For instance we need to evaluate the environmental context of monuments to establish how clearly horizons might have been visible.)

\subsubsection{The chronological framework and overview of monuments monuments}

The most abundant structures that we have surviving from the Neolithic period (as upstanding remains and cropmarks) are monuments. These are the most visible and tangible statements of Neolithic belief, treatment of the dead, and identity. In this context monuments are structures with no clear functional or domestic role, contingent on the problems with defining such concepts in a Neolithic context (see Theme 4). Monuments were usually associated with ceremony, ritual, mortuary rites and/or burial. In this section, a brief overview of the range and chronology of Neolithic monuments found in Scotland will be presented; more detailed case-studies and regional variations have already been discussed in Theme 3 .

At a general level, Neolithic monuments in Scotland could be viewed as falling into two 'phases'. The first are largely rectangular or linear in form, and mostly restricted to the $4^{\text {th }}$ millennium BC. The other group are circular, or sub-circular in form, and largely date to the later Neolithic (3000-2500 cal BC). The movement from rectangular to round (to simplify) can be recognised across the British Neolithic (Bradley 2007), and indeed is also reflected in house forms (Theme 4.3). This is not a hard and fast rule, however: for instance chambered tombs were built in a wide range of cairn shapes from round to long (although in the Neolithic all had linear, rectangular or square chambers). And it should also be recognised that in some cases a variety of monument forms (rectangular and round) occurred in the same location as part of monument complexes or multi-phase sites. This suggests that even if monument types were not enduring, some places were.

The brief characterisations of monument types below are based on typological labels that mask a good deal of variation. However these are commonly accepted terms, and used throughout this document.

\section{Causewayed enclosures}

No causewayed enclosures of Neolithic date have been confirmed in Scotland, although these monuments are commonly found in southern Britain. A number of potential examples have been identified in the cropmark record: Leadketty, Perth and Kinross; Sprouston, Scottish Borders (Figure 89) and West Lindsaylands, South Lanarkshire the most likely (RCAHMS 1978; Smith 1991; Barclay 1996; Oswald et al 2001). However, these enclosures could as easily be later prehistoric or medieval. It is also possible such enclosures could be found in an upland context, with many hilltop enclosures as yet undated.

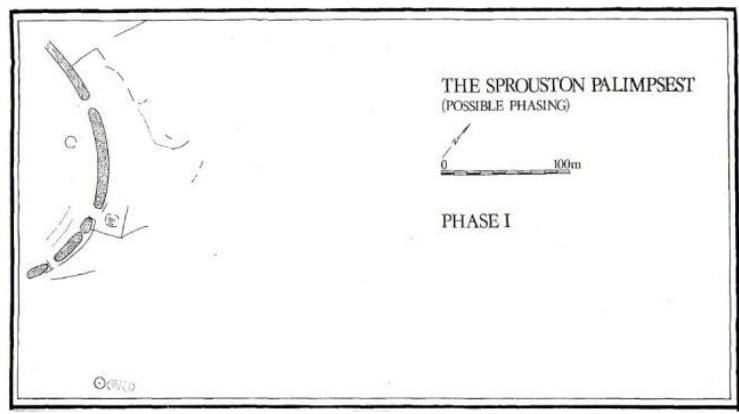

Figure 89: Transcription of the putative causewayed enclosure at Sprouston, Scottish Borders, with possible timber hall and barrow to the SE (from Smith 1991, illus 4).

\section{Chamber tombs}

The most commonly found (and amongst the earliest) Neolithic monuments found in Scotland are the chamber tombs, of which over 600 have been recognised. These are largely monuments of the west, southwest and north of Scotland, although there are examples in the east (Figure 90). These were 
extensively catalogued by Audrey Henshall (Henshall 1972; Davidson \& Henshall 1991; Henshall \& Ritchie 1995, 2001). Generally these megaliths consist of some kind of chamber set within a stone cairn, some with passages. The cairn and chamber forms vary considerably, leading to a series of different regional 'types' identified (see Theme 3). A review of dates by Noble $(2006,106-8)$ shows a wide date range for chambered tombs across Scotland from c3700 cal BC to the early centuries of the $3^{\text {rd }}$ millennium BC. Some Orkney cairns (Maes Howe-type) are very late in the sequence. For instance, Quanterness was in use over the period $3510-3220$ cal BC to $2850-2790$ cal BC (95.4\% probability) (Schulting et. al. 2010). Dating is further complicated by the multi-phase nature of these monuments, with, for instance, long cairns in the north being constructed in three or more phases of activity. The 'tail' of some long cairns may date to the final centuries of the Neolithic (e.g. Vestra Fiold, Orkney (C Richards pers. comm.); Tulach an t-Sionnaich, Caithness (Corcoran 1967).

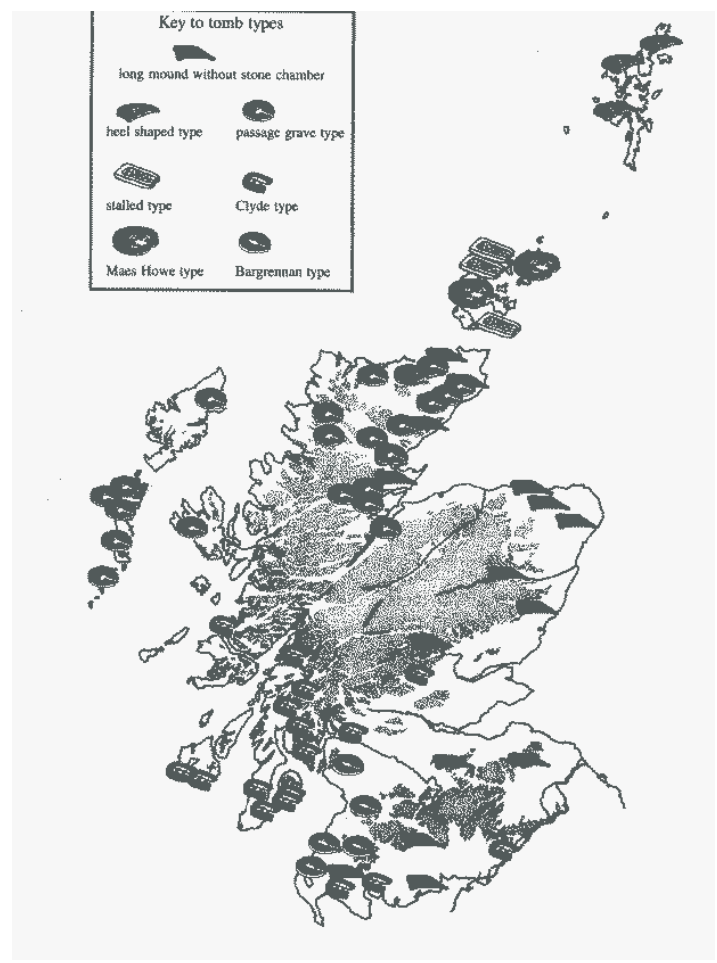

Figure 90: Patrick Ashmore's schematic map showing the distribution of chambered tombs and related monuments (some of which we now know to be Bronze Age) (Ashmore 1996, 57)

There have been few modern excavations of chambered tombs, and results of investigations have varied widely. Some (notably Orcadian monuments) have revealed huge assemblages of human and animal bone, and material culture. Others were largely empty. Earlier excavations have in some cases left large assemblages of material and human remains for analysis. Recent analysis of large bone assemblages from Orcadian tombs (Quanterness, Isbister, Holm of Papa Westray North) have revealed the potential of such monuments to help reveal information about diet, health and lifestyle. Chambered tombs seem to have been repositories of bones, with disarticulated skeletons the norm, often with a preference shown for long bones and skulls. In part this might be because corpses were probably excarnated before being put within tombs. The communal mass of bones may have been viewed as an ancestral resource, with the open entrances allowing bones to be taken in, and out, of the tombs, with forecourt areas at some monuments 
suggesting ceremonies took place. By the end of the $4^{\text {th }}$ millennium BC many chambered tomb entrances were formally 'blocked' (Monamore, Arran; Mid Gleniron, Dumfries and Galloway).

\section{Long barrows / mortuary structures and enclosures}

The eastern half of Scotland has few megaliths, but does have a preponderance of timber and earthwork structures that in some cases had a mortuary role. The early Neolithic of the south and east in particular is characterised by a series of rectangular structures, ranging from small settlement 'huts' to massive cursus monuments. Within this continuum could be placed timber halls, mortuary and long enclosures, long mounds (long barrows, bank barrows and perhaps long cairns) and timber and earthwork cursus monuments (Loveday 2006; Brophy forthcoming). Settlement and timber hall sites were discussed in Theme 4.3.

There are at least 20 long barrows known in Scotland, some of which have only been recorded as cropmarks (including a fine example near the base of Dunadd, Argyll, a rare western long barrow). Few examples have been excavated, with Dalladies, Aberdeenshire, being the best-known example (Piggott 1971-2). This long barrow began life as a few pits, then timber and stone mortuary structures were built, before being sealed by a long earth and turf mound. Noble (2006) has compared this sequence with evidence for activities found beneath Pitnacree round barrow, Perth \& Kinross, Slewcairn, and Lochhill long cairns, both Dumfries and Galloway. Unlike chambered tombs, long barrow burial areas were inaccessible once the mound was constructed. It seems likely that ceremonial activity was occurring in these locations pre-mound, with some so-called mortuary structures having no direct connection with human remains (Noble 2006).
Other monuments may also have served a mortuary role, perhaps for instance the exposure and excarnation of the dead. A range of rectangular timber settings and enclosures may have served such roles. Inchtuthil, Perth and Kinross (c50m by $10 \mathrm{~m}$ ), was defined by a wooden fence set within a palisade slot (Barclay \& Maxwell 1991), while the Balfarg Riding School, Fife, structures appear to have existed as free-standing timbers (Barclay \& Russell-White 1993). Some 'mortuary' structures were trapezoidal in plan, such as Eweford, East Lothian (Lelong \& MacGregor 2008). Other rectangular structures such as Carsie Mains and Littleour, both Perth and Kinross, may have served a ceremonial role (Brophy 2007). Indeed, these monuments probably served a range of purposes, with little explicit evidence for mortuary activity at even so-called mortuary enclosures. Such rectangular structures had a relatively long currency within the early Neolithic, dated from the middle of the $4^{\text {th }}$ millennium through to around $3000 \mathrm{BC}$.

\section{Cursus monuments / bank barrows}

There are at some 40 possible cursus monuments known in Scotland (see Brophy 1999; forthcoming). Cursus monuments are long -, and often wide - rectangular enclosures with rounded or squared ends ('terminals'), defined either by an internal bank and external ditch arrangement, or free-standing timber posts (apparently unique to Scotland). Over half of these sites are the timber variant, measuring between $60 \mathrm{~m}$ and $570 \mathrm{~m}$ in length, and usually $20 \mathrm{~m}$ to $30 \mathrm{~m}$ in width; most such sites have one of more internal divisions of partitions. The earthwork cursus monument show more variation in size, between $190 \mathrm{~m}$ and $2.5 \mathrm{~km}$ in length, with width varying from $20 \mathrm{~m}$ up to $160 \mathrm{~m}$. All but one of these is a cropmark site, and 14 cursus monuments have been excavated since the 1970s. Timber cursus monuments appear to be the earlier of the two cursus forms, dating either to 3900 3600 calBC (Thomas 2006) or perhaps slightly later (Whittle et al 2011). The earthwork cursus monuments in England tend to date to the second half of the $4^{\text {th }}$ millennium $B C$ 
(Barclay \& Bayliss 1999), and the one ditched cursus in Scotland to have been successfully dated so far, Broich, Perth, at 3640-3370BC, accords with this (Tamlin Barton pers comm). The timber then earthwork sequence of cursus building traditions was played out at Holywood North, Dumfries and Galloway, where a timber cursus was replaced by an earthwork variant sharing the same footprint (Thomas 2007). An apparent timber cursus at Ewwford, East Lothian, was shown to consist of two parallel lines of postholes that were intermittently added to towards the middle of the $3^{\text {rd }}$ millennium $B C$, rather than being a large cohesive monument (Lelong and MacGregor 2008); the cropmark record may include more examples of this type of structure masquerading as 'cursus monuments'.

Cursus monuments are traditionally regarded as having a processional role, although more recently they have been connected to both timber hall, and mortuary enclosure, traditions (Loveday 2006; Thomas 2006; Bradley 2007; Brophy forthcoming). Little evidence has been recovered for activities within cursus monuments, and material culture associations are rare. The only noncropmark cursus is the Cleaven Dyke, Perth and Kinross, an unusual cursus-type earthwork that is still visible as an upstanding single bank $1.8 \mathrm{~km}$ in length with two parallel, flanking ditches (illus c). Although an early Neolithic date could only be speculated upon during excavations, the monument was shown to be built in segments over an unknown period of time (Barclay \& Maxwell 1998). This monument shares certain characteristics of another early Neolithic linear form, the bank barrow.

Although bank barrows are relatively common in southern England, few examples have been identified in Scotland. Bank barrows are extremely lengthy long barrows (usually several hundred metres in length), with a single long mound, and in some cases, closely flanking ditches. Characteristically bank barrows have enlarged, or rounded, terminals, which may once have been freestanding barrows or mounds (Loveday 2006). The only non-cropmark example of this type of monument so far identified in Scotland is at Eskdalemuir, Dumfries and Galloway. Here, two lengthy earthworks run uphill on either side of the valley of the White Esk. This could be two separate monuments, or more likely one extremely long bank barrow (some $2 \mathrm{~km}$ in length) which was at one time bisected by the river (RCAHMS 1993). A number of possible bank barrows have been identified as cropmarks, mostly in the eastern lowlands, although none have been confirmed by excavation (Brophy 1999; forthcoming). Despite the name, no evidence for burial activity has been found associated with a bank barrow in Scotland, and none have been dated; English examples tend to belong to the early Neolithic, and appear to be related to the cursus tradition.

\section{Timber circles / henge monuments/ stone circles and settings}

These variations on circular enclosure forms all suffer from problems with chronology and classification. Each monument form has its around or just before $3000 \mathrm{BC}$, but variations on each were built well into the Bronze Age, and circles of earth, timber and stone seem to have been part of related traditions, often occurring in the same location.

At least 80 timber circles have been recorded in Scotland, almost all as cropmarks, with some found during excavations. These are circular or elliptical settings of standing timbers, mostly with diameters in the range of $5 \mathrm{~m}$ to 40 , with a few slightly larger (Millican 2007). Aside from one problematic early date from Temple Wood, Argyll \& Bute (Scott 1991), the remainder of timber circles, where dated, seem to have been built from 3100BC onwards, with examples continuing to be built throughout the $3^{\text {rd }}$ millennium BC. Excavations have shed little light on the function of these monuments, although they are commonly found in association with ceremonial 
monuments such as cursus monuments and henges.

Over 80 possible henge monuments have been found in Scotland, although recent excavations and radiocarbon dates suggest that many of these monuments were constructed in the Bronze Age (Bradley 2011; Brophy \& Noble forthcoming). These monuments were earthwork enclosures with an internal ditch, external bank and one or two entrances. Again, the majority of henges in Scotland are known only as cropmarks, and they display a remarkable variation in terms of size, ranging from mini-henges (formerly known as hengiforms) less than $10 \mathrm{~m}$ across, to the Ring of Brodgar, over $100 \mathrm{~m}$ in diameter (albeit with no bank) (Barclay 2005). The earliest henge in Scotland is the Stones of Stenness, Orkney, dated by animal bone on the ditch base to 3100-2650 (Ritchie 1976). The Ring of Brodgar has recently been dated to the late Neolithic throught OSL dating of the ditch base, while Balfarg Riding School seems to have a Grooved Ware association. The henges at Forteviot 1 and 2, North Mains, and Pict's Knowe all appear to be early Bronze Age, while Pullyhour, Caithness, is a monument of the $2^{\text {nd }}$ millennium BC. Our understanding of the role of henges remains vague, with little direct evidence for activities within the enclosures, although acts of deposition have been recorded in henge ditches. A ceremonial role seems most likely, perhaps offering a more solidly bounded arena that timber circles. Recently it has been suggested that the internal ditch indicates henges were built to control or seal something in (Barclay 2005; Bradley 2011; Brophy \& Noble forthcoming).

Some stone circles have their origin in the late Neolithic, although given the difficulty in dating standing stones, the chronology of stone circles is far from obvious. (The smallest stone circles may have been built as late as 1000 BC.) The evidence from Calanais is not fully published. It seems possible that there were stone settings by around $3000 \mathrm{BC}$ at the Ring of Brodgar and Cairnpapple (if the setting here was not timber) among other sites. The presence of standing stones within other henges, such as Balfarg, and Stones of Stenness, suggests a close relationship although again relative chronology here is unclear. Many stone circles, including the recumbent stone circles of NE Scotland, were built in the Bronze Age.

How did timber circles, henges and stone circles relate to one another? Gibson (2004) has noted that wherever timber circles are found within henges, the former is always earlier (where dating evidence is available). Where the two occur together, timber circles were situated within the henge (with a notable exception at Forteviot henge 1, Perth and Kinross (Noble \& Brophy 2011a)). Yet some timber circles stood alone and were never 'replaced' by a henge, while many henges have nothing to do with timber circles. More stone circles sit on their own than are found within henges, while evidence for stone replacing timber (as at Machrie Moor and Temple Wood) is to date limited. Many of these circular monument forms were subject to reuse and alteration in later prehistory, utilised as pyres, cremation cemeteries, or for metalworking, or transformed into cairns or barrows. Thus henges and stone circles must be investigated by Bronze Age specialists as well as those who study the Neolithic period.

\section{Round barrows / Round mounds}

Although rare in a Neolithic context, there are a number of possible late Neolithic round (non-megalithic) barrows known in Scotland, largely found in the northeast and east (Kinnes 1992; Sheridan 2010). The best-known example is Pitnacree, a large round mound in Strathtay that capped a complex sequence of timber and stone structures, perhaps in the late Neolithic. Sheridan (2010) has recently listed eight possible non-megalithic round barrows in Scotland (all but one in the NE), with some possible unexcavated examples identified in Strathtay (Brophy 2010). The chronology for these monuments is poor, with dates for the pre-mound activity at Pitnacree for instance unreliable (Ashmore et al. 2000). 
The recognition of Neolithic round barrows as opposed to Bronze Age examples (which are more common) is difficult without excavation, although Barclay (1999) suggests a heightdiameter ratio could be used to make this distinction. It may well be that activity in these locations (not all of which was directly associated with burial) was brought to a halt by mound construction.

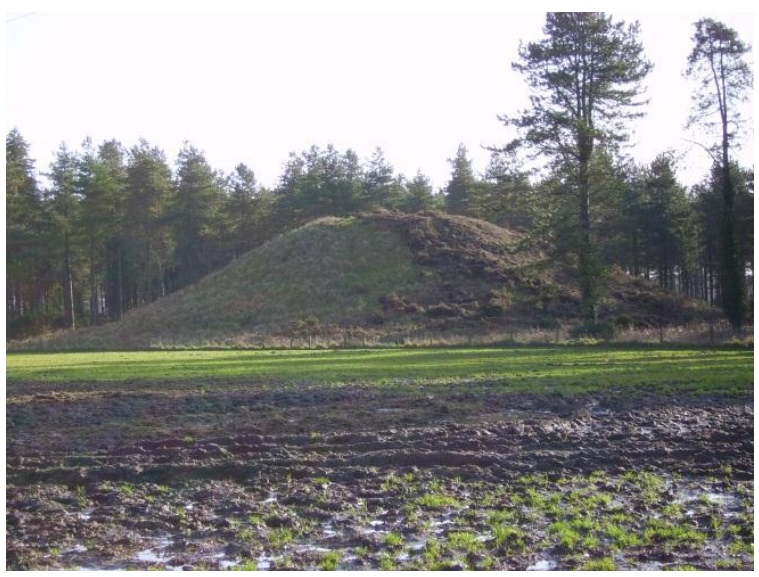

Figure 91: The Droughduil mound artificial mound (photo: K Brophy)

Only one artificial Neolithic mound has been recognised in Scotland to date, Droughduil, Dumfries and Galloway (Figure 91). Thomas (2002, 2004) demonstrated through excavation that this huge mound with diameter of some $50 \mathrm{~m}$ and height $10 \mathrm{~m}$ was a natural sandy mound that was augmented in the Neolithic. The avenue of the Dunragit palisaded enclosure aligns on this mound. Although not on the same scale as Silbury Hill, Wiltshire, Thomas's work has demonstrated the potential for such huge artificial mounds to be identified in Scotland.

\section{Palisaded enclosures}

These huge enclosures are perhaps the largest expressions of Neolithic monumentality found in Scotland. These monuments consist of a large enclosed space defined by a boundary of timber posts (erroneously known as a palisade in most cases), often with a narrow entrance avenue. Three of the monuments - Forteviot and Leadketty, Perth and Kinross, and Meldon Bridge, Scottish Borders - have one boundary defined by a natural feature. One further site has been confirmed - Dunragit, Dumfries \& Galloway, and excavations have been carried out at all but Leadketty, with radiocarbon dates suggesting these monuments were constructed c2800-2600 calBC (Noble \& Brophy 2011b, 74).These were huge enclosed spaces - Leadketty is some $400 \mathrm{~m}$ across, while Forteviot has a circumference of $c 750 \mathrm{~m}$. In each case the monument was shown to be defined by huge (oak) posts, with some kind of fence line connecting these at Meldon Bridge. These monuments in some cases enclosed earlier structures, and we have evidence for later monuments and activities within the boundaries. For instance at Forteviot (illus e) a middle Neolithic cremation cemetery preceded the palisaded enclosure, while two timber circles and two henges were later constructed within it (Noble \& Brophy 2011b). At Meldon Bridge, pits with a fine assemblage of Impressed Ware pottery were found (Speak \& Burgess 1999) while Dunragit has multiple phases of palisade construction (and was built in the location of a timber cursus (Thomas 2004)). It is likely these extravagant monuments were a last flourishing of mega-monumentality in Scotland's Neolithic, and although evidence for function is limited, they would have been places where large number of people could have gathered for a range of activities.

Other monuments may belong to related traditions, such as Blackshouse Burn, an embanked enclosure in an upland location, South Lanarkshire. This monument was originally defined by a double boundary of oak posts with a stone rubble bank between, surrounding an area some $300 \mathrm{~m}$ in diameter (Lelong \& Pollard 1998). Further megaenclosures like this may remain unidentified, either in the cropmark record, or the uplands.

\section{Monument complexes / special places}

A key characteristic of Neolithic landscapes in northwest Europe is the creation of complexes of monuments in certain places, for instance at Stonehenge, the Cranborne Chase, the Bend of the Boyne and Carnac. In Scotland, there are some exceptional 
examples, where Neolithic (and often Bronze Age) ceremonial and burial monuments cluster together, places that were in use and reworked for many centuries. Important examples in Scotland include the Heart of Neolithic Orkney central mainland area; Balfarg, Fife; Forteviot-Leadketty, Strathearn, Perth and Kinross; Kilmartin Glen, Argyll \& Bute, and Machrie Moor, Arran. Such landscapes appear to have had sacred importance in the Neolithic, perhaps established in the Mesolithic, or from pitdigging and deposition early in the Neolithic. These complexes offer excellent opportunities to follow social change through time, and suggest traditions that endured for huge periods of time and many generations.

\section{Rock-art}

Before completing this section, it is worth looking at one other expression of belief, or ideology, that seems to have originated in the Neolithic (but overlaps considerably with the Chalcolithic and Bronze Age, and see the panel document for these periods as well). The meaning of rock-art seems beyond our grasp, with cup-and-ring marks, and other abstract and geometrical symbols, defying attempts to read them as texts (cf. Morris 1977, 1981). Recently, excavations at rock-art sites have started to shed light on the context of their production, and also some of the activities that went in the vicinity of rock-art panels. Excavations at Torbhlaren rock-art outcrops, Argyll and Bute, produced radiocarbon dates for material recovered from a fissure in the rock, and a stake-circle beside one panel. This allowed the excavators to argue the rock-art dated to between 2900 and $2300 \mathrm{cal} \mathrm{BC}$ (Jones et al 2011, 261). That the rock-art here was associated with structures and 'deposits' jammed into cracks in the rock adds much depth to our understanding of activities associated with rock-art. Test-pitting in the vicinity of rock-art panels at Ben Lawers, Perth and Kinross, was equally illuminating. Outcrops with rock-art were found to be associated with quartz working and deposition, some flint was found jammed into cracks in the rocks, and a cobbled surface was found. Such investigations might not help us 'translate' motifs, but offer a context and chronology for the creation of rock-art.

\section{Conclusion}

This section of the document has offered an overview of the main types of Neolithic monuments found in Scotland, with a brief description of the main characteristics and chronology for each given. Inevitably these are broad brush labels, each of which hides considerable variability, although much of this level of detail can be explored in Theme 3 . 


\section{Research and methodological}

\section{issues}

\subsection{Introduction}

It is, perhaps, fair to say that much research goes on in isolation from other specialist research, with no sense of there being a coherent strategy for investigating the Archaeology of the Scottish Neolithic. While there would be little support for centralised control over research activities, nevertheless the development of a research framework i.e. the raison d'être of the ScARF project - is a useful way of seeing where individual projects can fit into a larger whole. In particular, there is a need for integrated, collaborative research that takes cognisance of what has been achieved elsewhere (e.g. in terms of effective methods and strategies) and is able to situate the research within different levels of understanding, the international, national and the local setting.

Current and recent research into Neolithic Scotland has taken a wide range of forms, as the foregoing text makes clear and as is evident from the following examples of topics and approaches:

\section{Approaches:}

- Isotopic and osteological analysis of human and faunal remains.

- radiocarbon dating programmes and Bayesian modelling of dates.

- palaeoenvironmental (including palaeoclimatic) analysis.

- underwater and aerial survey (including Lidar).

- analysis of absorbed lipids in pottery.

- targeted fieldwork to explore specific types of site, or as part of a broader study of an area through time (e.g.as in South Uist, Caithness, RCAHMS survey on Donside).

- raw material characterisation through petrology, chemical analysis and mineralogical analysis; material- specific mapping and inventorising (as in the case of Arran pitchstone and Alpine axeheads).

- Issues-based research programmes (e.g. the Nationalmuseet's Farming on the Edge project, comparing the Neolithic of Shetland with that of southern Scandinavia).

Topics:

- study of the Orkney Vole and its origins.

- experimental construction and destruction of a megalithic monument.

- investigation of Caithness stone alignments.

- investigation of Cursus monuments.

- reviewing assemblages from chambered tombs.

This research is being/has been undertaken by individuals and teams within and outside Scotland; on different scales; and in different capacities - some being university-based, some undertaken by museum curators, some by freelance individuals and voluntary groups.

Along with the results of previous research, it is helping to shape and transform our understanding of Neolithic Scotland. But there are various issues which mean that the broad potential of this work is not currently being fully realised.

These issues are explored briefly below; many are common to all the periods of ScARF's remit. In essence, they boil down to the following two main issues:

1. Accessibility and quality of existing information (ie dissemination and awareness issues)

2. Overall approach, including scope of the questions posed and organisation of research 


\subsection{Accessibility and quality of existing information (ie dissemination and awareness issues)}

Currently it can be very hard for a researcher Currently researchers into the Scottish Neolithic can find it very hard to discover what information already exists, and where it is held. The results of previous research may be widely scattered - in publications, in unpublished reports, in databases, in hard copy notes, etc. - and only a small proportion is available electronically Discovery and Excavation in Scotland, which has faced problems in the current economic climate, is an invaluable resource for Scottish archaeology which makes the establishment of knowledge about current work relatively easy in Scotland; that fact needs to be acknowledged and its future existence needs to be safeguarded. Scotland also has a copyright library and the Antiquaries Library in the Museum which again is a resource that is advantageous. Furthermore, the quality of some of the existing database information leaves something (or a lot) to be desired. RCAHMS are aware of the shortcomings of CANMORE and are committed to making corrections and improvements in the light of the ScARF exercise. Similarly, the AdLib museum database of National Museums Scotland (which is, however, not publicly available) contains much out of date and incorrect information and cannot be treated as a reliable research resource; furthermore, it does not contain accurate geographical information so cannot be used to create distribution maps. The disjunction between the sites and monuments-based CANMORE database and the artefact-based databases held by museums has long been recognised as a serious problem, and a pilot project, MAGI (Cowie \& McKeague 2011), has demonstrated the benefits to be gained from creating an integrated sites-and-finds database as has been developed in Wales. There is a pressing need for a full-scale integration project to be undertaken.
The problems associated with accessing grey literature and specialist reports from developer-funded excavations are wellknown; the fact that specialist reports are sometimes not included in final publications (as was the case with the A1 project publication, Lelong \& MacGregor 2008) makes accessing this valuable information difficult.

Perhaps this opportunity ought to be seized to remind all researchers that the British and Irish Archaeological Bibliography is available on-line ${ }^{1}$. Similarly the 1988 list of petrological identifications of stone axeheads and shafthole objects undertaken by the (formerly-named) Implement Petrology Committee, and published in Stone Axe Studies 2 (Clough \& Cummins 1988), is available electronically ${ }^{2}$ Other on-line datasets include the very useful, Historic Scotlandcommissioned SWAD database of information on Scottish wetland archaeology ${ }^{3}$ and SPAD, the Scottish Palaeoecological Archaeology Database ${ }^{4}$; other, national and international palaeoenvironmental databases also exist. It is perhaps unfortunate that none are advertised as broadly as, perhaps, they ought to be.

Other awareness issues arise from the fact that some scientific research is published in specialist journals, whose existence may not be known to non-specialist researchers on the Neolithic; while researchers may be aware of the Journal of Archaeological Science, few regularly access more specialist publications unless directed to these by the specialists in question.

This situation is complicated by the fact that there may be several researchers who are interested in undertaking a specific kind of study (e.g. isotope analysis of human remains)

\footnotetext{
${ }_{2}^{1}$ http://www.biab.ac.uk/

http://archaeologydataservice.ac.uk/archives/view/i ndex.cfm?CFID=3822133\&CFTOKEN=69541908 $\&$

${ }^{\frac{\&}{3}}$ http://xweb.geos.ed.ac.uk/ ajn/swad/

${ }^{4}$ http://xweb.geos.ed.ac.uk/ ajn/spad/
} 
but who may be unaware of other's research on the same topic (perhaps even involving the same specimens). There is a need for current research, and its published or web-available outcome to be notified systematically in Discovery and Excavation in Scotland. Furthermore, the attempt to create a Scottish Human Remains Database started by needs to be revived in order to ease access to material and to its research.

Finally, there is the issue of sustainability. This relates to all sets of data, including maintenance, updating and disseminating the ${ }^{14} \mathrm{C}$ database. The comprehensive database of Scottish radiocarbon dates needs to be revived; the Historic Scotland on-line ${ }^{14} \mathrm{C}$ database was taken down in 2011 and has not been reinstated, or updated since 2006. (The 2006 version is appended as a ScARF accessory document.) While some dates (including those obtained through NMS) are published each year in Discovery and Excavation in Scotland, there has not been an annual systematic trawl of new dates since 2006.

Sustainability is also relevant to the question of skills transfer: with an ageing cadre of specialists. There has been a tendency in the last three decades for artefact studies to be eschewed in favour of more social reconstructive studies and there is a danger of a skills gap opening if expertise is not passed on to younger researchers. Acquiring specialist knowledge requires many years of experience and some kind of mechanism for training and mentoring could usefully be developed, in addition to the existing IFA Skills Transfer initiative.

\subsection{Overall approach, scope of the questions posed and organisation of research}

While almost all research that is undertaken is of excellent quality, it is also highly specialised and there is always the danger of insufficient interdisciplinary collaboration. This has been a perennial problem as regards post-excavation research; the projects that have worked best are where the collaborative workers are engaged at an early and where feasible are introduced to the site itself 'on the ground' and there follow regular meetings of the entire team to assess progress and share insights right up to the point of production of a final report.

\subsection{Recommendations}

Many of the issues identified in Sections 7.2 and 7.3 are of course already being addressed. For example, making past editions of the Proceedings of the Society of Antiquaries of Scotland and Discovery and Excavation in Scotland freely available online has been one of the greatest steps forward in addressing the 'accessibility' problem. This is to be followed, in 2013, by the Proceedings of the Prehistoric Society becoming available online to members - an arrangement that is matched by subscriber e-access to other journals such as Antiquity and the European Journal of Archaeology. Other initiatives, to make grey literature available online, are also to be welcomed. However, there is much still to do, and the key recommendations are as follows:

- Create a hub for information on at least the Scottish Neolithic although it is difficult to believe that this would not be a valuable initiative for all periods, where all the diverse sources of information can be identified, with links to relevant online resources while also making more of the sources of information available online as well as in hard copy. Some suggestions as to the contents of this will be made available on the ScARF wiki.

- Develop databases, and in particular develop plans for integrating sites and monuments and artefact information on a national basis, and develop the Scottish Human Remains Database - 
an initiative that will be progressed during 2012.

- Reinstate a ${ }^{14} \mathrm{C}$ online database, and maintain and update it.

- Promote opportunities for interdisciplinary discussion of research needs, and encourage more major project applications (to bodies such as AHRC) that feature integrated strategies for enhancing our understanding.

- Develop mechanisms for skills transfer.

These recommendations should be viewed against the reminder that the individual researcher has the responsibility of developing her/his own expertise: there is a difference to be drawn between improving the efficiency of information dissemination and spoon-feeding. At the end of the day, we need debate about the Scottish Neolithic that is above all wellinformed; there is no short-cut to achieving knowledge and understanding of the rich resource of information that already exists, and to developing a critical faculty that is able to assess this information. 


\section{Bibliography}

Abercromby, J 1905 'The Ornament of the Beaker Class of Pottery'. Proc Soc Antiq Scot 39, 326-44

Abercromby, J 1907 'The Relative Chronology of some Cinerary Urn Types of Great Britain and Ireland'. Proc Soc Antiq Scot 41, 185-274

Abercromby, J A 1904 'Proposed Chronological Arrangement of the Drinking-Cup or Beaker Class of Fictilia in Britain'. Proc Soc Antiq Scot 38, 323-410

Addyman, T., Donnelly, M and Wilson, T 2004 'Station Brae, Dreghorn', Discovery Excav Scot, 87-8.

Andrews, M V., Beck, R B., Birks, H J B and Gilbertson, D D 1987 'The past and present vegetation of Oronsay and Colonsay', in Mellars, $\mathrm{P}$ (ed) Excavations on Oronsay. Edinburgh University Press: Edinburgh, 52-77.

Andrews, M V., Gilbertson, D D and Kent, M 1987 'Storm frequencies along the Mesolithic coastline', in Mellars, $\mathrm{P}$ (ed) Excavations on Oronsay. Edinburgh University Press: Edinburgh, 108-114.

Angell, I 01977 'Are Stone Circles, Circles' Science and Archaeology 19, 16-19

Armit, I 2003 'The Drowners: permanence and transience in the Hebridean Neolithic', in Armit, I et al. (eds) Neolithic Settlement in Ireland and Western Britain. Oxbow: Oxford, 93-100.

Armit, I., Murphy, E., Nelis, E and Simpson, D (eds) 2003 Neolithic settlement in Ireland and Western Britain. Oxbow: Oxford.

Ascough, P L., Cook, G T., Dugmore, A J and Scott E M 2007 'The North Atlantic marine reservoir effect in the Early Holocene: Implications for defining and understanding MRE values'. Nuclear Instruments and Methods in Physics Research Section B: Beam Interactions with Materials and Atoms 259(1), 438-447.

Ashmore, P 1996 Neolithic and Bronze Age Scotland. Batsford / Historic Scotland: Edinburgh.

Ashmore, P 1997 'Radiocarbon dates from archaeological sites in Argyll and Arran', in Ritchie, G (ed) The archaeology of Argyll, Edinburgh University Press: Edinburgh, 239-83.

Ashmore, P 2007 'Radiocarbon dates from the Pict's Knowe, Holywood and Holm', in Thomas, J (ed) 2007 'Place and Memory: Excavations at the Pict's Knowe, Holywood, and Holm Farm, Dumfries and Galloway, 1994-8'. Oxbow Books: Oxford, 248-59.

Atkinson, J 2002 'Excavation at a Mesolithic and Neolithic occupation site at Chapelfield, Cowie, Stirling', Proc Soc Antiq Scot 132, 123-92.

Austin, P 2000 'The emperor's new garden: woodland, trees and people in the Neolithic of southern Britain', in Fairbairn, A S (ed) Plants in Neolithic Britain and Beyond. Oxbow: Oxford, 63-78.

Bailey, J F et al. 1996 'Ancient DNA suggests a recent expansion of European cattle from a wild progenitor species', Proceedings of the Royal Society of London B263, 1467-1473. 
Baillie, M G L 1995 'Dendrochronology and past environmental change', Proceedings of the British Academy 77, 5-23.

Bailloud, G 1975 'Les céramiques 'cannelées' du Néolithique morbihannais'. Bulletin de la Société Préhistorique Française 72, 343-67

Bakels, C C 1997 'The beginnings of manuring in western Europe', Antiquity 71, 442-445.

Balasse, M., Tresset, A and Ambrose, SH 2006 'Stable isotope evidence $\left(\delta^{13} \mathrm{C}, \delta^{18} \mathrm{O}\right)$ for winter feeding on seaweed by Neolithic sheep of Scotland', Journal of Zoology 270, 170-176.

Barber, J (ed) 1997 The Archaeological investigation of a prehistoric landscape: excavations on Arran 1978-81, Scottish Trust for Archaeological Research: Edinburgh.

Barbarena, R and Borrero, L A 2005 'Stable isotopes and faunal bones. Comments on Milner et al. 2004', Antiquity 79, 191-195.

Barcham, R C 1981 'A lost radiocarbon date for Shetland', Proc Soc Antiq Scot 110, 503-4.

Barclay, G J 1983 'Sites of the third millennium BC to the first millennium AD at North Mains, Srathallan, Perthshire', Proc Soc Antiq Scot 113, 122-281.

Barclay, G J 1996 'Neolithic buildings in Scotland', in Darvill, T and Thomas, J (eds) 1996 Neolithic houses in Northwest Europe and beyond (Neolithic Studies Group Seminar Papers 1) Oxbow: Oxford, 61-76.

Barclay, G J 2001 'Metropolitan' and 'Parochial' / 'Core' and 'Periphery': a historiography of the Neolithic of Scotland', Proceedings of the Prehistoric Society 67, 1-18.

Barclay, G J 2003 'Neolithic settlement in the lowlands of Scotland: a preliminary survey' in Armit, I., Murphy, E., Nelis, E and Simpson, D (eds) 2003 Neolithic settlement in Ireland and Western Britain. Oxbow: Oxford, 71-83.

Barclay, G J., Carter, S P., Dalland, M M., Hastie, M., Holden, T., MacSween, A and Wickham-Jones, C R 2001 'A possible Neolithic settlement at Kinbeachie, Black Isle, Highland', Proc Soc Antiq Scot $131,57-85$.

Barclay, G J., Brophy, K and MacGregor, G 2002 'Claish, Stirling: an early Neolithic structure in its context', Proc Soc Antiq Scot 132, 65-137.

Barrett, J H., Nicholson, R A and Cerón-Carrasco, R 1999 'Archaeo-ichthyological evidence for longterm socioeconomic trends in northern Scotland: 3500 BC to AD 1500', Journal of Archaeological Science 26, 353-88.

Barry, G 1805 The History of the Orkney Islands

Bayliss, A., Bronk Ramsey, C et al. 2007 'Bradshaw and Bayes: Towards a Timetable for the Neolithic'. Cambridge Archaeological Journal 17 (Supplement S1), 1-28. 
Bayliss, A., Whittle, A et al. 2008 'Timing, tempo and temporalities in the early Neolithic of southern Britain', in Fokkens, H., Coles, B J., Van Gijn, A L et al. (eds) 2008 Between foraging and farming: an extended broad spectrum of papers presented to Leendert Louwe Kooijmans, Annalecta Praesitorica Leidensia 40, 25-42.

Behre, K E 2005 'The reduction of the Neolithic living space in NW Germany by climatic factors: sealevel rise and large-scale bog formation', in Gronenborm, D (ed) Climate Variability and Culture Change in Neolithic Societies of central Europe, 6700-2200 cal BC. Verlag des Römisch Germanischen Zentralmuseums: Mainz, 209-220 (English summary).

Behre, K E 2007 'Evidence for Mesolithic agriculture in and around central Europe?' Vegetation History and Archaeobotany 16, 203-219.

Beckensall, S 2001 Prehistoric Rock Art in Northumberland. Tempus: Stroud.

Bennett, K D 1989 'A provisional map of forest types for Britain and Ireland 5000 years ago', Journal of Quaternary Science 4, 141-144.

Berglund, B E 2003 'Human impact and climate changes - synchronous events and a causal link', Quaternary International 105, 7-12.

Birks, H J B and Williams, W W 1983 'Late-Quaternary vegetational history of the Inner Hebrides', Proceedings of the Royal Society of Edinburgh 83B, 269-282.

Bishop, R., Church, M J., Rowley-Conwy, P A 2009 'Cereals, fruits and nuts in the Scottish Neolithic', Proc Soc Antiq Scot 139, 47-103

Bjorck, S and Clemmensen, L B 2004 'Aeolian sediment in raised bog deposits, Halland, SW Sweden: a new proxy record of Holocene winter storminess variation in southern Scandinavia?', The Holocene $14,677-688$.

Blackford, J J and Innes, J B 2006 'Linking current environments and processes to fungal spore assemblages: surface NPM data from woodland environments', Review of Palaeobotany and Palynology 141, 179-187.

Blaauw, M., van Geel, B and van der Plicht, J 2004 'Solar forcing of climatic change during the midHolocene: indications from raised bogs in The Netherlands', The Holocene 14, 35-44.

Bogaard, A 2002 'Questioning the relevance of shifting cultivation to Neolithic farming in the loess belt of Europe: evidence from the Hambach Forest experiment', Vegetation History and Archaeobotany 11, 155-168.

Bogaard, A 2004 Neolithic Farming in Central Europe. Routledge: London.

Bogaard, A., Heaton, T., Poulton, P and Merbach, I 2007 'The impact of manuring on nitrogen isotope ratios in cereals: archaeological implications for reconstruction of diet and crop management practices', Journal of Archaeological Science 34, 335-43. 
Bogaard, A and Jones, G 2007 'Neolithic farming in Britain and central Europe: contrast or continuity?' in Whittle, A and Cummings, V (eds) Going over: the Mesolithic-Neolithic transition in north-west Europe. Oxford University Press for The British Academy: Oxford, 357-375.

Bogucki, P 1998 'Holocene climatic variability and early agriculture in temperate Europe: the case of northern Poland', in Zvelebil, M., Domańsla, L and Dennell, R (eds) Harvesting the Sea, Farming the Forest. The Emergence of Neolithic Societies in the Baltic Region. Sheffield Academic Press: Sheffield, 77-85.

Bohncke, S 1988 'Vegetation and habitation history of the Callanish area, Isle of Lewis, Scotland', in Birks, $\mathrm{H}$ H et al. (eds) The Cultural Landscape Past, Present and Future. Cambridge University Press: Cambridge, 445-462.

Bollongino, R., Edwards, C J., Burger, J., Alt, K W and Bradley, D G 2005 'Early history of European domestic cattle as revealed by ancient DNA', Biological Letters [online] 1-5.

Bond, G C et al. 1997 'A pervasive millennial-scale cycle in North Atlantic Holocene and glacial climates', Science 278, 1257-1266.

Bond, G C et al. 2001 'Persistent solar influence on North Atlantic climate during the Holocene', Science 294, 2130-2136.

Bonsall, C., Macklin, M G., Anderson, D E and Payton, R W 2002 'Climate change and the adoption of agriculture in north-west Europe', European Journal of Archaeology 5, 9-23.

Boyd, W E 1988 'Cereals in Scottish Antiquity', Circaea 5, 101-10.

Bradley, R 1997 Rock art and the prehistory of Atlantic Europe. Routledge: London.

Bradley, R 2003 'Neolithic expectations' in Armit, I., Murphy, E., Nelis, E and Simpson, D (eds) 2003 Neolithic settlement in Ireland and Western Britain. Oxbow: Oxford, 218-22.

Bradley, R., Harding, J and Mathews, M 1993 'The siting of prehistoric rock art in Galloway, southwest Scotland', Proceedings of the Prehistoric Society 59 (1993), 269-283.

Brinch Petersen, E and Meiklejohn, C 2009 Late Mesolithic or Early Neolithic Burials? Examining the 'Tauber line'. in Finlay, N., McCartan, S., Milner, N and Wickham-Jones, C (eds)2009 From Bann Flakes to Bushmills: Papers in Honour of Professor Peter Woodman, Oxbow Books and The Prehistoric Society: Oxford, 165-174.

Broecker, W S 2000 'Was a change in thermohaline circulation responsible for the Little Ice Age?' Proceedings of the National Academy of Sciences 97, 1339-1442.

Brophy, K 2006 'Rethinking Scotland's Neolithic: combining circumstance with context'. Proc Soc Antiq Scot 126, 7-46.

Brophy, K 2007 'From big houses to cult houses: early Neolithic timber halls in Scotland'. Proceedings of the Prehistoric Society 73, 75-96. 
Brophy, $\mathrm{K}$ 2007a 'The cursus monuments of south-west Scotland', in Thomas, J (ed) 'Place and Memory: Excavations at the Pict's Knowe, Holywood, and Holm Farm, Dumfries and Galloway, 19948'. Oxbow Books: Oxford, 158-65.

Brophy, K (in prep) 'Houses, halls and occupation in Britain and Ireland', in Fowler, C., Harding, J and Hofmann, D (eds) Oxford Handbook of Neolithic Europe.

Brown, A D 2007 'Dating the onset of cereal cultivation in Britain and Ireland: the evidence from charred cereal grains', Antiquity 81, 1042-1052.

Brown, A G 1997 'Clearances and clearings: deforestation in mesolithic/Neolithic Britain', Oxford Journal of Archaeology 16, 133-146.

Brown, A G 2000 'Floodplain vegetation history: clearings as potential ritual spaces?' in Fairbairn, A S (ed) Plants in Neolithic Britain and Beyond. Oxbow: Oxford, 49-62.

Brown, A G and Keough, M 1992 'Palaeochannels, palaeoland-surfaces and the three-dimensional reconstruction of floodplain environmental change', in Carling, P A and Petts, G E (eds) Lowland Floodplains: Geomorphological Perspectives. Wiley and Sons: Chichester, 185-202.

Bryce, T H 1902 'On the cairns of Arran', Proc Soc Antiq Scot 37, 36-67.

Buckland, P C and Edwards, K J 1984 'The longevity of pastoral episodes of clearance activity in pollen diagrams: the role of post-occupation grazing', Journal of Biogeography 11, 243-249.

Bunting, M J 1994 'Vegetation history from Orkney, Scotland; pollen records from two small basins in West Mainland', New Phytologist 128, 771-792.

Bunting, M J 1996 'The development of heathland in Orkney, Scotland: pollen records from Loch of Knitchen (Rousay) and Loch of Torness (Hoy)', The Holocene 6, 193-212.

Bunting, M J and Middleton, R 2005' Modelling pollen dispersal and deposition using HUMPOL software: simulating wind roses and irregular lakes', Review of Palaeobotany and Palynology 134, 185-196.

Burl, H A W 1976a The Stone Circles of Britain and Ireland, Yale University Press: Yale.

Burl, A 1976b 'Intimations of numeracy in the Neolithic and Bronze Age societies of the British Isles' Arch. Journ. 133, 9-32

Burl, A 1981 'Holes in the Argument' Archaeoastronomy 4(4), 19-21

Burl, A 1984 'Report on the excavation of a Neolithic mound at Boghead, Speymouth Forest, Fochabers, Moray, 1972 and 1974',Proc Soc Antiq Scot 114, 35-73.

Burl, A 1991 'Megalithic Myth or Man the Mover' Antiquity 65, 297-8

Burl, A 1995 A Guide to the Stone Circles of Britain, Ireland and Brittany, Yale University Press: New Haven 
SCARF Neolithic Panel Report

Burl, A 2006 A Brief History of Stonehenge, Robinson: London

Calder, C S T 1950 'Report on the excavation of a Neolithic temple at Stanydale in the Parish of Sandsting, Shetland', Proc Soc Antiq Scot 84, 185-205.

Calder, C S T 1952 'Report on the excavation of a Neolithic temple at Stanydale in the Parish of Sandsting, Shetland', Proc Soc Antiq Scot 84, 185-205.

Calder, C S T 1956 'Report on the discovery of numerous house-sites in Shetland', Proc Soc Antiq Scot 89, 340-97.

Calder, C S T 1964 'Cairns, Neolithic Houses and Burnt Mounds in Shetland' Proc Soc Antiq Scot 96, 37-86.

Callander, J G 1929 'Scottish Neolithic Pottery'. Proc Soc Antiq Scot 63, 29-98

Carter, S 1998 'Palaeopedology', in McCullagh, R P J and Tipping, R (eds) The Lairg Project 1988-1996 The Evolution of an Archaeological Landscape in Northern Scotland. STAR: Edinburgh, 150-161.

Caseldine, C J., Thompson, G., Langdon, P and Hendon, D 2005 'Evidence for an extreme climatic event on Achill Island, Co. Mayo, Ireland around 5200-5100 cal. yr BP', Journal of Quaternary Science 20, 169-178.

Caseldine, C J and Fyfe, R M 2006 A modelling approach to locating and characterising elm decline/landnam clearances. Quaternary Science Reviews 25, 632-644.

Caseldine, C J., Fyfe, R M., Langdon, C T and Thompson, G 2007 'Simulating the nature of vegetation communities at the opening of the Neolithic on Achill Island, Co. Mayo, Ireland - the potential role of models of pollen dispersal and deposition', Review of Palaeobotany and Palynology 144, 135-144.

Caseldine, C J., Fyfe, R M and Hjelle, K 2008 'Pollen modelling, palaeoecology and archaeology: virtualisation and/or modelling of the past?' Vegetation History and Archaeobotany 17, 543-549.

Cassen, S 2009 Autour de la Table. Laboratoire du recherches archéologiques, CNRS, Université de Nantes: Nantes.

Cassen, S., Lanos, P., Dufresne, P., Oberlin, C., Delque-Kolic and Le Goffic, M 2009 'Datations sur site (Table des Marchands, alignement du Grand Menhir, Er Grah) et modélisation chronologique du Néolithique morbihannais', in Cassen, S (ed), Autour de la Table. Laboratoire du recherches archéologiques, CNRS, Université de Nantes : Nantes, 737-68.

Chamberlain, A and Witkin, A 2003 'Early Neolithic diets: evidence from pathology and dental wear', in Parker Pearson, M (ed) Food, Culture and Identity in the Neolithic and Early Bronze Age, British Archaeological Reports International Series 1117: Oxford, 53-8,

Charman, D J 1992 'Blanket mire formation at the Cross Lochs, Sutherland, northern Scotland', Boreas 21, 53-72.

Cheddadi, R et al. 1997 'The climate of Europe 6000 years ago', Climate Dynamics 13, 1-9. 
Chesterman, JT 1979 'Investigation of the human bone from Quanterness', in Renfrew, C (ed) Investigations in Orkney Society of Antiquaries of London (Research Report 38): London, 97-109.

Childe, V G 1931 Skara Brae: a Pictish village in Orkney. Kegan Paul: London.

Childe, V G and Grant, W 1939 'A Stone-Age settlement at the Braes of Rinyo, Rousay, Orkney (First Report)', Proc Soc Antiq Scot 73, 6-31.

Clark, S H E and Edwards, K J 2004 'Elm bark beetle in Holocene peat deposits and the northwest European elm decline;, Journal of Quaternary Science 19, 525-528.

Clarke, A 1989 'The Skaill knife as a butchering tool', Lithics 10, 16-27.

Clarke, A 2006 Stone Tools and the Prehistory of the Northern Isles British Archaeological Report 406: Oxford.

Clarke, A 2008 Coarse stone reports for GUARD sites 2465 and 2531

Clarke, D V 1976 The Neolithic village at Skara Brae, Orkney: 1972-73 excavations, an interim report, HMSO: Edinburgh.

Clarke, D V 2003 'Once upon a time Skara Brae was unique', in Armit, I., Murphy, E., Nelis, E and Simpson, D (eds) 2003 Neolithic settlement in Ireland and Western Britain. Oxbow: Oxford, 84- 92.

Clarke, D V and Sharples, N 1985. 'Settlement and subsistence in the third millennium $\mathrm{BC}^{\prime}$ in Renfrew, C (ed) The Prehistory of Orkney, Edinburgh University Press: Edinburgh, 286-305.

Clough, T H M and Cummins, W A 1988 Stone Axe Studies, Volume 2. Council for British Archaeology: London

Clouston, R S 1885 'Notice of the Excavation of a Chambered Cairn of the Stone Age, at Unstan, in the Loch of Stennis, Orkney'. Proc Soc Antiq Scot 19, 341-51

Collard, M, Edinborough, K, Shennan, S and Thomas, M G 2010 'Radiocarbon evidence indicates that migrants introduced farming to Britain', Journal of Archaeological Science 37(4), 866-870.

Colledge, S., Conolly, J and Shennan, S 2005 'The evolution of farming from SW Asian origins to NW European limits', European Journal of Archaeology 8, 137-156.

Cooney, G 2003 'Rooted or routed? Landscapes of Neolithic settlement in Ireland', in Armit, I., Murphy, E., Nelis, E and Simpson, D (eds) 2003 Neolithic settlement in Ireland and Western Britain. Oxbow: Oxford, 47-55.

Cooney, G 2007 'Parallel worlds or multi-stranded identities? Considering the process of 'going over' in Ireland and the Irish Sea zone', in Whittle, A and Cummings, V (eds) Going Over: the MesolithicNeolithic Transition in North-West Europe, 543-566.

Copley, M S., Berstan, R., Dudd, S N., Aillaud, S., Mukherjee, A J., Straker, V., Payne, S and Evershed, R P 2005 'Processing of milk products in pottery vessels through British prehistory', Antiquity 79, 895-908. 
Corcoran, J X W P 1969a 'Excavation of two chambered tombs at Mid Gleniron Farm, Glenluce', Trans Dumfriesshire Galloway Natur Hist Antiq Soc 46, 29-90.

Corcoran, J X W P 1969b 'Excavation of two burial cairns at Mid Gleniron Farm, Glenluce, Wigtownshire', Trans Dumf Gall Nat Hist Antiq Soc 46 (1969), 91-9.

Cormack, W F 1963a 'Burial site at Kirkburn, Lockerbie', Proc Soc Antiq Scot 96, 107-35.

Cormack, W F 1963b 'Prehistoric site at Beckton, Lockerbie', Trans Dumf Gall Nat Hist Antiq Soc 41, 111-5.

Cowan, T 1988 'Megalithic compound ring geometry' in Ruggles, C (ed) Records in Stone Papers in Memory of Alexander Thom, Cambridge University Press: Cambridge, 378-391

Cowie, T 1988 Magic Metal: early metalworkers in the North-East. University of Aberdeen: Aberdeen

Cowie, T G 1996 'Torrs Warren, Luce Sands, Galloway', Trans Dumf Gall Nat Hist Antiq Soc 71, 11105.

Cowie, T and McKeague, P 2011 'Mapping material culture: exploring the interface between museum artefacts and their geographical context' in Ralston, I and Jones, R H (eds) Artefacts, Records, Monuments and Sites: Contextualising the Records. Scottish Archaeological Journal.

Cowley, D C and Brophy, K 2001 'The impact of aerial photography across the lowlands of southwest Scotland', Trans Dumf Gall Nat Hist Antiq Soc 75, 47-72.

Crombé, P and Vanmontfort, B 2007 'The neolithisation of the Scheldt basin in western Belgium', in Whittle, A W R and Cummings, V (eds.) Going Over: the Mesolithic-Neolithic Transition in NorthWest Europe, 263-285. Oxford: British Academy (Proceedings of the British Academy 144).

Crone, B A 1983 'The Clochmabenstane, Gretna', Trans Dumf Gall Nat Hist Antiq Soc 58, 16-20.

Cross, S 2003 'Irish Neolithic settlement architecture - a reappraisal', in Armit, I., Murphy, E., Nelis, E and Simpson, D (eds) 2003 Neolithic settlement in Ireland and Western Britain. Oxbow: Oxford , 195202.

Cummings, V 2003 'Monuments and landscape', Trans Dumf Gall Nat Hist Antiq Soc 77, 23-36.

Cummings, V 2009 A view from the west: the Neolithic of the Irish Sea zone. Oxbow: Oxford.

Cummings, V and Fowler, C 2007 From Cairn to Cemetery: an archaeological investigation of the chambered cairns and early Bronze Age mortuary deposits at Cairnderry and Bargrennan White Cairn, south-west Scotland. British Archaeological Reports British Series 434: Oxford.

Cummings, V and Whittle, A W R 2003 'Tombs with a view: landscape, monuments and trees', Antiquity 77, 255-266. 
Cummings, V and Robinson, G 2006 The Southern Kintyre Project: Interactions across the Irish Sea from the Mesolithic to the Bronze Age. Interim Report April 2006. UCLan Studies in Archaeology, Specialist Report Number 4.

Cummings, V and Harris, O 2011 'Animals, people and places: the continuity of hunting and gathering practices across the Mesolithic-Neolithic transition in Britain'. European Journal of Archaeology 14(3), 361-382.

Dark, P and Gent, H 2001 'Pest and diseases of prehistoric crops: a yield 'honeymoon' for early grain crops in Europe?', Oxford Journal of Archaeology 20, 59-78.

Darvill, T 1996 'Neolithic buildings in England, Wales and the Isle of Man', Darvill, T and Thomas, J (eds) 1996 Neolithic houses in Northwest Europe and beyond (Neolithic Studies Group Seminar Papers 1) Oxbow: Oxford,77-112.

Darvill, T and Thomas, J (eds) 1996 Neolithic houses in Northwest Europe and beyond (Neolithic Studies Group Seminar Papers 1) Oxbow: Oxford

Davidson, D A and Carter, S P 1997 'Soils and Their Evolution' in Edwards, K J and Ralston, I B M (eds) Scotland: Environment and Archaeology, 8000 BC-AD 1000, John Wiley and Son: New York and Chichester,45-62.

Davies, J I 1995 'Bolam and Shaftoe: A second survey', Northern Archaeology 12, 51-77.

Davies, P and Wolski, C 2001 'Later Neolithic woodland regeneration in the long barrow ditch fills of the Avebury area: the molluscan evidence', Oxford Journal of Archaeology 20, 311-317.

Davis, B A S et al. 2003 'The temperature of Europe during the Holocene reconstructed from pollen data', Quaternary Science Reviews 22, 1701-1716.

Dawson, S and Wickham-Jones, C 2007 'Sea level change and the prehistory of Orkney', Antiquity project gallery [online]. Available at < http://antiquity.ac.uk/projgall/wickham/index.html $>$. Accessed 21 December 2011.

de Jong, R., Bjorck, S., Bjorkman, L and Clemmensen, L B 2006 'Storminess variation during the last 6500 years as reconstructed from an ombrotrophic peat bog in Halland, southwest Sweden', Journal of Quaternary Science 21, 905-919.

de la Vega-Leinert, A C., Smith, D E and Jones, R L 2007 'Holocene coastal changes on the periphery of an area of glacio-isostatic uplift: an example from Scapa Bay, Orkney, UK', Journal of Quaternary Science 22, 755-772.

deMenocal, P B 2001 'Cultural responses to climate change during the Holocene', Science 292, 667672.

DES Discovery and Excavation in Scotland, The Journal of the Council for Scottish Archaeology, Edinburgh.

Dickson, CA 1983 'Macroscopic plant remains from Knap of Howar, Orkney', in Ritchie, A 'Excavations of a Neolithic farmstead at Knap of Howar, Papa Westray, Orkney', Proc Soc Antiq Scot $113,114-5$. 
Dickson, C A and Dickson, J H 2000 Plants and People in Ancient Scotland Tempus: Stroud.

Dimbleby, G W and Evans, J G 1974 'Pollen and land-snail analysis of calcareous soils', Journal of Archaeological Science 1, 117-133.

Dommett, K., Tayles, N and Nelsen, K 2000 'Agriculture and dental caries? The case of rice in prehistoric southeast Asia', American Journal of Physical Anthropology 30, 141.

Downes, J and Lamb, R 2000 Prehistoric houses at Sumburgh in Shetland: excavations at Sumburgh airport 1967-74. Oxbow: Oxford.

Dreibrodt, S et al. 2009 'Investigations on buried soils and colluvial layers around Bronze Age burial mounds at Börnhöved (northern Germany): an approach to test the hypothesis of 'landscape openness' by the incidence of colluviation', The Holocene 19, 487-498.

Edmonds, M 1998 Ancestral Geographies of the Neolithic. Routledge: London

Edmonds, M 1999 'Inhabiting Neolithic landscapes' in Edwards, K J and Sadler, J P (eds) Holocene Environments of Prehistoric Britain. Wiley: Chichester, 485-493.

Edmonds, M., Sheridan, J A and Tipping, R 1992 'Survey and excavation at Creag na Caillich, Killin, Perthshire', Proceedings of the Society of Antiquaries of Scotland 122, 77-112, fiche 1:A5-11.

Edwards, K J 1988 'The hunter-gatherer/agricultural transition and the pollen record in Britain and Ireland', in Birks, $\mathrm{H} \mathrm{H}$ et al. (eds) The Cultural Landscape: Past, Present and Future. Cambridge University Press: Cambridge, 255-266.

Edwards, K J 1989 'Meso-Neolithic vegetation impacts in Scotland and beyond: palynological considerations', in Bonsall, C (ed) The Mesolithic in Europe John Donald: Edinburgh, 143-163.

Edwards, K J 1993 'Models of mid-Holocene forest farming for north-west Europe', in Chambers, F M (ed) Climate Change and Human Impact on the Landscape, Chapman and Hall: London, 133-145.

Edwards, K J 1996 'The contribution of Tom Affleck to the study of the Mesolithic of southwest Scotland', in Pollard, T and Morrison, A The Early Prehistory of Scotland. Edinburgh University Press: Edinburgh,

Edwards, K J 1998 'Detection of human impact on the environment: palynological views', in Bayley, J (ed) Science and Archaeology: An Agenda for the Future. English Heritage: London, 69-88.

Edwards, K J 2004 'People, environmental impacts, and the changing landscapes of Neolithic and early Bronze Age times', in Shepherd, I A G and Barclay, G (eds) Scotland in Ancient Europe. The Neolithic and Early Bronze Age of Scotland in their European Context. Society of Antiquaries of Scotland: Edinburgh, 55-70.

Edwards, K J and McIntosh, C J 1988 'Improving the detection rate of cereal-type pollen grains from Ulmus decline and earlier deposits from Scotland', Pollen et Spores 30, 179-188. 
Edwards, K J., Whittington, G and Hirons, K R 1995 'The relationship between fire and long-term wet heath development in South Uist, Scotland', in Thompson, D B A., Hester, A J and Usher, M B (eds) Heaths and Moorlands: Cultural Landscapes. HMSO: Edinburgh, 240-48.

Edwards, K J., Mulder, Y., Lomax, T A., Whittington, G and Hirons, K R 2000 'Human-environment interactions in prehistoric landscapes: the example of the Outer Hebrides', in Hooke, D (ed) Landscape, the Richest Historical Record. Society for Landscape Studies Supplementary Series 1, 1332.

Edwards, $\mathrm{K} \mathrm{J}$ and Whittington, G 2001 'Lake sediments, erosion and landscape change during the Holocene in Britain and Ireland', Catena 42, 143-173.

Edwards, $\mathrm{K} J$ and Whittington, G 2003 'Vegetation change', in Edwards, $\mathrm{K} \mathrm{J}$ and Ralston, I B M (eds) Scotland: Environment and Archaeology 8000 BC-AD 1000. Wiley: Chichester, 63-82.

Ellis, C., Crone, A., Reilly, E and Hughes, P 2002 'Excavation of a Neolithic wooden platform', Proceedings of the Prehistoric Society 68, 247-256.

Evans, C and Hodder, I 2006 'A woodland archaeology: Neolithic sites at Haddenham', McDonald Institute for Archaeological Research: Cambridge.

Evans, C., Pollard, J and Knight, M 1999 'Life in woods: tree-throws, 'settlement' and forest cognition', Oxford Journal of Archaeology 18, 241-254.

Evans, J and Bick, L 1976 'Over-cooked food residues on pot sherds', Proceedings of the 16th international symposium on archaeometry and archaeological prospection, National Museums of Scotland: Edinburgh.

Fairweather, A D and Ralston, I B M 1993 'The Neolithic timber hall at Balbridie, Grampian Region, Scotland: the building, the date, the plant macrofossils', Antiquity 67, 313-323.

Farrer, J 1868 'Note of Excavations in Sanday, one of the North Isles of Orkney'. Proc Soc Antiq Scot 7, 398-401

Fenton, J H C 2008 'A postulated natural origin for the open landscapes of Scotland', Plant Ecology and Diversity 1, 115-127.

Fleming, A 1975 'Megalithic astronomy: a prehistorian's view' Nature 255, 575

Fleming, A 2005a St Kilda and the Wider World, Windgather Press.

Fleming, A 2005b 'St Kilda: the prehistory of a distant archipelago', PAST No. 49, April 2005

Fleming, A and Edmonds, M 1999 'St Kilda: quarries, fields and prehistoric agriculture', Proc Soc Antiq Scot 129, 119-60.

Fowler, C and Thomas, J 2007 'The Twelve Apostles stone circle', in Thomas, J (ed) 'Place and Memory: Excavations at the Pict's Knowe, Holywood, and Holm Farm, Dumfries and Galloway, 19948'. Oxbow Books: Oxford, 197. 
Gaffney, V., Stancic, Z and Watson, H 1995 'Moving from catchments to cognition: tentative steps towards a larger archaeological context for GIS', Scottish Archaeological Review 9/10, 41-64.

Gibson, A 1998 Stonehenge and timber circles. Tempus: Stroud.

Gibson, A 2002 Prehistoric pottery in Britain and Ireland, Tempus: Stroud.

Gibson, A 2003 'What do we mean by Neolithic settlement? Some approaches, 10 years on', Armit, I., Murphy, E., Nelis, E and Simpson, D (eds) 2003 Neolithic settlement in Ireland and Western Britain. Oxbow: Oxford , 136-45.

Gibson, A 2004 'Visibility and intervisibility: some thoughts on Neolithic and Bronze Age sites', in Shepherd, I A G and Barclay, G (eds) Scotland in Ancient Europe. The Neolithic and Early Bronze Age of Scotland in their European Context. Society of Antiquaries of Scotland: Edinburgh, 155-169.

Greenwell, Rev. W 1866 'An Account of Excavations in Cairns near Crinan'. Proc Soc Antiq Scot 6, 336-51

Greenwell, W and Rolleston, G 1877 British Barrows. Clarendon Press: Oxford.

Gregory, R A 2000, 'Prehistoric landscapes in Dumfries and Galloway. Part 1 - Mesolithic and Neolithic landscapes', Trans Dumf Gall Nat Hist Antiq Soc 74, 1-26.

Gronenborm, D 2005 Climate Variability and Culture Change in Neolithic Societies of central Europe, 6700-2200 cal BC. Verlag des Römisch-Germanischen Zentralmuseums: Mainz.

Gronenborm, D 2006 'Climate change and socio-political crises: some cases from Neolithic central Greece', Journal of Conflict Archaeology 2, 13-32.

Grudd, H et al. 2002 'A 7400-year tree-ring chronology in northern Swedish Lapland: natural climatic variability expressed on annual to millennial timescales', The Holocene 12, 657-666.

Guttmann, E B A 2005 'Midden cultivation in prehistoric Britain: arable crops in gardens', World Archaeology 37, 224-239.

Hannon, G E., Bradshaw, R H W., Nord, J and Gustaffson, M 2008 'The Bronze Age landscape of the Bjäre peninsula, southern Sweden, and its relationship to burial mounds', Journal of Archaeological Science 35, 623-632.

Hardy, K., Blakeney, T., Copeland, L., Kirkham, J., Wrangham, R and Collins, M 2009 'Starch granules, dental calculus and new perspectives on ancient diet', Journal of Archaeological Science 36, 248255.

Harding, A 1981 'Excavations in the prehistoric ritual complex near Milfield, Northumberland', Proceedings of the Prehistoric Society 46, 87-135.

Harding, A F and Lee, G E 1987 Henge Monuments and related Sites of Great Britain. British Archaeological Reports British Series 175: Oxford. 
Harrington, P and Pierpoint, S 1980 'Port Charlotte chambered cairn, Islay: an interim note', Glasgow Archaeological Journal 1980, 113-5.

Hedges, J W 1986 'Structures at Tougs, Burra Isle, Shetland', Glasgow Archaeological Journal 13, 143.

Hedges, J W and Parry, G W 1980 'A Neolithic multiple burial at Sumburgh Airport, Shetland', Glasgow Archaeol J 7, 15-26.

Hedges, R E M 2004 'Isotopes and red herrings: comments on Milner et al. and Lidén et al.' Antiquity 78, 34-37.

Heggie, D 1981 Megalithic Science, Thames and Hudson: London

Helama, S et al. 2002 'The supra-long Scots pine tree-ring record for Finnish Lapland: 2. interannual to centennial variability in summer temperatures for 7500 years', The Holocene 12, 681-688.

Henshall, A 1972 The chambered tombs of Scotland volume two. Edinburgh University Press: Edinburgh.

Hillman, G., Wales, S., McLaren, F., Evans., J and Butler, A 1993 'Identifying Problematic Remains of Ancient Plant Foods: A Comparison of the Role of Chemical, Histological and Morphological Criteria', World Archaeology 25, 94-121.

Hodgson, N., Stobbs, G C et al. 2001 'An Iron Age Settlement and Remains of Earlier Prehistoric Date beneath South Shields Roman Fort, Tyne and Wear', Archaeological Journal 158, 62-160.

Holden, T 1997 'Macroplant assessment', in Rideout, J S 'Excavation of Neolithic enclosures at Cowie Road, Bannockburn, Stirling 1984-5', Proc Soc Antiq Scot 127, 53-4.

Holden, T 1998 'Charred plant remains' in McCullagh, R P J and Tipping, R (eds) The Lairg Project. The Evolution of an Archaeological Landscape in N. Scotland 1988-1996, Scottish Trust for Archaeological Research, Edinburgh, 165-72.

Holmes, J et al. 2007 'Multi-proxy evidence for Holocene lake-level and salinity changes at An Loch Mór, a coastal lake on the Aran Islands, western Ireland', Quaternary Science Reviews 26, 2438-2462.

Hope-Taylor, B 1977 Yeavering. An Anglo-British Centre of Early Northumbria. HMSO: London.

Howard, A J and Macklin, M G1999 'A generic geomorphological approach to archaeological interpretation and prospection in British river valleys: a guide for archaeologists investigating Holocene landscapes', Antiquity 73, 527-541.

Hughes, P D M., Mauquoy, D., Barber, K E and Langon, P G 2000 'Mire-development pathways and palaeoclimatic records from a full Holocene peat archive at Walton Moss, Cumbria, England', The Holocene 10, 465-480.

Hunter, J 2000 'Pool, Sanday and a sequence for the Orcadian Neolithic', in Ritchie, A (ed) Neolithic Orkney in its European context, McDonald Institute Monograph: Cambridge, 117-25. 
Innes, J B., Blackford, J J and Davey, P J 2003 'Dating the introduction of cereal cultivation to Britain and Ireland: early palaeoecological evidence from the Isle of Man', Journal of Quaternary Science 18, 603-614.

Isbister, A 2000 '3.8 Pigment resources report: excavations at Sand, Applecross, 2000' in Hardy, K and Wickham Jones, C (eds) Mesolithic and later sites around the Inner Sound, Scotland: the work of the Scotland's First Settlers project 1998-2004 Scottish Archaeological Internet Reports [online] 31. Edinburgh: Society of Antiquaries of Scotland. Available at $<$ http://www.sair.org.uk/sair31/index.html $>$ [Accessed 23 ${ }^{\text {rd }}$ March 2012].

Jackson, M G et al. 2005 'Holocene loess deposition in Iceland: evidence for millennial-scale atmosphere-ocean coupling in the North Atlantic', Geology 33, 509-512.

Jacob, J et al. 2009 'Impacts of new agricultural practices on soil erosion during the Bronze Age in the French Prealps', The Holocene 19, 241-249.

Jobey, G 1968 'Excavations of Cairns at Chatton Sandyford, Northumberland', Archaeologia Aeliana 4th series 46, 5-50.

Johnson, B and Waddington, C 2009 'Excavation of Prehistoric and Dark Age sites at Cheviot Quarry, Milfield Basin, Northumberland', Archaeological Journal 165, 107-126.

Johnson, D A 1997 'Biggar Common, 1987-93: an early prehistoric funerary and domestic landscape in Clydesdale, South Lanarkshire', Proc Soc Antiq Scot 127, 185-253.

Johnstone E., Macklin M G and Lewin, J 2006 'The development and application of a database of radiocarbon-dated Holocene fluvial deposits in Great Britain', Catena 66, 14-23.

Jones, G 2000 'Evaluating the importance of cultivation and collecting in Neolithic Britain', in Fairbairn, A (ed) Plants in Neolithic Britain and Beyond Oxbow: Oxford, 79-84.

Jones, G and Rowley-Conwy, P 2007 'On the importance of cereal cultivation in the British Neolithic', in Colledge, S and Conolly, J (eds) The Origins and Spread of Domestic Plants in Southwest Asia and Europe. University College: London, 391-420.

Kalis, A J., Merkt, J and Wunderlich, J 2003 'Environmental changes during the Holocene climatic optimum in central Europe - human impact and natural causes', Quaternary Science Reviews 22, 3379.

Kalis, A J and Zimmermann, A 1988 'An integrative model for the use of different landscapes in Linearbandkeramik times', in Bintliff, J L., Davidson, D A and Grant, E G (eds) Conceptual Issues in Environmental Archaeology. Edinburgh University Press: Edinburgh, 145-152.

Karlen, W and Larsson, L 2007 'Mid-Holocene climatic and cultural dynamics in northern Europe', in Anderson, D G., Maasch, K A and Sandweiss, D H (eds) Climate Change and Cultural Dynamics: a Global Perspective on Mid-Holocene Transitions. Elsevier: Amsterdam, 407-434.

Keatinge, T H and Dickson, J H 1979 'Mid-Flandrian changes in vegetation on Mainland Orkney', New Phytologist 82, 585-612. 
Keigwin, L D and Boyle, E A 2000 'Detecting Holocene changes in thermohaline circulation', Proceedings of the National Academy of Sciences 97, 1343-1346.

Kinnes, I 1985 'Circumstance not context: The Neolithic of Scotland as seen from the outside', Proc Soc Antiq Scot 115, 15-57.

Kinnes, I A 1992 Non-Megalithic Long Barrows and Allied Structures in the British Neolithic. British Museum Occasional Paper No. 52: London.

Kinnes, I 2004 'Context not circumstance: a distant view of Scottish monuments in Europe', in Shepherd, I A G and Barclay, G J (eds) Scotland in Ancient Europe. Society of Antiquaries of Scotland: Edinburgh, 139-42.

Kirby, M 2006 'Broomhouses, Lockerbie', Discovery Excav Scot, 48-9.

Kreuz, A 2008 'Closed forest or open woodland as natural vegetation in the surroundings of Linearbandkeramik settlements?', Vegetation History and Archaeobotany 17, 51-64.

Langdon, P G., Barber, K E and Hughes, P D M 2003 'A 7500-year peat-based palaeoclimatic reconstruction and evidence for an 1100-year cyclicity in bog surface wetness from Temple Hill Moss, Pentland Hills, southeast Scotland', Quaternary Science Reviews 22, 259-274.

Larsen, C S 1995 'Biological changes in human populations with agriculture', American Journal of Physical Anthropology 37 109-54.

Larsen, C S 1997 Bioarchaeology: Interpreting behaviour from the human skeleton, Cambridge University Press: Cambridge.

Larsson, L 2003 'The Mesolithic of Sweden in retrospective and progressive perspectives', in Larsson, L., Kindgren, H., Knutsson, K., Loeffler, D and Åkerlund, A (eds) Mesolithic on the Move. Oxbow: Oxford, xxii-xxxii.

Lelong, O and MacGregor, G 2008 The Lands of Ancient Lothian. Interpreting the Archaeology of the A1. Society of Antiquaries of Scotland: Edinburgh.

Leuschner, $\mathrm{H}$ H et al. 2002 'Subfossil European bog oaks: population dynamics and long-term growth depressions as indicators of the Holocene hydro-regime and climate', The Holocene 12, 695-706.

Lockyer, N 1909 Stonehenge and Other Stone Monuments Astronomically Considered 2nd Edn, London

Loveday, R 2006 'Where have all the Neolithic houses gone? Turf - an invisible component', Scottish Archaeological Journal 28(2), 81-104.

Lubell, D., Jackes, M., Schwarcz, H., Knyf, M and Meiklejohn, C 1994 'The Mesolithic-Neolithic transition in Portugal: isotopic and dental evidence of diet', Journal of Archaeological Science 21, 201-216.

Lynch, A 1983 'The seed remains' in Hedges, J W Ibister: A Chambered Tomb in Orkney, British Archaeological Reports British Series 115: Oxford, 171-75. 
MacDonald, G M., Beilman, D W., Kremenetski, K V., Sheng, Y., Smith, L C and Velichko, A A 2006 'Rapid early development of circumarctic peatlands and atmospheric $\mathrm{CH}_{4}$ and $\mathrm{CO}_{2}$ variations', Science 314, 285-288.

MacGregor, G and McLellan, K 2007 'A burning desire to build: excavations at Eweford West and Pencraig Hill (3950-3380 BC)', in Lelong, O and MacGregor, G 2008 The Lands of Ancient Lothian. Interpreting the Archaeology of the A1. Society of Antiquaries of Scotland: Edinburgh, 15-45.

MacLean, C 1978 'Cereals From Pits A-C', in Ritchie, J N G 'The Stones of Stenness, Orkney', Proc Soc Antiq Scot 107, 43-4.

MacLean, C and Rowley-Conwy, P 1984 'The carbonized material from Boghead, Fochabers', Proc Soc Antiq Scot 114, 68-71.

Marshall, D and Taylor, I 1979 'The excavation of the chambered cairn at Glenvoidean, Isle of Bute', Proc Soc Antiq Scot 108, 1-39.

Macklin, M G., Bonsall, C., Davies, F M and Robinson, M R 2000 'Human-environment interactions during the Holocene: new data and interpretations from the Oban area, Argyll, Scotland', The Holocene 10, 109-122.

Macklin, M G., Johnstone, E and Lewin, J 2005 'Pervasive and long-term forcing of Holocene river instability and flooding in Great Britain by centennial-scale climate change', The Holocene 15, 937943.

Magny, M 2004 'Holocene climate variability as reflected by mid-European lake-level fluctuations and its probable impact on prehistoric human settlements', Quaternary International 113, 65-79.

Marret, F., Scourse, J and Austin, W 2004 'Holocene shelf-sea seasonal stratification dynamics: a dinoflagellate cyst record from the Celtic Sea, NW European shelf', The Holocene 14, 689-696.

Marshall, D N and Taylor, I D 1979 'The excavation of the chambered cairn at Glenvoidean, Isle of Bute', Proc Soc Antiq Scot 108, 1-39.

Mann, L McL 1903 'Report on the excavation of prehistoric pile-structures in pits in Wigtownshire', Proc Soc Antiq Scot 37, 370-415.

Marshall, D N 1978 'Excavations at Auchategan, Glendaruel, Argyll', Proceedings of the Society of Antiquaries of Scotland 109, 36-74.

Masser, P 2010 'Data structure report of an archaeological watching brief at Powmyre sand and gravel Quarry, Glamis, Angus. Phase 3 works.' Unpublished Client Report, Headland Archaeology Ltd.

Masters, LJ 1973 'The Lochhill long cairn', Antiquity 47, 96-100.

Masters, L J c.1977 Excavations at Slewcairn, Boreland of Southwick, Kirkcudbright. Typescript in National Monument Record of Scotland. 
Masters, L J 1981 'Chambered tombs and non-megalithic barrows in Britain', in Evans, J D., Cunliffe, B and Renfrew, C (eds) Antiquity and Man: Essays in honour of Glyn Daniel. Thames and Hudson: London, 161-76.

Masters, L 1984 'The Neolithic Long Cairns of Cumbria and Northumberland', in Miket, R and Burgess, C (eds) Between And Beyond The Walls: Essays in Honour of George Jobey. John Donald: Edinburgh, 52-73.

Mayewski, P A et al. 1996 'Climate change events as seen in the Greenland ice core (GISP2): implications for the Mesolithic of Scotland', in Pollard, T and Morrison, A (eds) The Early Prehistory of Scotland. Edinburgh University Press: Edinburgh, 74-86.

Mayewski, P A et al. 2004 'Holocene climate variability', Quaternary Research 62, 243-255.

Maynard, D 1993a 'Neolithic pit at Carzield, Kirkton, Dumfriesshire', Trans Dumf Gall Nat Hist Antiq Soc 68, 25-32.

Maynard, D 1993b 'Burnt mounds around a pipeline in Dumfries and Galloway', Trans Dumf Gall Nat Hist Antiq Soc 68, 33-52.

McCormick, F and Buckland, P C 1997 'Faunal change: the vertebrate fauna' in Edwards, K J and Ralston, I B M (eds) Scotland After the Ice Age: Environment, Archaeology and History, 8000 BC-AD 1000, Edinburgh University Press: Edinburgh, 83-103.

Mclnnes, I J 1964 'The Neolithic and Bronze Age pottery from Luce Sands, Wigtownshire', Proc Soc Antiq Scot 97, 40-81.

McLaughlin, T R 2008 Investigating food and diet in Mesolithic and Neolithic Europe: an exploratory approach using dental microwear analysis, unpublished Ph.D. thesis, Queen's University Belfast. Melton, N D 2008 'West Voe: a Mesolithic-Neolithic transition site in Shetland', in Noble, G et al. (eds) Scottish Odysseys. The archaeology of islands. Tempus: Stroud, 23-36.

Melton, N D 2004 'West Voe, Sumburgh (Dunrossness parish), midden', Discovery Excav Scot 5, 118.

Melton, N D 2005 'West Voe, Sumburgh, Shetland (Dunrossness parish), Late Mesolithic/Early Neolithic middens', Discovery Excav Scot 6, 127.

Melton, N D 2009 'Shells, seal and ceramics: an evaluation of a midden at West Voe, Sumburgh, Shetland, 2004-5' in McCartan, S., Schulting, R., Warren, G and Woodman, P (eds) Mesolithic Horizons Volume 1. Oxbow: Oxford, 184-189.

Melton, N D and Nicholson, R A 2004 'The Mesolithic in the Northern Isles: the preliminary evaluation of an oyster midden at West Voe, Sumburgh, Shetland, U.K.' Antiquity 78, 299.

Mellars, P 1987 Excavations on Oronsay. Edinburgh University Press: Edinburgh.

Michell, J 1989 A Little History of Astro-Archaeology 2nd Edn, Thames and Hudson: London

Miller, J and Ramsay, S 2002 'Plant macrofossils', in Barclay, G J., Brophy, K and MacGregor, G 'Claish, Stirling: an Early Neolithic structure and its context', Proc Soc Antiq Scot 132, 90-6. 
Milles, A 1986 'Charred remains of barley and other plants from Scord of Brouster', in Whittle, A W R (ed) Scord of Brouster: an Early Agricultural Settlement on Shetland, Oxford University (Committee for Archaeology Monograph 9): Oxford, 119-22

Mills, C M., Armit, I., Edwards, K J., Grinter, P and Mulder, Y 2003 'Neolithic land-use and environmental degradation: a study from the Western Isles of Scotland', Antiquity 76, 886-895.

Milner, N 2010 'Subsistence at 4000-3700 cal BC: landscapes of change or continuity?', in Finlayson, B and Warren, G (eds) Landscapes in Transition, 46-54. Oxbow (Levant Supplementary Series 8): Oxford and Oakville

Miket, R 1985 'Ritual Enclosures at Whitton Hill, Northumberland', Proceedings of the Prehistoric Society 51, 137-148.

Miket, R., Edwards, B and O'Brien, C 2009 'Thirlings, Northumberland, in the Neolithic', Archaeological Journal 165 (for 2008), 1-106 (93-95).

Milner, N 2006 'Subsistence', in Conneller, C and Warren, G M (eds) Mesolithic Britain and Ireland: new approaches. Tempus: Stroud, 61-82.

Milner, N 2010 'Subsistence at 4000-3700 cal BC: Landscapes of Change or Continuity?', in Finlayson, B and Warren, G M (eds) Landscapes in Transition. Oxbow/Council for British Research in the Levant (Levant Supplementary Series 8): Oxford, 46-54.

Milner, $\mathrm{N}$ et al. 2004 'Something fishy in the Neolithic? A re-evaluation of stable isotope analysis of Mesolithic and Neolithic coastal populations', Antiquity 77, 9-22.

Mitchell, A 1902 'Jubilee Address: The Pre-History of the Scottish Area - Fifty years' Work of the Society of Antiquaries of Scotland.' Proc Soc Antiq Scot 36, 11-65.

Mitchell, P 2008 'Practising archaeology at a time of climatic catastrophe', Antiquity 82, 1093-1103.

Mithen, S 2000a Hunter-gatherer landscape archaeology: the Southern Hebrides Mesolithic project. Oxbow: Oxford.

Morris, R W B 1979 The Prehistoric Rock Art of Galloway and the Isle of Man. Blandford Press: Poole.

Moros, $\mathrm{M}$ et al. 2004 'Sea surface temperatures and ice rafting in the Holocene North Atlantic: climate influences on northern Europe and Greenland', Quaternary Science Reviews 23, 2113-2126.

Mudie, G and Richardson, P 2006 'Excavation of a possible Neolithic structure, lithic finds and later ditch features at Kingarth Quarry, Isle of Bute', Scottish Archaeological Journal 28(2), 105-24.

Munro, R 1884 'Notice of Long Cairns near Rhinavie, Strathnaver, Sutherlandshire'. Proc Soc Antiq Scot $18,228-33$ 
Murphy, E and Simpson, D D A 2003 'Neolithic Northton: a review of the evidence', in Armit, I., Murphy, E., Nelis, E and Simpson, D (eds) 2003 Neolithic settlement in Ireland and Western Britain. Oxbow: Oxford, 101-111.

Murray, H K 2005 'Warren Field, Crathes', Discovery Excav Scot, 12-3.

Murray, H K and Murray, J C 2010 Westgate residential development, Blackhall Road, Inverurie Phase 3A: Archaeological Evaluation for proposed development. Murray Archaeological Services Ltd, Unpublished Client Report.

Murray, H K and Murray, J C (forthcoming) 'An early Neolithic building and Mesolithic occupation at Garthdee Road Aberdeen'. Proc Soc Antiq Scot

Murray, H K., Murray, J C and Fraser, S M 2009 A tale of unknown unknowns: a Mesolithic pit alignment and a Neolithic timber hall at Warren Field, Crathes, Aberdeenshire. Oxbow: Oxford.

Murray, J 1992 'The Bargrennan Group of chmbered cairns: circumstance and context', in Sharples, N and Sheridan, A S (eds) 1992 Vessels for the Ancestors Edinburgh University Press: Edinburgh, 3348.

Murray, J 1994 'Jade axes from Scotland: a comment on the distribution and supplementary notes', Proceedings of the Prehistoric Society 60, 97-104.

Murray, R (forthcoming) Archaeological Excavations at Culduthel, Phases 7 and 8.

Nesje, A et al. 2001 'Holocene glacier fluctuations of Flatebreen and winter-precipitation changes in the Jostedalsbreen region, western Norway, based on glaciolacustrine sediment records', The Holocene 11, 267-280.

Newbigin, N 1935 'Neolithic 'A' pottery from Ford, Northumberland', Archaeologia Aeliana $4^{\text {th }}$ ser, $12,148-157$.

Newman, T G 1976 'A Crop-Mark Site At Hasting Hill, Tyne and Wear, NZ355 541', Archaeologia Aeliana $5^{\text {th }}$ ser, $4,183-4$.

Noble, G 2005 'Ancestry, farming and the changing architecture of the Clyde Cairns of south-west Scotland', in Cummings, V and Pannett, A (eds) Set in Stone: new monuments to Neolithic monuments in Scotland. Oxbow Books: Oxford, 25-36.

Noe-Nygaard, $\mathrm{N}$ and Hede, M U 2006 'The first appearance of cattle in Denmark occurred 6000 years ago: an effect of cultural or climate and environmental changes', Geografiska Annaler A 88, 87-95.

Noe-Nygaard, N., Price, T D and Hede, M U 2005 'Diet of aurochs and early cattle in southern Scandinavia: evidence from ${ }^{15} \mathrm{~N}$ and ${ }^{13} \mathrm{C}$ stable isotopes', Journal of Archaeological Science 32, 855871.

Noren, A J et al. 2002 'Millennial-scale storminess variability in the northeastern United States during the Holocene epoch', Nature 419, 821-824. 
O'Connell, M 1987 'Early cereal-type pollen records from Connemara, western Ireland and their possible significance', Pollen et Spores 29, 207-224.

O'Connell, M and Molloy, K 2001 'Farming and woodland dynamics in Ireland during the Neolithic', Biology and Environment: Proceedings of the Royal Irish Academy 101B, 99-128.

O'Connor, B 2004 'The earliest metalwork since Coles', in Shepherd, I and Barclay, G (eds) Scotland in Ancient Europe: the Neolithic and Early Bronze Age of Scotland in their European Context, Society of Antiquaries of Scotland: Edinburgh, 205-216.

Oppo, D W., McManus, J F and Cullen, J L 2003 'Deepwater variability in the Holocene epoch', Nature 422, 277-278.

Parker, A G., Goudie, A S., Anderson, D E., Robinson, M A and Bonsall, C 2001 'A review of the midHolocene elm decline in Britain and Ireland', Progress in Physical Geography 26, 1-45.

Parks, R L 2009 'Seasonal resource scheduling in the Mesolithic and Neolithic of Scotland', in McCartan, S., Schulting, R., Warren, G and Woodman, P (eds) Mesolithic Horizons Volume 2. Oxbow: Oxford, 521-526.

Passmore, D G and Waddington, C 2009 Managing Archaeological Landscapes in Northumberland. Till-Tweed Studies Volume 1. Oxbow Books and English Heritage: Oxford.

Passmore, D G and Waddington, C (in press) Archaeology and Environment in Northumberland. TillTweed Studies Volume 2. Oxbow Books and English Heritage: Oxford.

Peeters, H 2009 'Early Holocene landscape dynamics and forager land use diversity: the example of Hoge Vaart-A27 (Almere, The Netherlands)', in McCartan, S., Schulting, R., Warren, G and Woodman, P (eds) Mesolithic Horizons Volume 1. Oxbow: Oxford, 269-276.

Peltenburg, E 1982 'Excavations at Balloch Hill, Kintyre', Proc Soc Antiq Scot 112, 142-214.

Pétrequin, P., Cassen, S., Errera, M., Klassen, L., Sheridan, J A and Pétrequin, A M 2012 'Jade. Grandes haches alpines du Néolithique européen. $V^{e}$ et IV millénaires av. J.-C.' Cahiers de la MSHE C.N. Ledoux, Besançon, Presses Universitaires de Franche-Comté et Centre de Recherche Archéologique de la Vallée de l'Ain.

Pickin, J 1997 'Two polished flint knives from Galloway', Trans Dumf Gall Nat Hist Antiq Soc 72,1102.

Piggott, S 1954 Neolithic cultures of Britain and Ireland. Cambridge University Press: Cambridge.

Piggott, S 1965 Ancient Europe. Edinburgh University Press: Edinburgh.

Piggott, S and Powell, T G E 1949 'The excavation of three Neolithic chambered tombs in Galloway', Proc Soc Antiq Scot 83, 103-61.

Pitts, M 2000 Hengeworld, Arrow: London 
Pollard, T 1997 'Excavation of a Neolithic settlement and ritual complex at Beckton Farm, Lockerbie', Proc Soc Antiq Scot 127, 69-121.

Price, T D and Noe-Nygaard, N 2009 'Early domestic cattle in southern Scandinavia and the spread of the Neolithic in Europe', in Finlay, N., McCartan, S., Milner, N and Wickham-Jones, C (eds) 2009 From Bann Flakes to Bushmills: Papers in Honour of Professor Peter Woodman, Oxbow Books and The Prehistoric Society: Oxford, 199-210.

Rackham, O 1977 'Neolithic woodland management in the Somerset Levels: Garvin's, Walton Heath and Rowland's tracks', Somerset Levels Papers 3, 65-71.

Rackham, O 1980 Ancient Woodland. Cambridge University Press: Cambridge.

Ray, K and Thomas, J 2003 'In the kinship of cows: the social centrality of cattle in the earlier Neolithic of southern Britain', in Parker Pearson, M (ed), Food, Culture and Identity in the Neolithic and Early Bronze Age. British Archaeological Reports International Series 1117: Oxford, 37-44.

RCAHMS 1912 Fourth Report and Inventory of Monuments and Constructions in Galloway, Vol I. County of Wigtown. The Royal Commission on the Ancient and Historical Monuments of Scotland: Edinburgh.

RCAHMS 1997 Eastern Dumfriesshire: an archaeological landscape. The Royal Commission on the Ancient and Historical Monuments of Scotland: Edinburgh.

RCAHMS 1999 Kilmartin: an inventory of the monuments extracted from Argyll Volume 6. RCAHMS: Edinburgh.

Rees, S 1979 Agricultural Implements in Prehistoric and Roman Britain British Archaeological Reports 69: Oxford.

Rees, S 1986a 'Stone implements and artefacts' in Whittle, A W R (ed) Scord of Brouster: an Early Agricultural Settlement on Shetland, Scord of Brouster, Oxford University (Committee for Archaeology Monograph 9): Oxford, 75-91.

Rees, S 1986b 'The rude stone implements' in Hedges, J W 1986 'Structures at Tougs, Burra Isle, Shetland', Glasgow Archaeological Journal 13, 17-18.

Richards, C 2005 'Dwelling amongst the monuments. The Neolithic village of Barnhouse, Maeshowe passage grave and surrounding monuments at Stenness, Orkney', McDonald Institute Monograph: Cambridge.

Richards, M P and Schulting, R J 2006 'Against the grain? A response to Milner et al. (2004)', Antiquity 80, 444-458.

Richards, M P and Schulting, R J 2006 'Touch not the fish: the Mesolithic-Neolithic change of diet and its significance', Antiquity 80, 444-56.

Ritchie, A 1983 'Excavations of a Neolithic farmstead at Knap of Howar, Papa Westray, Orkney', Proc Soc Antiq Scot 113, 40-121. 
Ritchie, G 1972 'Excavation of a chambered cairn at Dalineun, Lorn, Argyll', Proc Soc Antiq Scot 104, 48-62.

Ritchie, G 1997a 'Early settlement in Argyll', in Ritchie, G (ed) The archaeology of Argyll Edinburgh University Press: Edinburgh, 38-66.

Ritchie, G 1997b 'Monuments associated with burial and ritual in Argyll' in Ritchie, G (ed) The archaeology of Argyll Edinburgh University Press: Edinburgh, 67-94.

Ritchie, G (ed) 1997c The archaeology of Argyll. Edinburgh University Press: Edinburgh.

Ritchie, J N G 1970 'Excavation of the chambered cairn at Achnacreebeag', Proceedings of the Society of Antiquaries of Scotland 102, 31-55.

Ritchie, J N G 1970 'Beaker pottery in south-west Scotland', Trans Dumf Gall Nat Hist Antiq Soc 47, 123-46.

Ritchie, P R 1968 'The stone implement trade in third-millennium Scotland', in Coles, J M and Simpson, D D A (eds) Studies in Ancient Europe: Essays Presented to Stuart Piggott, Leicester University Press: Leicester, 117-136.

Roberts, C and Manchester, K 1995 ( $2^{\text {nd }}$ edition) The archaeology of disease Sutton: Stroud.

Robinson, D E 1987 'Investigations into the Aukhorn peat mounds, Keiss, Caithness: pollen, plant macrofossil and charcoal analyses', New Phytologist 106, 185-200.

Robinson, M 2000 'Coleopteran evidence for the elm decline, Neolithic activity in woodland, clearance and use of the landscape', in Fairbairn, A S (ed) Plants in Neolithic Britain and Beyond. Oxbow: Oxford, 27-36.

Robinson, S., Black, S et al. 2010 'A Geological Perspective on Climatic and Environmental Change in the Levant and Eastern Mediterranean from 25,000 to 5000 years BP', in Finlayson, B and Warren, G $M$ (eds) Landscapes in Transition. Oxbow/Council for British Research in the Levant (Levant Supplementary Series 8): Oxford, 55-65.

Romans, J C C and Robertson, L 1983 'An account of the soils at North Mains', in Barclay, G J 'Sites of the third millennium bc to the first millennium ad at North Mains, Srathallan, Perthshire', Proc Soc Antiq Scot 113, 260-9.

Rowley-Conwy, P 1981 'Slash and burn in the temperate British Neolithic', in Mercer, R J (ed) Farming Practice in British Prehistory. Edinburgh University Press: Edinburgh, 85-96.

Rowley-Conwy, P 2003 'No fixed abode? Nomadism in the northwest European Neolithic', in Burenhult, G and Westergaard, S (eds) Stones and Bones. Formal disposal of the dead in Atlantic Europe during the Mesolithic-Neolithic interface 6000-3000 BC. British Archaeological Reports International Series 1201: Oxford, 115-144.

Rowley-Conwy, P 2004 'How the west was lost. A reconsideration of agricultural origins in Britain, Ireland, and southern Scandinavia', Current Anthropology 45 (Supplement), S83-S113. 
Ruggles, C L N 1998 'Ritual astronomy in the Neolithic and Bronze Age British Isles: patterns of continuity and change' in Gibson, A and Simpson, D (eds) Prehistoric Ritual and Religion: Essays in Honour of Aubrey Burl, Sutton Publishing: Stroud, 203-208.

Ruggles, C L N 1999 Astronomy in Prehistoric Britain and Ireland Yale University Press

Ruggles, C L N and Barclay G 2000 'Cosmology, calendars and society in Neolithic Orkney: a rejoinder to Euan Mackie' Antiquity 74, 62-74

Russell, N J., Bonsall, C and Sutherland, D G 1995 'The exploitation of marine molluscs in the Mesolithic of western Scotland: evidence from Ulva Cave, Inner Hebrides', in Fischer, A (ed) Man and Sea in the Mesolithic. Oxbow (Monograph 53): Oxford, 273-288.

Sandweiss, D H., Maasch, K A and Anderson, D G 1999 'Transitions in the Mid-Holocene', Science $283,499-500$.

Saville, A 1999 'A cache of flint axeheads and other flint artefacts from Auchenhoan, near Campbeltown, Kintyre, Scotland', Proceedings of the Prehistoric Society 65, 83-123.

Schulting, R J 1998 'Slighting the sea: stable isotope evidence for the transition to farming in northwestern Europe', Documenta Praehistorica 15, 203-218.

Schulting, R J 2004 'An Irish sea change: some implications for the Mesolithic-Neolithic transition', in Cummings, V and Fowler, C (eds) The Neolithic of the Irish Sea: Materiality and Traditions of Practice. Oxbow Books: Oxford, 9-21

Schulting, R J and Richards, M P 2002 'The wet, the wild and the domesticated: the MesolithicNeolithic transition on the west coast of Scotland', Journal of European Archaeology 5, 147-189.

Scourse, J D et al. 2002 'Holocene evolution of seasonal stratification in the Celtic Sea: refined age model, mixing depths and foraminiferal stratigraphy', Marine Geology 191, 119-145.

Scott, J 1954 'The chambered cairn at Beacharra, Kintyre, Argyll', Proceedings of the Prehistoric Society 9, 134-158.

Scott, J 1955 'The excavation of the chambered cairn at Brackley, Kintyre', Proc Soc Antiq Scot 89, 2259

Scott, J 1960 'The excavation of the chambered cairn at Crarae, Loch Fyneside, mid Argyll', Proc Soc Antiq Scot 94, 1-27.

Scott, J 1969 'The Clyde cairns of Scotland', in Powell, T G E., Corcoran, J X W P., Lynch, F and Scott, J $G$ Megalithic enquiries in the west of Britain Liverpool University Press: Liverpool. 175-222, 309-328.

Scott, J G 1992 'Mortuary structures and megaliths', in Sharples, N and Sheridan, A S (eds) Vessels for the Ancestors Edinburgh University Press: Edinburgh, 104-19.

Searle, J B 2008 'The colonization of Ireland by mammals', in Davenport, J L., Sleeman, D P and Woodman, P C (eds) Mind the Gap. Postglacial Colonization of Ireland. Special supplement to The Irish Naturalists' Journal, 109-115. 
Selby, K A and Smith, D E 2007 'Late Devensian and Holocene relative sea-level changes on the Isle of Skye, Scotland, UK', Journal of Quaternary Science 22, 119-140.

Sharples, N and Sheridan, A S (eds) 1992 Vessels for the Ancestors Edinburgh University Press: Edinburgh.

Shearer, I and McLellan, K 2008 'Tracing time: excavations at Knowes and Eweford East (3370-2230 $\mathrm{BC})^{\prime}$, in Lelong, $\mathrm{O}$ and MacGregor, G 2008 The Lands of Ancient Lothian. Interpreting the Archaeology of the A1. Society of Antiquaries of Scotland: Edinburgh, 47-68.

Shennan, I and Horton, B 2002 'Holocene land and sea-level changes in Great Britain', Journal of Quaternary Science 17, 511-527.

Shepherd, I A G and Barclay, G J (eds) 2004 Scotland in Ancient Europe. Society of Antiquaries of Scotland: Edinburgh.

Sheridan, J A 1996 'Rotten Bottom - the discovery of Britain's oldest bow', Current Archaeology 149, $188-90$

Sheridan, J A 2003 'French Connections I: spreading the marmites thinly', in Armit, I., Murphy, E., Nelis, E and Simpson, D D A (eds) Neolithic Settlement in Ireland and Western Britain, 3-17. Oxbow: Oxford.

Sheridan, J A 2004 'Neolithic connections along and across the Irish Sea', in Cummings, V and Fowler, C (eds) The Neolithic of the Irish Sea: materiality and traditions of practice Oxbow: Oxford, 9-21.

Sheridan, J A 2007 'From Picardie to Pickering and Pencraig Hill? New information on the 'Carinated Bowl Neolithic' in northern Britain', in Whittle, A and Cummings, V (eds) 2007 Going over: the Mesolithic-Neolithic transition in NW Europe. British Academy: London, 441-92.

Sheridan, J A 2010a 'The Neolithization of Britain and Ireland: The 'Big Picture", in Finlayson, B and Warren, G M (eds) Landscapes in Transition. Oxbow/Council for British Research in the Levant (Levant Supplementary Series 8): Oxford, 89-105.

Sheridan, J A 2010b 'Scotland's Neolithic non-megalithic round mounds: new dates, problems and potential', in Leary, J., Darvill, T and Field, D (eds) Round Mounds and Monumentality in the British Neolithic and Beyond. Oxbow: Oxford and Oakville, 28-52

Sheridan, J A 2012 'Review of A. Whittle, F. Healy \& A. Bayliss, 'Gathering Time: Dating the Early Neolithic Enclosures of Southern Britain and Ireland". Antiquity 86 (331), 262-4.

Sheridan, J A., Pailler, Y., Pétrequin, P and Errera, M 2011 'Old friends, new friends, a long-lost friend and false friends: tales from Projet JADE', in Davis, R V and Edmonds, M (eds) Stone Axe Studies III, 411-426. Oxbow Books: Oxford and Oakville.

Sherratt, A 1981 'Plough and pastoralism: aspects of the secondary products revolution', in Hodder, I., Isaac, C and Hammond, $\mathrm{N}$ (eds) Pattern of the past: studies in honour of David Clarke, Cambridge University Press: Cambridge, 264-305. 
Simmons, I G 1996 The Environmental Impact of Later Mesolithic Cultures. Edinburgh University Press: Edinburgh.

Simpson, D D A., Murphy, E M and Gregory, R 2006 The Prehistoric Settlement of Northton, Harris, British Archaeological Reports British Series 408: Oxford.

Simpson, J Y 1862 ‘Address on Archaeology'. Proc Soc Antiq Scot 4, 5-51.

Smith, A N 1995 'The excavation of Neolithic, Bronze Age and Early Historic features near Ratho, Edinburgh', Proc Soc Antiq Scot 125, 69-138.

Smith, D E., Cullingford, R A and Firth, C R 2000 'Patterns of isostatic land uplift during the Holocene: evidence from mainland Scotland', The Holocene 10, 489-501.

Smith, D E., Firth, C R and Cullingford, R A 2002 'Relative sea-level trends during the early middle Holocene along the eastern coast of mainland Scotland', Boreas 31, 185-202.

Smith, I 1991 'Sprouston, Roxburghshire: an early Anglian centre of the eastern Tweed Basin', Proceedings of Society of Antiquaries of Scotland 121, 261-294.

Smith, M A 1998 'Holocene regional vegetation history of the Lairg area', in McCullagh, R P J and Tipping, R (eds) The Lairg Project 1988-1996: the Evolution of an Archaeological Landscape in Northern Scotland. STAR: Edinburgh, 177-199.

Smith, R A 1872 ‘Descriptive List of Antiquities near Loch Etive’. Proc Soc Antiq Scot 9, 396-418

Smyth, J 2006 'The role of the house in early Neolithic Ireland', European Journal of Archaeology 9(2), 229-57.

Somerville, H B 1912 'Prehistoric monuments in the Outer Hebrides and their Astronomical Significance' Journ. Roy. Anthrop. Inst. of Gt. Britain \& Ireland 42, 23-52

Somerville, B 1923 'Instances of Orientation in Prehistoric Monuments of the British Isles' Archaeologia II, 23, 193-224

Speak, S and Burgess, C B 1999 'Meldon Bridge: a centre of the third millennium BC in Peebleshire', Proc Soc Antiq Scot 129, 1-118.

Spence, M 1894 Standing Stones of Maeshowe of Stenness, Gardner: Kirkwall

Spurk, $M$ et al. 2002 'Depositional frequency of German subfossil oaks: climatically and nonclimatically induced fluctuations in the Holocene', The Holocene 12, 707-715.

Stevens, C J 2007 'Reconsidering the evidence: towards an understanding of the social contexts of subsistence production in Neolithic Britain' in Colledge, $\mathrm{S}$ and Conolly, J (eds) The Origins and Spread of Domestic Plants in Southwest Asia and Europe, Left Coast Press: Walnut Creek, 375-89.

Stevenson, J B 1997 'The prehistoric rock carvings of Argyll' in Ritchie, G (ed) 1997c The archaeology of Argyll. Edinburgh University Press: Edinburgh, 95-117. 
Strachan, R., Ralston, I and Finlayson, B 1998 'Neolithic and later prehistoric structures, and early medieval metal-working at Blairhall Burn, Amisfield, Dumfriesshire', Proc Soc Antiq Scot 128, 55-94.

Sugden, H 1999 High-resolution Palynological, Multiple Profile and Radiocarbon dated Studies of Early Human Impacts and Environmental Change in the Inner Hebrides, Scotland. Unpublished Ph.D. Thesis, University of Sheffield.

Tauber, $\mathrm{H} 1981{ }^{13} \mathrm{C}$ evidence for dietary habits of prehistoric man in Denmark', Nature 292, 332-333.

Taylor, M 1998 'Wood and bark from the enclosure ditch', in Pryor, F (ed) Etton: Excavations at a Neolithic causewayed enclosure near Maxey, Cambridgeshire, 1982-7. English Heritag: London.

Thom, A 1967 Megalithic Sites in Britain, Oxford University Press: Oxford

Thom, A 1973 Megalithic Lunar Observatories, Oxford University Press: Oxford

Thomas, J 1996 'Neolithic houses in Britain and Ireland - a sceptical view', Darvill, T and Thomas, J (eds) 1996 Neolithic houses in Northwest Europe and beyond (Neolithic Studies Group Seminar Papers 1) Oxbow: Oxford, 1-12.

Thomas, J 2003 'Thoughts on the 'repackaged' Neolithic revolution', Antiquity 77, 67-74.

Thomas, J 2004c 'Current debates on the Mesolithic-Neolithic transition in Britain and Ireland', Documenta Praehistorica 31, 113-130.

Thomas, J S 2004 'Recent debates on the Mesolithic-Neolithic transition in Britain and Ireland.' Documenta Praehistorica 31, 117-130.

Thomas J 2004a 'The ritual universe', in Shepherd, I A G and Barclay, G J (eds) Scotland in Ancient Europe. Society of Antiquaries of Scotland: Edinburgh, 171-8.

Thomas J 2004b 'Materiality and traditions of practice in Neolithic south-west Scotland' in Cummings, V and Fowler, C (eds) The Neolithic of the Irish Sea. Oxbow Books: Oxford, 174-184.

Thomas J 2006 'On the origin and development of cursus monuments in Britain', Proc Prehist Soc 72, 229-4.

Thomas, J (ed) 2007 'Place and Memory: Excavations at the Pict's Knowe, Holywood, and Holm Farm, Dumfries and Galloway, 1994-8'. Oxbow Books: Oxford.

Thomas, J S 2007 'Mesolithic-Neolithic transitions in Britain: from essence to inhabitation', in Whittle, A W R and Cummings, V (eds) Going Over: the Mesolithic-Neolithic Transition in North-West Europe British Academy (Proceedings of the British Academy 144): Oxford, 423-439.

Thomas, J 2008 'The Mesolithic-Neolithic Transition in Britain', in Pollard, J (ed) Prehistoric Britain. Blackwell: Oxford, 58-89.

Thornalley, D J R., Elderfield, H and McCave, I N 2009 'Holocene oscillations in temperature and salinity of the surface subpolar North Atlantic', Nature 457, 711-714.

Tilley, C 1994 A Phenomenology of Landscape: Places, Paths and Monuments. Berg: Oxford. 
Timpany, S., Haston, S-J and Scott, L (forthcoming) 'The Environmental Remains' in Jones, E and Sheridan, A (eds) Pots, pits and roundhouses at Meadowend Farm, Clackmannan. Society of Antiquaries of Scotland

Tinner, W., Nielsen, E H and Lotter, A F 2007 'Mesolithic agriculture in Switzerland? A critical review of the evidence', Quaternary Science Reviews 26, 1416-1431.

Tipping, R 1992 'The Determination of Cause in the Creation of Major Prehistoric Valley Fills in the Cheviot Hills, Anglo-Scottish Border', in Needham, S and Macklin, M C (eds) Alluvial Archaeology in Britain. Oxbow: Oxford, 111-121.

Tipping, R 1994 'The form and fate of Scottish woodlands', Proc Soc Antiq Scot 124, 1-54.

Tipping, R 1997 'The environmental history of the landscape;, in RCAHMS Eastern Dumfriesshire: an archaeological landscape. The Royal Commission on the Ancient and Historical Monuments of Scotland: Edinburgh, 10-25.

Tipping, R 2003 'Living in the past: woods and people in prehistory to 1000 BC', in Smout, T C (ed) People and Woods in Scotland: A History. Edinburgh University Press: Edinburgh, 14-39.

Tipping, R 2004 'Interpretative issues concerning the driving forces of vegetation change in the early Holocene of Britain and Ireland', in Saville, A (ed) Mesolithic Scotland and its Neighbours: The Early Holocene Prehistory of Scotland, its British and Irish Context, and some Northern European Perspectives. Society of Antiquaries of Scotland: Edinburgh, 45-54.

Tipping, R 2007 'Landscape history of the Don Valley and north east Scotland', in Royal Commission on Ancient and Historical Monuments (Scotland) In the Shadow of Bennachie: A Field Archaeology of the Valley of the Don. The Stationery Office: Edinburgh, 25-44.

Tipping, R 2008 'Blanket peat in the Scottish Highlands: timing, cause, spread and the myth of environmental determinism', Biodiversity and Conservation 17, 2097-2113.

Tipping, R 2010 'The case for climatic stress forcing choice in the adoption of agriculture in Britain and Ireland', in Finlayson, B and Warren, G (eds) Landscapes in Transition. Council for British Research in the Levant: Amman.

Tipping, R., Carter, S and Haggart, B A 1994 'Late Quaternary valley floor evolution in the lower reaches of Carradale, Kintyre', Scottish Journal of Geology 30, 131-145.

Tipping, R., Carter, S and Johnston, D 1994 'Soil pollen and soil micromorphological analyses of old ground surfaces on Biggar Common, Borders Region, Scotland', Journal of Archaeological Science 21, 387-401.

Tipping, R and Milburn, P 2000 'The mid-Holocene charcoal fall in southern Scotland: spatial and temporal variability', Palaeogeography, Palaeoclimatology, Palaeoecology 164, 193-209.

Tipping, R and McCulloch, R 2003 'Vegetation History and Human Impact at Reidchalmai, Little Rogart, near Golspie, Sutherland', Archive Report. Historic Scotland 
Tipping, R and Tisdall, E 2004 'Continuity, crisis and climate change in the Neolithic and early Bronze Periods of North West Europe', in Shepherd, I A G and Barclay, G (eds) Scotland in Ancient Europe. The Neolithic and Early Bronze Age of Scotland in their European Context. Society of Antiquaries of Scotland: Edinburgh, 71-82.

Tipping, R., Tisdall, E., Davies, A and Wilson, C 2007 'Living with peat in the flow country: prehistoric farming communities and blanket peat spread at Oliclett, Caithness, northern Scotland', in Barber, J et al. (eds) Archaeology from the Wetlands: Recent Perspectives. Society of Antiquaries of Scotland: Edinburgh, 165-174.

Tipping R, Haggart, B A and Milburn, P 2007 'The interaction of site and landscape around the Pict's Knowe', in Thomas, J (ed) 'Place and Memory: Excavations at the Pict's Knowe, Holywood, and Holm Farm, Dumfries and Galloway, 1994-8'. Oxbow Books: Oxford, 6-36.

Tipping, R., Ashmore, P., Davies, A., Haggart, A., Moir, A., Newton, A., Sands, R., Skinner, T T and Tisdall, E 2008 'Prehistoric Pinus woodland dynamics in an upland landscape in northern Scotland', Vegetation History and Archaeobotany 17, 251-267.

Tipping, R., Jones, A P., Carter, S., Holden, T and Cressey, M 2008 'The chronology and long term dynamics of a low energy river system: the Kelvin Valley, central Scotland', Earth Surface Processes and Landforms 33, 910-922.

Tipping, R., Bunting, M J., Davies, A L., Murray, H., Fraser, S and McCulloch, R 2009 'Modelling land use around an early Neolithic timber 'hall' in north east Scotland'. Journal of Archaeological Science $36,140-9$.

Topping, P 1996 'Structure and ritual in the Neolithic housel: some examples from Britain and Ireland', in Darvill, T and Thomas, J (eds) 1996 Neolithic houses in Northwest Europe and beyond (Neolithic Studies Group Seminar Papers 1) Oxbow: Oxford, 157-70.

Truckell, A E 1963 'The archaeological collections of the Society', Trans Dumf Gall Nat Hist Antiq Soc $41,55-66$.

Turner, J., Innes, J B and Simmons, I G 1993 'Spatial diversity in the mid-Flandrian vegetation history of North Gill, North Yorkshire', New Phytologist 123, 599-647.

Turner, V 1998 Ancient Shetland Batsford: London.

Turney, C S M et al. 2005 'Holocene climate change and past Irish societal response', Journal of Archaeological Science 33, 34-38.

Tweddle, J C., Edwards, K J and Fieller, N R J 2005 'Multivariate statistical and other approaches for the separation of cereal from wild Poaceae pollen using a large Holocene dataset', Vegetation History and Archaeobotany 14, 15-30.

Vanmontfort, B 2001 'The Group of Spiere as a new stylistic entity in the Middle Neolithic Scheldt Basin', Notae Praehistoricae 21, 139-143.

Vera, F W M 2000 Grazing Ecology and Forest History. CABI: Wallingford. 
Waddington, C 2001 'Breaking out of the morphological straightjacket: early Neolithic enclosures in northern Britain', Durham Archaeological Journal 16, 1-14.

Waddington, C and Schofield, D 1999 'A new stone-axe source in the Cheviot Hills, Northumberland.', Archaeologia Aeliana $5^{\text {th }}$ ser, 27, 175-6.

Waddington, C and Davies, J 2002 'Excavation of a Neolithic settlement and late Bronze Age burial cairn near Bolam Lake, Northumberland', Archaeologia Aeliana $5^{\text {th }}$ ser 30, 1-47.

Waddington, C., Mazel, A and Johnson, B 2005 E'xcavation of a rock art site at Hunterheugh Crag, Northumberland', Archaeologia Aeliana $5^{\text {th }}$ ser 34, 29-54.

Warren, G M 2007 'Mesolithic Myths'. Proceedings of the British Academy 144, 311-328.

Whitehouse, N J and Smith, D N 2004 “Islands' in Holocene forests: implications for forest openness, landscape clearance and 'culture-steppe' species', Environmental Archaeology 9, 199-208.

Whittington, G 1978 'A sub-peat dyke at Shurton Hill, Mainland, Shetland', Proc Soc Antiq Scot 106, 99-110.

Whittle, A 1980 'Prehistoric lynchets and boundaries on the Shetland Islands', Antiquity 54, 129-32.

Whittle, A 1986 Scord of Brouster: An Early Agricultural Settlement on Shetland. Oxford University (Committee for Archaeology Monograph No. 9): Oxford.

Whittle, A 2003 The archaeology of people: dimensions of everyday life. Routledge: London.

Whittle, A 2007 'The temporality of transformation: dating the early development of the southern British Neolithic', in Whittle, A and Cummings, V (eds) Going Over: the Mesolithic-Neolithic transition in North-West Europe. British Academy: London, 377-398.

Whittle, A., Keith-Lucas, M., Milles, A., Noddle, B., Rees, S and Romans, J 1986 Scord of Brouster: an early agricultural settlement on Shetland. Excavations 1977-1979, Oxford University (Committee for Archaeology Monograph 9): Oxford.

Whittle, A and Bayliss, A 2007 'The Times of Their Lives: from Chronological Precision to Kinds of History and Change'. Cambridge Archaeological Journal 17(01), 21-28.

Whittle, A and Cummings, V (eds) 2007 Going over: the Mesolithic-Neolithic transition in NW Europe. British Academy: London.

Whittle, A W R., Healy, F and Bayliss, A 2011 Gathering Time: Dating the Early Neolithic Enclosures of Southern Britain and Ireland. Oxbow: Oxford and Oakville.

Williams J 1970 'Neolithic Axes in Dumfries and Galloway', Trans Dumf Gall Nat Hist and Archaeol Soc 47, 111-122.

Wilson, P., McGourty, J and Bateman, M D 2004 'Mid- to late-Holocene coastal dune event stratigraphy for the north coast of Ireland', The Holocene 14, 406-416. 
Zvelebil, M 1998 'Agricultural Frontiers, Neolithic origins, and the transition to Farming in the Baltic Basin', in Zvelebil, M., Dennell, R and Domanska, L (eds) Harvesting the Sea, Farming the Forest: the emergence of Neolithic societies in the Baltic region. Sheffield Academic Press: Sheffield, 9-28. 